Universidad Nacional de La Plata

Facultad de Humanidades y Ciencias de la Educación

Secretaría de Posgrado

\title{
Expansión territorial, producción ganadera y relaciones de poder en la región Río de la Plata
}

\author{
Montevideo y Maldonado a fines del siglo XVIII
}

Nicolás Alberto Biangardi

Tesis para optar por el grado de Doctor en Historia

Director Dr. Fernando Alberto Jumar, Universidad Nacional de La Plata / Universidad Nacional de Tres de Febrero

Codirectora: Dra. María Inés Moraes, Universidad de la República

La Plata, 20 de abril de 2015 


\section{Resumen}

Este trabajo tiene por objetivo presentar un análisis de la relación entre la producción ganadera, la expansión territorial y el establecimiento de relaciones de poder en la constitución de una estructura territorial en el Río de la Plata de finales del siglo XVIII. Para eso luego de mostrar una definición de la región y una posible división de la misma en áreas, tomamos los casos de Montevideo y Maldonado para efectuar un estudio detallado abordando el tema desde todos los ángulos posibles. De esta manera, en primer lugar se presenta un estudio de la circulación de los productos pecuarios. En segundo lugar, se describen las diferentes actividades económicas involucradas en la explotación del ganado vacuno. En tercer lugar, se analiza la apropiación de los factores de producción (tierra, mano de obra y ganado) por parte de los agentes vinculados a esas actividades. En cuarto lugar, se efectúa una aproximación a un estudio prosopográfico de uno de los grupos de agentes, que denominamos corambreros montevideanos. Por último, se indaga en el accionar de los grupos de agentes vinculados a la explotación del ganado en las los cabildos de Montevideo y Maldonado y los avatares del gremio de hacendados de Montevideo. La imagen final resultante permite sostener que estos agentes utilizaron esas instituciones y establecieron relaciones de poder con el fin de controlar los factores de producción que le permitían explotar el ganado lo que, a su vez, tenía una configuración territorial que muestra una fragmentación de la región. En consecuencia, se puede observar una cierta estructura del poder durante los años finales del siglo XVIII que sobrevivió a la crisis del sistema político de la monarquía española y constituyó la base sobre la que se asentaron los movimientos políticos comienzos del siglo XIX y los primeros procesos de formación de estados en el Río de la Plata.

\section{Palabras claves}

Río de la Plata - Siglo XVIII - Producción ganadera - Expansión Territorial Relaciones de poder 


\section{Agradecimientos}

En el largo trayecto de la elaboración de una tesis de doctorado son innumerables las personas que brindan un apoyo y hacen posible el tránsito por ese tortuoso camino con éxito. Directores, profesores, compañeros de estudio y trabajo en seminarios y grupos de investigación, coordinadores y comentaristas en jornadas y empleados de archivos y bibliotecas. Todas esas ayudas están reflejadas en las páginas de este texto.

Indudablemente el primer lugar en estos agradecimientos está reservado para Fernando Jumar. En los últimos 12 años Fernando tuvo un lugar central en mi formación. Con su incansable curiosidad y voluntad organizó largas reuniones de grupos de investigación, viajes a jornadas y visitas de profesores de otras universidades que enriquecieron nuestra mirada sobre lo que queríamos estudiar. Además, por supuesto, de leer y comentar todos los textos que escribí desde los primeros intentos de recortar un objeto de estudio cuando aún era un joven estudiante de grado hasta esta tesis. Por último, y no menos importante, porque siempre fue muy generoso al momento de abrir puertas y enseñar todos los secretos para sobrevivir con éxito en el mundo académico. Sin las innumerables horas que dedicó a mi trabajo esta tesis existiría.

María Inés Moraes, por su parte, fue esencial en el giro que tomó esta investigación y gran parte del resultado se debe a su influencia. Su ayuda permitió, además, conformar una dirección verdaderamente rioplatense para esta tesis y llevar a la práctica uno de las cuestiones planteadas en el texto, traspasar los límites que nos imponen los estados-nación tanto con respecto a los objetos de estudio como a los debates dentro de cada campo científico.

Con Maximiliano Camarda compartimos este camino de ser estar trabajando en nuestras tesis al mismo tiempo. Fue el primer lector de mis textos, sus comentarios y sugerencias fueron siempre muy bien recibidos. Juntos compartimos muchas horas en archivos, bibliotecas, clases de seminarios y demás. Generosamente me brindó parte de su trabajo de fuentes antes de publicarlo, sin el cual una parte del análisis de la circulación interna de la región y algunas de las hipótesis planteadas en ese capítulo no habrían sido posibles. Así que una parte importante de esta tesis se la debo a su esmero. 
Las reuniones de nuestro grupo de investigación en La Plata tuvieron también su aporte a este trabajo. Los debates que allí surgieron encauzaron algunas de las preguntas de este texto. Además, ahí y en otras juntadas más recreativas se forjaron lazos que van más allá de lo laboral y que, sin duda, hicieron más ameno el, por momentos, solitario trabajo del tesista. Algunos ya no forman parte del grupo y eligieron otros caminos pero igual hicieron su aporte a este texto. Con los que siguen formando parte no tengo más que agradecimiento y espero seguir trabajando con ellos por mucho tiempo.

Muchas personas criticaron y comentaron avances parciales de esta tesis en seminarios, congresos y jornadas. A todos ellos les agradezco por sus sugerencias que ayudaron a enriquecer estas páginas. También les agradezco infinitamente por la paciencia y eficiencia en su trabajo a todos los que hicieron posible mi investigación en los archivos y bibliotecas de Argentina y Uruguay.

Sin duda las virtudes de esta tesis son el producto del trabajo generoso de todas las personas que me ayudaron en este camino. En cambio, todas las inconsistencias y errores que perduran en el texto son el producto de mis limitaciones individuales y son de mi exclusiva responsabilidad.

La investigación reflejada en esta tesis fue posible gracias al apoyo económico del CONICET a través de las becas internas de postgrado tipo I y tipo II.

Por último, y no por eso menos importante, nada de esto sería posible si Carla no hubiese soportado mis obsesiones, escuchado mis diatribas y leído la mayor parte de mis trabajos durante todos estos años. Pero ella hizo y hace mucho más que eso y nunca van a ser suficientes las breves palabras que puedo volcar en estas hojas para agradecerle. 


\section{Índice}

$\begin{array}{ll}\text { Introducción } & 13\end{array}$

1. La región Río de la Plata 15

1.1. Características del medio ambiente natural $\quad 15$

1.2. Ocupación del espacio y conformación del complejo portuario 22

1.3. Una definición de la región Río de la Plata 26

2. Estructura de la tesis, hipótesis y metodología 31

Capítulo 1. Producción agropecuaria, fronteras y relaciones de poder en las praderas rioplatenses

Capítulo 2. La circulación de productos pecuarios dentro de la región

2.1. Introducción de cueros, sebo y grasa a Montevideo, 1784-1790

2.2. Ingresos de cueros marcados y orejanos a Montevideo, 1791-1797 72

2.3. Envíos de derivados vacunos de Maldonado a Montevideo, 1782-1806 76

Capítulo 3. El negocio del cuero. Agentes, modos de producción y sistema de comercialización

3.1. Dos formas de explotación del vacuno: las vaquerías y la ganadería

3.2. El sistema de comercialización de los bienes pecuarios 87

3.2.1. Las pulperías en el área de Maldonado 88

3.3 Una caracterización de los agentes $\quad 94$ 
4.1. El aprovechamiento del sebo y la grasa 104

4.2. El consumo de carne fresca 107

4.3. La producción de carnes saladas 112

Capítulo 5. La apropiación de la tierra. Repartos, denuncias y mercado de tierras

5.1. Repartos y mercedes de tierras para chacras y estancias

5.2. Denuncias, ventas y composiciones de tierras realengas 125

5.3. El mercado de tierras regional: compra-ventas de bienes inmuebles rurales $\quad 135$

5.4. Arrendamientos de estancias y chacras

Capítulo 6. Entre la libertad y la esclavitud. La mano de obra: asalariados, esclavos y agregados

6.1. Los trabajadores asalariados

6.2. La mano de obra esclava

6.3. Los agregados

7.3.Acciones de los estancieros y corambreros por el control de las faenas y para reprimir el abigeato 
7.3.1. Por el control de las faenas: embargos de cueros realizados por el cabildo de Montevideo en 1784

7.3.2. Conflictos entre vecinos por extracción de ganados 169

7.3.3. Unos pocos juicios por abigeato: en busca de un castigo ejemplar 171

Capítulo 8. Los corambreros montevideanos

8.1. Proceso de conformación del grupo de agentes económicos. Las denuncias de tierras.

8.2. Recomposición del grupo de agentes económicos. El casamiento como forma privilegiada de acceder a los derechos de explotación sobre el ganado.

8.3. Desaparición de los corambreros montevideanos como grupo de agentes económicos ante las transformaciones productivas del espacio económico.

Capítulo 9. Las relaciones de poder en Montevideo y Maldonado

9.1 Accionar de los vecinos hacendados en el Cabildo de Montevideo

9.2 Presencia y accionar de los vecinos hacendados en el cabildo de Montevideo

9.3. Constitución y desempeño del Gremio de Hacendados

9.4. Accionar de los estancieros en el Cabildo de Maldonado

Conclusiones 
Anexos

Anexo 1. Mapas

Anexo 2. Cuadros

Anexo 3. Vecinos firmantes del acuerdo del Cabildo de Montevideo de 28 de junio de 1784

Anexo 4. Cabildantes de Montevideo 1730-1808

Anexo 5. Cabildantes de Maldonado 1784-1811

Fuentes

Bibliografía 


\section{Índice de mapas, gráficos, cuadros y figuras}

\section{Mapas}

Mapa 1. Morfología del Río de la Plata 18

Mapa 2. Ecosistema pastizales del Río de la Plata 20

Mapa 3. Plano del Río de la Plata con indicaciones de profundidad y tipos de fondos 24

Mapa 4. Región Río de la Plata 28

Mapa 5. Procedencia de los cueros acopiados por Juan Pedro Aguirre, noviembre de 1784

Mapa 6. Denuncias de tierras en la jurisdicción de Montevideo, 1774

Mapa 7. La propiedad de la tierra en la "Banda Oriental" en 1763

Mapa 8. La propiedad de la tierra en la "Banda Oriental" hacia 1780

Mapa 9. Denuncias de tierras en la "Banda Oriental" entre 1790 y 1799

Mapa A. 1. Esquema de la zonificación morfo-hidrológica del Río de la Plata 222

Mapa A. 2. Áreas de la zona fluvial del Río de la Plata 223

Mapa A. 3. Salinidad del Río de la Plata en invierno 224

Mapa A. 4. Mapa de salinidad del Río de la Plata en verano 224

Mapa A. 5. Batimetría del Río de la Plata 225

Mapa A. 6. Mapa de zonificación del Delta del Paraná 226

Mapa A. 7. Detalle del mapa $3 \quad 227$ 


\section{Gráficos}

Gráfico 1. Exportaciones de cueros desde el Río de la Plata 1699-1798

Gráfico 2. Cantidad de cueros exportados desde Buenos Aires y Montevideo 1779-1799

Gráfico 3. Totales mensuales de cueros ingresados a Montevideo de septiembre de 1784 a marzo de 1790

Gráfico 4. Totales mensuales de sebo y grasa (en arrobas) ingresados a Montevideo, de agosto de 1785 a marzo de 1790

Gráfico 5. Totales mensuales de ingresos de cueros a Montevideo, de septiembre de 1791 a febrero de 1797

Gráfico 6. Ingreso mensual de cueros marcados y orejanos a Montevideo, de septiembre de 1791 a febrero de 1797

Gráfico 7. Totales anuales de cueros enviados desde Maldonado hacia Montevideo, 1783-1806

Gráfico 8. Totales anuales de sebo y grasa (en arrobas) enviados desde Maldonado hacia Montevideo, 1782-1806

Gráfico 9. Índice del precio en reales de la cuartilla de sal en Montevideo 17621815

Gráfico 10. Ventas de bienes inmuebles en la región Río de la Plata 1701-1810

Gráfico 11. Ventas de bienes inmuebles rurales en Buenos Aires, Montevideo y Maldonado 1774-1806

Gráfico 12. Estructura etaria de agregados y peones en la jurisdicción de Montevideo, 1772-1773

\section{Cuadros}

Cuadro 1. Origen de los cueros ingresados a Montevideo, septiembre de 1784marzo de 1790

Cuadro 2. Cueros marcados y orejanos introducidos a Montevideo, 1792-1796 
Cuadro 3. Participación de los cueros enviados desde Maldonado en los cueros exportados desde Montevideo, 1783-1799 78

Cuadro 4. Cantidad y ubicación de pulperías en el área de Maldonado 1788-1806 91

Cuadro 5. Mayores introductores de cueros, sebo y grasa comprados, Montevideo septiembre de 1784- marzo de 1790

Cuadro 6. Mayores introductores de cueros, sebo y grasa de sus ganados o de su matadero, Montevideo septiembre de 1784- marzo de 1790

Cuadro 7. Mayores introductores de cueros a Montevideo, septiembre de 1791febrero de 1797

Cuadro 8. Sebo introducido en Montevideo por Fructuoso Calvo 1786-1790

Cuadro 9. Ingreso de tasajo, cecina y carne salada a Montevideo 1787-1788

Cuadro 10. Venta de esclavos en el área de Maldonado, 1782-1806

Cuadro 11. Agregados y peones en las estancias de la jurisdicción de Montevideo 1772-1773, cantidad y distinción por grupo étnico

Cuadro 12. Agregados y peones en las chacras de la jurisdicción de Montevideo 1772-1773, cantidad y distinción por grupo étnico

Cuadro 13. Remates de cueros en Montevideo 1784-1785

Cuadro A. 1. Cantidad de cueros exportados por la región Río de la Plata por quinquenios, 1699-1798.

Cuadro A. 2. Cantidad de cueros exportados desde Buenos Aires y Montevideo 1779-1799

Cuadro A. 3. Ingreso de carros cargados de cueros, noviembre de 1784

Cuadro A. 4. Destino de los cueros introducidos en noviembre de 1784

Cuadro A. 5. Totales mensuales de cueros, sebo y grasa introducidos a Montevideo de septiembre de 1784 a marzo de 1790

Cuadro A. 6. Introducciones de cueros y sebo pertenecientes a los diezmos

Cuadro A. 7. Ingreso de cueros marcados y orejanos a Montevideo 1791-1797

Cuadro A. 8. Envíos de derivados vacunos de Maldonado a Montevideo, 17821806

Cuadro A. 9. Introducciones de Manuel Campana a Montevideo 1787-1788

Cuadro A.10. Sebo introducido en Montevideo por Francisco de Alba, 1789-1790

Cuadro A.11. Sebo introducido en Montevideo por Custodio García, 1789-1790 
Cuadro A. 12. Precio de la cuartilla de sal en reales en Montevideo 1762-1815

Cuadro A 13. Venta de bienes inmuebles rurales en Buenos Aires, Montevideo y

Maldonado, 1701-1810

Cuadro A. 14. Venta de chacras y estancias en Montevideo

Cuadro A. 15. Venta de chacras y estancias en Maldonado

\section{Figuras}

Figura 1. Plano de fundación de la villa de Concepción de Minas (1783)

124

Figura 2. Descendencia de José Joaquín de Viana y María Francisca de Alzaybar 


\section{Introducción}

El presente trabajo tiene por objetivo analizar una parte esencial de la estructura productiva de las praderas rioplatenses que constituyó la base material para el establecimiento de relaciones de poder, que tuvieron su manifestación en el espacio geográfico en la construcción de diversas realidades territoriales. En este sentido, la tesis se enmarca dentro de un intento, compartido con otros historiadores, por estudiar la territorialidad de los actores que vivieron durante el siglo XVIII en las tierras que bordeaban el Río de la Plata, sin las restricciones que imponen recortes derivados de realidades posteriores.

La utilización de delimitaciones geográficas que remiten a las provincias y los estados-nación creados en el siglo XIX para analizar las manifestaciones territoriales del siglo XVIII es un anacronismo común entre los historiadores. Una parte de esa situación es producto de las políticas de los estados, que se traduce en los mapas oficiales y en los discursos que tienden a naturalizarlos. La reproducción masiva de esa cartografía genera que sus formas, generalmente resaltadas por distintos colores y con la supresión de todas las indicaciones geográficas, se conviertan en un símbolo más de la nacionalidad. Benedict Anderson (1993: 244-245) sostiene que ese mapa se transforma en un logotipo que por medio de la repetición constante penetra en la imaginación popular. El autor afirma, también, que existe un efecto rompecabezas por el cual cada pieza puede ser separada de las demás. El mapa político de la Argentina con las provincias pintadas con distintos colores vivos, sin indicaciones de latitud y longitud, sin nombres de lugares ni de accidentes geográficos y con los países vecinos en algún color más opaco es un ejemplo claro para todos nosotros. Sin contar el típico juego de encastre de madera en el que cada provincia es una pieza a encajar en el mapa nacional. De la misma manera, también podemos pensar en el mapa político de Sudamérica que ayuda a fijar y 
naturalizar las formas de los países y a ocultar, de ese modo, que esas fronteras son el producto de un proceso histórico reciente.

Por otro lado, desde el siglo XIX la historia, como disciplina científica, tuvo como uno de sus principales objetivos justificar la existencia de los estados-nación (Acevedo, 2014). En ese contexto, los historiadores construyeron relatos que tendían a legitimar a ese estado en un pasado que se perdía en la noche de los tiempos. Esto se tradujo en una concepción que se resume en la idea de la preexistencia de la nación que permitía extender en el tiempo su historia. Uno de los puntos que fundamentaba esa idea era una supuesta entidad territorial previa a la creación del estado ${ }^{1}$. En algunos casos, inclusive, se planteaba su existencia desde el período previo a la llegada de los europeos. Así, por ejemplo, los historiadores uruguayos observaban una unidad territorial que denominaron "Banda Oriental" que se repetía desde los charrúas, pasando por la gobernación de Montevideo, la provincia Cisplatina hasta que finalmente se sellaba el destino manifiesto con la creación de la República Oriental del Uruguay. Cuando en realidad la "Banda Oriental" del siglo XVIII es una construcción historiográfica que une varias jurisdicciones diferentes ${ }^{2}$. Lo mismo se puede decir de los historiadores argentinos que evitaban hablar del Alto Perú, el Paraguay o la "Banda Oriental" cuando estudiaban el período que va del siglo XVI a principios del XIX o cuando condenaban una supuesta araucanización de los pampas como si se tratara de chilenos y argentinos respectivamente. El conocimiento histórico actual reconoce que estos argumentos no resisten una confrontación con las fuentes pero sirvieron para construir relatos que los estados difundieron por medio de las escuelas, ceremonias y medios de comunicación para legitimar su existencia (Poggi, 2010; Sansón, 2011). No es este el lugar para realizar un análisis crítico de esa bibliografía y remitimos a los excelentes estudios que se han realizado en los últimos años sobre estos temas ${ }^{3}$.

Teniendo en cuenta la importancia de desprenderse de las constricciones que imponen las historiografías nacionales, en las páginas siguientes se procede a la descripción y delimitación del espacio geográfico que enmarca el objeto de estudio de la

\footnotetext{
${ }^{1}$ Chiaramonte (1997) ha mostrado, para toda Iberoamérica, que ese anacronismo, fundado en la suposición de que las naciones existían en el momento de la independencia, se basaba en un desconocimiento o incomprensión del vocabulario político de la época.

${ }^{2}$ Es decir: parte de la jurisdicción del cabildo de Buenos Aires, la del cabildo de Santo Domingo Soriano, parte del espacio de los pueblos misioneros, la gobernación de Montevideo y las comandancias de San Carlos, Maldonado (luego de 1784 de su cabildo) y de Santa Teresa.

${ }^{3}$ Ver: Buchbinder (1994), Sansón (2006), entre otros.
} 
tesis. En primer lugar, se realiza una breve síntesis de sus aspectos físicos y del ecosistema en el que está inserto. En segundo lugar, se reconstruye el proceso de ocupación del espacio, la conformación del complejo portuario rioplatense y la evolución demográfica. Luego se pasa a considerar ese espacio definiéndolo como una región y estudiando los elementos que la componen. De esta manera, determinamos las áreas de la región donde concentraremos nuestra atención a lo largo del desarrollo de la tesis. Por último, se enuncian las hipótesis que guían este trabajo, las fuentes y la metodología utilizada, al mismo tiempo que se describen la estructura y el contenido de los capítulos de la tesis.

\section{La región Río de la Plata}

\subsection{Características del medio ambiente natural}

El Río de la Plata no siempre fue un río y, estrictamente, en los tiempos actuales tampoco lo es, al menos no en su totalidad ${ }^{4}$. Por una convención se considera que el río es una unidad que se extiende desde el delta del Paraná hasta una línea imaginaria que va de Punta del Este hasta Cabo San Antonio ${ }^{5}$. En realidad, sólo es un río hasta otra línea que tendríamos que dibujar desde Punta Brava (en Montevideo) hasta Punta Piedra (cerca de Punta Indio) (Calcagno y Lovrich, 2013: 111). Una vez cruzado ese límite el "río" se transforma en un estuario que va aumentando su salinidad hasta que nos adentramos en el mar.

El "río", entonces, puede ser divido en tres áreas que poseen distintas características morfológicas e hidrológicas. Esas áreas o zonas son abstracciones útiles ya que ocultan distintos cambios graduales y los límites entre ellas varían constantemente debido a los movimientos mareales, los efectos de la mezcla que produce el viento y las modificaciones en el caudal de agua dulce (Masello y Menafra,

\footnotetext{
${ }^{4}$ En el mapa presentado en el libro de Nora Flegenheimer, Cristina Bayón y Alejandro Pupio se puede ver la línea de la costa hace 12.000 años cuando el nivel del mar estaba aproximadamente 100 metros más bajo que el actual y lo que ahora es el lecho del río conformaba un extenso valle (Flegenheimer, Bayón y Pupio, 2007: 36).

${ }^{5}$ La Argentina y Uruguay por conveniencia mutua fijaron ese límite en el Tratado del Río de la Plata y su frente marítimo $\mathrm{y}$, por esa razón, se encuentra en todos los mapas oficiales.
} 
1998: 119). De todas maneras, son más que suficientes para nuestro propósito de conocer las características generales del Río de la Plata. La zona fluvial interna o superior es un río mareal de agua dulce que incluye además el Delta del Paraná. La zona fluvial intermedia (de transición o estuarina) ${ }^{6}$, por su parte, se extiende desde el límite de la intrusión salina hasta un delta fluvio-mareal por lo que su extensión depende de las variaciones del viento y del caudal fluvial. Por último, la región exterior o marítima está compuesta por tres zonas el Canal Oriental, la Bahía de Samborombón y el Alto Marítimo (Nagy, Martínez, Caffera, Pedrosa, Forbes, Perdomo y Lopéz Laborde, 1998: 19) (ver mapas en Anexo 1). En consecuencia, podemos decir que Buenos Aires y Colonia del Sacramento se encuentran asentadas en las costas de un río, Montevideo dentro de un estuario y Maldonado en una zona marítima, lo que como veremos más adelante tenía consecuencias importantes para las condiciones de navegación de la época que estudiaremos.

En su conjunto, el Río de la Plata sorprende por sus dimensiones. La zona del río mareal tiene $250 \mathrm{~km}$ de largo y la distancia entre sus costas varía de $32 \mathrm{~km}$ entre Colonia y Punta Lara hasta $230 \mathrm{~km}$ entre Punta del Este y Cabo San Antonio. Su superficie total alcanza los $38.800 \mathrm{~km}^{2}$ y recibe el caudal de una cuenca, que incluye los ríos Paraguay, Paraná y Uruguay, con una extensión de 3.170 .000 km².

Las diferencias entre la costa norte y la sur son muy marcadas. Mientras la costa sur es baja y aplanada, de manera que da lugar a la existencia de un conjunto de pantanos y lagunas; la costa norte, en cambio, muestra playas arenosas, con barras, cordones litorales y dunas. Los principales rasgos geomorfológicos, muy importantes al momento de analizar las dificultades de navegación porque implican cambios en la profundidad del río, son los bancos, las cuencas erosivas y los canales.

Antes de ingresar al Río de la Plata las embarcaciones debían evitar los bancos Rouen, Inglés y Arquímedes situados en la zona exterior denominada Alto Marítimo. La navegación podía hacerse habitualmente por el Canal Oriental que se conecta con el Canal del Norte donde la profundidad disminuye hasta una media de 5 metros. La Franja Costera Sur, en cambio, no presenta la profundidad necesaria debido a que por su relación con los canales principales y su ubicación con respecto a los vientos dominantes es receptora de los sedimentos que arrastran las corrientes del río. Entre el

${ }^{6}$ Distintos autores coinciden en la división aunque les dan diferentes nombres. 
Canal del Norte y la Gran Hoya del Canal Intermedio se encuentra un nuevo obstáculo representado por el Banco Grande de Ortíz. Finalmente sobre la costa norte nos encontramos con el Sistema Fluvial Norte y la Playa Honda. El primero que consiste en una serie de canales que suelen cambiar por los procesos sedimentarios y que constituyen surcos producidos por la acción erosiva de los caudales provenientes de los ríos Uruguay y Paraná. La Playa Honda, en cambio, es una prolongación subacuática del Delta y tiene su origen la deposición de los materiales que transportan las aguas fluviales (López Laborde, 1998: 3-10).

Los ríos Paraná y Uruguay son los responsables del $97 \%$ de agua dulce ingresada al Río de la Plata. Las crecidas de ambos ríos se dan en distintos momentos de año por lo que se compensan ${ }^{7}$ y la variabilidad estacional de la entrada fluvial es mínima. Sin embargo, las crecidas del río Uruguay (que tienen una media del 17\%) tienen su influencia en la variabilidad hidrológica de la costa norte (Nagy, Martínez, Caffera, Pedrosa, Forbes, Perdomo y Lopéz Laborde, 1998: 23).

Durante todo el año predominan los vientos del norte y noreste. Sin embargo, en invierno se incrementa la frecuencia de los vientos del oeste y en verano del este o sudeste. Se dan dos fenómenos de vientos fuertes. El Pampero, un viento frío que sopla en invierno desde el sudoeste y la Sudestada, que constituye un ciclón frontal extratropical que se produce especialmente en verano con importantes consecuencias en las zonas costeras. En general, la regularidad del viento y la velocidad resultante no son importantes. Por otra parte, las precipitaciones son uniformes durante todo el año, con un leve pico en otoño, con un promedio anual de $1.060 \mathrm{~mm}$ (Ibíd.: 27-32).

Las tierras adyacentes al río forman parte del ecosistema pastizales del Río de la Plata. Estas amplias planicies, que alternan superficies planas con relieves levemente ondulados, se caracterizan por una vegetación que presenta un predominio de las especies de gramíneas y una ausencia casi total de árboles. El clima es templado y disfruta de la influencia moderadora del océano Atlántico, por lo que muestra condiciones menos extremas que otros lugares situados en las mismas latitudes (Bibenca y Miñaro: 6).

\footnotetext{
${ }^{7}$ Las crecidas del Paraná se dan en verano y otoño y las del Uruguay en invierno.
} 


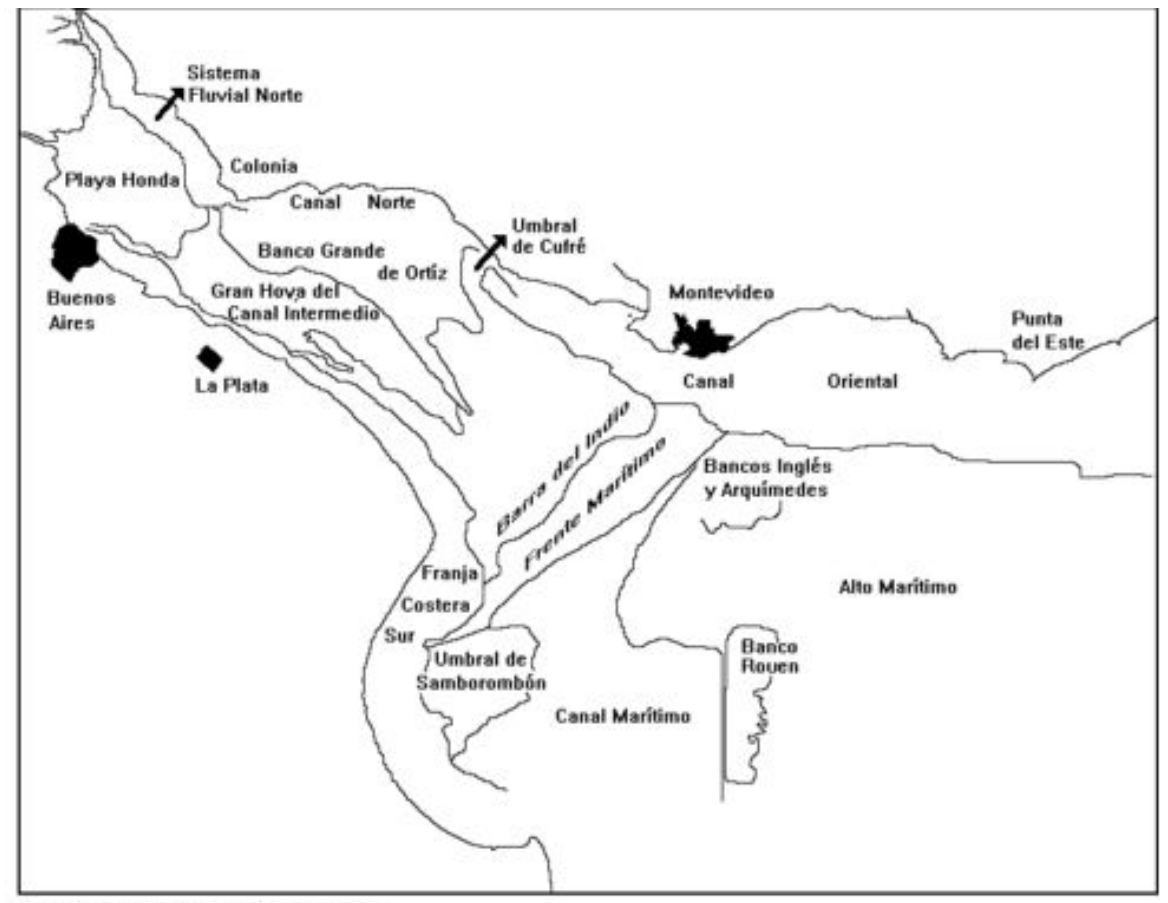

Figura 1,4 - Mortologia del Río de la Ptata

(Dec Cavalbotio, 1987; Parber \& Lipez Lahorde, 1990).

Fuente: López Laborde (1998: 9)

El ecosistema puede ser subdividido en ocho zonas de acuerdo a algunas diferencias geológicas, de vegetación o geomorfológicas (Mapa 2). En el período que nos interesa (segunda mitad del siglo XVIII) la ocupación y uso de la tierra por parte de la sociedad que vamos a estudiar incluía prácticamente la totalidad de la Pampa ondulada, la Pampa mesopotámica y los Campos del sur, y se expandía hacia los Campos del norte y la Pampa inundable. Por supuesto, los otros espacios no estaban vacíos, en el resto de la Pampa habitaban todavía los pueblos originarios y en los Campos del Norte se situaban las misiones jesuíticas y el sector más austral de los dominios portugueses.

Desde el punto de vista geológico, la Pampa se diferencia de los Campos porque posee una gruesa capa de sedimentos loésicos y arcillosos, que oscila entre los $300 \mathrm{y}$ 5.000 metros de profundidad. En los Campos, en cambio, la estructura cristalina se mantiene próxima a la superficie. Tanto la Pampa ondulada, como la mesopotámica y los Campos del sur presentan un relieve levemente ondulado y tienen un sistema de 
drenaje exorreico con cursos de agua bien definidos que desembocan en los ríos Paraná, Uruguay y de la Plata. Esos ríos y arroyos eran fundamentales para la ganadería con las condiciones de producción del siglo XVIII. En el área de Maldonado la ondulación de los Campos del sur se transforma hasta adquirir un aspecto serrano. El relieve de los Campos del norte, en cambio, es plano salvo en las nacientes del río Negro. Por su parte, la Pampa deprimida o inundable es una depresión con una pendiente escasa que torna muy difícil el drenaje y suele inundarse durante el invierno ${ }^{8}$ (Ibíd. 15-20).

La variación interanual de las precipitaciones, en la cantidad de agua o en su distribución a lo largo del año, puede provocar que en un lugar se alternen períodos de déficit hídrico con otros de exceso hídrico (Ibíd., 2004: 5-7). En la época que vamos a estudiar esas sequías eran más frecuentes que en la actualidad ${ }^{9}$ debido al fenómeno climático denominado Pequeña Edad de Hielo (siglos XV a XIX) ${ }^{10}$ (Favier Dubois y Zárate, 2012: 74).

La llanura o el relieve ligeramente ondulado, el clima, la densa cobertura y el estrato herbáceo se conjugan para producir suelos de gran fertilidad. Aunque predominan los suelos mollisoles, en el sector occidental de los Campos y en el este de la Pampa mesopotámica son habituales los vertisoles (Bibenca y Miñaro, 2004: 8, 19). Los vertisoles contienen una gran cantidad de arcilla expansiva en su parte superficial que se contrae ante la falta de humedad y suele agrietarse en períodos de sequías (Soriano, León, Sala, Lavado, Deregibus, Cahuepé, Scaglia, Velazquez y Lemcoff, 1992: 379). En consecuencia, si bien como dijimos son suelos fértiles, la agricultura de secano encontraba, bajo las condiciones tecnológicas del siglo XVIII, dificultades para su desarrollo y, como veremos, estas zonas linderas al río Uruguay tendieron a ser predominantemente ganaderas.

\footnotetext{
${ }^{8}$ Esa reserva de agua atraía al ganado alzado en los períodos de sequía lo que generaba dificultades entre los hispanocriollos y las sociedades indígenas que tenían en la zona sus potreros (Montoya, 1984: 34; Alioto, 2011: 66).

${ }^{9}$ Según los Acuerdos del Cabildo de Buenos Aires en la campaña bonaerense durante la segunda mitad del siglo XVIII se registraron sequías en los siguientes años: 1753-1760, 1764, 1766-1768, 1773-1774, 1780-1782, 1785, 1787-1791, 1794-1795, 1798-1799 (Montoya, 1984: 32-33).

${ }^{10} \mathrm{La}$ Pequeña Edad del Hielo fue un período de clima frío y seco que se extendió entre mediados del siglo XIV y mediados del XIX. Las investigaciones coinciden en que este fenómeno climático se debió a una disminución de la actividad solar y un aumento de la actividad volcánica que cambió las concentraciones de Dióxido de Carbono en la atmosfera. (Maenza y Compagnicci, 2010).
} 
Mapa 2. Ecosistema pastizales del Río de la Plata

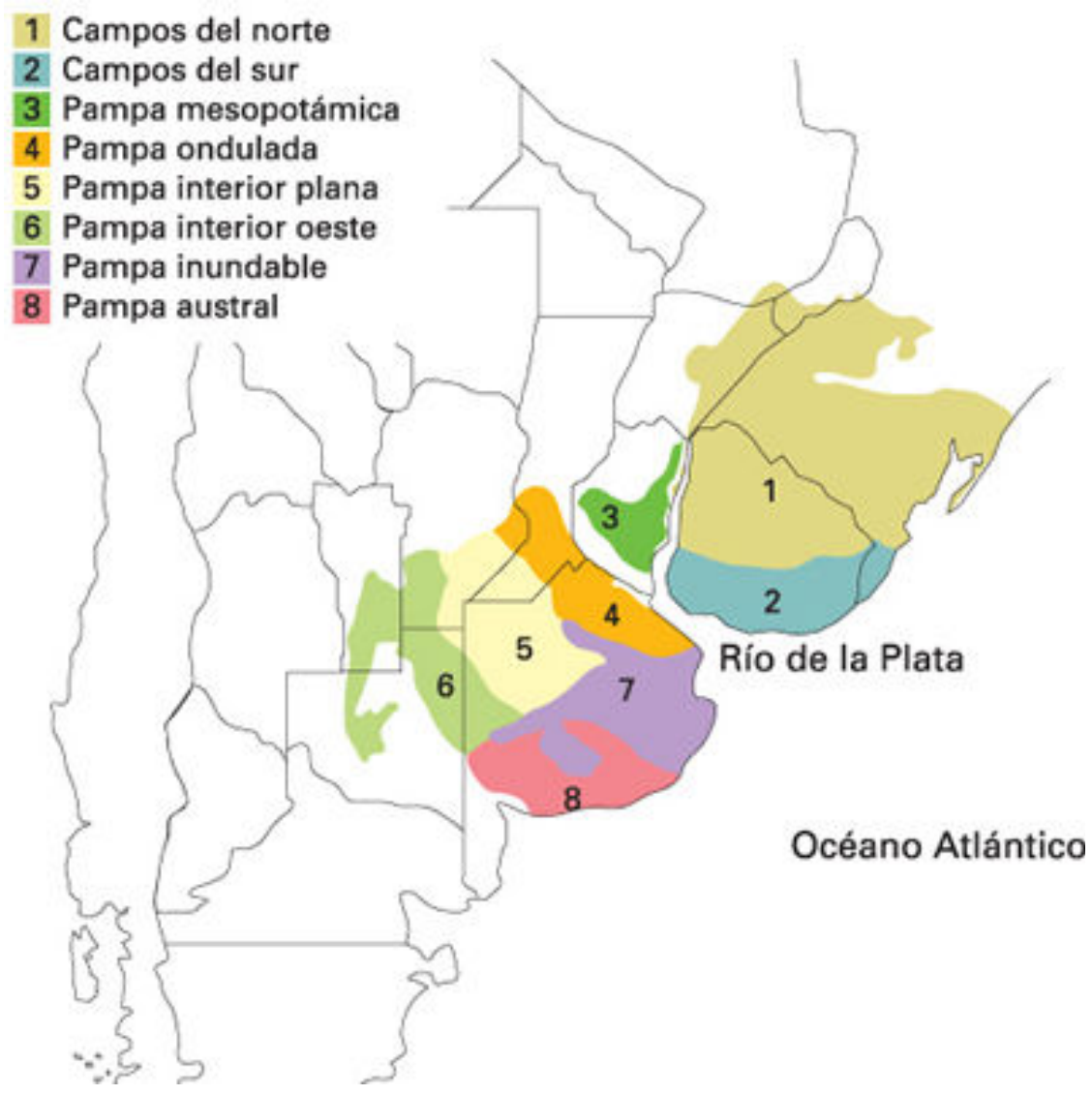

Fuente: Tomado en línea de: www.cienciahoy.org.ar/In/hoy101/agricultura.htm

En los últimos cinco siglos el ecosistema ha sufrido importantes modificaciones por efecto de la acción del hombre. En primer lugar, la introducción del ganado por parte de los europeos produjo distintos cambios que antecedieron, incluso, a la efectiva ocupación del espacio. Luego la actividad agropecuaria transformó esos ecosistemas en agroecosistemas. Es decir, ecosistemas manipulados por el hombre que modifica sus componentes bióticos (por ej: introducción de nuevas especies) y abióticos (por ej: cambios en los nutrientes o la humedad del suelo) para producir alimentos y fibras. Los arreos de ganado que ayudan a la dispersión de semillas ayudaron a difundir especies leñosas como el caldén y el chañar desde los montes cercanos. El pastoreo y el fuego, por su parte, implicaron un aumento de los cardos y la consecuente disminución de las gramíneas. Por otro lado, la plantación de álamos para producir sombra, sirvió también para que los horneros, zorzales y cotorras pudieran anidar y se convirtieran en nuevos 
diseminadores de semillas. En conclusión, la combinación de estos procesos implicó un aumento de la diversidad y una disminución de las especies dominantes (Bibenca y Miñaro, 2004: 22-27).

Por último, para terminar con esta breve descripción de las condiciones medio ambientales hace falta considerar dos áreas que aportan una importante biodiversidad. Entre la Pampa ondulada y la Pampa mesopotámica se encuentra el Delta del Paraná. Esta zona presenta características únicas dentro de la región. El Delta se extiende a lo largo de $300 \mathrm{~km}$, desde el sur de Diamante hasta las proximidades de la ciudad de Buenos Aires, y cubre una superficie de $17.000 \mathrm{~km}^{2}$. Siguiendo la propuesta de Malvárez (1999: 36-47), esta área puede ser definida como un mosaico de humedales compuesto por once unidades de paisaje diferentes ${ }^{11}$ (Anexo 2). Los humedales evitan las deficiencias hídricas temporarias y las temperaturas extremas generando un clima similar al subtropical. Esas condiciones climáticas permiten que las especies de flora y fauna procedentes de las llanuras templadas convivan con otras más típicas de las regiones subtropicales de los ríos Uruguay y Paraná (Ibíd.: 32-34).

En el extremo opuesto de la región existen otros humedales con características muy diferentes a las del Delta. Acompañando la costa atlántica ${ }^{12}$, desde Punta del Este hasta la laguna Merin, se encuentran una serie de lagunas con y sin conexión con el mar. Las lagunas del Sauce y Negra no tienen conexión con el océano, en cambio Garzón, Rocha y Castillo se comunican con el mar de manera intermitente por una barrera arenosa (Clara y Manegro: 73). Un caso particular es el de la laguna de José Ignacio que se mantiene abierta por la intervención del hombre. Al igual que la zona estuarina del Río de la Plata, esas lagunas constituyen áreas de cría para muchas especies que son relevantes para las actividades pesqueras (corvina blanca, lenguado, lisa, entre otros) (Masello y Menafra, 1998: 126).

En consecuencia, las características ambientales del espacio que nos ocupa han mostrado ser bastante más complejas que un simple río rodeado por llanuras. Hemos podido observar la diferencias entre el río y las zonas estuarinas y marítimas, así como la composición de sus canales con las lógicas consecuencias que esa morfología

\footnotetext{
${ }^{11}$ Malvárez (1999: 36) distingue cada unidad a partir de sus distintos patrones de paisaje, el régimen hidrológico a la que esta sometida y el tipo de vegetación predominante.

${ }^{12}$ Las zonas costeras, en realidad, también son consideradas humedales hasta los 15 metros de profundidad en los momentos de marea baja. (Clara y Manegro, 1999: 71).
} 
implicaba para la navegación de la época. Por otro lado, vimos de qué manera los diferentes tipos de suelos podían implicar la posibilidad de éxito o fracaso para la agricultura en las condiciones técnicas del siglo XVIII. Así como la existencias de montes y humedales permitía el surgimiento de actividades económicas que, como veremos más adelante, brindaban alternativas de ocupación diferentes a las habitualmente consideradas.

\subsection{Ocupación del espacio y conformación del complejo portuario}

Las costas del río fueron el lugar donde se establecieron los primeros asentamientos de los europeos en la zona. Las ciudades portuarias que surgieron en ambas bandas del río fueron conformando, junto a los incontables desembarcaderos informales, lo que Fernando Jumar (2000: 112-113) denominó como complejo portuario rioplatense. Ese complejo constituyó el núcleo de la región Río de la Plata y cumplía una función integradora de la economía regional.

Jumar distingue una primera etapa de formación del complejo portuario que comienza con la segunda fundación de Buenos Aires en 1580 y se prolonga hasta la restitución de Colonia de Sacramento a los portugueses en $1716^{13}$. A pesar de las restricciones legales al comercio impuestas por la corona española, desde 1716 hasta 1777 el complejo portuario funcionó como algo similar a una zona franca para el comercio internacional debido a que la presencia portuguesa en Colonia del Sacramento impedía el control efectivo de la circulación de navíos por parte de la corona española dentro del río. La expulsión definitiva de los portugueses en ese último año cambió esa situación hasta que los sucesos políticos de los primeros años del siglo XIX y la rendición de Montevideo ante las tropas lusitanas en diciembre de 1816 liberaron nuevamente la navegación dentro del río.

\footnotetext{
${ }^{13}$ De acuerdo al autor, esta etapa formativa, a su vez, puede ser dividida en cuatro fases. La primera fase se corresponde al período 1580-1618 durante el cuál los vecinos de Buenos Aires sobrevivían gracias a las licencias que otorgadas por la corona española para comerciar con el territorio brasileño. La fase siguiente se extiende desde la apertura de la ruta Andalucía - Río de la Plata por medio de los navíos de registros en 1622 hasta la instalación, de manera permanente, de los portugueses en Colonia del Sacramento en 1683. Desde ese año hasta la expulsión de los portugueses en 1705 tenemos la tercera fase que se presenta como una antecedente del funcionamiento que luego va a tener el complejo portuario. Finalmente durante los años de la Guerra de Sucesión tiene lugar la última fase formativa (Jumar, 2000: 112-113).
} 
La fundación de Montevideo en 1724-26 tuvo importantes consecuencias en el funcionamiento del complejo portuario. Como vimos, la ciudad está ubicada sobre el canal oriental en la zona estuarina del Río de la Plata. Por lo tanto, el trayecto hasta ese puerto permitía evitar los peligrosos bancos y, al mismo tiempo, presentaba una profundidad adecuada para recibir a las embarcaciones del comercio ultramarino. Con el tiempo, Montevideo se transformó en el puerto de aguas profundas de Buenos Aires. Los navíos detenían su recorrido en ese lugar y trasbordaban las mercancías a otras embarcaciones más adecuadas para realizar el viaje por el río hasta la capital virreinal. De esa manera, un intenso tráfico de lanchas ${ }^{14}$ conectaba íntimamente a las dos ciudades.

A partir 1755, año de la fundación de Maldonado, los navíos contaron con una escala en la entrada del estuario. El puerto de Maldonado proporcionaba abrigo a las embarcaciones que se quedaban un par de días realizando reparaciones, abasteciéndose o simplemente esperando que las condiciones climáticas del estuario mejorasen para ingresar o para emprender la salida al mar.

Por otro lado, como Buenos Aires no tenía condiciones óptimas para recibir embarcaciones surgieron en sus cercanías puertos alternativos que poseían mejores condiciones naturales para hacerlo. Al norte de la ciudad se situaba el puerto de Las Conchas ${ }^{15}$. Su ubicación lo hacía receptor natural de las embarcaciones que bajaban por los río Paraná y Uruguay por lo que era una zona de una gran actividad comercial.

Unos kilómetros al sur de la capital virreinal se encontraba la Ensenada de Barragán, que recibía las lanchas que debían interrumpir su navegación hacía Buenos Aires cuando las condiciones climáticas no eran adecuadas. De esta manera, las mercancías eran descargadas y continuaban el viaje por tierra. El puerto también ofrecía abrigo para que los navíos pudieran ser carenados ${ }^{16}$.

Además de estos puertos y apostaderos navales había una cantidad innumerable de desembarcaderos informales y muchas estancias poseían sus propios puertos

\footnotetext{
${ }^{14}$ Lancha es un término impreciso con el que se denominaba los distintos tipos de embarcaciones que surcaban el río y que podían ir desde un bote hasta un pequeño bergantín.

${ }^{15}$ Estaba emplazado en el lugar que actualmente ocupa la localidad de Tigre.

16 La carena comprendía todas las operaciones necesarias para mantener las embarcaciones en condiciones aptas para la navegación lo que incluía tanto reparaciones como la limpieza de los fondos para evitar que las maderas se pudran entre otras actividades.
} 
naturales desde donde podían enviar su producción a las ciudades-puertos ${ }^{17}$ Jumar (2012: 127).

Mapa 3. Plano del Río de la Plata con indicaciones de profundidad y tipos de fondos

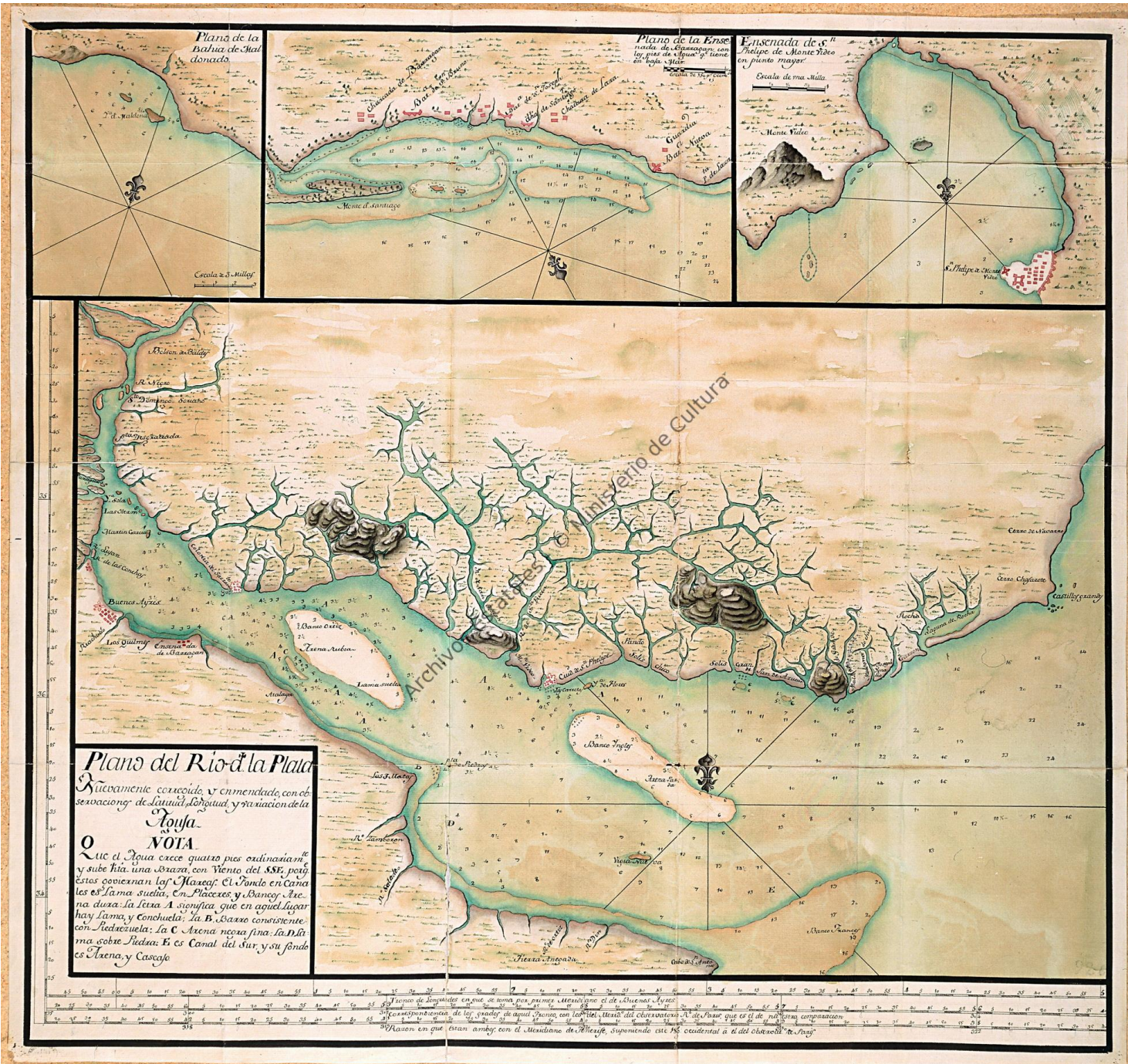

Fuente: Archivo General de Indias (en adelante AGI), Mapas y planos, Buenos Aires, 92B. Disponible en línea: pares.mcu.es

${ }^{17}$ Como, por ejemplo, la Estancia del Colla donde Francisco Medina instaló un saladero de carne en 1787 (Montoya, 1984: 127). 
El mapa 3 elaborado por la administración de los correos marítimos en $1770^{18}$ es una muestra de los conocimientos sobre las condiciones de navegación del Río de la Plata que se tenían en la segunda mitad del siglo XVIII. En la parte superior podemos ver los planos de los puertos de Maldonado, Ensenada de Barragán y Montevideo respectivamente. En todos los planos están indicadas las variaciones en la profundidad y en el plano general del Río de la Plata se específica, además, la composición de los distintos tipos de fondos. También se destaca la crecida del río producto de las mareas y la influencia del viento del sudeste en las mismas (ver Anexo 3). En el mapa se encuentran señalados todos los elementos del complejo portuario que hemos analizado.

Esos atracaderos, puertos naturales, apostaderos navales y ciudades portuarias se fueron consolidando propiciando el asentamiento de pobladores. Con el tiempo, las demandas de las ciudades incentivaron también la ocupación del territorio circundante y la consecuente producción agropecuaria en esas tierras con el fin abastecer a los habitantes de las ciudades y a la población flotante portuaria.

Los datos muestran que la expansión demográfica de esos años fue más que considerable. La ciudad de Buenos Aires y su campaña crecieron de manera constante: 17.663 habitantes en 1744, 37.288 en 1778 y 78.728 en 1810. Las tasas anuales de crecimiento demográfico entre estas fechas $(2,21 \%$ y $3,24 \%)$ muestran que durante la segunda mitad del siglo XVIII existió una aceleración de ese aumento (Cuesta, 2006: 211).

Ese crecimiento demográfico se repite en el resto de la región. De acuerdo a los datos proporcionados por Jorge Gelman (1998: 246-247) la población total del área de Colonia del Sacramento creció entre 1778 y 1798 de 3.067 a 5.192 habitantes en un promedio anual de 2,9 \%. La jurisdicción de Montevideo durante el mismo período presentaba una tasa de crecimiento anual de 5,56 \% y pasó de 5.652 a 16.256 habitantes (Pollero y Vicario, 2009: 46).

En ese mismo año de 1798 la población del área de Maldonado, que incluía también a San Carlos y Rocha, ascendía a 3178 personas (Biangardi, 2013: 25). Finalmente, contamos con escasos datos para las poblaciones ubicadas al occidente del río Uruguay. En 1781 había 365 pobladores en el Arroyo de la China, en el mismo lugar

\footnotetext{
${ }^{18}$ El mapa lleva el título de "Plano del Río de la Plata, nuevamente corregido y enmendado, con observaciones de latitud, longitud y variaciones de la aguja" y fue remitido por el Administrador de Correos de la Coruña a los directores generales de Correos, con carta de 14 de marzo de 1770.
} 
en el que poco después se fundó la villa de Concepción. Por otro lado, algunos padrones para formar milicias realizados entre 1782 y 1784 revelan la presencia de 270 varones adultos (227 "blancos" y 43 “naturales") en Gualeguay, Gualeguaychú y Concepción (Djenderedjian, 2003: 110-111). En 1803, en cambio, la población de Gualeguay ascendía a 1408 habitantes (Ibíd.: 137).

En consecuencia, más allá de los datos un poco dispersos con los que contamos, podemos decir que en su conjunto la región se encontraba en la segunda mitad del siglo XVIII en un momento de un importante crecimiento demográfico y de expansión del espacio ocupado ${ }^{19}$ lo que, sin duda, es revelador de la vitalidad de esa sociedad y constituye un indicio de la existencia de un crecimiento económico.

\subsection{Una definición de la región Río de la Plata}

Con los elementos retenidos sobre las características del medio ambiente, la historia de la ocupación del espacio y la evolución demográfica de esa sociedad podemos pasar a definir la región que constituye el marco de nuestro estudio. Al mismo tiempo, podremos precisar algunos conceptos que utilizaremos al momento de elaborar nuestras hipótesis.

Partiendo del estudio de la circulación mercantil y usando la noción elaborada por Perroux, Fernando Jumar (2011) propone definir la región Río de la Plata como un espacio económico homogéneo. La noción de espacio económico permite estudiar los flujos mercantiles sin las restricciones de los límites políticos y, al mismo tiempo, resalta el hecho de que la circulación interna es mayor que los intercambios con otros espacios. Por otro lado, el adjetivo de homogéneo implica que no es un espacio económico polarizado, lo que no significa que la región como un todo no se pueda transformar en un polo de atracción de un espacio mayor ${ }^{20}$.

\footnotetext{
${ }^{19}$ Esa expansión territorial implicó que los niveles de densidad poblacional se mantuvieron muy bajos a pesar del crecimiento demográfico.

${ }^{20}$ El espacio económico polarizado es aquel que se construye alrededor de una aglomeración urbana. Las distintas zonas de la región mantienen intercambios de bienes y servicios con mayor intensidad con la ciudad que con las regiones vecinas e incluso mayor que el que mantienen entre sí. De esta manera, el mercado urbano se transforma en un polo de atracción (Ferreira da Lima, 2003, 9). Daniel Santilli (2013, 254-256)) en su análisis del debate sobre el impacto económico de las reformas borbónicas en Buenos Aires destaca el papel del mercado urbano de Buenos Aires "como activador de producción para su propio consumo" con lo que parece asimilarlo a un polo de atracción pero esto se debe a que elije reducir
} 
Jumar (2012: 138) delimita la región de acuerdo a la medición de lo que considera como circulación interna de la región. Los flujos de estos circuitos, revelados por los datos contenidos en las guías de la Aduana de Buenos Aires, estarían conformados por los traslados de trabajadores temporarios y de alimentos frescos. El mapa 4 ilustra de manera aproximada esa delimitación correspondiente a los primeros años virreinales. El autor plantea, además, que hay cuatro aspectos a tener en cuenta a la hora de estudiar la historia de ese espacio. Por un lado, el cumplimiento de la función de intermediario entre la circulación interregional y el comercio ultramarino. Otro punto íntimamente ligado al anterior lo constituye la provisión de bienes y servicios que aseguran el funcionamiento de ese comercio. También es necesario considerar el consumo de los bienes importados por parte de los habitantes de la región. Por último, la presencia de un complejo productivo regional que gracias a la existencia de ese movimiento mercantil pudo exportar sus excedentes (Ibíd.: 126). Esta tesis, como se verá más adelante, aborda principalmente el estudio de este último aspecto.

La primer nota distintiva de la región, entonces, estaba dada por la presencia del complejo portuario que articulaba los distintos circuitos mercantiles que la atravesaban. Ese complejo también incluía un sector proveedor de bienes y servicios. A su vez, en las tierras circundantes encontramos un complejo productivo que podemos dividir en dos zonas: una primera zona de producción agropecuaria mixta y otra, más alejada de los puertos, donde predomina la ganadería extensiva. La localización de esas zonas en los años finales del siglo XVIII se puede observar en el mapa 4. La línea azul delimita de manera aproximada el complejo portuario y la línea verde sugiere una línea de división entre la zona de producción agropecuaria mixta y la zona donde predomina la ganadería extensiva.

En tanto que constituye una representación estática que no permite ilustrar los procesos históricos sujetos a cambios en el tiempo, este mapa no es más que una aproximación para mostrar la localización de las actividades económicas. Una delimitación exacta de las zonas con distintas orientaciones productivas sería

su objeto de estudio a Buenos Aires y su entorno. Lo que lo lleva también a la desdeñar la importancia de la exportación como actividad económica cuando dice que "..el motor del incremento productivo de Buenos Aires no fue el mercado externo sino el interno, no fueron los cueros para el mercado exterior, sino la carne y el trigo para abastecer a los habitantes de la ciudad...". Si, en cambio, tomamos la región Río de la Plata tal como se presenta en este trabajo Buenos Aires no aparece como un polo de atracción que polarice el espacio económico regional. Más allá de que, sin dudas, era el mercado urbano más importante. 
prácticamente imposible de realizar. Habitualmente los límites entre un sector y otro son difusos. A su vez, la región se encontraba en un momento de una importante expansión territorial y crecimiento demográfico por lo que las líneas del mapa deberían cambiar según el momento histórico en el cual nos situemos.

Las líneas rojas expresan una propuesta para dividir la región en áreas. Realizamos esa separación con fines analíticos con el recaudo, que siempre se debe tener en cuenta cuando se hace una abstracción, de que cada sección es parte de un todo más complejo. La división fue delineada a modo de trazo grueso para resaltar que esa división es hipotética y debe ser confirmada por las investigaciones en curso. Creemos que cada área podría estar determinada por la territorialidad que muestra el grado de control de los factores productivos por parte de agentes locales. Esta puede ser una manera de complementar el espacio económico comprendido por la circulación mercantil con la dinámica de la producción y sus consecuencias sociales. En el desarrollo de la tesis concentraremos nuestra atención en las áreas de Montevideo y Maldonado para poner a prueba esa idea.

Mapa 4. Región Río de la Plata

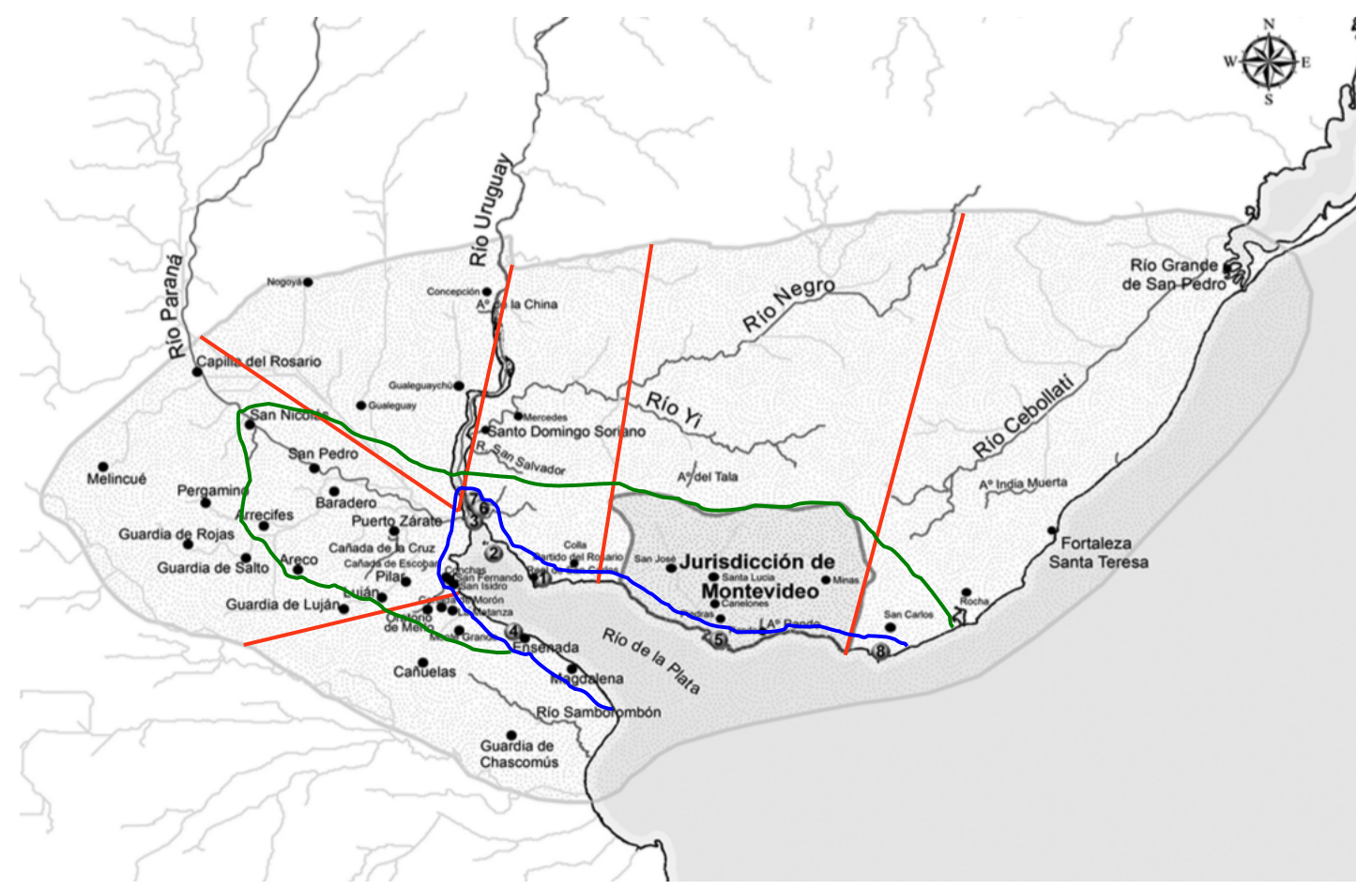

Fuente: Jumar y Biangardi (2013). 
De todas maneras, tal como están planteadas en el mapa, esas áreas se corresponden a los estudios realizados por Julio Djenderedjian (2003) para la zona de Concepción, Gualeguay y Gualeguaychú, por Jorge Gelman (1998) sobre Colonia de Sacramento y Santo Domingo Soriano, por María Inés Moraes (2011) para la jurisdicción de Montevideo y por nosotros (Biangardi, 2013) para el área de Maldonado. En este sentido, no son una novedad y se sostienen a partir de los datos que proporcionan las respectivas investigaciones.

Con respecto al espacio circundante a la ciudad de Buenos Aires existen, al menos, dos propuestas para fraccionarla. Por un lado, Juan Carlos Garavaglia (1999) analizó la campaña bonaerense a partir de los seis partidos decimales (Arrecifes, Areco, Luján, Matanza, San Isidro y Magdalena). Por otro lado, el Grupo de Investigación en Historia Rural Rioplatense plantea dividir la campaña en cuatro subregiones (cercana, norte, oeste y sur) a partir de las distintas características que presenta su población. ${ }^{21}$ Más allá de que las dos propuestas están ampliamente justificadas en los argumentos de los autores y de que tienen sus virtudes, pensamos que pueden ser revisadas en función de los criterios que nosotros planteamos para dividir en áreas la región. Por eso no están representadas en el mapa y sólo se plantea una supuesta división en dos partes que únicamente indica que la campaña de Buenos Aires debe ser dividida en áreas pero todavía no tenemos en claro como estaban constituidas a partir de los criterios que aquí se establecen.

De todas maneras, la mayoría de las investigaciones sobre la campaña bonaerense optaron por reducir la escala de análisis hasta los límites de una localidad. ${ }^{22}$ Entendemos que esa escala es asimilable a lo que en geografía se identifica con el concepto de lugar (Montañez Gómez, 2001: 27). Esa reducción de escala hasta lo local forma parte de una tendencia general que afectó tanto a la historia, especialmente por la

\footnotetext{
${ }^{21}$ Cada subregión incluía los pagos que se detallan a continuación. Cercana: Flores, Matanza, Morón, Quilmes, San Fernando, Las Conchas y San Isidro. Norte: San Nicolás de los Arroyos, San Pedro, Baradero, Pergamino, Arrecifes, Cañada de la Cruz, San Antonio de Areco, Fortín de Areco y Areco Arriba. Oeste: Luján, Pilar, Guardia de Luján, Navarro y Lobos. Sur: San Vicente, Magdalena, Chascomús, Monsalvo, Tordillo y Montes Grandes. Grupo Investigación en Historia Rural Rioplatense (2004: 29-30).

${ }^{22}$ Ver: Andreucci (2011), Banzato (2002), Barcos (2010), Birocco (2003), Canedo (2001), Ciliberto (2004), Contente (1999), Di Stefano (1991), Dupuy (2004), Mateo (2001), Marquiegui (1990), Mascioli (2004).
} 
influencia de la microhistoria (Schmit, 2004: 59-60), como a la geografía, aunque por motivos diferentes ${ }^{23}$.

El mayor inconveniente de ese recorte del objeto de estudio es el de separar la oferta de la demanda. Implica analizar la producción separada de sus centros consumidores y, viceversa, el consumo sin analizar el origen de los bienes. De la misma manera, separar los puertos de las fronteras donde se explota el ganado cimarrón tiene como consecuencia la imposibilidad de corroborar la correlación entre la producción corambrera y la disponibilidad de espacio en las bodegas de los barcos.

En este sentido, consideramos que el concepto de región Río de la Plata, elaborado por Fernando Jumar, que venimos analizando brinda la posibilidad de realizar un juego de escalas. Es decir, ampliar o reducir la escala uniendo distintos niveles de análisis. Así se puede incluir la región en un espacio rioplatense más amplio para entender los circuitos mercantiles que atraviesan el territorio regional o dividirla en áreas para dar cuenta del control de los factores productivos por parte de los agentes económicos. De esta manera, en el análisis se unen distintos niveles que habitualmente se consideran de manera separada: producción, circulación, consumo y fiscalidad.

Por último, queremos destacar que la división en áreas de la región que se propone tiene su origen en una hipótesis de trabajo según la cual la territorialidad de los actores locales explicaría la fragmentación de la región y la formación de nuevas entidades políticas a partir de la segunda década del siglo XIX. A pesar de que la región, como tal, continúo existiendo como espacio económico ya que la circulación mercantil se mantuvo constante, aunque con algunas variaciones en sus características como reflejo de esas cambiantes condiciones políticas e institucionales.

Desde este punto de vista es clave la distinción entre territorio y territorialidad. El territorio se define a partir del dominio hegemónico que un actor, en este caso la monarquía, ejerce sobre un espacio geográfico. Recordemos que la hegemonía implica tanto coerción como consenso, entonces la corona mantiene el dominio sobre el espacio porque el resto de los actores sociales reconocen ese dominio aunque el aparato coercitivo sea débil. Pero ese dominio hegemónico no excluye la posibilidad de que otros agentes tengan un grado de dominio sobre parte de ese mismo espacio aunque de

23 "En los últimos tiempos se advierte una tendencia a integrar la escala regional en lo local, pasando de una meso-región, o región media, a una de carácter micro.” (Ramírez, 2007: 127). 
manera subordinada (Montañez Gómez, 2001: 22). Esa dominación implica, necesariamente, un control sobre el acceso a los principales factores productivos, lo que en Río de la Plata significaba una intima relación entre las posibilidades de acumulación que brinda la ganadería ${ }^{24}$ y la constitución de esos grupos con poder local.

De todas maneras, si bien esta distinción entre territorio y territorialidad puede resultar muy útil a la hora de la reflexión, es necesario reconocer que no es tan nítida en el período que vamos a estudiar. Esto tiene que ver especialmente con las características de la monarquía como sistema político. En este sentido, los estudios que plantean una caracterización de la monarquía como compuesta o policéntrica ${ }^{25}$ matizan la idea de una unidad de la monarquía y, por ende, nos obligan a pensar en una concepción territorial que se acerca mucho a la territorialidad de estos actores con poder local o regional que estamos mencionando.

En consecuencia se torna necesario estudiar la territorialidad de los actores locales dominantes en distintas partes de la región. Cuando la monarquía desapareció como agente hegemónico, esos actores locales quedaron con su dominio territorial para establecer negociaciones a nivel regional y constituyeron la base sobre la que se cimentaron los nuevos movimientos políticos surgidos en los primeros años del siglo XIX.

\section{Estructura de la tesis, hipótesis y metodología}

En esta tesis realizaremos un análisis de la circulación y producción de bienes pecuarios y del accionar de los agentes involucrados en esas actividades económicas en la región Río de la Plata durante los años finales del siglo XVIII. Como veremos más adelante, ese accionar no se limitaba a la esfera de la economía por lo que su estudio implica abordar también aspectos de la política y la sociedad de la época.

El presente trabajo busca destacar la importancia de la producción y circulación de bienes pecuarios en la economía de la región Río de la Plata, particularmente en las

\footnotetext{
${ }^{24}$ Julio Djenderdjian (2003: 96) sostiene que, a diferencia del comercio, la ganadería proporcionaba una posibilidad de acumulación independiente de la relación con la ciudad capital.

${ }^{25}$ Para un análisis de la monarquía compuesta ver: (Russell y Gallego, 1996); y para una caracterización de las monarquía policéntrica ver: (Cardim, Herzog, Ruiz Ibáñez y Gaetano, 2012).
} 
áreas de Montevideo y Maldonado, dejando para investigaciones futuras la tarea de corroborar los planteos de esta tesis para el resto del espacio regional. Este recorte del objeto de estudio es necesario para poder profundizar en los diferentes aspectos a tratar, que permiten poner a prueba las hipótesis esgrimidas en el texto. Ese análisis destaca que existían dos maneras de producir los mismos bienes, las vaquerías y la ganadería de rodeo, y, a partir del análisis de las diferencias entre esas dos actividades productivas proponemos una categorización de los agentes económicos acorde a esa situación ${ }^{26}$.

El análisis de esas actividades económicas muestra que la expansión territorial de la región Río de la Plata de los años finales del siglo XVIII habría propiciado el surgimiento de grupos de agentes vinculados a la producción de bienes pecuarios, con posibilidades de entablar relaciones de poder en el ámbito local y negociaciones a nivel regional, que los situaron como actores locales dentro de la monarquía policéntrica. La territorialidad de estos grupos de agentes habría implicado una cierta fragmentación de la región. Ese fraccionamiento antecede a la situación desencadenada por la crisis final del sistema político de la monarquía borbónica durante los primeros años del siglo XIX. De esta manera, la presente investigación se propone realizar aportes que contribuyan a lograr una visión de largo plazo sobre la estructura económica del espacio rioplatense y sus manifestaciones políticas; entre las que se destacan los procesos de formación de estados, ya sean provinciales o nacionales, en la región..

Con este objetivo se utilizó la información contenida en un conjunto de fuentes de distinta índole. En primer lugar, a partir de fuentes cuantitativas se elaboraron series que, con un tratamiento estadístico simple, permitieron observar la circulación de los productos pecuarios, la existencia de establecimientos comerciales en el ámbito rural y los comportamientos de los mercados de compra-venta de tierras y esclavos.

Para medir la circulación de los productos se recurrió a tres fuentes inéditas. Para el circuito montevideano de cueros, grasa y sebo durante el período 1784-1790 se elaboraron series a partir de relaciones mensuales que contenían los nombres de los introductores de esos productos a la ciudad, el día en que esa operación tuvo lugar y las cantidades respectivas de cada bien. La información contenida en esas relaciones se originaba en el control que llevaba a cabo un funcionario del aparato virreinal en el

\footnotetext{
${ }^{26}$ En esta tesis utilizamos el término agente económico para indicar los individuos, grupos $\mathrm{u}$ organizaciones que tienen una capacidad de agencia (control, disponibilidad, etc.) sobre los factores de producción.
} 
portón de la ciudad ${ }^{27}$. Las relaciones eran enviadas mensualmente por el gobernador de Montevideo al virrey por lo que se encuentran dentro de esa correspondencia. Para las series de cueros introducidos a Montevideo en el período 1791-1797 las series se construyeron a partir de la información contenida en las listas de contribuyentes de una contribución que en esos años se pagaba por cada cuero que ingresaba a la ciudad que se encuentran dentro de la documentación de la fábrica de la iglesia matriz de Montevideo. En estas listas el síndico de la iglesia anotaba el día, el nombre, y la cantidad de cueros orejanos y marcados por los que cada individuo abonaba la contribución. Ambas fuentes se encuentran en la sala IX del Archivo General de la Nación (en adelante AGN) de Argentina. En cambio, para los envíos de cueros, sebo y grasa desde Maldonado hasta Montevideo entre los años 1782 y 1806 las series se elaboraron con los datos contenidos en los libros auxiliares de alcabala de la Caja Real de Maldonado que registraban las guías para el tránsito de bienes. Las guías se asentaban de manera completa y contenían: el número de guía, nombre del dueño de los bienes y/o del transportista, los bienes con sus respectivas cantidades, aforo y cuanto se debía pagar de alcabala por cada uno. Es importante destacar que los productos que estaban exentos del pago también se asentaban. Estos libros eran remitidos al Tribunal de Cuentas situado en Buenos Aires para su control y por eso se encuentran en la Sala XIII del AGN de Argentina.

En el caso de los establecimientos comerciales en la campaña de Maldonado se recabo la información de los libros de composturas de pulperías de la Caja Real de Maldonado que registraban el nombre del dueño (a veces también el del empleado a cargo) del establecimiento, el lugar donde se encontraba, el dinero que abonaba y el período por él que lo hacía. Para las compra-venta de bienes inmuebles y de esclavos en Maldonado se recogieron los datos de los libros auxiliares de alcabala de ventas de la Caja Real de Maldonado que contiene la información del bien por el que se efectuaba la operación, el valor declarado del bien, el dinero abonado por el impuesto, la fecha en que se lo hacía y los nombres del vendedor y del comprador. Al igual que los anteriores, todos estos libros eran remitidos al Tribunal de Cuentas y se pueden consultar en el mismo lugar. En cambio, para las series del mercado de compra-venta de bienes inmuebles rurales del área de Montevideo se recurrió a los datos provenientes de los

\footnotetext{
${ }^{27}$ Recordemos que Montevideo era una ciudad fortificada.
} 
protocolos notariales de esa ciudad editados en la colección de documentos dirigida por Pivel Devoto (1964).

Por otro lado, se utilizó el padrón de Aldecoa de 1772-1773 editado por Apolant (1966a) para realizar una comparación entre agregados y peones en el área de Montevideo. El padrón contiene información sobre los nombres, las edades, el estado civil, los orígenes geográficos o étnicos de cada individuo y el lugar donde habitaba con lo cuál permite observar cuántos peones y agregados había, su estructura etaria, si estaban casados o no y de dónde provenían.

En segundo lugar, se utilizaron fuentes cualitativas, como juicios, informes de funcionarios y actas de los cabildos, para analizar el accionar de los agentes económicos estudiados que se centraba especialmente en asegurar la apropiación de los factores productivos y tratando de eliminar, o más bien disminuir, la competencia de otros agentes que buscaban el usufructo de esos mismos recursos.

Para el análisis de la apropiación de la tierra se analizaron las denuncias, juicios y contratos de arrendamientos editados en la colección de documentos dirigida por Pivel Devoto (1964). Para el caso de Maldonado se estudiaron las solicitudes de tierras efectuadas ante los comandantes militares y el encargado de la Caja Real de Maldonado que no están editadas en dicha colección sino que se encuentran entre la documentación del Cabildo de Maldonado en el Archivo Judicial del AGN de Uruguay.

Con respecto a los embargos de cueros llevados a cabo por el aparato represivo virreinal se utilizaron los informes efectuados por los comandantes y capitanes que patrullaban la campaña y que luego eran enviados al virrey por el gobernador de Montevideo y, por lo tanto, están dentro de esa correspondencia que, como ya mencionamos, se encuentra en la sala IX del AGN de Argentina. Por otro lado, para el estudio del los embargos efectuados por el cabildo de Montevideo, conflictos entre vecinos y la represión del abigeato se analizaron juicios que tuvieron lugar en los cabildos de Montevideo y Maldonado y están en la documentación de esas instituciones en el Archivo Judicial del AGN de Uruguay.

Para el estudio prosopográfico de los corambreros montevideanos se utilizó la información sobre casamientos y nacimientos de los libros parroquiales de la iglesia matriz de Montevideo editados por Apolant (1966b) y los datos sobre circulación de 
bienes pecuarios y sobre denuncias y compra-ventas contenidos en las fuentes mencionadas con anterioridad.

Por último, para analizar la actuación de los agentes en las instituciones y corporaciones se estudiaron los acuerdos del Cabildo de Montevideo editados por el AGN de Uruguay y los acuerdos inéditos del Cabildo de Maldonado que se encuentran en la sede central de ese archivo.

El resultado de esa investigación se encuentra volcado en las páginas que siguen y fue organizado en nueve capítulos. En el primer capítulo se realiza una balance historiográfico que repasa los análisis existentes sobre la producción agropecuaria en las distintas áreas de la región, las distintas formas de encarar el concepto de frontera y las características de las distintas zonas enmarcadas dentro de esa categoría y las relaciones de poder que emergen del estudio de todos estas actividades económicas y sus manifestaciones sociales y políticas. Ese repaso permite retener varios elementos que servirán para estructurar el desarrollo de la tesis. Sobre todo la existencia de dos actividades económicas diferentes dedicadas a la explotación del ganado, las peculiaridades de la expansión territorial de la región, así como del acceso a los recursos institucionales para el control de los factores productivos y la consecuente conformación de grupos con poder local con intervención en el sistema político de la monarquía,

En el capítulo 2 se presenta la circulación de los bienes pecuarios desde su lugar de producción hasta su arribo a la ciudad portuaria de Montevideo. En primer lugar, se realiza un repaso de los datos disponibles sobre la exportación de cueros y otros derivados del ganado vacuno de la región, de la información sobre la procedencia de esos bienes y del debate historiográfico sobre el diezmo de cuatropea para dar cuenta de la producción ganadera. Luego se pasa al análisis de la circulación de los bienes a partir de las series construidas con la información relevada de tres fuentes diferentes, que ya fueron mencionadas más arriba. Así, se puede observar el crecimiento de la producción de cueros durante 1784-1790 y el estancamiento en el período posterior de 1791-1797, además de la procedencia de los bienes pecuarios, la incidencia de las vaquerías en la estacionalidad de las introducciones de cueros, el peso de la ganadería de rodeo en la producción de sebo y la expansión durante un período más amplio 1782-1806 del área de Maldonado. 
En el capítulo 3 se presentan las características de las dos actividades económicas, las vaquerías y la ganadería de rodeo, que implican dos maneras muy diferentes de producir los bienes pecuarios y, también, se describen los establecimientos productivos. Además, se realiza un análisis del sistema de comercialización de esos bienes y se ensaya una categorización de los agentes involucrados acorde a las actividades presentadas.

En el capítulo 4 nos ocupamos de la producción de los otros bienes que derivaban del ganado, además del cuero. De esta manera, se analiza la extracción y destino del sebo y la grasa, el consumo de carne fresca y las condiciones de producción de las carnes saladas.

Los capítulos 5, 6 y 7 analizan la manera en que una parte de esos agentes se apropió de los factores necesarios para la producción pecuaria, en este caso la tierra, el trabajo y el ganado. El capítulo 5, entonces, presenta las distintas formas de apropiarse del factor tierra. En consecuencia se describen los repartos y mercedes de tierras para chacras y estancias, las denuncias, ventas y composiciones de tierras realengas, así como el surgimiento de un incipiente mercado de tierras a nivel regional y, por último, damos cuenta de algunos contratos de arrendamiento que, contrariamente a lo acostumbrado,se hicieron por escrito.

El capítulo 6 describe la utilización de distintos tipos de mano de obra en la producción de bienes pecuarios. Es decir, se analizan el salario a destajo en las vaquerías, las causas de la escasez de mano de obra para las estancias, el recurso de la utilización de mano de obra esclava y el caso particular de los habitualmente denominados como agregados.

En el capítulo 7 se indaga sobre los diferentes modos de asegurar la propiedad del ganado derivada de la tenencia de la tierra y los establecimientos productivos. A tal fin, se analizan las disputas entre distintos grupos de agentes (por ejemplo, entre los administradores misioneros y los autodenominados hacendados montevideanos) y, especialmente, los embargos de cueros y juicios por abigeato, en donde se vislumbra la actividad represiva ejercida sobre los diferentes competidores por la apropiación del recurso. En este sentido, veremos que existen diferencias entre la represión llevada a cabo por los mismos agentes económicos y la emprendida desde el estado virreinal. 
El capítulo 8 presenta una primera aproximación a un estudio prosopográfico de un grupo de agentes económicos vinculados a la explotación del ganado cimarrón que definimos como corambreros montevideanos. De esta manera, se describen tres etapas que pudimos identificar. Primeramente un momento de constitución del grupo comformado por individuos que pudieron realizar denuncias de grandes extensiones de tierra realenga, consiguiendo así una posición privilegiada para explotar el ganado cimarrón. La segunda etapa se corresponde a un proceso de recomposición del grupo, acontecido durante la década del 1780, a partir de la incorporación de nuevos individuos. Esa inserción se realizó predominantemente mediante enlaces matrimoniales, coincidiendo con el momento en el que las denuncias de tierras realengas se hallaban suspendidas. Finalmente, en los años finales del siglo XVIII se puede empezar a observar una paulatina desaparición de este agente económico por la transformación de las condiciones de producción. Es decir, por el avance de la ganadería de rodeo que se evidencia en la fragmentación de las propiedades, tal como podemos observar en ventas, contratos de arrendamientos y testamentarias que presentamos en el texto.

Por último, en el capítulo 9 se estudia la manera en la que esos agentes se constituyeron como grupos sociales con poder local. Para eso se analizan las actuaciones en defensa de sus intereses que parte de esos agentes desarrollaron en el marco de su participación en los cabildos de Maldonado y Montevideo, en las negociaciones que emprendieron con las autoridades virreinales y en sus intentos de organización corporativa a través de las juntas de hacendados.

De esta manera, se espera que el conjunto de los temas tratados brinde una imagen bastante completa de los diferentes aspectos de la producción pecuaria en las áreas de Montevideo y Maldonado durante los años finales del siglo XVIII que es posible extender a otras áreas ganaderas de la región Río de la Plata. Ese análisis permite, además, observar que el accionar de esos agentes económicos en el plano político y social tuvo importantes repercusiones en la constitución de una determinada trama de relaciones de poder político y social. En este sentido, los resultados de esta investigación pueden contribuir a la construcción de una visión de largo plazo sobre las relaciones de poder en el Río de la Plata. Esa perspectiva permitiría comprender mejor 
los factores internos que gravitaron en los procesos históricos de fines del siglo XVIII y comienzos del XIX en el Río de la Plata. 


\section{Capítulo 1}

\section{Producción agropecuaria, fronteras y relaciones de poder en las praderas rioplatenses}

La visión tradicional sobre el mundo rural del siglo XVIII y de los primeros años del XIX en Argentina y en Uruguay se inició a partir de los planteos de los fundadores de las historiografías nacionales (Mitre y Bauza) que a fines del siglo XIX coincidían en una visión negativa y simplificada de las campañas rioplatenses que justificaban sus críticas al caudillismo como uno de los principales males de sus respectivos países. Esa perspectiva estaba teñida por la dicotomía civilización/barbarie que se representaba geográficamente en la distinción ciudad/campo. Es decir, la ciudad como un polo civilizador que en momentos de anarquía podía ser invadido por la barbarie circundante ${ }^{28}$. En esa línea argumental el caudillismo era el producto de ese mundo rural.

Partiendo de esa perspectiva, autores posteriores construyeron un relato que se sustentaba en las impresiones que habían en los relatos de los viajeros europeos y los informes de funcionarios. Varios autores, como Levene (1927, 1940), Coni (1945, 1979), Giberti (1986) y Slatta (1985), tomaron esas fuentes y describieron un campo compuesto por grandes estancias ganaderas y habitadas por hombres solteros a los que se denominaba como gauchos, que con matices confirmaban lo central de la visión tradicional. Ahora podemos decir que esos planteos eran aplicados al siglo XVIII por el error de retrotraer una realidad más típica de algunas zonas de las praderas rioplatenses durante el siglo XIX.

\footnotetext{
${ }^{28}$ En Argentina se identifica esta modalidad argumental con el pensamiento de Sarmiento debido a la difusión de su ensayo sobre Facundo Quiroga y la potencia persuasiva de su pluma, pero esas ideas fuerza eran una constante en todo el pensamiento hispanoamericano en la época. Una muestra de esto son las llamativas similitudes en las obras de Mitre y Bauzá.
} 
De todas maneras, el lugar central que ocupaba la figura de Artigas en la historia uruguaya obligó a que ya desde la década del cincuenta del siglo XX comenzaran a estudiarse con más detenimiento la historia rural. El trabajo de Pivel Devoto (1952) sentó las bases de la nueva interpretación sobre el mundo rural, en este caso, de la "Banda Oriental". Su obra tenía por objetivo desentrañar las causas del alzamiento oriental de 1811, destacando al mismo tiempo la figura de Artigas. El autor subrayó el carácter rural de ese alzamiento y, en consecuencia, ubicó en un lugar central de su argumentación a los problemas estructurales de la campaña.

Para los objetivos de nuestra investigación nos interesa destacar tres puntos de la argumentación de Pivel que tuvieron una continuidad en las obras de los autores posteriores. En primer lugar, el autor destacó la existencia de dos tipos de unidades productivas ganaderas. Un tipo de "estancia cimarrona” donde no había cría de animales y solamente se explotaba el cuero de los animales y otro tipo estancia donde "la explotación se efectuaba de forma más metódica" ya que el ganado estaba sujeto a rodeo (Pivel Devoto, 1952: 13). En segundo lugar, describió una trama de relaciones sociales que asimilo a la del feudalismo europeo siendo la estancia una especie de señorío y, por ende, el estanciero un señor feudal con dependientes que conformaban su hueste (Ibíd.: 14). En tercer lugar, hizo hincapié en una serie de informes de funcionarios que plateaban los problemas de la campaña, especialmente en la "Banda Oriental”, y proponían planes para solucionarlos, que desde su obra se conocerán como la cuestión del arreglo de los campos y tendrán un lugar central en el análisis de los historiadores posteriores ${ }^{29}$.

La obra de Pivel Devoto se constituyó en la visión dominante en Uruguay sobre este tema que en la década siguiente se consolidó con las obras de Campal (1962), Barrán y Nahum (1964), Reyes Abadie, Bruschera y Melogno (1966) y Sala de Tourón, de la Torre y Rodríguez $(1967$; 1968), que con algunos matices confirmaron los argumentos principales de esa perspectiva. Ninguno de estos autores discutió los puntos centrales de perspectivas, incluyendo la naturaleza feudal de las relaciones sociales en la campaña, aunque incorporaron algunos matices. Entre estos se puede destacar el debate

\footnotetext{
${ }^{29}$ Hay otros aspectos de la obra de Pivel Devoto que pueden ser destacados como el relato que construye sobre el poblamiento del territorio, la preexistencia de la nación uruguaya, el lugar central que le otorga al contrabando o la sucesión de hechos que provocaron un sentimiento autonomista en Montevideo y su campaña, especialmente frente al poder de Buenos Aires. Para esto se pueden ver los excelentes análisis de la obra de Pivel Devoto que hicieron María Inés Moraes (2004) y Tomás Sansón (2006).
} 
sobre el lugar del latifundio en el origen de los problemas que derivaron en el movimiento artiguista.

Lucía Sala de Tourón, Nelson de la Torre y Juan Carlos Rodríguez (1967; 1968) efectuaron un estudio sobre la estructura económica y la distribución de la tierra en la "Banda Oriental" que buscaba demostrar que el latifundio era un problema central. De acuerdo a la interpretación de los autores, la presencia asfixiante del latifundio para los habitantes de la campaña había generado una serie de disputas por la tierra que estaban en el origen del reglamento promulgado por Artigas en 1815, que ellos identificaban como una verdadera revolución agraria. Barrán y Nahum (1964: 86) criticaron esta perspectiva indicando que el latifundio no pudo haber provocado una lucha por la tierra mientras existían tierras vacantes en el norte. En este sentido, proponían introducir la noción de frontera, utilizada para el estudio de la historia de Estados Unidos, para ese análisis. Pero más allá de este debate los autores confirmaban los tópicos de la visión piveliana de la campaña oriental. Estas obras conformaron la visión dominante sobre el tema en Uruguay hasta los recientes estudios de María Inés Moraes que analizaremos más adelante.

En Argentina fue necesario esperar hasta la década del ochenta del siglo XX para que se revisara la visión tradicional sobre la historia del mundo rural del siglo XVIII. En esos años surgieron nuevos trabajos que plantearon una renovación temática y metodológica que dio origen a algunos debates sobre las características de la producción, las fuentes para estudiarla, la rentabilidad y la mano de obra, entre otros temas. En ese contexto los aportes que autores como Amaral, Mayo, Garavaglia y Gelman hicieron dejaron una impronta en los trabajos posteriores.

Durante los últimos treinta años la imagen tradicional fue desmontada gracias a la utilización de nuevas fuentes. En primer lugar, el estudio de los padrones de 1744 (Moreno, 1989)y de 1815 (GIHRR, 2004) mostró que la mayor parte de los pobladores de la campaña eran labradores que vivían en unidades domésticas con lo que se desmentía la preponderancia de los hombres solteros. Además, esos estudios demográficos permitieron tener una primera aproximación sobre las diferencias regionales.

En segundo lugar, Juan Carlos Garavaglia $(1987,1999)$ propuso la utilización de los diezmos para estudiar la producción agraria. A partir de los datos de los remates de 
las distintas especies ${ }^{30}$ el autor resaltó la importancia de la agricultura, llegando a afirmar que está era la actividad predominante y no la ganadería. Ese planteo generó numerosas críticas de Amaral y Ghío (1990), Moutoukías (1995) y Azcuy Ameghino (2002) que discutieron la pertinencia de los remates como indicador de la producción, indicaron las dificultades que presentaba el cobro del diezmo de la cuatropea y, por ende, juzgaron incorrecta la comparación que Garavaglia hacía entre las dos actividades económicas a partir de los datos brindados por esa fuente. Más recientemente, Moraes (2011) también resaltó la insuficiencia de los diezmos como indicador de las economías agrarias rioplatenses, aunque sin negar su utilidad como indicador de la producción agraria de las campañas de Montevideo y Buenos Aires.

En tercer lugar, se estudiaron las cuentas de varias estancias que permitieron debatir sobre las características de la mano de obra. A partir de la contabilidad de la estancia de Clemente López Osorio, situada en Magdalena, Samuel Amaral (1987) determinó que existía una complementariedad en el uso de mano de obra esclava y asalariada. El autor indicó que existía cierta dificultad para contratar un trabajador libre por un período de tiempo largo y que era más barato utilizar esclavos para las tareas permanentes de la estancia. Además, partiendo de un cálculo de la productividad diaria sostuvo que los peones eran más convenientes para los trabajos estacionales. Por su parte, Carlos Mayo (2004: 136-137) crítico el argumento señalando que los estancieros de la época no podían haber hecho los complicados cálculos de Amaral. Planteaba que el mercado laboral estaba restringido por el lado de la oferta debido a que los posibles trabajadores asalariados encontraban en el cuatrerismo, el acceso a recursos de subsistencia y la frontera abiertas alternativas al trabajo en las estancias (Ibíd.: 101104).

En cuarto lugar, se relevaron todos los inventarios post mortem disponibles. A partir de esos inventarios, Garavaglia (1999) analizó la composición del stock animal, los instrumentos de trabajo, las edificaciones y otros recursos disponibles en las estancias y chacras. Los datos de la fuente permitieron también el estudio de los precios agrarios en el período que va de 1756 a $1826^{31}$. Garavaglia mostró que esos precios tuvieron en general un comportamiento negativo hasta 1814 (Ibíd.: 272-273).

\footnotetext{
${ }^{30}$ Se relizaban remates separados para el procreo de animales (cuatropea), para la agricultura de cereales (granos) y para la producción de hortícola, a la que a veces se sumaba la cría de aves.

${ }^{31}$ Más tarde Garavaglia (2004) extendió el estudio de esos precios hasta 1857.
} 
Por otro lado, Carlos Mayo (2004: 34-35) sostuvo que el escaso poder de los estancieros radicaba en su imposibilidad de controlar a los hombres y los ganados. Esto se revelaba, especialmente, en la existencia de circuitos clandestinos de comercialización de productos pecuarios. Los pulperos fueron agentes claves de esos circuitos y por eso ocuparon la atención de los historiadores ${ }^{32}$. Eso permitió, también, iniciar el estudio de los hábitos de consumo rurales (Mayo, 2000).

A todos estos textos se le sumaron una importante cantidad de investigaciones en las cuales, en general, los historiadores optaron por reducir la escala de análisis hasta las dimensiones de una localidad o pago ${ }^{33}$. La mayor parte de esos estudios confirmaron en el nivel local los planteos que habían hecho los autores antes mencionados, especialmente los lineamientos principales del trabajo de Garavaglia.

Sin embargo, paralelamente a esta corriente historiográfica, Eduardo Azcuy Ameghino $(1995 ; 2002)$ y su grupo de investigaciones mantuvieron una perspectiva más cercana a la visión tradicional al destacar la importancia del poder de los terratenientes, de la exportación de cueros y las denuncias de tierras ${ }^{34}$. Esta perspectiva se emparenta con la línea argumental de Pivel Devoto y Sala de Touron, de la Torre y Rodríguez ya que pretendían demostrar el peso del latifundio y las relaciones de dependencia personal en la campaña de Buenos Aires.

Paralelamente a esas investigaciones sobre la campaña bonaerense, surgieron otros trabajos que dieron cuenta del resto de las zonas que componen la región. Jorge Gelman fue pionero, en este sentido, al estudiar la parte de la "Banda Oriental" más próxima a Buenos Aires: es decir, las áreas en torno a Colonia de Sacramento y Santo Domingo Soriano. En su trabajo, Gelman (1998: 43) caracterizó a ese territorio como una zona que si bien en sus inicios tenía características de frontera, luego se fue convirtiendo hacia una estructura agraria similar a la de la campaña bonaerense. Aunque esa transformación no se completó durante el siglo XVIII, la expulsión definitiva de los portugueses de Colonia del Sacramento marcó un punto de inflexión. El autor también identificó un crecimiento sostenido de la actividad ganadera y, en contraste, un estancamiento de la agricultura de la zona, o más bien una cierta fluctuación en las

\footnotetext{
${ }^{32}$ Ver: Carrera (2011)

${ }^{33}$ Ver: Andreucci (2011), Banzato (2002), Barcos (2010), Birocco (2003), Canedo (2001), Ciliberto (2004), Contente (1999), Di Stefano (1991), Dupuy (2004), Garavaglia (2009), Mateo (2001), Marquiegui (1990), Mascioli (2004).

${ }^{34}$ Ver: Azcuy Ameghino et all (1996)
} 
cosechas (Ibíd.: 60, 68-69). Además, Gelman descubrió un proceso de polarización entre los productores ganaderos por el cual los grandes estancieros aumentaron su participación a costa de los productores medianos pero sin afectar a los pequeños (Ibíd.: 86, 210-211). De esta manera, mientras un porcentaje importante del stock ganadero se encontraba concentrado en pocas manos, en cambio el trigo era producido en su mayor parte por familias campesinas (Ibíd.: 94). La ganadería permitía una acumulación porque durante los períodos de guerra, cuando el precio de los cueros bajaba, los estancieros podían disminuir el faenamiento, aumentando así el rebaño que poseían para volver a vender sus productos en momentos más favorables (Ibíd.: 62, 150). Por otro lado, al comparar los datos de los envíos de cueros a Montevideo, proporcionados por las guías de aduana para un par de años, con el tamaño del stock del área, Gelman afirmó que una parte de esos cueros provenía del ganado alzado de las zonas fronterizas cercanas (Ibíd.: 146). Finalmente, identificó un sistema de comercialización de los productos agropecuarios que involucraba, por un lado, a los grandes y medianos estancieros que tenían un acceso directo a los mercados de las ciudades-puerto y, por el otro, a los pulperos que recogían los excedentes de los pequeños productores (Ibíd.: 152).

Julio Djenderedjian, por su parte, estudió los territorios situados al oeste del río Uruguay entre la segunda mitad del siglo XVIII y las primeras dos décadas del XIX. Esta área, contigua a la de Colonia y Soriano, presentó características similares a la zona estudiada por Gelman. Djenderedjian (2013: 194) encontró un proceso de expansión ganadera dominado por grandes estancias orientadas al mercado ultramarino. Esas estancias eran más grandes y tenían un mayor peso en la economía y en la sociedad que las de la campaña de Buenos Aires (Ibíd.: 10). En consecuencia, había una menor cantidad de explotaciones con rebaños más amplios, lo que implicaba una mayor concentración de la riqueza. Además, la escasez de mano de obra, con su natural correlato en el mayor costo de los salarios, habría sido un factor adicional a favor de la producción ganadera (Ibíd.: 31). En ese contexto, el recurso a la mano de obra esclava era un elemento importante para esos grandes establecimientos. El autor considera que el mercado de esclavos tenía un cierto dinamismo y permitía que en momentos de menor necesidad de trabajadores el propietario pudiera vender sus esclavos $\mathrm{y}$ 
recomprarlos en momentos más favorables. Es decir, que la mano de obra esclava no era necesariamente más inelástica que la asalariada (Ibíd.: 276).

Djenderedjian destacó, además, la influencia que el proyecto de poblamiento estratégico llevado a cabo por los funcionarios de la corona tuvo en la historia de ese espacio. El proyecto revelaba la intención del estado borbónico de tomar el control de la defensa y vigilancia de las fronteras. La crisis del sistema misionero hizo especialmente necesario el desarrollo de esa política en el Río de la Plata, razón por la cual se intentó cercar con pueblos, que tuvieran sus respectivas milicias organizadas, la extensa área fronteriza con los territorios portugueses (Ibíd.: 12, 81, 412). Los tres pueblos del área estudiada por el autor (Gualeguay, Guaeguaychú y Concepción) fueron fundados en el año 1783. En ese proceso fundacional recibieron la categoría de villa y la posibilidad de tener cabildos propios. Esa institucionalización brindó nuevos elementos para ejercer el control a nivel local que fueron aprovechados por un reducido grupo de hacendados y comerciantes que conformaban la notabilidad local (Ibíd.: 184, 379). Djenderedjian afirma que ese acceso a los instrumentos de poder era un elemento clave en la gestión empresaria, en tanto implicaba permisos para el acceso a la tierra o el manejo de tropas milicianas que podían ayudar a controlar la mano de obra, además de generar lazos de lealtades y solidaridades, especialmente a través de los beneficios del fuero militar (Ibíd.: 295-296).

Por otro lado, aunque se refiere a un espacio que quedaba fuera de la región Río de la Plata ${ }^{35}$, otro trabajo de interés para nuestro estudio es el de Helen Osório sobre Río Grande del Sur, que comprende el mismo período que el de Djenderedjian y ofrece interesantes posibilidades para comparar similitudes y diferencias con el área que vamos a estudiar. Además, nos permite observar las vinculaciones económicas y sociales existentes entre ambos espacios en distintas épocas, aunque no forme enteramente parte de nuestra región. La autora considera que existe una estructura productiva similar en los territorios que van desde la campaña de Buenos Aires hasta el actual departamento de Río Grande del Sur. La misma se caracteriza por una ocupación de la tierra más laxa y una más baja densidad demográfica que otras regiones americanas, y por la presencia

\footnotetext{
35 Sin embargo, podríamos considerar que entre 1763, año en el que los españoles ocupan la villa de Río Grande, y 1776, cuando es recuperada por los portugueses, el área estaba incluida dentro de la circulación de bienes que partía desde el Río de la Plata, como veremos más adelante, por lo que la situación al respecto fue fluctuando.
} 
de una cantidad importante de unidades productivas de carácter mixto (que combinan agricultura y ganadería) en las zonas más cercanas a los escasos núcleos urbanos junto a un número reducido de grandes explotaciones ganaderas (Osorio, 2007: 39, 58). También existían algunos contrastes: en Río Grande había una mayor concentración de ganado vacuno, menos arrendatarios y una mayor utilización de mano de obra de esclava (Ibíd.: 93, 114, 149, 328). Otras diferencias, en cambio, remitían al plano de la circulación que estaba orientada por los circuitos creados por cada imperio (Ibíd.: 40). Las vinculaciones mercantiles de ese espacio se daban mayoritariamente con el mercado interno brasileño. El desarrollo de la producción de carne salada encontraba su mercado de consumo en las plantaciones esclavistas de Bahía y Pernambuco (Ibíd.: 193-196).

Un aspecto interesante de la investigación de Helen Osório tiene que ver con su análisis de los efectos que, en esa zona de frontera política, tenía la guerra en la estructura productiva. A partir del estudio de los inventarios post mortem la autora comparó los cambios en la composición de los patrimonios. Así determinó que durante los conflictos el precio de los animales aumentaba, mientras que el valor de las tierras crecía de manera lenta pero constante. Por consiguiente, durante el primer período de inestabilidad (1765-1785) la participación del valor del rebaño en los patrimonios era muy importante, luego en el período que va de 1790 a 1810, durante el cual predominó la paz y existió un rápido crecimiento económico, aumentó la participación del valor de las tierras y, finalmente, con la nueva coyuntura de guerra (1815-1825) los animales ocuparon nuevamente el lugar más importante en los patrimonios rurales aunque el valor de las tierras se mantuvo. (Ibíd.: 69-72)

María Inés Moraes (2011), por su parte, analiza los paisajes agrarios misionero y montevideano de la segunda mitad del siglo XVIII comparándolos con la campaña bonaerense. De esta manera, busca considerar de manera conjunta lo que considera tres espacios nucleares dentro de la región. A partir de la medición del producto agrario, la autora sostiene que las economías campesinas de Buenos Aires y Montevideo no crecieron de manera sostenida o, al menos, no lo hicieron en la misma medida que el aumento demográfico. En cambio, a partir de la década de 1770 la producción de cueros para la exportación adquirió una nueva escala transformándose en el sector más dinámico de las economías agrarias regionales. La actividad corambrera fue llevada a cabo por nuevos agentes que explotaron las reservas de ganado cimarrón que la crisis 
del espacio misionero dejó disponibles (Ibíd.: 29). Entre esos agentes se destaca un grupo autodenominado "hacendados montevideanos" que en ese proceso de avance sobre tierras y ganados se consolidaron como grupo social con poder local (Ibíd.: 271).

Moraes destaca que dentro de lo que podemos considerar como producción ganadera existían, en realidad, dos actividades económicas de distinta índole. La producción masiva de cueros se efectuaba mediante expediciones de caza denominadas vaquerías y tenía una racionalidad económica diferente a la ganadería de cría. En una el producto final era el cuero, mientras en la otra el objetivo era el abastecimiento de carne siendo el cuero un subproducto (Ibíd.: 40).

La autora señala, además, que había un comportamiento tendencial similar entre los precios de las Misiones, de Buenos Aires y de Montevideo lo que le permite sugerir la existencia de mercados regionales integrados. Esto nos remite nuevamente a considerar la región como un todo. En este sentido, Moraes (Ibíd.: 322-325)se pregunta si la consolidación económica y demográfica de los nuevos espacios provocó un debilitamiento de los lazos con Buenos Aires o si los mismos se reformularon. Creemos que ese interrogante puede ser la punta del ovillo de una cuestión a resolver en otras investigaciones: ¿cuál es el lugar que le cabe a Buenos Aires dentro de ese nuevo escenario regional que se da a fines del siglo XVIII?

Por último, el área de Maldonado ha sido analizada recientemente en una investigación en la cuál hemos estudiado el poblamiento y crecimiento económico de esa zona (Biangardi, 2013). Al mismo tiempo, efectuamos el ejercicio de complementar los datos sobre la circulación de mercancías contenidos en las guías de aduana con el estudio de los diezmos del lugar mostrando que, de esa manera, se puede dar una dimensión más real del peso de la ganadería en la producción local. Por otro lado, también pudimos comprobar la importancia que en ese sitio tuvieron las erogaciones efectuadas por la Real Hacienda, en concepto de gastos ocasionados por el poblamiento y por el aparato militar, en esa expansión.

Una de las características principales de la región Río de la Plata fue la de ser en su mayor parte una zona fronteriza. Esa situación llevó a los historiadores a revisar el concepto de frontera. Para la campaña bonaerense, por ejemplo, se destacaron dos grandes posturas. Por un lado, algunos autores plantearon que, desde el punto de vista 
de la historia agraria, podía ser útil recuperar algunas ideas elaboradas por Turner para la frontera oeste de Estados Unidos y otros aportes de las corrientes intelectuales que le siguieron, ya sea las que continuaron desarrollando esos postulados o las que los criticaron $^{36}$. Por otro lado, otra corriente historiográfica, más interesada en estudiar las relaciones entre la sociedad hispana y los pueblos originarios, remarcó otra concepción de la frontera considerándola como un espacio social dónde se articulaban tanto relaciones económicas como sociales y políticas (Mandrini, 1997: 24).

En esta ocasión, y atendiendo a los objetivos de esta tesis no vamos a realizar un estado de la cuestión exhaustivo de la amplia bibliografía sobre las fronteras en Hispanoamérica en general y del Río de la Plata en particular sino que simplemente nos interesa destacar que las fronteras de la región Río de la Plata no eran iguales, que cada una presentaba características y un desarrollo histórico diferente. La desestructuración del espacio misionero en la frontera norte con su reserva de tierras, mano de obra y ganado cimarrón, que distintos agentes de la región se disputaron ${ }^{37}$, determinó una expansión territorial hacia esa zona. La frontera sur se vio, en cambio, limitada por las relaciones con las sociedades indígenas. La expansión de los primeros años del virreinato, que suscitó una situación de gran conflictividad, fue sucedida por una etapa de relaciones pacíficas que duró hasta principios del siglo XIX y que, necesariamente, limitaba la expansión territorial de la región. Raúl Mandrini (1997: 30-31) afirma que la paz, aunque no estaba exenta de violencia, era conveniente porque existía una complementariedad económica entre las dos sociedad. Esa complementariedad y la sugerencia de Eugenia Néspolo (2006: 2) sobre la existencia de un espacio políticamente concertado en esa frontera parecen ser las bases de esa estabilidad que duró más de veinte años.

La frontera sur, situada en torno al río Salado, tuvo en los primeros años del virreinato un momento de expansión y de gran conflictividad con la sociedad indígena que duró hasta mediados de la década de 1780. Varios son los factores que desencadenaron los conflictos. Por un lado, las reiteradas sequías que sufría la zona

\footnotetext{
${ }^{36}$ Garavaglia (1999: 36) considera que hay “...algunos aspectos del tipo de expansión en la frontera pampeana que tienen un parentesco con ciertos planteos turnerianos, pero que no se refieren a la "idea fuerza" central del autor". Consecuentemente con esto se realizaron varios estados de la cuestión que indagaron sobre los aportes de la historiografía norteamericana y latinoamericana al estudio de las fronteras, como por ejemplo: Ratto (2001) y Schmit (2008).

${ }^{37}$ Entre ellos se destaca la disputa entre los administradores misioneros y los vecinos hacendados de Montevideo (Moraes, 2011: 168-169).
} 
pampeana en esos años producían un desplazamiento del ganado hacia el área de la depresión del Salado lo que generaba tensiones con los indios que utilizaban esos campos para potrear y, en consecuencia, podían también llevarse las vacas (Alioto, 2011: 66). Por otro lado, el virrey Vértiz estableció una línea de fortines que incorporó alrededor de 17.175 kilómetros cuadrados al territorio bajo dominio español (Barba, 1997: 34). Al mismo tiempo, cortó el comercio con los indígenas y tomó cautivos a los que habían ido a comerciar a Buenos Aires. Los malones constituyeron, entonces, un mecanismo de presión de la sociedad indígena ante una política que los perjudicaba y una reacción contra la no restitución de los cautivos (Alioto, 2011: 67).

Con el cambio de autoridades de 1784 los funcionarios borbónicos modificaron su postura y promovieron una política que buscaba mantener relaciones pacíficas con los indios. Desde ese momento se mantuvo una situación de relativa paz, aunque no exenta de violencia ${ }^{38}$, que se prolongó hasta 1810 . Existió en esos años un crecimiento constante del comercio y de la población fronteriza ${ }^{39}$. Según Raúl Mandrini (1997: 30), la paz convenía a ambas sociedades porque había entre ellas una complementariedad económica, la sociedad colonial necesitaba sal y los indios productos agrícolas y artesanales. Luego de 1810 la frontera se desestabilizó y la sociedad occidental comenzó a avanzar sobre territorio indígena ${ }^{40}$. Esa violencia creciente fue un anticipo del retorno a los conflictos abiertos que se dieron durante la década de 1820 , cuando el estado provincial de Buenos Aires, en pleno proceso de formación, impulsó nuevamente la expansión territorial de la zona ${ }^{41}$.

La frontera norte de la región, en cambio, presentaba un carácter diferente. Los territorios al norte del río Negro poseían importantes reservas de ganado cimarrón que habían sido usufructuadas por las misiones jesuíticas. Con el aumento de la demanda de cueros del comercio atlántico en el último cuarto del siglo XVIII se generó un conflicto

\footnotetext{
38 "La violencia -aunque reducida- no fue nunca totalmente eliminada de las fronteras y la paz lograda no excluía ataques indios a otras provincias y por parte de otros grupos” (Mandrini, 1997: 31).

${ }^{39}$ En 1783 la población en torno a los fuertes era de 2.232 habitantes: 335 en Chascomús, 196 en Ranchos, 259 en Monte, 447 en la Guardia de Luján, 347 en Rojas, 524 en Salto y 124 en Carmen de Areco. A fines del siglo XVIII, en cambio, ascendía a 6.640 (Barba, 1997: 52).

${ }^{40}$ Una de las primeras manifestaciones de esa expansión fue la fundación de Dolores en agosto de 1817, primer pueblo al sur del río Salado (Barba, 1997: 77).

${ }^{41}$ Aunque la apropiación de las tierras fronterizas había comenzado con mucha anterioridad. Según Azcuy Ameghino (2002: 251) entre 1791 y 1810 se efectuaron 108 denuncias de tierras que en conjunto totalizaban 1.443 .875 hectáreas.
} 
por el acceso al recurso entre los administradores civiles de las misiones y agentes montevideanos y porteños (Moraes, 2011: 238).

Al mismo tiempo, esta frontera era un lugar de contacto con los dominios portugueses del sur de Brasil. Los intercambios entre españoles y lusitanos se basaban también en la riqueza ganadera, ya sea a través del tráfico de ganado en pie o del comercio de cueros por tabaco, esclavos y mercancías de origen europeo. Además, más allá del hecho de que es casi imposible de medir, existen indicios de que el contrabando era muy intenso en esa zona e incluso era efectuado por los mismos funcionarios que debían custodiar y defender el territorio ${ }^{42}$.

La frontera norte, además, fue objeto de otro importante proceso. Con la expulsión de los jesuitas y la crisis del sistema misionero la monarquía debió hacerse cargo de la defensa y la vigilancia de la frontera con el imperio portugués que antes había dejado en manos de la orden religiosa (Djenderedjian, 2003: 81). Esto se tradujo en un proyecto de poblamiento de inspiración fisiocrática que se mantuvo hasta los primeros años del siglo XIX y que tuvo como consecuencia la fundación de nuevos poblados y la asignación de la categoría de villa a otros ya existentes. Djenderedjian (Ibíd.: 4) sostiene que esa política creo las condiciones para la conformación de espacios de poder local brindando a las personas del lugar recursos institucionales, como los cabildos y las milicias, con los que podían ejercer presión ante las autoridades centrales al mismo tiempo que se recortaba la jurisdicción de una ciudad preexistente . Esos espacios de poder eran, además, esenciales para la producción ganadera ya que implicaban el acceso y control de los recursos. El reparto de tierras, la apropiación de ganados y el control de la mano de obra se realizaban por medio de los cabildos ${ }^{43}$, alcaldes y jueces territoriales y de los comandantes militares. El autor afirma (Ibíd.: 420), además, que la importancia de la ganadería residía en que proporcionaba una base de acumulación independiente de las vinculaciones con la ciudad capital, lo que no sucedía en el caso del comercio.

La jurisdicción de esos cabildos (Montevideo, Luján, Santo Domingo Soriano, Concepción, Gualeguay, Gualeguaychú y Maldonado) implicaron una reducción del

\footnotetext{
${ }^{42}$ Ver: (Gil, 2002).

${ }^{43}$ Según Ana Frega (2007: 59): "El reparto de tierras, junto con la apropiación de ganados, fueron dos de los privilegios que el Cabildo de Soriano reivindicó con mayor fuerza.". En el mismo sentido, Julio Djenderedjian (2003: 96) considera que: "Siendo éstos [los cabildantes] (...) medianos estancieros del área o comerciantes con inversiones en la producción agropecuaria, no es raro que los cabildos se transformaran en caja de resonancia de conflictos por linderos, por robo de ganado o por otorgamiento de tierras.".
} 
territorio del cabildo de Buenos Aires. Aunque con la instauración del virreinato esa pérdida fue contrapesada con la influencia que los sectores dominantes de la ciudad podían ejercer sobre las nuevas autoridades, el control del acceso a los factores decisivos para la producción pasó a manos de los nuevos espacios de poder local. Los robos de ganado, la apropiación de la tierra ${ }^{44}$ y la vigilancia sobre la mano de obra eran resueltas a través de los vínculos locales entre cabildantes, hacendados y oficiales de milicias que en muchas ocasiones podían ser las mismas personas, lo que les daba cierta independencia con respecto a las autoridades virreinales ${ }^{45}$. En consecuencia, aún en los casos en los que las disputas aparentan no tener una resolución efectiva en los hechos, los agentes locales lograron sus cometidos. El ejemplo más claro lo constituye el conflicto entre la administración de los pueblos misioneros, los hacendados montevideanos y las estructuras del gobierno virreinal que tal como plantea María Inés Moraes (2011: 273, 325) entre 1785 y 1805 parece haberse estancado en un "empate político", a pesar de lo cual los hacendados montevideanos avanzaron sobre las tierras y los ganados misioneros.

La desaparición del virreinato y la construcción de nuevas formas de gobierno después de 1810 hacen más visibles esos poderes a los ojos de los historiadores. Es posible que esa visibilidad no signifique necesariamente que el cambio de poder redunde en un beneficio para esos grupos sino que los nuevos gobiernos deben emprender negociaciones nuevas. Raúl Fradkin y Silvia Ratto (2008: 37) consideran, a partir del estudio de la frontera entre Buenos Aires y Santa Fe en el período 1815-1820, que los gobiernos dependían de los liderazgos locales ${ }^{46}$ para ejercer un control sobre la población y el territorio. Lo mismo puede decirse tanto de la organización del gobierno artiguista como del proceso político que se dio en la "Banda Oriental" a partir de la invasión portuguesa.

\footnotetext{
${ }^{44}$ Esto era así incluso en los casos en los que se efectuaban denuncias en los aparatos centrales ya que según Eduardo Azcuy Ameghino (2002: 239): “...muchos detalles -como medir y valuar terrenos- de la apropiación del espacio rural era controlada por los miembros de la elite comarcal, y otros personajes vinculados con ellos por parentescos, asociaciones y dependencias.".

${ }^{45}$ Según Djenderedjian (2003: 92): “...esos grandes hacendados que ejercían funciones policiales a nivel local se encontraban en una situación de semi o total independencia con respecto al control de las autoridades de la colonia.".

46 Según los autores, esos liderazgos: “...expresaron un tipo de movilización política fragmentada territorialmente en la cual los entramados sociales preexistentes ofrecieron los recursos organizativos para la formación de liderazgos." (Fradkin y Ratto, 2008: 55).
} 
Por otro lado, Ana Frega sostiene que Artigas nunca pudo consolidar una base territorial y perdió el apoyo de los grupos dirigentes debido a su temor a una posible revolución social. Este factor, junto al desgaste que ocasionó la prolongación de la guerra, pudo haber contribuido a su derrota (Frega, 2007: 168). A su vez, el ejército lusitano, aún siendo vencedor en el conflicto bélico, debió brindar amplias concesiones a los pueblos y comandantes militares que capitulaban debido a que los nuevos gobernantes necesitaban apoyarse en las "redes vinculares preexistentes" (Frega, 2008: 136). Ambos procesos son indicativos de la importancia que cobraron los espacios de poder local en la región. En este sentido, es interesante destacar que existía una relación directa entre su condición fronteriza y la autonomía que tenían esos espacios de poder.

Entonces, en tanto que la producción ganadera constituía una base de acumulación para actores que establecieron relaciones de dominación a nivel local, las que, a su vez, les permitieron negociar en las relaciones que se establecieron a nivel regional, el análisis de esa producción nos lleva a estudiar a esos actores para comprender cómo lograron controlar los factores productivos y, al mismo tiempo, forjar esas relaciones de poder en su comunidad. En este sentido, creemos que la noción de espacio económico se debe complementar con una conceptualización de la territorialidad que logran los actores a través de los medios institucionales que manejan. Es decir, cómo se extiende en el territorio la apropiación de tierras y ganado, la exclusión de otros actores del acceso a esos recursos y el control sobre la mano de obra ${ }^{47}$.

Luego de identificar a los productores ganaderos mediante el análisis de fuentes cuantitativas, se puede estudiar la territorialidad de estos actores analizando el control que efectuaban por medio de los Cabildos ya sea en los repartos o denuncias de tierras, en los acuerdos o en la administración de la justicia, o en la acción de los comandantes militares donde se pude entrever los entramados sociales que existían detrás de cada situación.

\footnotetext{
${ }^{47}$ Dario Barriera es el que más ha trabajado la relación entre poder político, control de factores y territorio. Por ejemplo, ver: (Barriera, 2010).
} 


\section{Capítulo 2}

\section{La circulación de productos pecuarios dentro de la región}

La región Río de la Plata por medio de su complejo portuario articulaba tres circuitos mercantiles diferentes: el comercio ultramarino, las transacciones mercantiles al interior del continente y la circulación interna regional. Dentro de los flujos que no traspasaban los difusos límites de la región se distinguen dos tipos de movimientos: los que se daban entre los puertos que eran parte del complejo portuario y los traslados de mercancías entre esas ciudades portuarias y la campaña (Jumar, 2012: 127-131). Las ciudades-puerto funcionaban como centros distribuidores de los bienes destinados a satisfacer las necesidades de los habitantes de la zona. Esos intercambios eran compensados con la producción agropecuaria que confluía en los puertos para alimentar a la población urbana, tanto la permanente como la flotante ${ }^{48}$, o para ser exportada a los mercados ultramarinos. Este último aspecto de la circulación intrarregional será el objeto de nuestro análisis.

Los cueros vacunos constituían el principal bien exportable producido en la región durante el siglo XVIII. En los estudios sobre el comercio rioplatense existen dos posturas en cuanto a la importancia de la exportación de cueros. Por un lado, Moutoukías (1995a: 780-784) considera que los cueros eran un bien ocioso sin costo de oportunidad que simplemente complementaba las operaciones comerciales. Dada su relación entre valor-volumen los cueros no podían representar más del $20 \%$ de lo importado por una embarcación. Al mismo tiempo, por esa misma relación, aunque en este caso muy favorable, los metales preciosos ocupaban un espacio muy reducido en el navío y, como se necesita peso para mantener la línea de flotación, las embarcaciones no podían retornar vacías. En consecuencia, la opción era viajar con cueros o lastre (por

\footnotetext{
${ }^{48}$ Los espacios portuarios son receptores de población que permanece una cierta cantidad de tiempo en el lugar. Esa población a la que se denomina flotante está compuesta, generalmente por tripulantes, pasajeros, comerciantes y transportistas y debe ser alimentada, alojada y demás servicios lo que constituye un importante incentivo para la economía local. Ver: Jumar, Biangardi, Bozzo, Orlowsky, Querzoli y Sandrín, 2006.
} 
lo general, piedras) y ya que los primeros podían venderse al final del recorrido aumentando las ganancias, constituían, entonces, era alternativa más lógica. En cambio, Jumar (2012: 145-146) sostiene que los metales exportados son el resultado de las transacciones de todos los circuitos comerciales interiores y los cueros, en su mayor parte, la exportación de una sola región. De esta manera, los cueros pueden representar solamente del 10 al $20 \%$ de las exportaciones totales del virreinato pero son fundamentales para la economía rioplatense. Desde nuestro punto de vista, estas dos líneas argumentales, en realidad, no son contradictorias sino que se corresponden al análisis de la misma situación desde distintas perspectivas. Para el capitán del navío o para el comerciante consignatario de una casa comercial gaditana seguramente los cueros representaban un complemento a las operaciones mercantiles que tenían a los metales preciosos como el objetivo principal. Pero para los productores locales el espacio de las bodegas de los navíos constituía una oportunidad única para colocar sus mercancías.

Recientemente el trabajo de Maximiliano Camarda (2014) emprendió el estudio de las exportaciones de cueros y de los cargadores que las efectuaban. Su investigación aporta dos elementos que son importantes para el análisis que realizaremos. En primer lugar, a partir de la comparación entre las estimaciones de Moutoukías, que estaban hechas teniendo en cuenta la capacidad de las bodegas de los navíos, y las cifras de exportaciones legales Camarda demuestra que el fraude en esas exportaciones era mínimo y, por ende, carecía de importancia. Al mismo tiempo, esa situación es una muestra de la fiabilidad de las fuentes fiscales borbónicas para medir los embarques de cueros. En segundo lugar, el número de cargadores asentados en Montevideo, que aumenta exponencialmente en la década de 1790, casi duplica a los que habitaban en Buenos Aires. Es probable que esto se deba a que la capital virreinal se hallaba más alejada de los lugares de producción masiva de esos cueros $\mathrm{y}$, por lo tanto, los cargadores debían tener un control mayor de los circuitos mercantiles. Ese escenario tiene una importancia fundamental en las características de los mercados locales de cueros.

El gráfico 1 muestra la cantidad de cueros embarcados desde la región por períodos quinquenales a lo largo de todo el siglo XVIII a partir de los datos aportados por los estudios de Fernando Jumar (2008) y Maximiliano Camarda (2014). Las cifras 
de esas exportaciones indican dos momentos importantes de crecimiento de esas exportaciones.

Gráfico 1. Exportaciones de cueros desde el Río de la Plata 1699-1798 en cantidad de unidades por quinqueños

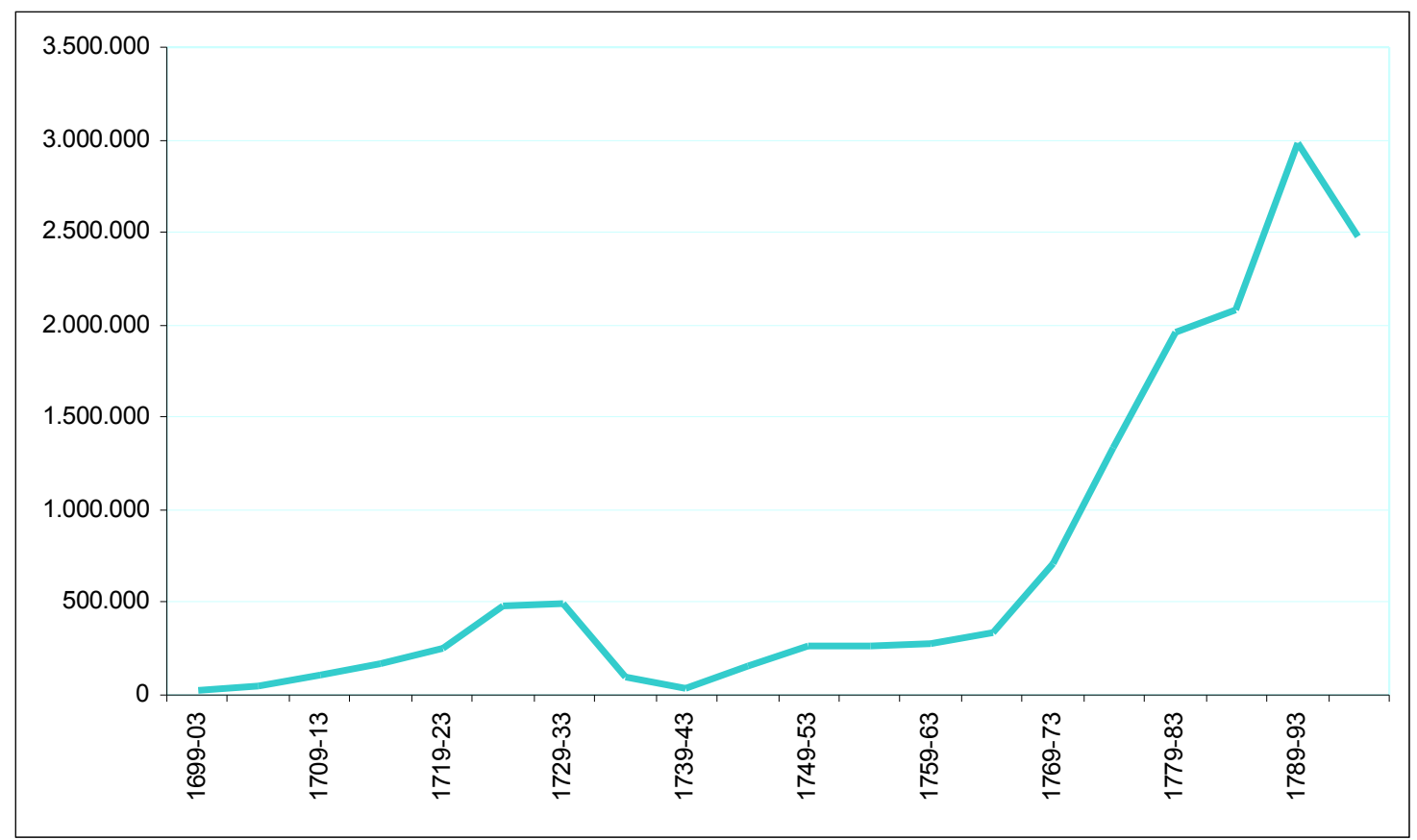

Fuente: Elaboración propia a partir de Jumar (2008) para 1699-1778 y Camarda (2014) para 1779-1798. Exportaciones de cueros en el sistema legal de comercio español desde los puertos de Buenos Aires (para todo el período) y Montevideo (a partir de 1779). No incluye estimaciones de cueros salidos de forma ilegal, ni los cueros exportados desde Colonia del Sacramento en los períodos de dominio portugués.

El primero consistió en lo que Fernando Jumar (2008) denominó como el primer boom exportador de principios de siglo que se verifica en el tibio crecimiento de la década de 1710 y, especialmente, en los períodos 1724-1728 y 1729-1733 cuando los embarques se aproximan a los 500.000 cueros (ver Anexo 2 Cuadro A.1.), promediando una cifra cercana a los 100.000 cueros anuales ${ }^{49}$.

El segundo momento de crecimiento sucedió con el sorprendente aumento exponencial de las exportaciones de cueros de las últimas tres décadas del siglo cuando

\footnotetext{
${ }^{49}$ El promedio anual para el período $1724-1728$ fue de 96.608 cueros y para 1729-1733 fue de 99.115.
} 
las cifras pasaron de estar por debajo del medio millón de cueros para 1764-1768 a los casi tres millones de 1789-1793 es decir una cifra cercana al promedio de 600.000 cueros anuales ${ }^{50}$.

María Inés Moraes (2011: 238) sostiene que ese aumento exponencial tuvo como base productiva a lo que ha caracterizado como nueva economía del cuero que se diferenciaba de la anterior en una mayor escala, en la ubicación geografía de la producción y en la intervención de nuevos agentes. Esa nueva economía del cuero tuvo su epicentro en las vaquerías de corambre realizadas en el espacio misionero situado al norte de los ríos Yi y Negro. Luego de la expulsión de los jesuitas, en 1767, los administradores laicos de las misiones debieron disputarse el control de los factores productivos de ese espacio con agentes bonaerenses y montevideanos que buscaron apropiarse de las reservas de ganado cimarrón y de trabajadores de lo que Moraes denomina paisaje pastoril misionero.

Gráfico 2. Cantidad de cueros exportados desde Buenos Aires y Montevideo 1779-1799

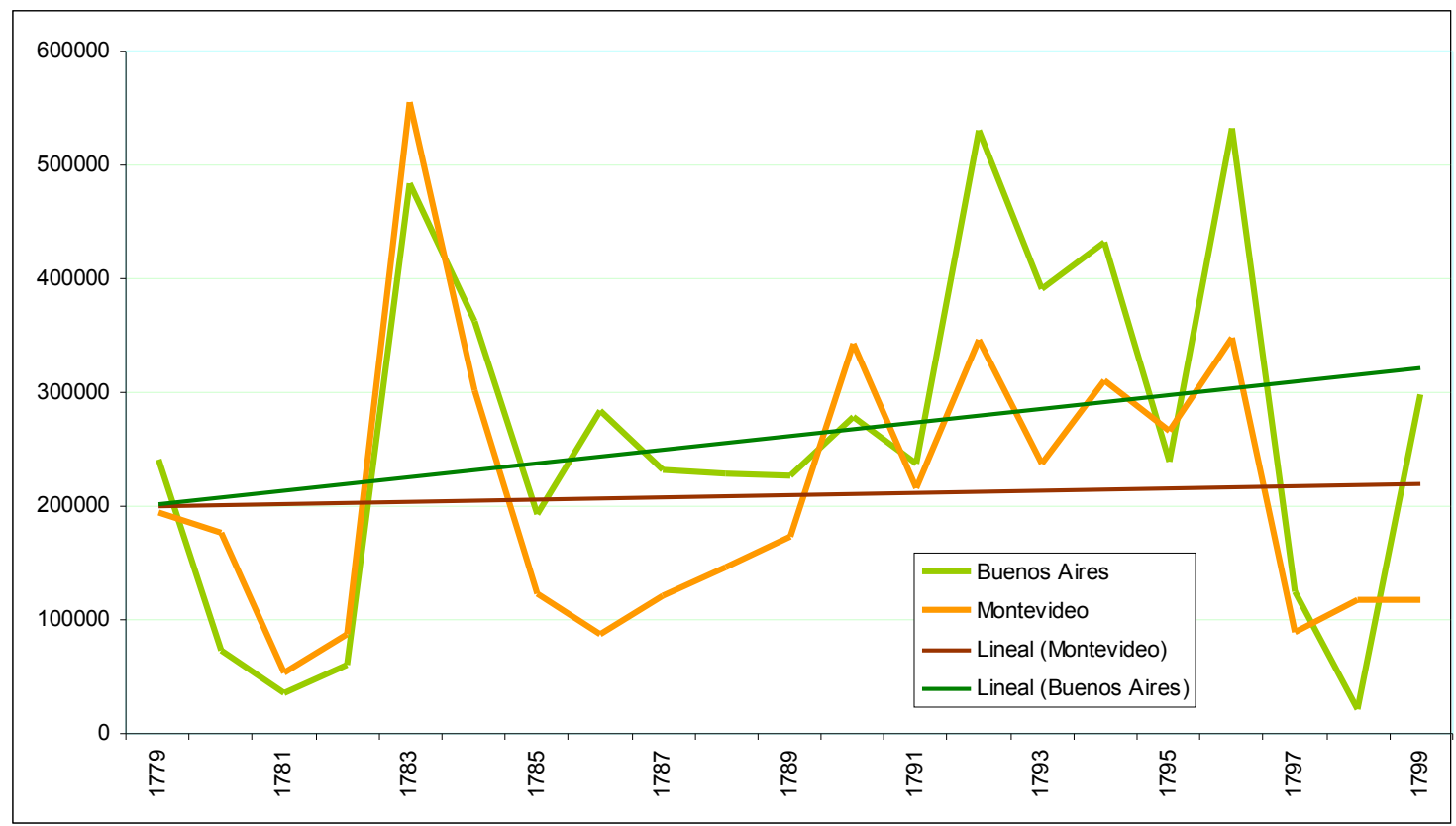

Fuente: Elaboración propia a partir de Camarda, 2014

\footnotetext{
${ }^{50}$ El promedio anual para el período 1789-1793 fue de 595.980 cueros. Los datos proporcionados por Maximiliano Camarda (2014) permiten ver que ese promedio fue superado en varios años: 1783, 1784, 1790, 1792, 1793, 1794 y 1796 (ver Anexo 4 Cuadro A. 2.).
} 
El gráfico 2 permite ver las exportaciones de cueros discriminadas por puerto para el período situado entre los años 1779 y 1799. Del análisis de esa información queremos destacar dos situaciones que desarrollaremos más adelante. En primer lugar, existió una disminución importante de los embarques desde el puerto de Montevideo durante el período de gobierno del virrey Loreto coincidiendo con la suspensión de las faenas misioneras y la política represiva contra las faenas "ilegales" emprendida en ese momento, que se tradujo en una importante cantidad de embargos (ver capítulo 7). En segundo lugar, las líneas de tendencia lineales indican un cierto estancamiento en la cantidad de cueros exportados desde Montevideo en contraste con un marcado crecimiento de los que salen desde el puerto de Buenos Aires. Además de los cueros exportados, existía un consumo interno de los cueros. Mientras los cueros más grandes y gruesos se destinaban para el mercado ultramarino, el resto de los cueros de menor calidad o con algún tipo de deterioro (por ejemplo, los que no se habían podido librar de las polillas) se destinaban innumerables usos. Especialmente se utilizaban como sacos para los cereales o cualquier otro producto, en la construcción de cercos y viviendas, para proteger los bienes en carros y carretas y para impermeabilizar las bodegas de las embarcaciones.

Por otro lado, en los años finales del siglo se produjo un crecimiento de las exportaciones de otros derivados vacunos promoviendo un aprovechamiento más integral de los animales sacrificados. Entre ellos se destacan los distintos tipos de carnes saladas que tuvieron un impulso importante a partir de la instalación de los primeros saladeros luego de 1786 aunque, como veremos más adelante (ver capítulo 4), la elaboración de esos bienes a pequeña escala no era despreciable. El mercado más importante de esa producción fue la economía de plantación cubana. De acuerdo a los datos proporcionados por Arturo Bentancur (1997: 52-55) las exportaciones a la Habana no dejaron de crecer en los períodos que la guerra no interrumpía el tráfico marítimo. Entre 1792 y 1796 se enviaron 157.125 quintales de carnes saladas en 41 embarcaciones y en 1802-1806 salieron 97 embarcaciones que transportaron 382.471 quintales. En ese último período, las medidas liberalizadoras del comercio a las que recurrió la corona permitieron la apertura de nuevos mercados exportándose otros 149.246 quintales a colonias y países extranjeros, especialmente a Brasil a donde fueron a para el $71 \%$ de esos embarques. 
El sebo, en rama o en forma de velas, fue otro de los rubros destacados en las exportaciones de derivados vacunos. Los mercados del sebo rioplatense eran mucho más variados que los de la carne salada e incluían distintas plazas europeas, el Caribe, la costa africana y el Brasil. Los datos disponibles indican que entre 1793 y 1796 se exportaron 100.987 arrobas (Silva, 1993: 35) y en los años 1802-1804 los embarques ascendieron a 364.984 arrobas (Bentancur, 1997:54, 58).

Los derivados vacunos, especialmente las carnes saladas, fueron aumentando su participación en el total de las exportaciones rioplatenses pero sin llegar a disputar la primacía de los cueros. Miguel Ángel Rosal y Roberto Schmit (2004: 166) sostienen que la contribución de los cueros vacunos en el valor total de los bienes exportados disminuyó desde el 95\% en el período 1779-1783, pasando a 87\% en 1792-1796 y llegando a $67 \%$ para la década de 1820 .

Finalmente, la ganadería rioplatense no se limitaba al ganado vacuno. El stock de animales de las unidades productivas de las campañas rioplatenses incluían caballos, bueyes, mulas, ovinos y porcinos ${ }^{51}$. Caballos y bueyes eran herramientas fundamentales del trabajo en las condiciones de la producción agropecuaria de la época. La cría de mulas se destinaba a los mercados del Alto Perú y su importancia había declinado a fines de siglo, especialmente luego de los levantamientos de 1782 (Garavaglia, 1999: 137). Los ovinos y porcinos estaban destinados al consumo doméstico, además del aprovechamiento de la lana de los primeros para la confección de vestimenta.

Más allá de este consumo interno, conocemos bastante bien la demanda de cueros, y en menor medida de sebo, grasa y carne, del período que estaría reflejada en los embarques. Sin embargo, los datos que poseemos sobre la oferta hasta el momento son escasos (Moraes, 2011: 40). El primer paso para determinar las características de esa oferta consiste averiguar de dónde provienen los cueros exportados por cada puerto. Garavaglia (1987: 17-18) sostiene que solamente el $30 \%$ de los cueros exportados desde Buenos Aires podían haber sido producidos por la campaña circundante a la capital virreinal. De acuerdo a los datos de las guías de alcabala del período 1781-1790 el resto de los cueros, unos 100.000 al año, llegaban en un 46\% desde la "Banda

\footnotetext{
${ }^{51}$ De acuerdo a los datos tomados de los inventarios post mortem Garavaglia (1999: 131-132) estima que el establecimiento típico de la campaña bonaerense, calculado a partir de los promedios de cada rubro, tenía una extensión de 2.500 hectáreas y su stock animal estaba compuesto de 790 vacunos, 300 equinos, 490 ovinos y 40 mulas.
} 
Oriental" ${ }^{52}, 22 \%$ de las misiones, $12 \%$ de Santa Fe y $10 \%$ de Córdoba ${ }^{53}$. De la misma manera, los primeros datos de una investigación en curso presentados por José Sovarzo y María Claudia Errecart (2013) permite afirmar que de los cueros ingresados entre julio de 1782 y junio de 1783: 45.116 procedían de la "Banda Oriental", 5.635 de Córdoba, 1.675 del Litoral, 1.400 de los pueblos misioneros y 10 de Chile. Más allá de la importancia de estas cifras la dificultad reside en que las guías registraban los ingresos provenientes desde otros lugares pero no los de la campaña cercana que no pasaban por ninguna receptoría antes de llegar a la ciudad portuaria.

De todas maneras, parece evidente la preponderancia de los cueros arribados desde la cuenca del río Uruguay. El crecimiento de las exportaciones desde el puerto de Buenos Aires en comparación con las efectuadas desde Montevideo que se puede observar en las toscas pero ilustrativas tendencias lineales del gráfico 2 podría indicar una mayor incidencia de esa zona. Una hipótesis, a comprobar en investigaciones futuras, es que la explotación de ganado cimarrón en tierras cada vez más al norte alejándose de la ribera del río Negro implicó que esos cueros se trasladaran por vía fluvial hacia Buenos Aires por el mayor coste del traslado terrestre hasta Montevideo. Cuando dispongamos de los datos de los ingresos a la aduana de Buenos Aires, revelados por las guías de alcabala para esos años, podremos comprobar el peso de esa zona en la producción corambrera ${ }^{54}$.

Conociendo las cantidades exportadas de cueros y otros derivados bovinos nos proponemos estudiar la circulación interna de estos bienes para conocer las condiciones de producción y comercialización de los mismos y a los agentes involucrados en esas actividades económicas. El estudio de esta circulación cobra especial importancia ante las deficiencias del diezmo de cuatropea para brindar una información fiable de la producción ganadera.

El análisis de los diezmos del Río de la Plata ha sido objeto de un intenso debate por parte de los historiadores. El punto de partida de ese debate estuvo dado por la presentación de las series de los diezmos del obispado de Buenos Aires por parte de Juan Carlos Garavaglia (1987). A partir del análisis de esos datos el autor sostiene que

\footnotetext{
${ }^{52}$ Dentro de esta categoría podrían estar también incluidos los cueros que se producían en la banda occidental del río Uruguay.

${ }^{53}$ Garavaglia no menciona el origen del $10 \%$ restante.

${ }^{54}$ Los datos de las guías de la Aduana de Buenos Aires están siendo procesados por un grupo de investigación, del que formamos parte, dirigido por Fernando Jumar.
} 
las cifras de la recaudación de decimal muestran un posición predominante de la producción agrícola por sobre la actividad ganadera en Buenos Aires, Montevideo y Maldonado a fines del siglo XVIII ${ }^{55}$.

Varios son los autores que desde distintas perspectivas han criticado este planteo. En primer lugar, Samuel Amaral y José María Ghío (1990) llegaron a la conclusión contraria, aunque sin rechazar la validez de los diezmos para estimar el volumen la producción agropecuaria. Los autores consideran que dadas las dificultades mayores que existían para recaudar el diezmo de cuatropea, los montos del remate no manifiestan la evolución de la producción como si parecen hacerlo los del diezmos de granos (Ibíd.: 631). En consecuencia, sostienen que el hecho de que el diezmo de granos haya sido superior al de cuatropea no demuestra la superioridad de la producción agrícola con respecto a la ganadera y que esa situación no se refleja ni en el valor de producción, ni en la superficie destinada a cada actividad, ni en la cantidad de capital y mano de obra invertida en cada una (Ibíd.: 637).

Por su parte, para Zacarías Moutoukias (1995: 779) los datos del diezmo en realidad confirman el predominio de la ganadería ya que los bajos valores relativos se debían a la abundancia de la oferta de productos pecuarios. De todas maneras, considera que la comparación entre las actividades sólo tiene sentido si se cuenta con información sobre el mercado local de esos bienes, sus precios y los costos de exportación.

Por otro lado, Eduardo Azcuy Ameghino (2002: 263-264) rechazó la utilización de la cuatropea como indicador de la producción ganadera. A partir de fuentes cualitativas, mostró que el diezmo de cuatropea era muy resistido por los hacendados y solamente se cobraba de manera parcial. Para el autor los montos de la recaudación decimal solamente son el reflejo de un negocio particular, controlado por unos pocos, sin relación con los precios y el stock ganadero y, por lo tanto, es un error metodológico establecer una relación entre el monto del remate, la cantidad del procreo anual y el precio de los animales (Ibíd.: 290).

\footnotetext{
${ }^{55}$ Para un análisis más completo de la fuente y de la producción agraria vista a través de los diezmos ver: Garavaglia (1999: 97-122) A pesar de las críticas, en la actualidad el autor sigue sosteniendo los mismos argumentos, ver: Fradkin y Garavaglia (2009: 103). Otro trabajo que utiliza los diezmos como fuente es el de García Belsunce (1988) pero no figura en este breve repaso porque no analiza el diezmo de cuatropea, ya que solamente considera el diezmo de granos debido a que su intención era realizar un estudio de la producción cerealera.
} 
Desde una perspectiva totalmente diferente, María Inés Moraes (2011: 312) demostró la insuficiencia de la fuente decimal para dar cuenta de la economía agropecuaria rioplatense. Utilizando herramientas propias de la econometría, la autora estimó el producto agrario de la región, deflactando la serie de los diezmos con la ayuda de un índice de precios agrarios. De acuerdo a sus resultados, el aumento demográfico no fue acompañado por un ajuste en la recaudación ${ }^{56}$. En consecuencia, los datos del diezmo subestiman la producción campesina y van perdiendo representatividad con el correr de los años, lo que en el caso montevideano parece darse especialmente a partir de 1787. Además, plantea la necesidad de estudiar la producción de cueros para la exportación a partir de la explotación del ganado sin marca, que no se refleja en el tributo eclesiástico porque no estaba comprendido dentro de la materia imponible (Ibíd.: 95).

En consecuencia, ante las deficiencias del diezmo para dar cuenta de la producción ganadera nos vemos obligados a recurrir a otras fuentes alternativas sobre la producción ganadera. Entendemos que el estudio de la circulación de los bienes pecuarios nos brinda una información más efectiva para realizar esa indagación. En esta ocasión concentraremos nuestra atención en el análisis de la llegada de cueros y otros derivados vacunos a la ciudad portuaria de Montevideo. Para ello recurriremos a tres fuentes de distinta índole que serán tratadas en detalle en los apartados siguientes. La primera consiste en el registro diario del ingreso de cueros, grasa y sebo contenido en relaciones mensuales y abarca el período que va desde septiembre de 1784 hasta marzo de 1790. Esta fuente tiene su origen en la política de control desplegada por el virrey Loreto que incluyó también la suspensión de las faenas misioneras y de las denuncias de tierras. La segunda consiste en otro registro diario, también contenidos en resúmenes mensuales, pero solamente del ingreso de cueros y nos brinda datos desde el mes de septiembre de 1791 hasta febrero de 1797. El origen de esta fuente es una contribución a los cueros orejanos y marcados cobrada en Montevideo para la reforma edilicia de su Iglesia Matriz. Las dos fuentes, con sus virtudes y defectos que analizaremos en breve, poseen la ventaja de incluir la producción de la campaña circundante que no aparece en las fuentes fiscales, como ya tuvimos oportunidad de mencionar para el caso de Buenos

\footnotetext{
${ }^{56}$ Martín Cuesta (2006) realizó una operación similar pero restringida a los diezmos de Buenos Aires. Sus estimaciones le permiten afirmar durante el siglo XVIII no hubo un crecimiento de la producción agropecuaria per cápita en Buenos Aires.
} 
Aires. Por último, la tercera fuente está constituida por las guías de alcabala de Maldonado que permiten estudiar los cueros y otros derivados vacunos que se enviaban desde ese lugar hacia Montevideo para un período más amplio que las anteriores y que se extiende desde el año 1782 hasta 1806. De esta manera, esa mayor extensión temporal nos va a permitir observar el crecimiento de la producción en el área de Malldonado y, al mismo tiempo, ver la influencia que tenían las interrupciones en el tráfico ultramarino ocasionadas por las guerras europeas.

\subsection{El circuito montevideano de cueros y otros derivados de la ganadería,} $1784-1790$

Como mencionamos, la primera fuente tiene su origen en la política de control sobre las faenas de cueros que impuso el virrey Loreto a partir de 1784. Como parte de esa política, el virrey ordenó que se llevara a cabo un registro de los cueros, el sebo y la grasa que ingresaban a Montevideo. En consecuencia durante más de cinco años un funcionario designado por el gobernador de Montevideo revisaba, día a día, los carros que traspasaban las puertas de la ciudad y, luego, el gobernador informaba al virrey mediante relaciones mensuales.

Las relaciones mensuales indican la fecha de cada registro, el nombre y apellido de cada introductor, la cantidad de cueros (en unidades), de sebo y grasa (ambos en arrobas) y la procedencia de los mismos. Además, en algunos casos la fuente aclara cuando los cueros no son de vaca sino de novillo, toro o buey. Del mismo modo, esporádicamente se hace mención a la ocupación del introductor, como en el caso de los capataces o soldados. Durante los primeros meses también se señala el lugar donde se almacenará la carga y el medio de transporte utilizado (la cantidad de carros o carretas).

La fuente abarca el período comprendido entre septiembre de 1784 y marzo de 1790. Su desaparición coincide con el cambio de autoridades posterior a la muerte del rey Carlos III y con la presión de los vecinos para que los funcionarios reales no llevasen a cabo un control sobre el ingreso de la producción. En 1790 el Cabildo de Montevideo propuso que sean los vecinos los que controlasen los ingresos por el portón 
de la ciudad ${ }^{57}$. Es probable que la ausencia de las relaciones de algunos meses ${ }^{58}$ tenga su explicación en esa resistencia y que la fuente refleje la negociación del gobernador Joaquín del Pino con los vecinos, aunque también es posible que se deba al azar, siempre presente, en la conservación de los documentos.

Se conservan 54 relaciones mensuales que contienen 4.390 introducciones realizadas por 924 personas diferentes ${ }^{59}$. En total en esos 54 meses se introdujeron 563.868 cueros. En las 10 primeras relaciones no se registró el ingreso de sebo y grasa, en los 44 meses en los que se lo dejó asentado se ingresaron un total de 104.145 arrobas de sebo y 23.288 de grasa.

En los primeros meses la fuente va cambiando hasta que luego se estandariza. Esta situación implicó que en algunas relaciones aparezcan datos que luego no se consignaron más. En especial, en el mes de noviembre de 1784 se indica el medio de transporte utilizado y el lugar donde se almacenaron los cueros. Esos datos nos permiten, por ejemplo, realizar una estimación de cuántos cueros podía trasladar un carro. Durante ese mes se registraron 67 introducciones, de las cuales solamente en 4 no se registró el medio de transporte, en 3 ocasiones los cueros ingresaron en carretillas y en 60 fueron trasladados en carros. Los datos muestran que un carro podía llevar hasta 100 o 110 cueros pero que por lo general trasladaban 80(ver Anexo 2. Cuadro A. 3). Por supuesto, es probable que algún carro o carretilla no haya estado colmado del todo y que los cueros ocuparan distinto espacio, ya que pueden haber tenido diversos tamaños. Sin embargo, existe una cierta regularidad que, por lo menos, refleja una estimación que era plausible para la persona que hizo el registro. Es importante retener este dato ya que cuando, más adelante, analicemos el accionar de los introductores de cueros a la ciudad, ya sean productores o comerciantes, esta capacidad de transporte impone un límite a lo que se podía introducir por viaje. En este sentido, nos volvemos a encontrar con la desfavorable relación entre volumen y valor que tenían los cueros.

Por otro lado, todas las introducciones de ese mes indican el sitio dónde se van a almacenar los cueros. Aparecen 17 lugares de almacenamiento, todos ellos huecos, exceptuando una casa y la plaza. Solamente 5 introductores guardan los cueros en sus

\footnotetext{
${ }^{57}$ AGN IX 2-6-8

${ }^{58}$ Los meses que faltan son diciembre de 1784; septiembre, octubre, noviembre y diciembre de 1785; enero, abril, mayo, junio y julio de 1786; y agosto, septiembre y noviembre de 1787.

${ }^{59}$ Lo que representa un porcentaje importante de la población, aún teniendo en cuenta algún error que haga contabilizar dos veces a una misma persona.
} 
propios huecos ${ }^{60}$. Los principales lugares de almacenamiento durante ese mes son los de Juan Pedro Aguirre y Luis Gutiérrez, con 8.822 y 7.748 cueros respectivamente (ver Anexo 2. Cuadro A. 4). El análisis de la procedencia de los cueros de unos de esos sitios muestra la vastedad de las redes de abastecimientos de algunos de los barraqueros asentados en Montevideo. La mayor parte de los cueros almacenados en el hueco de Juan Pedro Aguirre en noviembre de 1784 (4.906) procedían de las faenas realizadas por Antonio Pereyra para la Administración de las Misiones del otro lado del río Negro. Además, José Núñez introdujo 300 del consumo del fuerte de Santa Teresa (situado sobre la costa atlántica), Antonio Monasterio 130 comprados en Santa Lucía y Maldonado, Francisco Sánchez 82 también desde Maldonado, José Estreyte 80 comprados a vecinos de San José, Vicente Garzón 150 del matadero de Montevideo, Juan Trapani 635 de su propio matadero y María Francisca Alzaybar 277, Melchor de Viana 240 y José Llorens 240 procedentes de sus estancias ${ }^{61}$. Este ejemplo refleja la variedad de lugares desde donde llegaban los cueros (mapa 5) y es, además, un indicio de la red de vínculos personales en las que se asentaba el exportador para adquirir, transportar y acopiar la mercancía exportable.

Mapa 5. Procedencia de los cueros acopiados por Juan Pedro Aguirre, noviembre de 1784

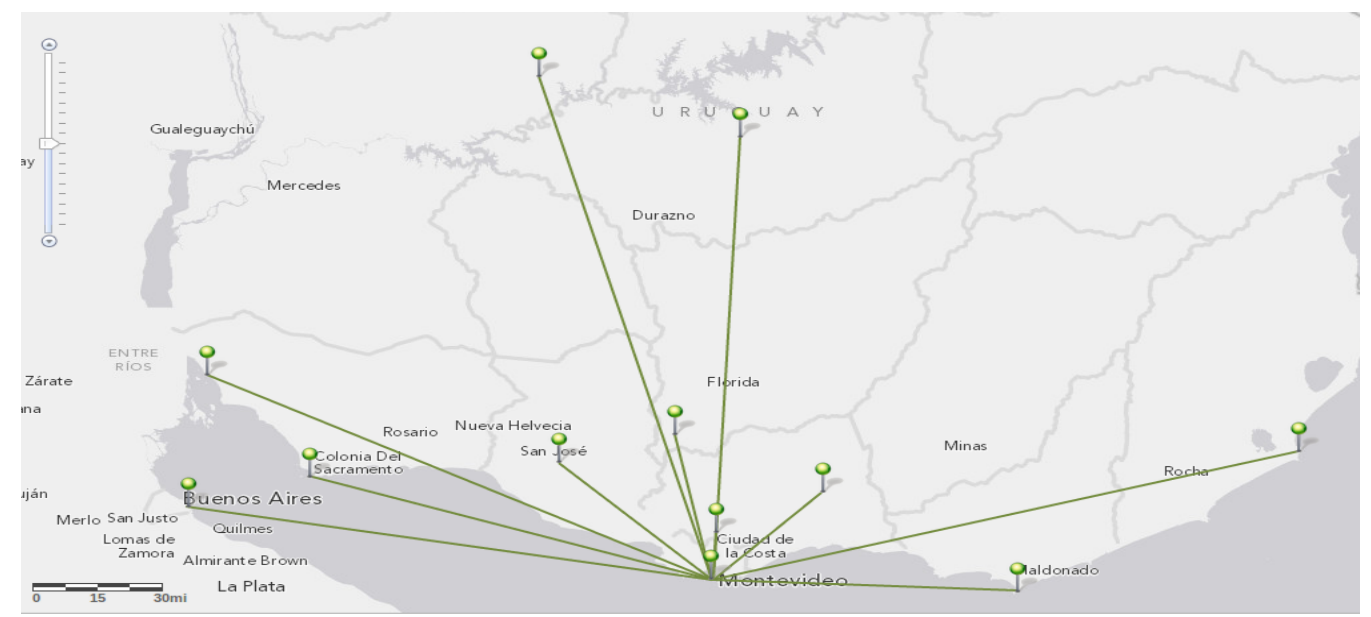

Fuente: Elaboración propia en línea en www.arcgis.com

\footnotetext{
${ }^{60}$ Un hueco era una porción de terreno que podía tener una especie de techo o toldo y que se utilizaba para acopiar los cueros apilándolos.

${ }^{61}$ AGN, Montevideo, IX, 2-4-3.
} 
Más allá de la riqueza de esta información esporádica, el resto de los datos aportados por estas relaciones mensuales permiten realizar series cuantitativas que brindan indicios importantes para el estudio de la circulación de productos pecuarios en el área de Montevideo durante ese período. En consecuencia, trabajaremos con esa información que, una vez que la fuente se estandariza, se limita a la fecha, el introductor, la procedencia y la cantidad de cueros. Luego, a partir de agosto de 1785, comienza a registrar también la cantidad de sebo y grasa ingresados, lo que aumenta la cantidad de introducciones ya que en muchas ocasiones no se transportaban cueros.

En el gráfico 3 se puede observar el comportamiento de los totales mensuales de cueros ingresados a la ciudad portuaria de Montevideo. La línea color celeste representa esos ingresos mensuales que se encuentran detallados en el Anexo 2 Cuadro A.5. Con color azul aparece la tendencia por medias móviles que indica una estimación probable de los datos faltantes. En color rojo se encuentra graficada la tendencia polinómica permite observar con mayor claridad el comportamiento de la variable más allá de las oscilaciones estacionales típica de la producción pecuaria. De esta manera, el gráfico muestra una caída muy marcada en el bienio 1785-1786 y una recuperación de los ingresos tímida durante 1787 que luego se torna más intensa, especialmente a partir de septiembre de 1788. El descenso de los ingresos de cueros a la ciudad puede ser explicada por varias situaciones que se dieron de manera simultánea. En primer lugar, el pico muy alto de ingresos de los meses finales de 1784 se corresponde con el auge producido por la recomposición del tráfico ultramarino posterior a la guerra con Inglaterra. Es probable que, en ese momento, el faenamiento excesivo tuviese un impacto sobre el stock de animales disponible que, de esa manera, repercutiera en los ingresos posteriores provocando su caída. En segundo lugar, la caída coincide con las medidas tomadas en agosto de ese año por la administración del virrey Loreto para, justamente, mantener el stock ganadero. Entre esas medidas, la suspensión de las faenas de cueros de los pueblos misioneros parece haber tenido un impacto muy importante en la disminución de las introducciones de cueros a la ciudad. Por otro lado, la lenta recuperación de los años posteriores puede ser comprendida tanto por un relajamiento en la política de control de las faenas de ganado cimarrón como por un progresivo avance de los productores montevideanos sobre tierras y ganados del espacio pastoril misionero, que veremos con más detalle en otros capítulos. 
Gráfico 3. Totales mensuales de cueros ingresados a Montevideo de septiembre de 1784 a marzo de 1790

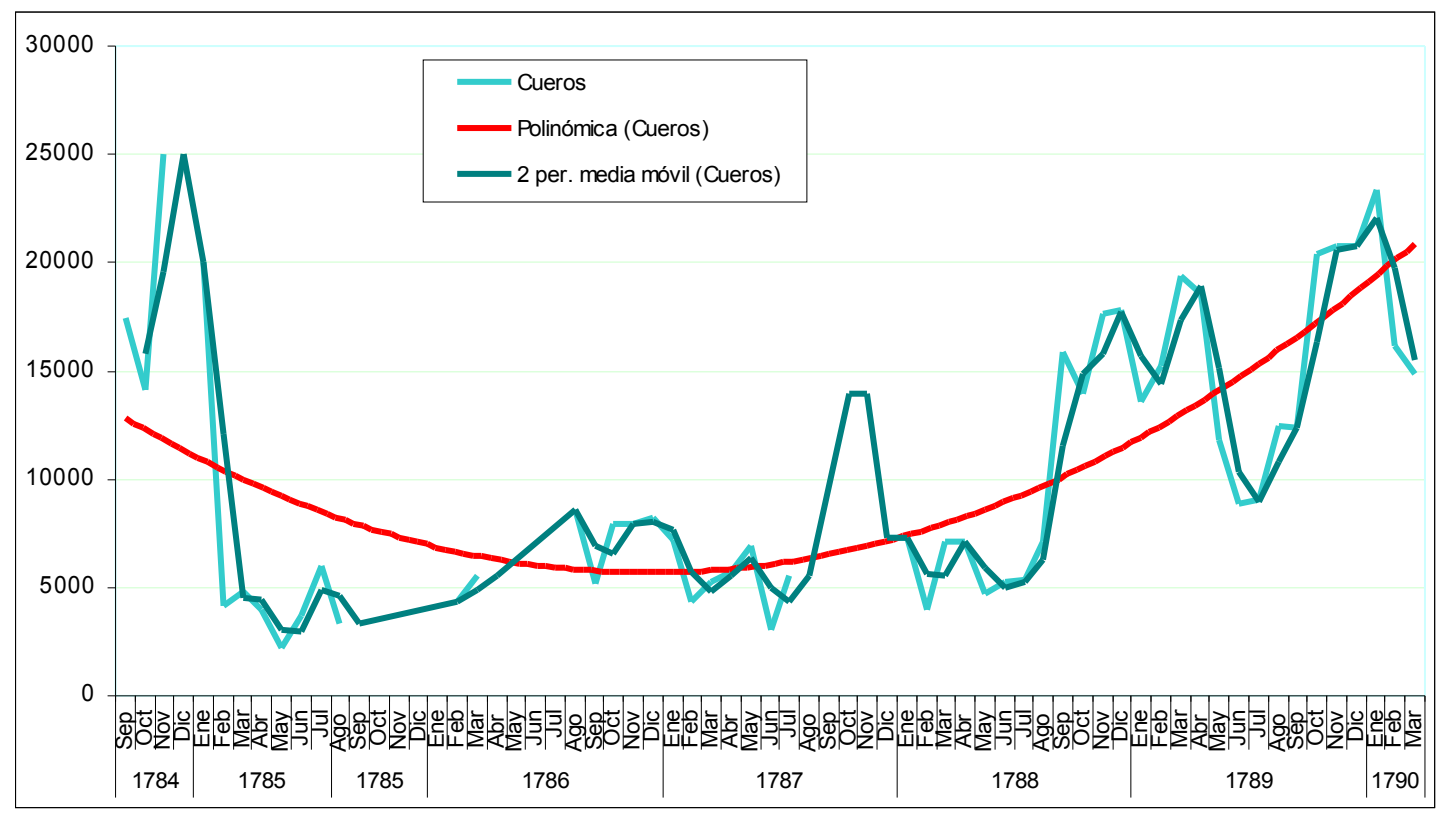

Fuente: Elaboración propia a partir de AGN IX: 2-4-3, 2-4-4, 2-4-5, 2-4-6, 2-5-1, 2-5-2, 2-5-3, 2-5-4, 2-5-5, 2-5-6, 2-6-1, 2-6-2, 2-6-3, 2-6-4, 2-6-5, 2-6-6 у 2-6-7.

Gráfico 4. Totales mensuales de sebo y grasa (en arrobas) ingresados a Montevideo, de agosto de 1785 a marzo de 1790

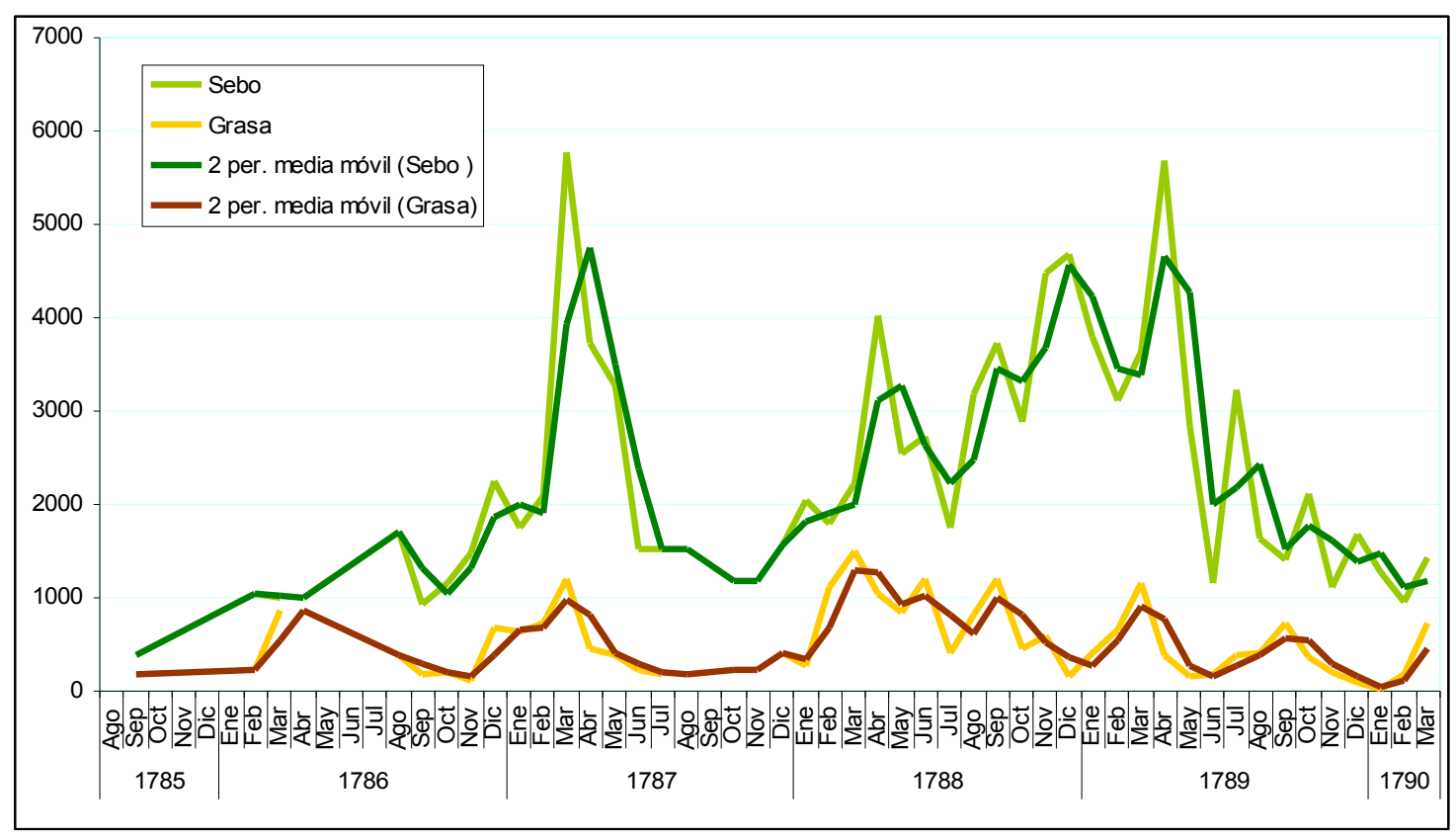

Fuente: Elaboración propia a partir de AGN IX: 2-4-3, 2-4-4, 2-4-5, 2-4-6, 2-5-1, 2-5-2, 2-5-3, 2-5-4, 2-5-5, 2-5-6, 2-6-1, 2-6-2, 2-6-3, 2-6-4, 2-6-5, 2-6-6 у 2-6-7. 
La comparación con los datos de los cueros embarcados anualmente en el puerto de Montevideo, que proporciona Maximiliano Camarda (2014) a partir de información fiscal, es un buen indicador de la fiabilidad de la fuente que estamos analizando. Los cueros ingresados en los dos años para los que poseemos todas las relaciones mensuales, 1788 y 1789, muestran una escasa diferencia con las cifras de las exportaciones. En 1788 ingresaron 113.143 cueros y se exportaron 143.399 y en 1789 se introdujeron 183.235 cueros a la ciudad y se embarcaron 173.070. Es lógico que las cifras difieran por varias razones. Existía una diferencia entre la llegada de los bienes y la exportación de los mismos que se reflejaba en el tiempo que quedaban almacenados en los huecos. Algunos cueros podían arruinuarse durante ese período, por ejemplo por el apolillamiento que era muy habitual hasta que en el siglo XIX se generalizase el uso de arsénico para evitarlo. Además, una parte de los cueros podía ser consumida en la propia ciudad, como ya mencionamos más arriba. De todas maneras, si observamos nuevamente el gráfico 2 podemos confirmar el brusco descenso en la exportación de cueros desde Montevideo y la lenta recuperación en los años siguientes que también identificamos al analizar la llegada de los cueros a la ciudad.

El gráfico 4 muestra, por su parte, la introducción mensual de sebo y grasa. Como en el gráfico anterior, las líneas de color más claro representan las cantidades totales mensuales ingresados de sebo y grasa en arrobas (ver Anexo 2 Cuadro A.5.) y las líneas más oscuras indican la tendencia por medias móviles que presentan una estimación posible del comportamiento de la variable para suplir los datos de los meses faltantes. Podemos observar que las introducciones más importantes se daban en los meses de marzo y abril del año, mientras que los de los cueros se concentraban especialmente en los últimos meses de cada año.

La diferente temporalidad de los ingresos puede ser explicada en el hecho de que los cueros provienen de dos actividades productivas diferentes y su marcada estacionalidad se debe al peso de las vaquerías en el total de la producción de cueros, mientras que la mayor parte de la producción de sebo y grasa proviene de la ganadería de rodeo, que permite un aprovechamiento más integral de los animales sacrificados. De hecho, como veremos más adelante (ver capítulo 3), una parte importante de las arrobas de sebo y grasa ingresados provenían de las compras realizadas por fabricantes de velas de sebo y pequeños comerciantes en los mataderos situados en las cercanías a la ciudad, 
lo que confirma que se originaban en animales que eran producto de la ganadería de rodeo. Por otra parte, la oferta de sebo y grasa no dependían de manera lineal de la cantidad de animales sacrificados. Las condiciones climáticas, especialmente las sequías, afectaban también la disponibilidad de esos bienes; ya que una alimentación deficiente del ganado vacuno tenía que disminuir necesariamente la proporción de lípidos existente en el cuerpo de cada animal.

Por otro lado, además de informarnos sobre los volúmenes y la estacionalidad de la producción ganadera, la fuente brinda datos sobre la procedencia de los bienes. De esta manera, podemos saber si provenían de los ganados o del matadero de los introductores, si habían sido comprados en la campaña, si eran parte de la recaudación del diezmo de cuatropea o si eran remitidos por comandantes, ya sea como consecuencia de embargos realizados o del consumo de los destacamentos militares en la campaña. La caracterización de esos introductores como agentes económicos y el análisis del sistema de comercialización de los bienes pecuarios serán analizados en el capítulo siguiente. En este lugar nos concentraremos en determinar qué proporción de los bienes eran transportados hasta el puerto por los propios productores y qué porcentaje llegaba por otros medios.

El cuadro 1 resume la información sobre el origen de los bienes pecuarios que ingresaron a Montevideo durante el período. Conocemos la procedencia de la mayor parte de esos bienes ya que solamente no disponemos de datos para $4,87 \%$ de los cueros y de los insignificantes $0,22 \%$ y $0,65 \%$ del sebo y la grasa respectivamente. En líneas generales, el análisis de los datos del cuadro confirma la misma situación que describió Jorge Gelman (1998: 152) para la zona de Santo Domingo Soriano. Es decir, un grupo de grandes y medianos productores que podían llevar su producción hasta los mercados y un sector de pulperos, fijos o volantes, que recogían los excedentes de una gran cantidad de pequeños productores. En el caso de Montevideo, el cuadro nos permite observar que nuevamente existen diferencias entre los cueros, el sebo y la grasa.

Antes que nada debemos aclarar que las categorías correspondientes a los productores son tres. La primera es la que se encuentra identificada con la expresión Sus ganados que es la que con más frecuencia aparece en la fuente. En la segunda categoría que figura en el cuadro como Su estancia... hemos agrupado los datos que en la fuente aparecen con varias expresiones referentes a los establecimientos de los 
productores $^{62}$. Preferimos mantener la distinción entre las dos categorías porque el hecho de que la mayor parte de los ingresos hayan sido asentados con la expresión sus ganados, sin hacer referencia a un establecimiento productivo, es muy interesante en tanto es indicativo de las condiciones de la producción ganadera en esa época. La tercera categoría es la de $S u$ matadero ya que consideramos que esos individuos eran productores porque realizaban la matanza y la extracción del cuero, el sebo y la grasa del ganado, aunque no lo hayan criado.

Cuadro 1. Origen de los cueros, sebo y grasa ingresados a Montevideo, septiembre de 1784- marzo de 1790

\begin{tabular}{|c|c|c|c|c|c|c|c|}
\hline & Origen & Cueros & Porcentaje & Sebo & Porcentaje & Grasa & Porcentaje \\
\hline 1 & Sus ganados & 277.966 & $49,3 \%$ & 48.556 & $46,6 \%$ & 17.882 & $76,8 \%$ \\
\hline 2 & Su estancia. & 17.873 & $3,2 \%$ & 551 & $0,5 \%$ & 637 & $2,7 \%$ \\
\hline \multirow[t]{2}{*}{3} & Su matadero & 10.654 & $1,9 \%$ & 960 & $0,9 \%$ & 713 & $3,1 \%$ \\
\hline & Subtotal & 306.493 & $54,4 \%$ & 50.067 & $48,1 \%$ & 19.232 & $82,6 \%$ \\
\hline 4 & Comprados & 157.493 & $27,9 \%$ & 47.652 & $45,8 \%$ & 3.550 & $15,2 \%$ \\
\hline 5 & Matadero de.. & 4.207 & $0,7 \%$ & 4.756 & $4,6 \%$ & 258 & $1,1 \%$ \\
\hline 6 & Diezmo & 6.894 & $1,2 \%$ & 120 & $0,1 \%$ & 0 & $0,0 \%$ \\
\hline 7 & Embargados & 11.341 & $2,0 \%$ & 156 & $0,2 \%$ & 0 & $0,0 \%$ \\
\hline 8 & Consumo de. & 2.260 & $0,4 \%$ & 0 & $0,0 \%$ & 0 & $0,0 \%$ \\
\hline 9 & Otros & 47.382 & $8,4 \%$ & 919 & $0,9 \%$ & 97 & $0,4 \%$ \\
\hline \multirow[t]{3}{*}{10} & Sin datos & 27.798 & $4,9 \%$ & 475 & $0,5 \%$ & 151 & $0,7 \%$ \\
\hline & Subtotal & 257.375 & $45,6 \%$ & 54.078 & $51,9 \%$ & 4.056 & $17,4 \%$ \\
\hline & Total & 563.688 & $100,0 \%$ & 104.145 & $100,0 \%$ & 23.288 & $100,0 \%$ \\
\hline
\end{tabular}

Fuente: Elaboración propia a partir de AGN IX: 2-4-3, 2-4-4, 2-4-5, 2-4-6, 2-5-1, 2-5-2, $2-5-3,2-5-4,2-5-5,2-5-6,2-6-1,2-6-2,2-6-3,2-6-4,2-6-5,2-6-6$ у 2-6-7.

Por otra parte, la categoría Comprados indica todos los bienes ingresados que habían sido comprados en diferentes lugares de la campaña. La categoría Matadero de... agrupa todos los bienes identificados como adquiridos en alguno de los mataderos cercanos a la ciudad. Si bien la fuente no dice específicamente que los productos hayan sido comprados, inferimos que así fue porque, como veremos en el capítulo 3, la mayor parte de esos introductores eran fabricantes de velas de sebo que compraban sus

\footnotetext{
${ }^{62}$ Algunas de las expresiones son: su estancia, sus estancias, su hacienda, sus haciendas, faenados en su estancia, etc. El término hacienda puede referirse a los ganados o un establecimiento pero, a pesar de esto, optamos por incorporarlo dentro de esta categoría.
} 
insumos a intervalos regulares. Por lo tanto, lo mantenemos aparte, sin incluirlos dentro de la categoría comprados, para poder ver la incidencia de la producción de los mataderos pero lo consideramos como parte de los bienes comerciados en la campaña.

En la categoría Otros están contenidas distintas situaciones en las que, a pesar de que disponemos algunos datos, no podemos determinar con exactitud su procedencia. Por ejemplo, porque eran remitidos o pertenecían a terceros, eran parte de una testamentaria o solamente indicaban su procedencia geográfica. Por lo general, no parecen ser bienes comercializados pero no es posible asegurarlo con certeza. La categoría Diezmo se corresponde a los cueros y el sebo procedente de los ganados recogidos como parte del diezmo de cuatropea. Por último, en Embargados figuran los bienes remitidos por los comandantes producto de los decomisos efectuados en la campaña y en Consumo de... se incluyen los cueros originados por el consumo de reses vacunas para la alimentación diaria de los diversos destacamentos militares de la zona.

En consecuencia, podemos afirmar que los productores ingresaron a la ciudad el $54,35 \%$ de los cueros, $48,07 \%$ del sebo y $82,58 \%$ de la grasa, mientras que el $28,68 \%$ de los cueros, el 50,32\% del sebo y el $16,35 \%$ de la grasa habían sido comprados en diversos sitios por sus introductores. Es probable que la diferencia tan marcada en los cueros ingresados por los productores con respecto a los comprados en la campaña se deba a que se conjugan los provenientes de la ganadería de rodeo con los de las vaquerías. Como veremos más adelante, los productores buscaban identificar el ganado cimarrón como ganado que se había alzado de sus establecimientos para tener prioridad en la explotación de esos animales, por lo que es lógico que al indicar el origen de los cueros declarasen que provenía de sus ganados. Por otro lado, como ya mencionamos, el sebo provenía en su mayor parte de la ganadería de rodeo lo que explica que las proporciones en que era introducido en la ciudad por los propios productores o por compradores hayan estado equilibradas.

Por su parte, los ingresos provenientes de los diezmos alcanzaban el total de 6.894 cueros $(1,22 \%$ del total) y 120 arrobas de sebo (Cuadro 6). Si tomamos el año 1789 podemos ver que los 5.004 cueros introducidos como producto del diezmo de cuatropea representan el 2,72 \% del total de 183.368 que llegan a la ciudad. Esto en realidad no es tan sorprendente si tenemos en cuenta que se cobraba sobre el procreo anual y, sobre todo, que la reticencia de los hacendados a pagarlo era muy importante. 
Por último, los cueros embargados en diferentes lugares de la campaña ascienden a 11.341 y los que provienen del consumo de los destacamentos fueron 2.260. Además, se decomisaron 156 arrobas de sebo.

En muchas ocasiones, la fuente también indica la procedencia geográfica. De esta manera, sabemos que a Montevideo llegaron productos de toda la "Banda Oriental", exceptuando los lugares donde resulta más práctico, y menos costoso, el transporte fluvial; como Santo Domingo Soriano y Colonia ${ }^{63}$. Al formar parte de la jurisdicción de Buenos Aires, los cueros provenientes del área próxima a esos dos puertos se registran en la Aduana de Buenos Aires. Esto nos advierte de un contraste importante entre las dos ciudades principales de la región. Mientras que, como vimos, la campaña de Buenos Aires aporta apenas el $30 \%$ de los cueros que llegan a la ciudad y el resto proviene desde las dos bandas del río Uruguay, las Misiones, Santa Fe y Córdoba; en cambio, a Montevideo solamente ingresan de distintos sitios de la "Banda Oriental".

Entre los lugares de origen destaca especialmente Maldonado, desde donde llegaron 40.130 cueros, 6.235 arrobas de sebo y 985 de grasa en 279 introducciones. Si bien en un primer momento esto parece llamativo por ser Maldonado un puerto atlántico donde arribaban navíos que comerciaban con Europa, es necesario recordar que no era un puerto autorizado por la Corona para ese comercio y, por lo tanto, los cueros que circulaban de manera legal debían ser trasladados hasta Montevideo. Como ya mecionamos, más adelante trataremos en detalle estos envíos de productos pecuarios desde Maldonado a partir de los datos más completos que nos proporcionan las guías elaboradas en ese lugar.

Finalmente, en los últimos tres meses de 1784 ingresaron 12.437 cueros provenientes de las Misiones en apenas 19 introducciones; sin embargo, en los años siguientes no se registran cueros con esa procedencia. La explicación de este hecho nos remite nuevamente a la política virreinal. Como ya mencionamos, el virrey Loreto ordenó la suspensión de las faenas por parte de la administración de las misiones y efectuó un control sobre la faenas de cueros que se tradujo en la importancia de los decomisos que se efectuaron, en su mayor parte, durante los primeros meses del período que estamos analizando.

${ }^{63}$ Según Jorge Gelman, que ha estudiado esa zona, entre enero de 1776 y marzo de 1779 se enviaron 203.734 cueros de Colonia a Montevideo (Gelman, 1998: 145) 
Luego de marzo de 1790 las relaciones mensuales se interrumpen. El cambio de autoridades tuvo sin duda que ver con esto. Es probable que las nuevas autoridades virreinales cedieran ante la presión de los vecinos hacendados que pretendían desembarazarse de ese control. Al mismo tiempo que disminuía la represión que esporádicamente llevaba a cabo el estado virreinal contra las faenas clandestinas de cueros (ver capítulo 6). Por eso debemos recurrir a otros lugares para recoger datos sobre la circulación de los cueros dentro del área para los años siguientes.

\subsection{Ingresos de cueros marcados y orejanos a Montevideo, 1791-1797}

La información sobre la circulación de los productos pecuarios para el período siguiente proviene de una fuente de distinta índole. Como ya mencionamos, luego del mes de marzo de 1790 el aparato burocrático virreinal dejó de controlar los cueros en el portón de ingreso a Montevideo de manera que las relaciones mensuales que estuvimos analizando se discontinuaron. Sin embargo, contamos con registros de los cueros ingresados entre septiembre de 1791 y febrero de 1797 que se encuentran en los libros de cuentas de la iglesia matriz de Montevideo.

Esos listados de introducciones de cueros tienen su origen en una decisión tomada por los vecinos de Montevideo en el cabildo abierto del 17 de agosto de 1791 donde acordaron pagar un real por cuero orejano y un cuartillo por cuero marcado que ingresaran a la ciudad para contribuir a la fábrica de la iglesia matriz (Acuerdos del Extinguido Cabildo de Montevideo [en adelante AECM], 1742: 420). El aporte que en principio estaba estipulado se realizara durante un año se extendió, finalmente, por casi cinco años y medio.

La fuente brinda información solamente sobre la fecha, el nombre de la persona y la cantidad de cueros marcados y orejanos que introdujo en la ciudad. Si bien es menos rica que la analizada en el apartado anterior, ya que no proporciona datos sobre los ingresos de sebo y grasa o sobre el origen de los bienes, posee, sin embargo, la ventaja de presentar una serie completa. 
Gráfico 5. Totales mensuales de ingresos de cueros a Montevideo, de septiembre de 1791 a febrero de 1797

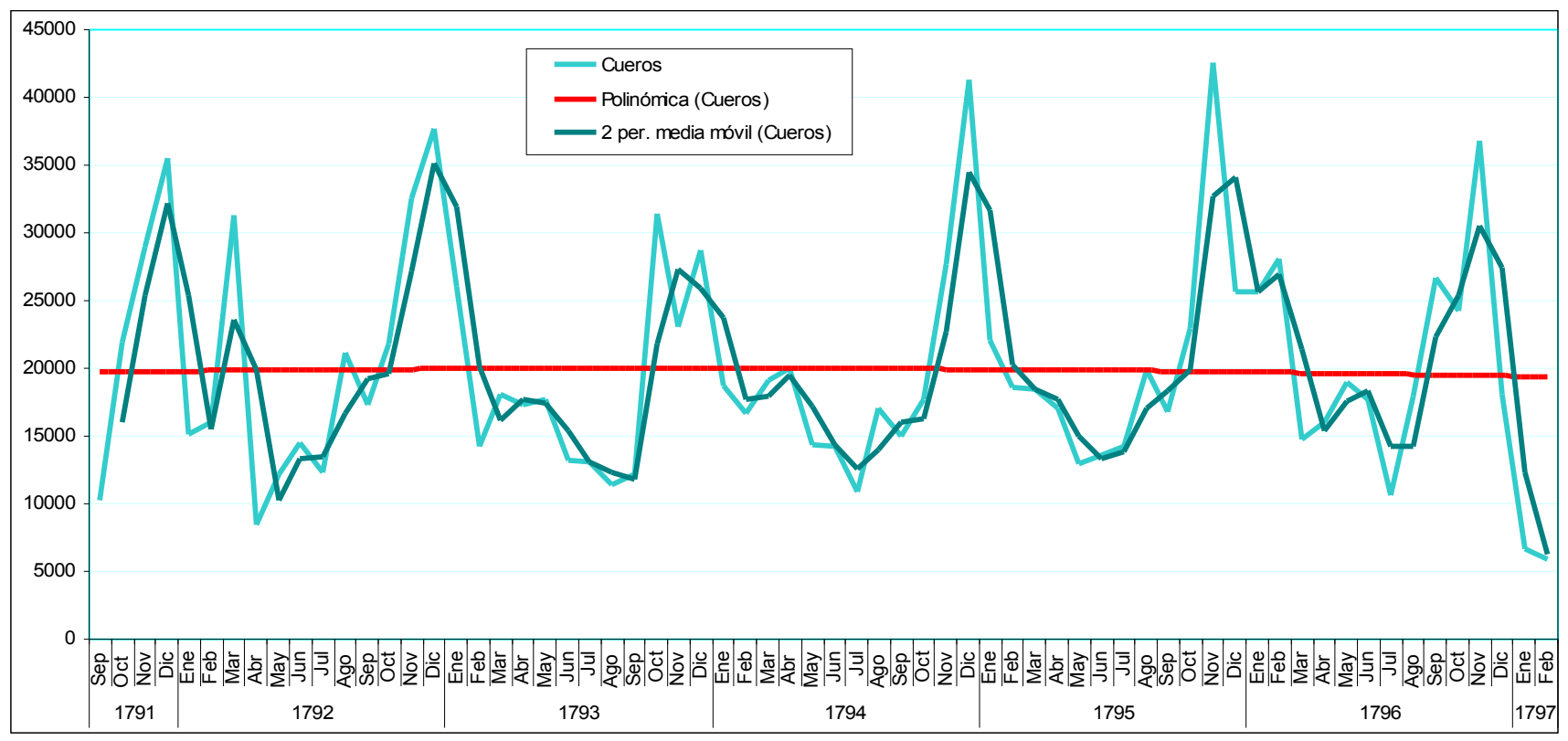

Fuente: AGN IX 3-2-5

Durante los 65 meses que abarcan el período comprendido por la fuente se efectuaron 6.026 introducciones por 940 individuos diferentes que ingresaron un total de 1.308.619 cueros. Con un promedio anual de 240.033 cueros. El gráfico 5 muestra la evolución del ingreso de cueros durante el período. La línea celeste representa los totales mensuales de cueros ingresados a la ciudad. La línea azul indica la tendencia por medias móviles que, si bien en este caso no existe ningún dato faltante que cubrir, hemos colocado para mantener la homogeneidad con el gráfico 3 y permitir, así, una mejor comparación entre los mismos. La tendencia polinómica, que aparece en color rojo, refleja que, a pesar de su estacionalidad, los ingresos mensuales de cueros adquieren durante esos años una estabilidad que contrasta con el crecimiento verificado en el período anterior. Es probable que ese estancamiento en la cantidad anual de cueros que ingresan a la ciudad refleje que el hinterland del puerto de Montevideo llegó en esos momentos a un nivel de ocupación plena de sus recursos productivos. Al mismo tiempo, el crecimiento de la región se mantuvo gracias a la expansión territorial que incorporó tierras y ganados situados cada vez más al norte. En este sentido, como ya 
mencionamos, es probable que los cueros faenados en esos nuevos espacios corambreros se hayan trasladado cada vez más por vía fluvial hasta Buenos Aires, lo que explicaría el aumento de la exportación de cueros desde ese puerto.

Gráfico 6. Cantidad de cueros marcados y orejanos entrados a Montevideo, de septiembre de 1791 a febrero de 1797

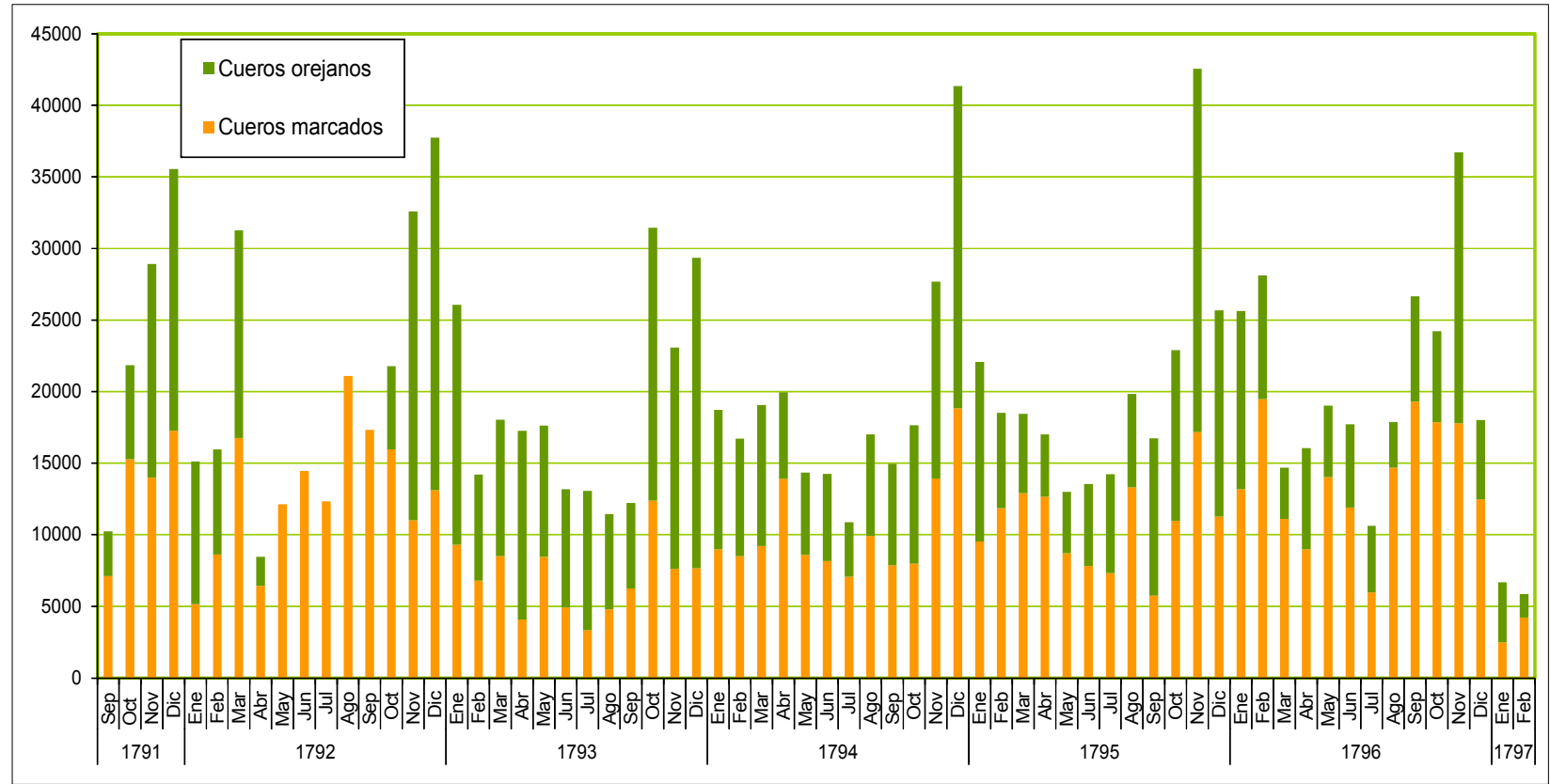

Fuente: AGN IX 3-2-5

El gráfico 6, por su parte, distingue entre cueros marcados y cueros orejanos ingresados cada mes. Los cueros orejanos eran los cueros provenientes de animales que no habían sido marcados. Es probable que algunos de esos cueros hayan sido producto de la ganadería de rodeo, en tanto que algún productor dejase una porción de ganado sin marcar o algunos animales podrían haber muerto antes de ser marcados. Sin embargo, creemos que se puede suponer que la mayor parte de los cueros orejanos se producían en las expediciones de caza de ganado para extraer sus cueros, habitualmente denominadas vaquerías. El gráfico permite, entonces, una aproximación a la incidencia de los cueros orejanos generados por las vaquerías en los ingresos al puerto. Si bien los 
cueros orejanos ingresaban de manera constante ${ }^{64}$, se puede ver un crecimiento significativo durante los últimos meses de cada año. En consecuencia, podemos afirmar que la marcada estacionalidad que se observa en los ingresos totales (ver gráficos 3 y 5) se debía a la importancia de las vaquerías de corambre en la producción de la zona.

Cuadro 2. Cueros marcados y orejanos introducidos a Montevideo, 1792-1796

\begin{tabular}{|c|c|c|c|c|c|}
\hline Año & Cueros marcados & $\%$ & Cueros orejanos & $\%$ & Total \\
\hline 1792 & 154463 & $64 \%$ & 85937 & $36 \%$ & 240400 \\
1793 & 84162 & $37 \%$ & 142896 & $63 \%$ & 227058 \\
1794 & 123067 & $53 \%$ & 109586 & $47 \%$ & 232653 \\
1795 & 129318 & $57 \%$ & 115336 & $43 \%$ & 244654 \\
1796 & 166787 & $65 \%$ & 88614 & $35 \%$ & 255401 \\
\hline
\end{tabular}

Fuente: AGN IX 3-2-5

Observamos, también, que durante el último año descienden los ingresos de los cueros orejanos, lo que se confirma con los datos anuales presentados en el cuadro 2. Esta reducción puede reflejar una reacción más rápida de la vaquería, con respecto a la ganadería de rodeo, a las condiciones del mercado. Es decir, a la disminución del tráfico ultramarino debido al inicio de la guerra en Europa. Sin una demanda de cueros que las justifique las vaquerías no se llevaban a cabo, lo que permitía una recomposición del stock de ganado cimarrón. Pero en la ganadería de rodeo, si bien los grandes estancieros podían suspender la matanza de ganado a la espera de mejores condiciones de mercado, los pequeños productores, en cambio, debían seguir vendiendo su producción para poder sobrevivir.

Por otro lado, esa reducción en los ingresos de cueros orejanos puede deberse también al agotamiento de las reservas de ganado cimarrón más cercanas, lo que habría implicado el traslado de la mayor parte de las vaquerías de corambre hacia territorios situados más al norte. Como dijimos anteriormente, creemos que al situarse los focos corambreros más al norte, la opción más lógica habría sido el traslado de los cueros de manera fluvial descendiendo por la cuenca del río Uruguay hasta el apostadero de Las

\footnotetext{
${ }^{64}$ Con la excepción de algunos meses del año 1792 cuando estaba vigente una prohibición virreinal
} 
Conchas. En ese caso, la exportación de esos cueros quedó asentada en los libros de la Aduana de Buenos Aires.

De todas maneras, la caída abrupta de los ingresos durante los dos primeros meses de 1797 y la posterior desaparición de la contribución para la fábrica de la iglesia matriz son sintomáticas del peso que tenía para estas actividades el comercio ultramarino. Las dos fuentes que analizamos nos permitieron brindar una panorama del período que va de septiembre de 1784 a febrero de 1797 para el área de Montevideo durante el cual predominaron condiciones ideales para la explotación del ganado en cuanto a la demanda que significaban las bodegas de los navíos que continuamente arribaban al estuario rioplatense. En el próximo apartado podremos abarcar un período más amplio que, aunque se restrinja al área de Maldonado, nos permite tener una idea de los efectos que tenía sobre la producción de cueros y otros derivados de la ganadería las interrupciones del tráfico ultramarino que ocasionaban las guerras europeas así como estudiar el crecimiento de la ganadería en un período que es un poco más amplio.

\subsection{Envíos de derivados vacunos de Maldonado a Montevideo, 1782-1806}

En este apartado se analizan los envíos de derivados vacunos desde el área de Maldonado hacia el puerto de Montevideo a partir de la información que proporcionan las guías de alcabala generadas por la Real Hacienda de Maldonado. Aunque representan un porcentaje menor de los bienes pecuarios ingresados al puerto, el estudio de esos envíos permite analizar un período más largo y sopesar los efectos de las interrupciones del tráfico ultramarino por las guerras europeas. Al mismo tiempo, esta fuente permite indagar sobre el crecimiento de la producción ganadera en un área que vivió una rápida expansión territorial durante el período.

Las guías de tránsito de bienes se elaboraban con el objetivo de cobrar la alcabala al comercio terrestre. Permitían, además, ejercer un control sobre la circulación $\mathrm{y}$, de esta manera, contribuían a combatir el contrabando o los robos. La fuente contiene los datos del dueño de los productos, a veces también los del destinatario y/o del transportista, de los productos indicando su cantidad y aforo, de su destino y de lo que se había abonado de alcabala. Los bienes eximidos del impuesto también están 
anotados. En este caso, utilizamos los libros auxiliares de guías de alcabala de la Real Hacienda de Maldonado, donde están anotadas de manera completa todas las guías elaboradas por esa institución. De esta manera, sabemos con seguridad que contamos con todas las guías que se generaron en ese lugar.

Disponemos de 4.148 guías que abarcan el período que va de enero de 1782 a octubre de 1806, con la excepción del año 1787 para el que no contamos con datos porque no ha sobrevivido el libro auxiliar correspondiente. Lo primero que surge del análisis es la fuerte vinculación que existía entre Maldonado y Montevideo, ya que prácticamente la totalidad de las guías tiene ese lugar como destino ${ }^{65}$.

Gráfico 7. Totales anuales de cueros enviados desde Maldonado hacia Montevideo, $1783-1806$

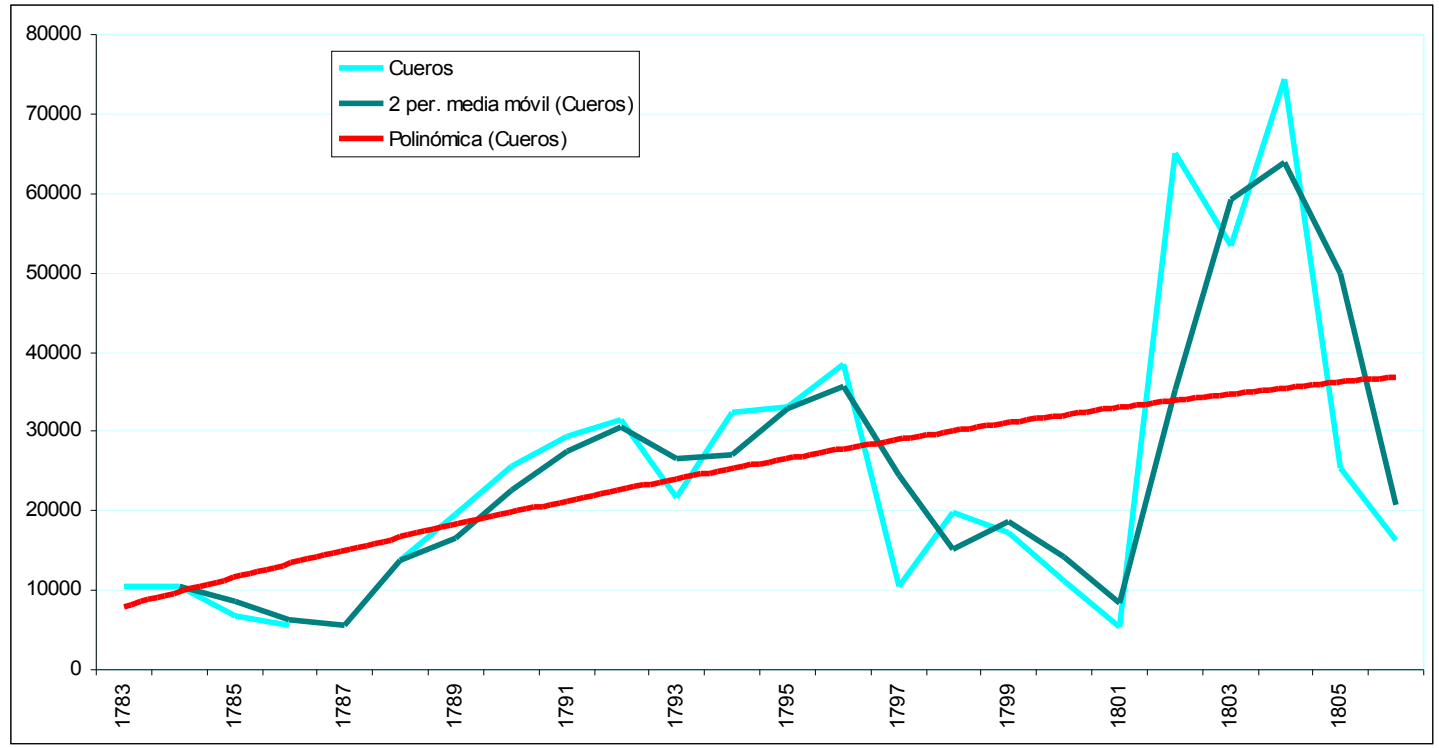

Fuente: AGN XIII Maldonado Legajos de 3288 a 3312

El gráfico 7 muestra los totales anuales de cueros enviados desde Maldonado hacia Montevideo entre los años 1783 y 1806. Las referencias son iguales a las de los gráficos 3 y 5 . Es decir, la línea celeste representa los totales anuales de cueros

\footnotetext{
${ }^{65}$ De las 4.148 guías solamente 78 tienen como destino Buenos Aires, 12 Puerto Deseado, 9 Santa Teresa, 1 Santo Domingo Soriano y 1 la línea divisoria con los territorios lusitanos.
} 
enviados, la línea azul la tendencia por medias móviles y la línea de color rojo la tendencia polinómica ${ }^{66}$.

Se observa un crecimiento de los envíos de cueros hacia el puerto montevideano a lo largo del período. Al igual que cuando analizábamos los ingresos totales a Montevideo es evidente que siguieron las fluctuaciones del comercio ultramarino. Eso explica las drástica disminución de los envíos que se dieron en los períodos de guerra 1797-1801 y a partir de 1804. Pero, más allá de esos períodos, la producción ganadera del área muestra un crecimiento importante. En los años posteriores a las guerras (17831784 y 1802-1804), cuando el repunte de las exportaciones era muy importante, los cueros enviados a Montevideo pasaron de rondar los 10 mil a superar los 50 mil. En consecuencia, podríamos decir que la producción ganadera del área por lo menos se quintuplicó.

Cuadro 3. Participación de los cueros enviados desde Maldonado en los cueros exportados desde Montevideo, 1783-1799

\begin{tabular}{|c|c|c|c|}
\hline Año & Montevideo & Maldonado & Porcentaje \\
\hline 1783 & 554.714 & 10.567 & $1,90 \%$ \\
1784 & 301.176 & 10.589 & $3,51 \%$ \\
1785 & 122.761 & 6.831 & $5,56 \%$ \\
1786 & 86.614 & 5.674 & $6,55 \%$ \\
1787 & 121.099 & $\mathrm{~s} / \mathrm{d}$ & $\mathrm{s} / \mathrm{d}$ \\
1788 & 146.399 & 13.694 & $9,35 \%$ \\
1789 & 173.070 & 19.600 & $11,32 \%$ \\
1790 & 342.334 & 25.576 & $7,47 \%$ \\
1791 & 216.674 & 29.359 & $13,54 \%$ \\
1792 & 346.041 & 31.518 & $9,10 \%$ \\
1793 & 238.127 & 21.699 & $9,11 \%$ \\
1794 & 311.579 & 32.521 & $10,43 \%$ \\
1795 & 266.728 & 33.178 & $12,43 \%$ \\
1796 & 347.335 & 38.368 & $11,04 \%$ \\
1797 & 89.552 & 10.589 & $11,82 \%$ \\
1798 & 117.722 & 19.796 & $16,81 \%$ \\
1799 & 118.545 & 17.350 & $14,63 \%$ \\
\hline
\end{tabular}

Fuente: Elaboración propia a partir de AGN XIII Maldonado Legajos de 3288 a 3312 y Camarda, 2014.

${ }^{66}$ Durante el año 1782 no se envío ningún cuero desde Maldonado hacia Montevideo (ver Anexo 2. Cuadro A.8). No lo hemos incluido en el gráfico 7 para que la línea de tendencia no de un crecimiento exagerado partiendo de una situación átipica. Es decir, de la interrupción total del tráfico marítimo o del no cobro del impuesto durante ese año. 
La expansión ganadera de la zona se puede ver, además, en el aumento de la participación de los cueros del área dentro de los totales exportados desde Montevideo que se detalla en el cuadro 3. Los cueros procedentes de Maldonado pasaron de menos del 10\% de los cueros exportados desde el puerto montevideano hasta superar el $15 \%$ en los años finales del siglo.

Por otro lado, además de los cueros se enviaban importantes cantidades de sebo, grasa y distintos tipos de carnes saladas. El gráfico 8 muestra los totales anuales de sebo y grasa en arrobas desde Maldonado hacia Montevideo durante el período que estamos analizando. Al igual que en el gráfico 4 (que también se refería al sebo y la grasa) los colores claros representan los totales anuales y en color un poco más oscuro aparecen las tendencias por medias móviles. La línea roja presenta la tendencia polinómica de los envíos de sebo.

Observando el gráfico es evidente que los envíos de sebo acompañaron el crecimiento que identificamos al analizar los cueros. Al mismo tiempo, por las razones que ya mencionamos ese aumento en la circulación del sebo puede ser interpretado como un indicio de la expansión de la ganadería de rodeo en la zona. Especialmente luego de que la ocupación de la zona de Rocha impulsara la ampliación de la frontera ganadera del área ${ }^{67}$.

La información contenida en las guías permite observar, además, que en el área de Maldonado existía una producción significativa de carnes saladas. Desde 1782 hasta agosto de 1806 se enviaron hacia Montevideo 4.412 arrobas de distintos tipos de carnes saladas y 9.749 lenguas saladas. Esos envíos se realizaron en pequeñas cantidades lo que parece ser indicativo de una producción doméstica ${ }^{68}$. El salado de carnes, que es una parte esencial de un aprovechamiento más integral de los animales sacrificados, aparece como otro indicio de la importancia de la ganadería de rodeo en el área.

\footnotetext{
${ }^{67}$ La importancia de la ocupación de Rocha se ve reflejada también en los diezmos de la zonas que a partir del año 1794 incluyen el remate por separado de todas las especies del arroyo Garzón, que recién en 1812 pasó a denominarse como Rocha (Biangardi, 2013).

${ }^{68}$ La producción de carnes saladas del único saladero de la zona, propiedad de Miguel O’Ryan, no aparece en las guías, aunque si figuran sus envíos de cueros y astas. Esto se puede deber a que los primeros saladeros estaban vinculados al abastecimiento de las raciones de los destacamentos del ejército y la marina real y, por lo tanto, no quedaban asentados en las guías. Otra posibilidad es que este saladero haya estado vinculado a las actividades de la Real Compañía Marítima que para su funcionamiento disponía de ciertos privilegios fiscales.
} 
Gráfico 8. Totales anuales de sebo y grasa (en arrobas) enviados desde Maldonado hacia Montevideo, 1782-1806

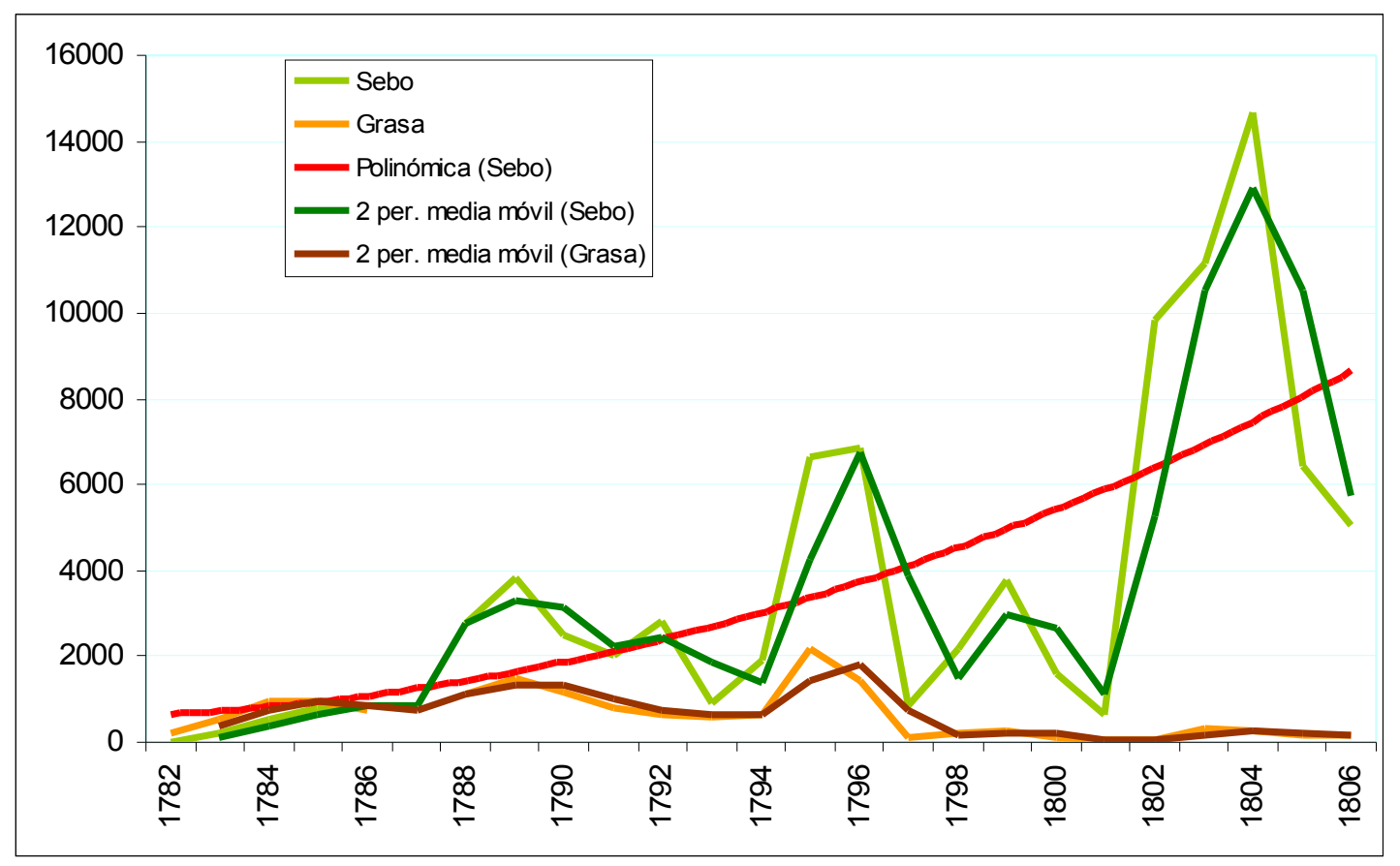

Fuente: AGN XIII Maldonado Legajos de 3288 a 3312

En consecuencia, los envíos de bienes pecuarios desde el área de Maldonado hasta el puerto de Montevideo nos indican que la expansión territorial de la región también se produjo hacia el noreste ocupando las tierras adyacentes a la costa atlántica. Ese crecimiento del espacio económico regional hacia el este se suma a la ya mencionada ocupación de las tierras situadas al norte del río Negro confirmando que, en comparación con la situación de la campaña de Buenos Aires, esta era la frontera en expansión en el período.

Este panorama de la circulación de productos pecuarios en las áreas de Montevideo y Maldonado nos permitió comprobar situaciones y elaborar hipótesis sobre el crecimiento de la producción de bienes pecuarios y sobre la expansión territorial de la región en el período. El estudio de las guías de ingreso de la Aduana de Buenos Aires va a completar ese análisis a nivel regional. Mientras tanto, la información volcada en el presente capítulo es suficiente para los objetivos de esta tesis que se centra en el estudio de las áreas mencionadas. En el capítulo siguiente tendremos 
la oportunidad de profundizar sobre algunos aspectos de la producción y posterior circulación de esos bienes pecuarios: las características de las dos actividades económicas que producían los bienes pecuarios, el sistema de comercialización de esos productos y los agentes involucrados. 


\section{Capítulo 3}

\section{El negocio del cuero}

\section{Agentes, formas de explotación del vacuno y sistema de comercialización}

De acuerdo a lo que venimos tratando, sabemos que los cueros vacunos eran el principal bien exportable de la región durante el siglo XVIII. Esa situación era el resultado lógico de la combinación de un conjunto de factores. Las condiciones ecológicas de las tierras adyacentes promovían la reproducción del ganado. La baja densidad demográfica y las grandes distancias hasta los puertos propiciaban la especialización ganadera de la región. La llegada de numerosas embarcaciones en busca de metales preciosos y con bodegas disponibles para llevar productos voluminosos y evitar así el retorno en lastre. En consecuencia, la producción y comercialización de los cueros ocupaba un papel preponderante en la economía ocupando a una parte importante de la población.

Los cueros que, cuando eran trasladados por los numerosos carros que circulaban por la campaña sólo se diferenciaban por el tamaño, el grado de conservación y el grosor, provenían, sin embargo, de dos actividades productivas diferentes: las vaquerías y la ganadería de rodeo. A pesar de que esas dos maneras de producir cueros fueron consideradas como distintas etapas en la evolución económica de la región (Giberti, 1986: 39) en realidad la formación de estancias no implicó la desaparición de las vaquerías sino que ambas actividades coexistieron. La existencia de reservas de ganado cimarrón, especialmente en las tierras situadas al norte del río Negro, permitieron la continuidad de las vaquerías de corambre durante todo el siglo XVIII. Esas vaquerías no eran un rubro marginal de la producción pecuaria regional, por el contrario, tienen una importancia fundamental en las rápidas reacciones que tenía la oferta de cueros ante las marcadas fluctuaciones de la demanda del mercado ultramarino 
(Pérez, 1996: 162-163 y Moraes, 2011: 28). Recordemos, además, que, de acuerdo a los datos que presentamos en el capítulo anterior, las vaquerías podrían haber proporcionado aproximadamente la mitad de los cueros que llegaban por tierra a Montevideo. Aunque, lógicamente, a medida que se iban agotando las reservas de ganado cimarrón cobraba mayor importancia la ganadería de rodeo.

3.1. Dos formas de explotación del vacuno: las vaquerías y la ganadería de rodeo

Si bien el producto final era prácticamente el mismo, las vaquerías para hacer corambre y la ganadería de rodeo eran maneras de explotar del ganado vacuno que diferían en casi todos los aspectos posibles: ubicación geográfica de la actividad, forma de contratación de la mano de obra, organización, estacionalidad y, también, en los agentes que la llevaban acabo.

En primer lugar, estos dos sistemas de explotar el ganado vacuno estaban destinados a animales con distintos grados de domesticación. Las vaquerías recurrían a las reservas de animales salvajes, habitualmente denominados como cimarrones, y, por eso, la actividad no puede ser asimilada a la ganadería, que implica la cría de un animal domesticado. Por ende, eso determinaba también su ubicación geográfica ya que las vaquerías se realizaban en las zonas más alejadas donde se ubicaban las reservas de ganado cimarrón. Mientras que las estancias de rodeo se ubicaban en zonas más cercanas a las ciudades.

Por otro lado, la actividad en sí difería considerablemente. Las vaquerías eran expediciones de caza que tenían como objetivo extraer los cueros de los animales. Consistían en varios hombres a caballo que se internaban en los campos. Una vez alcanzado, el ganado vacuno era rodeado con la ayuda de los perros que los acompañaban. Luego, con un instrumento denominado desjarretador ${ }^{69}$, les seccionaban los tendones a los animales para que queden imposibilitados de mantenerse en movimiento o se los enlazaba. Por último se procedía a extraerles el cuero, el sebo y la lengua dejando el resto (Giberti, 1986: 29).

\footnotetext{
${ }^{69}$ El desjarretador era estaba compuesto por una medialuna filosa atada a una caña.
} 
La estancia de rodeo, en cambio, aprovechaba el hecho de que el vacuno es un animal que se desplaza poco y se acostumbra a permanecer en un mismo sitio, es decir que se aquerencia. Una vez recogido, el ganado era trasladado hasta una aguada de la estancia, cuando se distanciaba un poco era rodeado y vuelto a llevar al lugar elegido y en unos tres o cuatro meses ya tendía a volver a su querencia cada vez que se alejaba. Por esta razón eran apreciados los campos que tenían acceso al agua y, especialmente, los que contaban con "rincones" (por ejemplo, donde se unen dos arroyos o un arroyo y una laguna) (Giberti, 1986: 52). Además de la vigilancia y el rodeo del ganado, en las estancias se realizaban una importante cantidad de actividades, algunas permanentes y otras temporales. La parición tenía lugar de marzo a septiembre, la yerra se realizaba a mediados de invierno y la doma de potros de febrero a abril. También se procedía a la castración de los machos jóvenes, la esquila de ovejas, la cría de mulas y el exterminio de perros cimarrones (Garavaglia, 1999: 209-212).

Otra diferencia importante estaba marcada por el hecho de que las estancias se dedicaban a la reproducción de varios tipos de ganado (vacuno, equino, ovino, mular y porcino) mientras que el objetivo de las vaquerías se limitaba a la explotación del vacuno.

La utilización de la mano de obra también era muy distinta en cada actividad. En ambas se recurría a trabajadores asalariados. Sin embargo, la forma del salario era diferente ya que en las vaquerías eran remunerados a destajo y en las estancias, por lo general, se le abonaba el salario por jornal. El alto costo de la mano de obra asalariada llevaba a que los estancieros contaran, además, con esclavos para las tareas permanentes, dejando a los peones libres para las actividades estacionales (Mayo, 2004: 141).

Las vaquerías eran empresas que requerían una especialización de sus trabajadores. Por lo general, el empresario proporcionaba las herramientas de trabajo y raciones de yerba y tabaco. Los empleados, por su parte, trabajaban a destajo y utilizaban sus propios caballos. Aunque Eduardo Saguier (1991: 117) afirma que la paga por cuero incluía el costo del desgaste de la tropilla de caballos. Las tareas se dividían en: vaqueros desjarretadores, peones desolladores, barraquero, sebero y peón caballerizo (Pérez, 1996: 176). En cada vaquería había un promedio de dos o tres vaqueros y de tres a diez desolladores y cada empleado recibía una remuneración 
distinta de acuerdo a su tarea. Los vaqueros se encargaban de desjarretar y acodillar al animal. Los peones desolladores cuereaban el vacuno y procedían a estaquear y marcar el cuero. Luego el barraquero recogía, desgarraba, clasificaba, apilaba y prensaba cada cuero (Saguier, 1991: 112-114).

Es necesario tener en cuenta que existía también un número de situaciones que podríamos considerar intermedias. Por un lado, una estancia situada en el límite de la frontera ganadera podía recomponer su stock de animales recurriendo a la recogida de ganado cimarrón. Por otra parte, se puede considerar la sugerencia de Osvaldo Pérez sobre que en la "Banda Oriental" existió un sistema de explotación ganadera intermedio, es decir, a mitad de camino entre las vaquerías y las estancias de rodeo, que el autor denominó estancia de alzados (Pérez, 1996: 166).

Se denominaba ganado alzado a los animales que se habían ido de la estancia, generalmente porque había perdido su aquerenciamiento debido a una sequía prolongada. En muchas ocasiones, los productores utilizaban esa denominación como un artilugio para reclamar como propio el ganado que en realidad era cimarrón. Las estancias de alzados consistían, entonces, en grandes extensiones lindantes o cercanas a tierras realengas que contaban con unos pocos animales mansos pero que sobre todo se dedicaba a explotar las reservas de ganado cercanas a la propiedad.

Esa distinción entre una estancia de alzados y una estancia de rodeo aparece en la memoria redactada por Andrés Oyarvide como parte de las partidas de demarcación cuando en 1785 pudo visitar las estancias de María Francisca de Alzaybar y de José Llorens. Al respecto el funcionario observaba que "Aquí no se conoce ganado manso ó de rodeo, como llama, todo es alzado, todo es campestre" (Calvo, 1865: 265). En cambio en el segundo establecimiento existían unas 10.000 cabezas de ganado manso sujetas a rodeo (Ídem: 273$)^{70}$.

Además de las mencionadas, existieron otros dos tipos de estancias: las estancias ganaderas misioneras y las estancias del rey. Las estancias misioneras, situadas al norte de los ríos Yi y Negro, tenían como objetivo la producción de carne para los pueblos de las Misiones. Las grandes reservas de ganado cimarrón de la zona permitieron que esas estancias recurrieran a la recogida y posterior amancebamiento de esos animales. A partir de la década de 1770 la desestructuración del espacio misionero y el auge de las

\footnotetext{
${ }^{70}$ La descripción de las estancias también se encuentra citada en Pivel Devoto (1952: 12-13).
} 
vaquerías de corambre organizadas por agentes con residencia en Buenos Aires y Montevideo implicaron el retroceso y la crisis de estas estancias (Moraes, 2011: 169172).

Las estancias del rey, en cambio, eran administradas por la Real Hacienda y tenían como objetivo principal solucionar las necesidades de transporte y alimentación de las tropas de la corona. Por ende, estaban dedicadas a la cría de caballos para montar, bueyes para las carretas del rey y ganado para abastecer de carne a las tropas. En el área de Maldonado había cuatro de estas estancias situadas en Pan de Azúcar, José Ignacio, Don Carlos y Santa Teresa que se formaron entre 1766 y 1778 (Díaz de Guerra, 1988: 304-307).

De esta maneras, si bien los dos sistemas de explotación del ganado vacuno coexistieron, el desarrollo de estancias de diferentes tamaños (pequeñas, medianas y grandes) permitió un mejor aprovechamiento de los subproductos de la ganadería, especialmente el sebo y la carne, y complementar la cría de ganado vacuno y equino con la de ovinos, mulas, bueyes y porcinos. Por otro lado, el agotamiento de las reservas de ganado cimarrón alejaba cada vez más el espacio donde se realizaban las vaquerías, modificando así sus costos de transporte y los circuitos por donde tenían salida los bienes producidos. Ese espacio liberado, por decirlo de alguna manera, era ocupado por nuevas estancias en un paulatino proceso de expansión territorial que la región vivió de manera ininterrumpida a lo largo de todo el siglo XVIII.

Además de las estancias, en las zonas cercanas a los puertos o embarcaderos del río existieron otros dos tipos de establecimientos, relacionados con la ganadería de rodeo, que producían cueros y otros derivados del ganado vacuno: los mataderos y los saladeros. Ambos dependían de la provisión de animales por parte de las estancias. Los mataderos eran sitios destinados, como su nombre indica, a la matanza de ganado. El establecimiento contaba con corrales de diferente tamaño. Por lo general, podía tener uno más grande donde se mantenía al ganado que iba arribando y otro más pequeño donde se trasladaba a los animales para su sacrificio.

Ciudades y pueblos tenía mataderos públicos para asegurar el abastecimiento de carne fresca de sus habitantes, pero también había mataderos cuyos dueños eran individuos particulares. A partir de la información de la introducción de cuero, sebo y 
grasa para el período 1784-1789, que analizamos en el capítulo anterior, pudimos verificar la existencia en esos años de 16 mataderos (4 públicos y 12 de particulares ${ }^{71}$ ).

Los saladeros también eran sitios donde se efectuaba la matanza del ganado pero su principal objetivo era la producción de carne salada. Por eso además de los corrales debían tener tinas para sumergir las carnes en salmuera y un lugar techado donde poder almacenar el tasajo. Pero, en líneas generales, parece que los mataderos pudieron fácilmente transformarse en saladeros durante el auge de producción de tasajo ${ }^{72}$.

Tanto los mataderos como los saladeros, producían cueros, sebos, grasas y astas, además de la carne fresca o salada. Sin embargo, como vimos en el cuadro 1, el volumen de su producción no tuvo un peso relevante. Su importancia estuvo en el hecho de que esos establecimientos propiciaron un aprovechamiento de la carne disponible en cada cabeza de ganado. Sin embargo, la mayor parte de los animales continuaron siendo sacrificados durante las vaquerías y en las estancias.

\subsection{El sistema de comercialización de los bienes pecuarios}

Una vez que el cuero estaba en condiciones debía ser trasladado hasta las ciudades portuarias. Como ya mencionamos en el capítulo anterior, el sistema de comercialización de cueros que podemos percibir a partir de los datos que nos proporcionan nuestras fuentes posee las mismas características que identificó Jorge Gelman (1998: 152) para la campaña de Santo Domingo Soriano. Por un lado, un grupo

\footnotetext{
${ }^{71}$ Los mataderos públicos eran los de Montevideo, Canelón, Santa Lucía y Maldonado. Los mataderos de particulares pertenecían a Domingo Bauza, Juan Esteban Durán, Francisco Blanco, Juan Camilo Trapani, Juan Díaz, Juan Francisco García, Juan José Seco, Juan Pablo Vernón, Manuel Pérez, Miguel Rian, Santiago Ladero y del finado Ramírez.

${ }^{72}$ No sabemos con exactitud cuantos saladeros había en esos años. Montoya (1984: 307-308) brinda una lista de las personas vinculadas a la producción de carnes saladas en la "Banda Oriental" hasta 1810. Algunos de los nombres se repiten con respecto los que dimos para los mataderos y otros aparecen también en los cuadros 4 y 6 de esta tesis. La lista es la siguiente: Manuel Melian, Miguel Ryan, Melchor y Francisco Albín, Francisco Antonio Maciel, Mateo Magariños, Miguel Antonio Vilardebó, José Mila de la Roca, Manuel Solsona, José Antonio Pereyra de Melo, Juan Balbín Vallejo, Juan Camilo Trapani, Nicolás Lacort, Luis Antonio Gutiérrez, Fernando Martínez, Esteban Durán, Juan Ignacio Martínez, Juan José Seco, Salvador Tort, Alejandro Torres, Pedro Manuel García, Josñe de María, Nicolás Mora, Manuel José de Lavardén, Antonio Pereyra, Bernardo Lacumbe, José Ramírez Pérez, Juan Francisco Martínez, Francisco Bueno, José de Silva, Juan de Arze, Miguel Zamora, Pedro Casavalle, Juan José Durán, Manuel Pérez, Joaquín de Chopitea, Agustín Sierra y Manuel Vázquez de España. Sin embargo, esto no nos dice nada acerca de cuántos saladeros había en un momento determinado. Varios de estos individuos pudieron estar asociados en un mismo emprendimiento y no todos estuvieron produciendo carnes saladas al mismo tiempo.
} 
de grandes y medianos productores que poseen los medios para transportar los bienes hasta las grandes ciudades. Por otro lado, una importante cantidad de pulperos, fijos o en movimiento, que recogen los excedentes de un gran número de pequeños productores.

Nos ocuparemos de los productores en el apartado siguiente cuando realicemos una caracterización de los agentes involucrados en la producción pecuaria. En este punto, analizaremos la presencia de las pulperías en la campaña de las áreas que estamos estudiando.

Los pulperos cumplían una función de intermediarios entre los productores y los mercados de las ciudades portuarias. Gelman (1998: 163) afirma que la presencia de varios de estos establecimientos en un lugar constituía un freno a la explotación mercantil de campesinos y peones ya que la competencia imposibilitaba que un pulpero individual impusiera condiciones a sus clientes. No podemos determinar la cantidad de pulperías volantes o mercachifles ocasionales que circulaban pero el estudio de las composturas de pulperías nos permite determinar un nivel mínimo de la cantidad de pulperías y su distribución a lo largo de los diferentes pagos de la campaña. Pero como era imposible controlar las ventas de estos establecimientos comerciales, las composturas de pulperías consistían en el pago de un monto fijo anual, que a veces se dividía en períodos de varios meses. Por ende, no es posible estudiar el giro comercial de esas pulperías. Para tener una imagen de la manera cómo se distribuían esos establecimientos comerciales en la región tomaremos como ejemplo el caso del área de Maldonado, analizando los datos contenidos en los libros auxiliares de compostura de pulperías del lugar.

\subsubsection{Las pulperías en el área de Maldonado}

El cuadro 4 indica la cantidad y distribución de las pulperías existentes en el área entre los años 1788 y 1806 según los datos consignados en los libros que registraban el pago de la compostura de pulperías en la Real Hacienda de Maldonado ${ }^{73}$. La fuente

\footnotetext{
${ }^{73}$ Es probable que en algunos años la cantidad de pulperías pueda estar subrrepresentada ya que pudo haberse dado una situación similar a la que identificó Julián Carrera (2010: 86) para las pulperías de la campaña de Buenos Aires, donde algunos pulperos dejaban de pagar durante un año o dos antes de volver a pagar.
} 
indica el nombre del pulpero, la ubicación geográfica, el monto abonado y el período de tiempo correspondiente. Esa información muestra que existía una proporción muy alta de pulperías con respecto a la población del área. Las 53 pulperías que pagaron el impuesto en 1798 indican que había uno de esos establecimientos por cada 60 habitantes ${ }^{74}$. Esta cifra es particularmente alta si la comparamos con los datos que tenemos para otras zonas de la región rioplatense. De acuerdo a la información proporcionada por Jorge Gelman (Ibíd.: 164) en el área de Colonia durante el año 1796 había 63 pulperías para una población de más de cinco mil personas, lo que representa más de un establecimiento cada 100 individuos. Por otro lado, Julián Carrera sostiene que para la campaña de Buenos Aires existía en 1778 una pulpería cada 107 habitantes y en 1816 una cada 77 (Carrera, 2010: 96-98). Si tenemos en cuenta el poblamiento más tardío, el área de Maldonado presenta un desarrollo mercantil acelerado que se relaciona con las particularidades de la zona $^{75}$.

El pago de las composturas se realizaba sobre un monto fijo que no sufrió modificaciones a lo largo de todo el período. Los pulperos debían abonar treinta pesos anuales. Las pulperías más establecidas abonaban el gravamen cada seis meses, excepto durante los años 1791 y 1792 en los que el pago fue anual. El resto de los establecimientos pagaba por períodos de variada duración pero siempre menores a los seis meses, con la excepción de los dos años antes mencionados. Las composturas fueron recaudadas incluso para períodos muy cortos. Por ejemplo, el 5 de noviembre de 1802 Antonio Rodríguez Maurenti pagó 6 reales y medio por haber mantenido su comercio durante 10 días en la Villa de San Carlos. Una situación similar se dio en 1789 cuando Antonio Buceta abonó 7 reales por 11 días de actividad comercial en San Fernando de Maldonado. La existencia de un monto a pagar fijo, igual para todos los comerciantes, nos impide hacer cualquier tipo de especulación sobre la magnitud del giro de estos establecimientos.

Algunos pulperos pagaron el impuesto con intermitencias. Es realmente difícil determinar si suspendieron la actividad de su comercio o si evadieron el tributo durante ese tiempo. Varios de esos mercaderes realizaron viajes a Montevideo, que quedaron

\footnotetext{
${ }^{74}$ La población de Maldonado, San Carlos y Rocha sumaban 3.178 personas (Biangardi, 2013: 13-14).

${ }^{75}$ Los pueblos de Gualeguay, Gualeguaychú y Concepción, que constituyeron otra zona de poblamiento tardío (los tres se formaron en 1783), no superaban, a comienzos del siglo XIX, las 30 pulperías (26 en 1797-1798, 28 en 1800-1801 y 30 en 1801-1802) (Djenderedjian, 2003: 313).
} 
registrados en las guías, para vender los productos acopiados y abastecerse de mercancías. Aunque otra posibilidad es que durante esos viajes pueden haber dejado el comercio a cargo de algún empleado. De todas maneras, solamente 34 de un total de 166 pulperos interrumpieron en algún momento el pago del gravamen lo que puede ser un indicio de una evasión moderada. Además, si realmente existió, esa evasión fue realizada con la complicidad de los recaudadores ya que la mayor parte de los deudores eran personas reconocidas dentro de su comunidad (16 de los 34 posibles morosos ocuparon diferentes cargos en el cabildo de Maldonado). Por último, podemos observar la paulatina concentración de establecimientos en Rocha

Otro problema relacionado con esto es el problema de la estabilidad de esos establecimientos comerciales. Con respecto a la permanencia en el tiempo de las pulperías, Julián Carrera (2010: 164) sostiene que las pulperías de la campaña de Buenos Aires tenían un promedio de vida de unos 15 años. Afirma, además, que en las zonas fronterizas y costeras existieron más posibilidades de efectuar negocios de corta duración debido al intenso flujo de bienes y personas y que, en cambio, las pulperías más estables se situaron en pueblos de antiguo poblamiento donde no existía tanto tránsito comercial. En contraste, a partir del estudio del caso de Chascomús, Antonio Galarza (2012: 80) plantea una duración más corta, de apenas un par de años, para los establecimientos comerciales de la zona. 
Cuadro 5. Cantidad y ubicación de pulperías en el área de Maldonado 1788-1806

\begin{tabular}{|c|c|c|c|c|c|c|c|c|c|c|c|c|c|}
\hline & Maldonado & San Carlos & Pan de Azúcar & Mataojo & Aiguá & India Muerta & Rocha & Don Carlos & Alferez & José Ignacio & Castillos & Santa Teresa & Total \\
\hline 1788 & 20 & 14 & 3 & & & & & 1 & & & & 3 & 41 \\
\hline 1789 & 22 & 14 & 2 & & 1 & & 1 & 1 & & 1 & & 4 & 46 \\
\hline 1790 & 19 & 14 & 2 & 1 & 2 & & 1 & & 1 & 1 & & 3 & 44 \\
\hline 1791 & 19 & 15 & 2 & & 1 & & & & 1 & 1 & & 3 & 42 \\
\hline 1792 & 22 & 18 & 2 & & 4 & & & & & 1 & & 3 & 50 \\
\hline 1793 & 23 & 21 & 3 & & 4 & 1 & 1 & & & & & 3 & 56 \\
\hline 1794 & 24 & 20 & 3 & & 3 & 1 & 2 & 1 & & & 1 & 3 & 58 \\
\hline 1795 & 20 & 15 & 3 & & 4 & 1 & 3 & 1 & & & 1 & 3 & 51 \\
\hline 1796 & 19 & 17 & 3 & & 5 & & 3 & 1 & & & 1 & 3 & 52 \\
\hline 1797 & 20 & 10 & 1 & & 3 & 1 & 2 & 1 & & & 1 & 3 & 42 \\
\hline 1798 & 26 & 12 & 2 & & 3 & 1 & 2 & 1 & & & 1 & 5 & 53 \\
\hline 1799 & 29 & 12 & 2 & & 2 & 1 & 2 & & 1 & & 1 & 5 & 55 \\
\hline 1800 & 30 & 14 & 1 & & 2 & & 2 & & 1 & & 1 & 5 & 56 \\
\hline 1801 & 25 & 12 & 1 & & 1 & & 3 & & & & & 7 & 49 \\
\hline 1802 & 25 & 16 & 1 & & 1 & & 4 & & & & & 6 & 53 \\
\hline 1803 & 20 & 16 & 2 & & 2 & & 6 & & & & & 6 & 52 \\
\hline 1804 & 16 & 22 & 2 & & 2 & & 7 & & 1 & 1 & & 6 & 57 \\
\hline 1805 & 15 & 19 & 3 & & 2 & & 8 & & & 1 & & 6 & 54 \\
\hline 1806 & 15 & 16 & 1 & & 1 & & 8 & & & & & 6 & 18 \\
\hline
\end{tabular}

Fuente: Elaboración propia a partir de Libros auxiliares de compostura de pulperías en AGN Sala XIII Maldonado Legajos de 3.294 a 3.312. 
El área de Maldonado presenta dos dificultades para comparar con la campaña bonaerense. Por un lado, no existe ningún lugar que podamos considerar como de antigua población, toda el área es de ocupación reciente al momento que comenzamos a disponer de datos sobre las pulperías. Por otro lado, la fuente que estamos utilizando contiene datos para un período limitado (16 años y 6 meses). Sin embargo, de 198 establecimientos que aparecen en los libros de composturas ${ }^{76} 19$ superaron los diez años de existencia (solamente dos lo hicieron para la totalidad del tiempo que abarca la fuente) y 28 permanecieron abiertos entre 5 y 10 años. En cambio, 97 pagaron el gravamen para un período de entre 1 y 5 años y 58 para unos pocos $\operatorname{meses}^{77}$. En consecuencia el 78,28 por ciento de las pulperías no superaron los cinco años de permanencia.

La mayor parte de las pulperías que tuvieron un tiempo de duración mayor a 10 años estaban asentadas en los pueblos: 9 en Maldonado, 5 en San Carlos y 2 en Rocha. Las tres restantes se situaron en las inmediaciones de la fortaleza de Santa Teresa, como ya habíamos mencionado más arriba. Las dos pulperías que superaron la década en Rocha se establecieron en 1794 y 1795 luego de que comenzara el proceso de formación del pueblo y todavía seguían abiertas cuando finaliza el período abarcado por la fuente ${ }^{78}$.

Por otro lado, el análisis de la distribución de las pulperías en el área muestra aspectos interesantes que ayudan a explicar ese desarrollo mercantil. En primer lugar, la mayor parte de los establecimientos mercantiles se concentraban en los núcleos urbanos cercanos de Maldonado y San Carlos. En este sentido, la cantidad de pulperías existentes en Maldonado es similar a la que presentaban los otros puertos rioplatenses, como Las Conchas 28 en 1787 y 20 en 1788 (Carrera, 2010: 91-92) o Colonia 24 en 1796 (Gelman, 1998: 164). En segundo lugar, la concentración de pulperías en torno a Santa Teresa se relaciona con el abastecimiento de las tropas, lo que nos remite nuevamente al rol dinamizador de la economía que tenía el gasto que realizaba la Real Hacienda para la defensa del territorio. La estabilidad de las pulperías asentadas en el

\footnotetext{
${ }^{76}$ Varios pulperos tenían más de un establecimiento.

${ }^{77}$ Para los 37 casos en los que pagan de manera intermitente hemos optado por sumar los períodos y no por tomar como referencia las fechas extremas asumiendo la evasión. Pero no cambiarían mucho los guarismos al hacerlo de la otra manera. Si nos guiamos por los años extremos, las pulperías que permanecieron abiertas por más de diez años fueron 26.

${ }_{78}$ Miguel de Yarza comenzó a pagar las composturas a partir del $1^{\circ}$ de noviembre de 1794 y Alberto Camino lo hizo a partir del $1^{\circ}$ de noviembre del año siguiente.
} 
lugar nos permite suponer que el abastecimiento de las tropas asentadas en la fortaleza constituía un buen negocio ya que las tres pulperías que aparecen en 1788 abonaron las composturas durante casi todo el período ${ }^{79}$. Hay que tener en cuenta, además, que la cercanía con los territorios portugueses podía implicar negocios adicionales ${ }^{80}$. En tercer lugar, la inestabilidad de las pulperías de los pagos de la campaña podría ser un indicio de pulperías estacionales o de una intermitencia en el pago de las composturas por parte de éstas. José Velázquez, por ejemplo, tenía lo que podemos considerar como una pulpería volante ya que se trasladó por períodos del valle de Aiguá al contiguo pago de India Muerta $^{81}$. Por último, podemos observar la paulatina concentración de establecimientos en Rocha, a medida que se formaba el pueblo. En ese sentido, es interesante destacar que de los 12 pulperos que se establecieron en el lugar, 5 ya habían tenido su pulpería en otro poblado de la zona.

El correlato de esa concentración en los pueblos y en el fuerte de Santa Teresa era la escasa presencia de establecimientos en la campaña. Como se puede observar en el cuadro 4, la mayor parte de los pagos contaban con una sola pulpería o no contaban con ninguna por largos períodos de tiempo. Por ende, siguiendo el razonamiento de Gelman, esta falta de competencia exponía a los peones y campesinos a términos de intercambio abusivos o a la necesidad de trasladarse muchos kilómetros para poder vender su producción y abastecerse de bienes de consumo.

En consecuencia, el estudio del pago de la compostura de pulpería en el área de Maldonado nos muestra que existía una importante cantidad de establecimientos que podían recibir los excedentes de los pequeños y medianos productores. Sin embargo, las pulperías fijas se concentraban en los poblados, siendo escasas e intermitentes en los pagos de la campaña. De esta manera, los pequeños productores y los peones asalariados no disponían de muchas alternativas para comprar bienes de consumo o

\footnotetext{
${ }^{79}$ Martín Aguirre pagó por el período completo (18 años y 6 meses), Ramón Arzuaga durante 16 años y Miguel Urrutia lo hizo por 1 años, pasó dos años y 7 meses sin pagar y luego abonó las composturas por 11 años y 11 meses.

${ }^{80}$ En este sentido es sugerente el hecho de que esos dos pulperos se dedicaron también a la compra-venta de esclavos. Según consta en los libros de alcabala de ventas Martín Aguirre compró 13 esclavos y vendió 3, Ramón Arzuaga compró 7 y vendió 5 y Miguel Urrutia compró 3 y vendió 2.

${ }^{81}$ De acuerdo a lo que declaró al momento de abonar las composturas, José Velázquez tuvo su pulpería en el valle de Aiguá (en la fuente aparece como "valle de la Igua") del 15 de mayo de 1792 al $1^{\circ}$ de mayo de 1793, luego estuvo 6 meses en India Muerta hasta el $1^{\circ}$ de noviembre de ese año, posteriormente volvió al valle de Aiguá por un año y 6 meses hasta el $1^{\circ}$ de mayo de 1797 para luego volver a estar 6 meses en India Muerta, retornó a Aiguá por otro año y medio y, finalmente, permaneció un año en India Muerta hasta el $1^{\circ}$ de mayo de 1799.
} 
colocar en el mercado su producción. Ante esta situación quedaban dos opciones, someterse a las condiciones de los pocos comerciantes que se establecían en la campaña o la recorrían con sus pulperías volantes o trasladarse hasta los pueblos. En el caso de los grandes y medianos productores podían, en cambio, trasladarse directamente hasta Montevideo, tal como vimos en el capítulo anterior. En este punto, es evidente que es necesario especificar y tratar con detenimiento estas diferencias de los distintos tipos de agentes económicos con lo que en el apartado siguiente procederemos a realizar una caracterización de los mismos.

\subsection{Una caracterización de los agentes}

De acuerdo a lo que venimos desarrollando nos encontramos con dos grandes grupos de agentes económicos: los que estaban involucrados directamente en la producción pecuaria y los que se dedicaban a la comercialización de esos bienes una vez que los productores los introducían al mercado. A su vez se puede observar cierta estratificación dentro de cada uno de eso grupos de agentes.

La caracterización de los acopiadores/intermediarios no parece ser problemática diferenciándose principalmente por el tamaño de su giro comercial y la estabilidad de su accionar. En este sentido, participaban en el comercio del cuero desde los pulperos de la campaña, ya sea los que estaban asentados en los pagos o los volantes que recorrían la campaña, hasta los embarcadores que acopiaban el cuero en sus barracas de Buenos Aires o Montevideo.

El cuadro 5 es una muestra de los acopiadores/intermediarios que salieron a comprar cueros a la campaña o que tenían su establecimiento comercial en algún pago rural y viajaban a Montevideo a vender los cueros, el sebo y la grasa que habían acopiado durante 54 meses durante el período que va de septiembre de 1784 a marzo de 1790.

El cuadro nos permite observar las diferencias dentro de estos acopiadores/intermediarios. En primer lugar, la cantidad de cueros que podían adquirir variaba en una proporción significativa que va desde los 11.296 cueros ingresados por Bernardo Suárez hasta los 1.114 de Juan Sánchez, lo que implicaba un promedio 
mensual de 209 para el primero de sólo 20 para el segundo. Es decir, si suponemos cierta regularidad en sus viajes en el primer caso el comerciante efectuaba un viaje mensual a Montevideo con tres $\operatorname{carros}^{82}$ mientras que al otro le alcanzaba con llevar un carro cada cuatro meses o un viaje anual con tres carros.

Cuadro 5. Mayores introductores de cueros, sebo y grasa obtenidos por compra, Montevideo septiembre de 1784- marzo de 1790

\begin{tabular}{|l|c|c|c|}
\hline Nombre & Cueros & Sebo & Grasa \\
\hline Suárez, Bernardo & 11296 & 1475 & 18 \\
Monasterio, Antonio & 8641 & 2175 & 48 \\
Pérez, Gregorio & 7785 & 2769 & 12 \\
Susviela, Pedro & 7584 & 3528 & 70 \\
Vázquez Delgado, Jose & 7235 & 394 & 5 \\
Martínez, Juan Ignacio & 4796 & 146 & 0 \\
Gallego, Mateo & 4407 & 90 & 0 \\
Lacort, Nicolás & 3775 & 1309 & 36 \\
Roche, José & 3752 & 0 & 0 \\
Alemán, Antonio & 3323 & 262 & 0 \\
Crespo, Fernando & 2842 & 427 & 0 \\
Ramos, Miguel & 2734 & 36 & 0 \\
Silva Matos, Juan de & 2509 & 187 & 72 \\
Lagos, Ramón & 2480 & 200 & 0 \\
Pereyra, Zacarías & 2405 & 0 & 6 \\
Silvani, José & 1988 & 242 & 12 \\
Balbín de Vallejo, Juan & 1780 & 0 & 106 \\
García, Pedro & 1550 & 30 & 0 \\
Paula Manguelo, Francisco de & 1241 & 0 & 0 \\
Lemos, José & 1248 & 105 & 0 \\
González, Pedro & 1205 & 170 & 0 \\
Vidal, Juan & 1196 & 20 & 0 \\
Sánchez, Juan & 1114 & 87 & 24 \\
\hline Totales & 86886 & 13652 & 409 \\
\hline
\end{tabular}

Fuente: Elaboración propia a partir de AGN IX: 2-4-3, 2-4-4, 2-4-5, 2-4-6, 2-5-1, 2-5-2, $2-5-3,2-5-4,2-5-5,2-5-6,2-6-1,2-6-2,2-6-3,2-6-4,2-6-5,2-6-6$ y 2-6-7. Cueros en unidades, sebo y grasa en arrobas.

\footnotetext{
${ }_{82}^{82}$ Recordemos que, como vimos en el capítulo anterior, los carros llevaban una media de 80 cueros.
} 
Varios de los intermediarios poseían también sus ganados. De hecho dos de los que aparecen en el cuadro 5 (Bernardo Suárez y Juan Balbín de Vallejos) tienen también su lugar entre los mayores productores del área (cuadro 6). Salvo por estas dos excepciones, en general se advierte que existe una especialización de los comerciantes y no una diversificación de las actividades económicas de los agentes.

Los pocos grandes comerciantes que tenían la posibilidad de diversificar sus inversiones recién entraban en el negocio del cuero en la ciudad. Sin embargo, como ya mencionamos, no sabemos mucho del mercado de cueros en Montevideo porque no quedó registrado en las fuentes fiscales ya que las tiendas y pulperías de la ciudad pagaban montos fijos anuales por la alcabala, de la misma manera que sucedía en el espacio rural.

Por otro lado, muchos de esos intermediarios recorrían distintos lugares de la campaña comprando cueros, en vez de establecerse en un sitio determinado. Por ejemplo, Pedro Susviela compró cueros en Canelones, Pando, Pintado, Santa Lucía, San Juan Bautista y Maldonado a personas no identificadas y, en otras ocasiones, efectuó compras a varios individuos de los que si tenemos registro ${ }^{83}$, incluso algunos de ellos también eran comerciantes dedicados a la compra-venta de cueros.

Con respecto a los productores recordemos que los bienes pecuarios procedían de distintas actividades económicas. Sin embargo, pese a esa diferencia, en el plano social se producía cierta confusión que se evidencia el uso de la categoría de hacendados. En ella se solían mezclar agentes que explotaban las reservas de ganado cimarrón con otros dedicados a la cría en estancias de rodeo.

En consecuencia, es necesario que, en primer lugar, revisemos la categoría de hacendado. Un repaso de los significados que ha tenido el término a lo largo del tiempo parece brindar algunos indicios. Para esto los diccionarios, si bien no son la mejor fuente porque por lo general reflejan de manera tardía los cambios de significados de los términos, constituyen, sin embargo, una primera aproximación al problema.

Parte de la confusión podría tener su origen en que en la actualidad el término hacendado tiene en Hispanoamérica el significado de: "Estanciero que se dedica a la

\footnotetext{
${ }^{83}$ Los individuos a los que declaró haberle comprado cueros son los siguientes: Antonio Monasterio, Hermenegildo Laguna, Tomás Barragán, Andrés García, Lorenzo Domínguez, Teodoro Ballesteros, Lorenzo Callero, Felipe Hernández, Juan José Seco, Bernardo Suárez, Segundo González, Francisco Ortiz, Carlos Pintos, Bernardo Navarro y Pedro Delgado.
} 
cría de ganado" "84. Sin embargo, en 1734 el significado se restringía a otra connotación, que todavía conserva: "Rico, acomodado, y que tiene muchos bienes y hacienda". Lo mismo que en 1803: "El que tiene hacienda en bienes raíces, y comúnmente se dice solo del que tiene muchos de estos bienes". Lo que se ajusta perfectamente a los individuos que se reunían en las Juntas de Hacendados. Además, hacendado es el participio del verbo hacendar que en esa época significaba: "Dar o conferir el dominio de haciendas: lo que hacían frecuentemente los Reyes con los Conquistadores" ${ }^{85}$. Así, podemos pensar que autodenominarse hacendados también era para esos actores una manera de reafirmarse en su proceso de apropiación de las tierras realengas que todavía no se había completado. Por otro lado, el término ganadero ha conservado un significado inmutable desde 1734 hasta la actualidad: "El dueño de los ganados, que trata de ellos, y hace granjería". Si bien los hacendados del Río de la Plata pretendían ser dueños de todo el ganado salvaje con la estrategia de denominarlo "alzado", los reiterados bandos combatiendo las faenas clandestinas demuestran que el resto de la sociedad se resistía a aceptar esa situación ${ }^{86}$.

En la época la categoría de hacendado no implicaba solamente la condición de productor ganadero. Raúl Fradkin (1993: 27) plantea que ser reconocido como hacendado estaba relacionado a la riqueza, la capacidad de control social y el arraigo dentro de la comunidad. Los que se autoidentificaban como hacendados tenían residencia urbana y sumaban la actividad comercial y/o la burocrática (Ibíd.: 40). Según el autor estos serían los hacendados principales.

Por otro lado, Fernando Jumar (2008: 11) propone denominar a esos agentes como empresarios ganaderos ya que a pesar de cambiar de fisonomía con el correr de los años (de vecino accionero a hacendado y de hacendado a estanciero) en todos los casos continúan siendo, esencialmente, personas que lucran con la explotación del ganado. Sin embargo, al menos para la "Banda Oriental", preferimos mantener la distinción entre hacendados y estancieros porque, como vimos, efectuaban dos formas de explotar el ganado vacuno que diferían considerablemente.

\footnotetext{
${ }^{84}$ Real Academia Española, Diccionario de la Lengua Española. Disponible en línea en: www.rae.es.

${ }^{85}$ Real Academia Española, Nuevo Tesoro Lexicográfico de la Lengua Española. Disponible en línea en: www.rae.es.

${ }^{86}$ Fernando Jumar y Javier Kraselsky plantean que: "La reiteración de los bandos en el tiempo seguramente muestran las resistencias de la población subalterna al igual que la poca voluntad de los exportadores para fijarse de quién eran los cueros que compraban” (Jumar y Kraselsky, 2007: 9)
} 
Una solución posible podría ser, entonces, utilizar el concepto de hacendado restringiéndolo a estos grandes poseedores de tierras que se dedicaban a las faenas de corambre y usar la categoría de productor ganadero para los que se dedicaban a la cría de ganado. A pesar de esto, preferimos reservar el término hacendado para el análisis de su constitución y accionar como grupo social en tanto que esa autodenominación brinda indicios sobre los objetivos y las intenciones de ese grupo. En cambio, para el estudio económico de los agentes involucrados con las vaquerías sugerimos la restringir la denominación a corambreros.

De esta manera, los corambreros eran individuos de residencia urbana que tenían como principal actividad económica la explotación de reservas de ganado cimarrón mediante la organización de vaquerías de corambre en tierras realengas que tenían denunciadas como propias, independientemente de la instancia en la que el proceso de apropiación de esas tierras estuviese. En consecuencia, podemos identificar a varios de los individuos del cuadro 6 como corambreros con residencia en Montevideo, pero eso va a ser objeto de un análisis pormenorizado en el capítulo 7 de esta tesis.

Por otro lado, dentro de los productores ganaderos podemos seguir la distinción que plantea Jorge Gelman (1998: 249-250) para la zona de Colonia y Santo Domingo Soriano entre estancieros y campesinos, siendo estos últimos los productores que solamente disponen de la mano de obra de su grupo familiar porque susituación económica no les permitía contratar asalariados. Gelman destaca también distintas situaciones en cada una de las categorías. De esa manera, distingue entre estancieros ausentistas, que viven en la ciudad y su establecimiento es administrado por un empleado, y los estancieros con residencia en el lugar. Además, resalta que entre los campesinos existe un grupo que produce lo suficiente para ser económicamente autosuficiente y otro sector que necesita trabajar periódicamente como peón asalariado para la supervivencia de su familia. De todas maneras, los campesinos tienen un lugar más importante dentro de la producción de cereales que en la cría de ganado. Esto se debe principalmente a la importancia de los cursos de agua para las condiciones en que se efectuaba la ganadería en esa época y a que la tierras que los poseían generalmente ya estaban apropiadas o eran más caras y no eran de fácil acceso para los pobladores más humildes que, por eso, debían dedicarse principalmente a la agricultura (Ibíd.: 106). Por 
ende, este estrato campesino tenía un peso menor dentro de la producción ganadera, a diferencia de la importancia que poseía en el cultivo de cereales de la región.

Volvamos, entonces, a los estancieros. Los estudios sobre la campaña de Buenos Aires han recalcado que los estancieros conformaban un grupo muy heterogéneo (Mayo, 2004: 55 y Marquiegui, 1990: 41). Dedier Marquiegui (Ibíd.: 41, 80) planteó que la conflictividad interna revela que no constituían un grupo consolidado y que, por el contrario, durante la segunda mitad del siglo XVIII se hallaban en un etapa formativa. La mayoría de la investigaciones indicaron, también, que esos estancieros ocupaban un "lugar secundario en la estructura de poder regional" (Fradkin, 1993a: 17) y que su poder ser restringía al pago que habitaban (Mayo, 2004: 66). Carlos Mayo (Ibíd.: 34-35) argumentó que esa situación tenía su origen en las dificultades que estos tenían para controlar hombres y ganados y la imposibilidad de eliminar a los competidores por el acceso a los recursos. El autor resaltó, además, que esos individuos llevaban una vida modesta y que su consumo y educación estaba muy por debajo de los que ostentaban los comerciantes de la capital virreinal (Ibíd.: 62). Esta comparación, sin embargo, no nos parece muy adecuada por varias razones. En primer lugar, se compara a todos los estancieros con un grupo selecto de grandes comerciantes con residencia en la ciudad más grande de la región. En segundo lugar, un estudio que incluyera a todos los comerciantes también revelaría una heterogeneidad muy importante y un estilo de vida bastante modesto. En tercer lugar, las investigaciones mencionadas solamente se refieren a los estancieros de la campaña de Buenos Aires. En cuarto lugar, cuando hay individuos con un importante patrimonio y vinculados a las dos actividades Carlos Mayo presupone que el comercio era el centro de las preocupaciones de esas personas y, por ende, es renuente a calificarlos como estancieros (Ibíd.: 65-66). 
Cuadro 6. Mayores introductores de cueros, sebo y grasa de sus ganados o de su matadero $1784-1790$

\begin{tabular}{|c|c|c|c|}
\hline Nombre & Cueros & Sebo & Grasa \\
\hline García, Juan Francisco & 24147 & 5370 & 5773 \\
\hline Pérez, Manuel & 23402 & 2451 & 799 \\
\hline Seco, Juan José & 22180 & 1422 & 604 \\
\hline Alzaybar, María Francisca & 19723 & 780 & 64 \\
\hline Martínez, Fernando & 14222 & 2654 & 202 \\
\hline Maciel, Francisco Antonio & 11278 & 726 & 346 \\
\hline Quadra, Miguel Ignacio de la & 8172 & 411 & 322 \\
\hline Durán, Juan Esteban & 8116 & 306 & 226 \\
\hline Trapani, Juan Camilo & 6194 & 1488 & 606 \\
\hline Bauzá, Domingo & 6980 & 1538 & 42 \\
\hline Bustillos, Juan Antonio & 6639 & 1481 & 150 \\
\hline Gutiérrez, Luis Antonio & 6426 & 561 & 264 \\
\hline Oribe, Francisco & 5801 & 92 & 18 \\
\hline Balbín de Vallejo, Juan & 5570 & 1403 & 612 \\
\hline Vázquez de España, Manuel & 5456 & 831 & 334 \\
\hline Hernández, Francisco & 4711 & 1033 & 128 \\
\hline Márquez, Claudio & 4417 & 253 & 150 \\
\hline Cardoso, Jose & 3918 & 379 & 110 \\
\hline Aguirre, Juan Pedro & 3479 & 712 & 219 \\
\hline Solsona, Manuel & 2922 & 400 & 93 \\
\hline Viana, Melchor & 2915 & 311 & 205 \\
\hline Artigas, Martín Jose & 2615 & 945 & 522 \\
\hline Sierra, José Agustín & 2562 & 88 & 0 \\
\hline Viana, José Joaquín & 2558 & 380 & 12 \\
\hline Suárez, Bernardo & 2352 & 619 & 232 \\
\hline Llorens, José & 2338 & 623 & 319 \\
\hline Yañez, Andrés & 2334 & 271 & 150 \\
\hline Rodríguez, Francisco & 2017 & 533 & 87 \\
\hline Ascorra, Catalina & 1719 & 551 & 285 \\
\hline Estrada, Tomás & 1606 & 436 & 108 \\
\hline Totales & 216769 & 29048 & 12982 \\
\hline
\end{tabular}

Fuente: Elaboración propia a partir de AGN IX: 2-4-3, 2-4-4, 2-4-5, 2-4-6, 2-5-1, 2-5-2, $2-5-3,2-5-4,2-5-5,2-5-6,2-6-1,2-6-2,2-6-3,2-6-4,2-6-5,2-6-6$ y 2-6-7. Cueros en unidades, sebo y grasa en arrobas. 
Cuadro 7. Mayores introductores de cueros a Montevideo, septiembre de 1791- febrero de 1797

\begin{tabular}{|c|c|c|c|}
\hline Nombre & Cueros marcados & Cueros orejanos & Total \\
\hline Seco, Juan José & 51.521 & 6 & 51.527 \\
\hline Balbín Vallejo, Juan & 22.556 & 18.875 & 41.431 \\
\hline Maciel, Francisco Antonio & 31.846 & 1.325 & 33.171 \\
\hline Pérez, Manuel & 30.130 & 1.554 & 31.684 \\
\hline García, Juan Francisco & 17.767 & 7.833 & 25.600 \\
\hline Martínez, Juan Ignacio & 23.005 & 2.239 & 25.244 \\
\hline Gutiérrez, Luis Antonio & 8.344 & 16.065 & 24.409 \\
\hline Vazquez de España, Manuel & 14.368 & 5.607 & 19.975 \\
\hline Bustillos, Juan Antonio & 15.527 & 4.402 & 19.929 \\
\hline Aguirre, Juan Pedro & 8.739 & 10.966 & 19.705 \\
\hline Fernández, Juan Manuel & 10.358 & 8.583 & 18.941 \\
\hline Solsona, Manuel & 15.316 & 2.818 & 18.134 \\
\hline Suárez, Bernardo & 4.930 & 12.372 & 17.302 \\
\hline Aguiar, Juan Benito & 12.983 & 2.410 & 15.393 \\
\hline Silva, José de & 7.696 & 4.862 & 12.558 \\
\hline Lagos, Ramón & 9.385 & 2.440 & 11.825 \\
\hline Mujica, Joaquín & 10.781 & 521 & 11.302 \\
\hline Porcel de Peralta, Juan & 9.802 & 1.267 & 11.069 \\
\hline Trapani, Juan Camilo & 10.998 & 0 & 10.998 \\
\hline Tort, Salvador & 10.702 & 165 & 10.867 \\
\hline Martínez, Fernando & 8.926 & 792 & 9.718 \\
\hline Ramírez Pérez, Jose & 970 & 7.780 & 8.750 \\
\hline Sefons, Pablo & 353 & 7.800 & 8.153 \\
\hline Fachani, Nicolás & 4.779 & 3.002 & 7.781 \\
\hline Durán, Juan Esteban & 7.374 & 80 & 7.454 \\
\hline Moreno, José & 978 & 6.209 & 7.187 \\
\hline Márquez, Claudio & 2.791 & 4.048 & 6.839 \\
\hline Monasterio, Antonio & 2.603 & 4.036 & 6.639 \\
\hline Cardoso, José & 1.591 & 4.979 & 6.570 \\
\hline Masague, Manuel & 539 & 5.898 & 6.437 \\
\hline Durán, Inés & 1.184 & 5.174 & 6.358 \\
\hline Riesgo, Bartolomé & 100 & 6.192 & 6.292 \\
\hline Sánchez, Hilario José & 6.082 & 85 & 6.167 \\
\hline Artigas, Esteban & 3.200 & 2.927 & 6.127 \\
\hline Toscano, Francisco & 4.890 & 1.009 & 5.899 \\
\hline Pérez, Gregorio & 2.603 & 3.199 & 5.802 \\
\hline Vázquez, Juan & 611 & 5.190 & 5.801 \\
\hline López, Fernando & 1.462 & 4.315 & 5.777 \\
\hline Bauzá, Pedro Celestino & 5.736 & 0 & 5.736 \\
\hline Carrasco, Juan Antonio & 3.305 & 2.280 & 5.585 \\
\hline Rodríguez, Antonio & 770 & 4.657 & 5.427 \\
\hline Pírez, Felipe & 1.554 & 3.778 & 5.332 \\
\hline Totales & 389.155 & 187.740 & 576.895 \\
\hline
\end{tabular}

Fuente: AGN IX 3-2-5 
La diversificación de las inversiones era común en esa época y nos encontramos con varios individuos que se dedicaban en distintos grados al comercio y a la explotación del ganado. En esos casos es difícil trazar la línea que separa un tipo de agente de otro. Por ejemplo, los dueños de los mataderos y saladeros aparecen vinculados tanto a los productores que le proporcionan el ganado como a los comerciantes ultramarinos a los que proveen de cueros y carne salada, cuando no son ellos mismo los que se dedican a la exportación. Por otro lado, un mismo individuo puede cambiar de actividad a lo largo de su vida. Al respecto Fernando Jumar (2008) considera que existía una cierta evolución por la cual algunos inmigrantes pasaban de tener como centro de sus actividades al comercio para luego dedicarse principalmente a la explotación del ganado.

Ahora bien, cuál fue el peso de cada uno de estos agentes en la producción pecuaria durante el período que estamos analizando. Para el área de Montevideo podemos distinguir cierta concentración de la producción corambrera. El cuadro 6 muestran los introductores que ingresaron mayores cantidades de cueros provenientes de sus estancias o mataderos entre septiembre de 1784 y marzo de 1790. Los treinta mayores introductores de bienes de sus propios establecimientos ingresaron 216.769 cueros. O para decirlo de otra manera, el $4 \%$ de las 924 personas que ingresaron bienes pecuarios durante el período producían el $38 \%$ del total. Esto es un indicio de el negocio del cuero en Montevideo tenía un alto nivel de contración.

Hay dos nombres (Bernardo Suárez y Juan Balbín de Vallejos) que ya aparecían en el cuadro 5, lo que nos advierte que algunos estancieros además de producir, les compran a otros productores. Esto también se confirma, en proporciones menores, en otros $\operatorname{casos}^{87}$. Sin embargo, en general se advierte una cierta especialización que diferencia a los productores de los comerciantes en la campaña.

En el cuadro 7 se puede observar los mayores introductores de cueros para el período que se extendió entre septiembre de 1791 y febrero de 1797. En este caso, la fuente no nos permite determinar si los cueros fueron producidos o comprados por el introductor por lo que debemos cruzar esos datos con los de otras fuentes para determinar cuáles de los individuos se dedicaban al comercio y cuáles eran estancieros, corambreros o dueños de mataderos.

\footnotetext{
${ }^{87}$ Por ejemplo: Juan Francisco García, Manuel Pérez y María Francisca de Alzaybar compraron 80, 408 y 213 cueros respectivamente.
} 
En muchas ocasiones es difícil distinguir si un individuo era un corambrero o un estanciero. De hecho, podía ser las dos cosas a la vez. Dependiendo de la ubicación de sus estancias podía dedicarse en una a la cría de ganado sujetándolo a rodeo y en otro establecimiento más alejado podía organizar partidas de faenadores para explotar el ganado cimarrón existente en esas tierras o en los lugares cercanos. Este último caso parece ser el de Juan Francisco García de Zúñiga. Por otro lado, un individuo puede haber empezado el período como corambrero y luego haberse transformado en estanciero a medida que las reservas de ganado en las zonas donde tenía sus puestos se fueron agotando. Como se puede observar en el cuadro 7 , casi todos los individuos ingresaron cueros marcados $\mathrm{y}$ orejanos en distintas proporciones lo que dificulta efectuar la distinción. Por eso trataremos de los corambreros con más detalle en el capítulo 7 a partir de la utilización de otras fuentes.

Por otro lado, los dueños de mataderos (como Juan José Seco, Manuel Pérez y Juan Camilo Trapani) eran esencialmente intermediarios entre la ganadería de rodeo y el mercado de cueros de la ciudad portuaria de Montevideo. Aunque en si eran productores ya que organizaban la matanza y la extracción del cuero, el sebo y la grasa en sus establecimientos. Sin embargo, esto no descarta que también hayan sido propietarios de algunas estancias y que criasen su propio ganado.

Por último, de la comparación entre los dos cuadros se puede observar que entre una década y otra existió un recambió en la composición de los agentes vinculados a la producción y la comercialización de los cueros en la campaña de Montevideo y otras áreas cercanas. Esta situación se dio de manera natural por la incorporación de nuevos inmigrantes y porque algunos de los agentes insertos en la actividad en las décadas anteriores fueron llegando al ocaso de sus vidas ${ }^{88}$, $\operatorname{como}$ veremos para el caso de los corambreros montevideanos que analizaremos en el capítulo 7.

\footnotetext{
${ }^{88}$ Por ejemplo, Melchor de Viana falleció en 1796 y en 1803 murieron María Francisca de Alzaybar y Miguel Ignacio de la Cuadra.
} 


\section{Capítulo 4}

\section{La producción de derivados vacunos}

Si bien el cuero era el principal bien producido a partir del ganado vacuno, no era el único. Otros derivados fueron cobrando una importancia creciente tanto entre las mercancías exportadas como en el mercado interno. Ese incremento estaba directamente relacionado con un aumento de la demanda debido al crecimiento demográfico de la región y con la expansión de la ganadería de rodeo que propiciaba un aprovechamiento más integral de cada animal sacrificado. En este capítulo nos ocuparemos de la producción de esos bienes. En primer lugar, analizaremos el aprovechamiento del sebo y la grasa ya que su extracción se realizaba en las dos actividades productivas que venimos desarrollando, aunque, como ya vimos, la mayor parte provenía de la ganadería de rodeo. La producción de carne estaba únicamente relacionado con la cría y engorde de novillos. La carne fresca tenía un lugar muy destacado en la alimentación de la población rioplatense y la expansión de su consumo estuvo íntimamente ligada al crecimiento demográfico. Por eso pondremos en relación la magnitud de esa demanda con respecto a la oferta disponible. Por último, estudiaremos el auge de la producción de carne salada que estimuló la instalación de nuevos establecimientos productivos, los saladeros, con miras a abastecer el consumo de las economías de plantación del Caribe, principalmente de Cuba, y también de otras geografías. Sin embargo, como veremos, su elaboración ya se realizaba en estancias y chacras con anterioridad a esa apertura del mercado externo aunque en una escala bastante más modesta. También tendremos la oportunidad de observar que la producción de carne salada a escala masiva si bien aprovechó la abundancia de carne, dependió de las vicisitudes de la provisión de sal y de las condiciones del tráfico atlántico, lo que la hacía particularmente frágil. 
El sebo y la grasa acompañaban a los cueros en su periplo interno hasta las ciudades portuarias y también en la exportación a los mercados europeos. Su producción dependía de la demanda de los navíos y de las necesidades del consumo de la población. Sin embargo, la disponibilidad de esos bienes podía estar restringida por el lado de la oferta. En períodos de sequías, cuando escaseaban las pasturas y el ganado se trasladaba varias leguas en busca de agua, la cantidad de grasa en cada animal disminuía. Por otro lado, la proporción de grasa era mayor en los novillos que se criaban para vender su carne por lo que la ganadería de rodeo, especialmente la cercana a las poblaciones que podía tener como objetivo la producción de carne proporcionaba una mayor cantidad de sebo y grasa que las vaquerías. Esa posible mayor influencia de la ganadería de cría con respecto a las vaquerías en los envíos de sebo y grasa podría explicar la diferente estacionalidad de esos ingresos en comparación con los cueros, que ya observamos en el gráfico 4 del capítulo 1.

El sebo ${ }^{89}$ se comercializaba de dos maneras: en rama y derretido. Para producir el sebo en rama primero se lo derretía y luego se dejaba el sebo distribuido sobre cueros durante toda la noche. Esa exposición al frío nocturno lo tornaba más firme y al parecer le daba cierto brillo. Luego se lo vendía en forma de marquetas. En el segundo caso, se limitaba a transportar el sebo derretido en barriles cerrados lo más herméticamente posible. El sebo derretido era un producto más delicado y de mayor valor. De acuerdo a los aforos de la alcabala el precio del sebo derretido duplicaba al que se comercializaba en rama ${ }^{90}$. Sin embargo, si bien tenía un precio más elevado, la necesidad de disponer de barriles también elevaba los costos.

La elaboración del sebo era muy sencilla y solamente requería algún recipiente de cobre, una olla o una tina, y algún combustible para generar calor ${ }^{91}$. Esa situación sumada a la fácil disponibilidad del insumo hacía que la producción de sebo del Río de la Plata estuviese muy descentralizada. Arturo Bentancur (1997: 56-57) sostiene que en

\footnotetext{
${ }^{89}$ Recordemos que el sebo era parte de la grasa que en el animal se encuentra en forma sólida y dura.

${ }^{90}$ En los libros manuales de la alcabala terrestre de Montevideo para los años 1787 y 1789 el sebo en rama está aforado en 4 y 5 reales la arroba y el sebo derretido en 8 y 9 reales. AGN XIII 15-10-1 y 15-102.

${ }^{91}$ En el Río de la Plata la escasez de árboles hacía que no fuera tan sencillo conseguir leña de manera que, en ciertas ocasiones, se utlizaban excrementos de animales y huesos como parte del combustible para general calor.
} 
la jurisdicción de Montevideo se derretía sebo en las estancias y en distintos establecimientos dentro y fuera de los muros de la ciudad. Era habitual que se lo procesara en los fondos de los casas generando problemas de salubridad lo que llevó a que el Cabildo de Montevideo a intentara erradicar esa práctica dentro la ciudad en 1809.

Cuadro 8. Sebo introducido en Montevideo por Fructuoso Calvo 1786-1790

\begin{tabular}{|c|l|c|}
\hline Fecha & \multicolumn{1}{|c|}{ Proveedor } & Sebo \\
\hline $20-2-1786$ & Manuel Perez & 100 \\
$15-3-1786$ & Manuel Perez & 100 \\
$31-12-1787$ & Pedro Agüero & 50 \\
$14-1-1788$ & Fernando Martinez & 50 \\
$30-1-1788$ & Fernando Martinez & 50 \\
$22-2-1788$ & Fernando Martinez & 40 \\
$1-3-1788$ & Fernando Martinez & 50 \\
$10-3-1788$ & Fernando Martinez & 50 \\
$17-3-1788$ & Fernando Martinez & 50 \\
$26-3-1788$ & Fernando Martinez & 50 \\
$7-4-1788$ & Fernando Martinez & 40 \\
$15-4-1788$ & Fernando Martinez & 50 \\
$26-4-1788$ & Fernando Martinez & 50 \\
$3-5-1788$ & Juan Jose Seco & 100 \\
$18-5-1788$ & Fernando Martinez & 100 \\
$23-5-1788$ & Fernando Martinez & 40 \\
$6-6-1788$ & Fernando Martinez & 40 \\
$17-6-1788$ & Fernando Martinez & 50 \\
$9-7-1788$ & Fernando Martinez & 70 \\
$19-7-1788$ & Juan Jose Seco & 100 \\
$8-8-1788$ & Fernando Martinez & 70 \\
$22-8-1788$ & Juan Jose Seco & 100 \\
$6-9-1788$ & Fernando Martinez & 80 \\
$23-9-1788$ & Juan Jose Seco & 60 \\
$6-10-1788$ & Bernardo Lacumbe & 40 \\
$16-10-1788$ & Juan Jose Seco & 50 \\
$6-11-1788$ & Juan Jose Seco & 15 \\
$24-11-1788$ & Juan Jose Seco & 16 \\
$4-12-1788$ & Juan Jose Seco & 50 \\
$13-12-1788$ & Juan Jose Seco & 140 \\
$9-1-1789$ & comprados a varios vecinos & 50 \\
$22-1-1789$ & Bernardo Lacunbe & 50 \\
\hline
\end{tabular}

\begin{tabular}{|c|l|c|}
\hline $5-2-1789$ & Fernando Martinez & 50 \\
$9-2-1789$ & Juan Jose Seco & 10 \\
$21-2-1789$ & Juan Jose Seco & 50 \\
$31-3-1789$ & Juan Jose Seco & 40 \\
$4-4-1789$ & Juan Jose Seco & 40 \\
$22-4-1789$ & Juan Jose Seco & 60 \\
$2-5-1789$ & Juan Jose Seco & 80 \\
$17-5-1789$ & Juan Jose Seco & 70 \\
$23-5-1789$ & Juan Jose Seco & 60 \\
$3-6-1789$ & Bernardo Lacumbe & 60 \\
$4-6-1789$ & Juan Jose Seco & 60 \\
$13-6-1789$ & Juan Jose Seco & 80 \\
$27-6-1789$ & Juan Jose Seco & 80 \\
$14-7-1789$ & Juan Jose Seco & 80 \\
$31-7-1789$ & Juan Jose Seco & 80 \\
$13-8-1789$ & Juan Jose Seco & 60 \\
$22-8-1789$ & Juan Jose Seco & 80 \\
$9-9-1789$ & Juan Jose Seco & 40 \\
$22-9-1789$ & Juan Jose Seco & 60 \\
$8-10-1789$ & Juan Jose Seco & 50 \\
$21-10-1789$ & Juan Jose Seco & 60 \\
$30-10-1789$ & Juan Jose Seco & 80 \\
$16-11-1789$ & Juan Jose Seco & 100 \\
$7-12-1789$ & Juan Jose Seco & 100 \\
$18-12-1789$ & comprados a varios vecinos & 100 \\
$30-12-1789$ & Juan Jose Seco & 100 \\
$29-1-1790$ & Juan Jose Seco & 100 \\
$17-2-1790$ & Juan Jose Seco & 100 \\
$5-3-1790$ & Juan Jose Seco & 100 \\
$12-3-1790$ & Juan Jose Seco & 100 \\
$20-3-1790$ & Juan Jose Seco & 100 \\
\hline & Total & 4181 \\
\hline & & \\
\hline
\end{tabular}

Fuente: Elaboración propia a partir de AGN IX: 2-4-3, 2-4-4, 2-4-5, 2-4-6, 2-5-1, 2-5-2, $2-5-3,2-5-4,2-5-5,2-5-6,2-6-1,2-6-2,2-6-3,2-6-4,2-6-5,2-6-6$ y 2-6-7. Sebo en arrobas.

El sebo y la grasa de origen vacuno tenían un lugar importante en el consumo interno ya que contribuían a la alimentación, iluminación e higiene de la población 
rioplatense La grasa se utilizaba para la elaboración y cocción cotidiana de alimentos por su mayor abundancia, y el consecuente menor precio, con respecto a los aceites vegetales. El sebo, por su parte, era el insumo principal para la elaboración de velas y también se utilizaba para la limpieza, por ejemplo, de los fondos de las embarcaciones. La producción de jabón, por su parte, tenía lugar principalmente en la ciudad de Buenos Aires.

Varias personas ingresaban sebo a Montevideo en intervalos regulares que, a su vez, habían comprado en los mataderos y las estancias cercanas de algunos de los mayores introductores de cueros. Quince individuos aparecen en esa situación en los 54 meses de los que tenemos datos durante el período que va de septiembre de 1784 a marzo de $1790^{92}$. El Cuadro 8 ofrece un caso a modo de ejemplo ${ }^{93}$. Encontramos a cuatro de ellos, en otra fuente vendiendo sebo y velas de sebo e identificados como "fabricante de velas de sebo" o como "maestro velero" $"$. Más adelante, en los años 1809 y 1810 los fabricantes de velas de sebo de Montevideo parecen haber aumentado hasta el número de 39, de acuerdo a los que se presentaron ante el cabildo para registrar sus marcas (Bentancur, 1997: 57).

\subsection{El consumo de carne fresca}

La carne fresca era una parte esencial de la dieta de la población de la región Río de la Plata. Juan Carlos Garavaglia (1999: 243) ha estimado que a fines del siglo XVIII los habitantes de la ciudad de Buenos Aires consumían una media anual per cápita de 193 kilos de carne vacuna, lo que implica un consumo de carne muy elevado comparado con el de otras partes del mundo. Sin embargo, la cantidad de reses constituía una pequeña cantidad de los vacunos sacrificados si cotejamos los datos del abasto con los de las exportaciones de cueros. Para los períodos 1783-1787 y 1788-1792 se consumían un promedio de 36.178 y 46.052 reses en el abasto de la ciudad de Buenos Aires que era por lejos la ciudad con mayor población de la región (Ibíd.: 218). En Montevideo, por

\footnotetext{
${ }^{92}$ Francisco Alba, José Alonso, Inocencia Álvarez, Fructuoso Calvo, Francisco Carvallo, Andrés Franco, Custodio García, Ángel Gomar, Pedro Morlanes, Gregorio Pérez, María Inocencia Ríos, Fernando Rodríguez, Ignacio Rojas, Gregorio Sánchez, María Manuel de Soto.

${ }^{93}$ Para otros dos ejemplos ver: Anexo 4 cuadros A.7 y A.8.

${ }^{94}$ Los cuatro son: Francisco Alba, Fructuoso Calvo, Custodio García y Gregorio Pérez. Libro de carenas de las fragatas correo. AGN XIII 15-6-2. Para un análisis detallado de la fuente ver: (Jumar et al., 2006).
} 
su parte, de acuerdo a las estimaciones realizadas por María Inés Moraes (2011: 199) se faenaban un promedio anual de 7.582 cabezas de ganado en 1780-1789 para una población promedio de 8.584 habitantes y 13.025 reses en la década siguiente para una población promedio de 14.746 individuos. Si tenemos en cuenta que Buenos Aires y Montevideo eran las ciudades más densamente pobladas y que en el mismo período las exportaciones de cueros del Río de la Plata llegaron a promediar las 600.000 unidades anuales, es evidente que aún si pudiésemos estimar el consumo total de los habitantes de la región es indudable que existía un desperdicio de carne muy grande.

En consecuencia, la carne era un bien abundante y barato, de fácil acceso para toda la población. Esa situación determinó que el abasto urbano de carne, que tenía que estar regulado por los cabildos, tuviese ciertos inconvenientes. En teoría cada cabildo debía, licitación pública mediante, dar la concesión del abasto de carne a un individuo o grupo de individuos que se comprometía a mantener una provisión regular a un precio determinado. Sin embargo, la realidad podía ser muy distinta, Andrea Dupuy (2010: 212, 226) afirma que en Buenos Aires el estanco no funcionaba de manera eficiente y ocasionaba inconvenientes y quejas de diversos sectores lo que llevó a que, con la construcción de los corrales y tabladas municipales en 1748, fuera sustituido por un sistema de libre competencia.

En Montevideo, los intentos de licitar el abasto de carne fracasaron hasta los años finales del siglo XVIII. Esto se debió a que gran parte de la población tenía acceso directo a la carne fresca por medio del autoconsumo o a través de circuitos informales ${ }^{95}$ (Moraes (2011: 199). Durante los primeros años, el cabildo de Montevideo debía prácticamente obligar a los estancieros para que abastezcan de carne al pueblo. En 1742, ante la escasez de ganado, y luego de un recuento de los ganados que poseía cada estanciero, los cabildantes dispusieron que Francisco de Alzaybar debía llevar a cabo el abasto durante nueve meses y los tres meses restantes quedaban a cargo del resto de los

\footnotetext{
${ }^{95}$ En el acuerdo del 26 de marzo de 1761 los cabildantes de Montevideo afirmaban que había personas que mataban ganado semanalmente para vender carne a particulares y reiteraban que no podía haber más expendio que el del matadero público (RAGA, 1887:212). En esos años el abasto de carne estaba a cargo de Juan de Achucarro quien se había comprometido a destinar las ganancias para cubrir los gastos que había ocasionado la fiesta de proclamación Carlos III. En 1763 el mismo Achucarro presentó un escrito ante el cabildo quejándose de que algunos particulares vendían carne por su cuenta. Señalaba que, especialmente, Esteban de Ledesma que por las noches ingresaba desde su estancia un carro cargado con 4 o 5 reses y luego vendía la carne en su casa. Los cabildantes acordaron cobrar multas a los vendedores a excepción de algún vecino que introduzca un carro de su estancia con un cuarto o media res para consumo de su casa. Ibíd. pp. 432-433.
} 
productores (RAGA, 1886: 68). En esos momentos Alzaybar disponía de un stock de 12.000 animales. Mientras que el resto de los habitantes solamente disponía de 4.000. Según el cabildo el abasto requería 4.000 reses cada 3 meses lo que parece una suma bastante exagerada si tenemos en cuenta las estimaciones de consumo anteriormente mencionadas. La escasez de carne había llevado a que el cabildo regulase el precio a 2 pesos la res muerta y 20 reales la res viva "por ser precio moderado" (Ibíd.: 63) cuando en los años finales del siglo el abasto se remató ofreciendo la res a 7 o 9 reales.

Salvada esa coyuntura de escasez de ganado, el abasto no volvió a suscitar interés hasta la década de 1770. En 1773 Juan Francisco García de Zúñiga se hizo cargo del mismo por tres años. Sin embargo, luego de esa experiencia se determinó que los distintos estancieros se hicieran cargo de la provisión de carne por turnos, lo que no parece haber durado por mucho tiempo. Finalmente, el abasto no se volvió a rematar hasta 1797.

En los remates los cabildantes privilegiaban la oferta que ofreciera la carne a menor precio. En algunos casos aceptaban que el abastecedor vendiera la res a mayor precio a cambio de una suma que el cabildo podía destinar a distintos fines. En 1797 Manuel Vázquez ofreció vender en Montevideo la res a 10 reales por los siguientes tres años y un donativo de 20.000 pesos. En 1800 Antonio Pereira ganó el remate ofertando la res a 9 reales por tres años y 40.000 pesos para el cabildo. En 1803 Juan de Arce ofreció la res al precio anterior y un donativo de 21.500 pesos por un año. Al año siguiente el mismo postor mantuvo el precio y donó 47.000 pesos al cabildo por tres años. Debido a las pérdidas sufridas por las invasiones de los ingleses el cabildo aceptó extenderle el contrato por dos años más a cambio de 24.000 pesos. Por último, Miguel Zamora ganó el remate de 1808 con la postura de la res a 9 reales y un donativo de 74.000 pesos por tres años. Los términos de este último contrato no se cumplieron y el cabildo terminó declarando libre el abasto de carne de la ciudad (Sala de Tourón, Rodríguez y de la Torre, 1968: 50). Los montos que los abastecedores le ofrecieron al cabildo de Montevideo parecen indicar que a fines del siglo XVIII el consumo de carne fresca de la ciudad ya era un mercado apetecible para ciertos individuos que podían disponer de la cantidad necesaria de ganado.

En Montevideo existía, además, otro importante segmento de demanda de carne representado por las raciones proporcionadas a los presos que trabajaban de manera 
forzosa en las fortificaciones y a los integrantes de la marina real establecidos en el apostadero naval (Moraes, 2011: 200-201). Este segmento del mercado era rematado de forma independiente y durante las últimas dos décadas del siglo esa demanda fue provista de manera exclusiva por algunos asentistas que firmaban contratos por varios años ${ }^{96}$.

En el área de Maldonado también se remató el abasto de carne aunque el mercado era considerablemente más reducido, lo que se veía reflejado en los montos que los postores ofrecían al cabildo de Maldonado. De todas maneras, el negocio debía ser atractivo para algunos estancieros, especialmente en el caso de Maldonado ya que el reglamento que elaboró en $1787 \mathrm{el}$, entonces recientemente creado, cabildo de Maldonado estipulaba que el abastecedor debía proveer de carne a la tropa y a las embarcaciones, además del vecindario ${ }^{97}$. Por lo menos los resultados de los remates que se sucedieron desde 1792 así parecen indicarlo. José Osorio ganó el remate para abastecer a la ciudad Maldonado durante 1793 ofreciendo la res a 8 reales y medio ${ }^{98}$. Para el abasto de 1795 Manuel Silva ofreció la res a 6 reales pero separando la cola y la cabeza. En los tres años siguientes el remate fue ganado por el saladerista Miguel O’Ryan. En el primero de los años O'Ryan inició el remate con una postura de la res a 10 reales y un donativo de 100 pesos para el cabildo pero después de varias pujas con otros dos interesados (Juan Mendoza y Manuel Silva) debió rebajar el precio a 6 reales y medio para salir airoso. En los dos años siguientes, en cambio, ganó el abasto ofreciendo la res a 9 reales. El abasto para el año de 1800 fue realizado por José de Sosa vendiendo la res a 8 reales. Al año siguiente el remate tuvo varias pujas por parte de tres postores: José de Sosa, Ventura Gutiérrez y Lucas Castellano. Finalmente, Ventura Gutiérrez obtuvo la obligación del abasto por tres años a cambio de 1.500 pesos en concepto de donativo que fue destinado a la construcción de la iglesia de Maldonado, 130 pesos para el cabildo y la res de novillo al precio de 7 reales y la de vaca a 6 reales. El mismo Ventura Gutiérrez ganó el remate para el año 1804 por 500 pesos para la iglesia, 130 pesos para el cabildo y la res de novillo a 8 reales y la de vaca a $6^{99}$. Por último, en 1812 el cabildo de Maldonado tenía dificultades para encontrar postores para el abasto. Esa situación llevó a los cabildantes mandar un edicto a la vecina villa de San

\footnotetext{
${ }^{96}$ Sobre los asentistas de la marina ver: (Sandrín, 2014).

${ }^{97}$ AGN Uruguay Archivo Judicial (en adelante AJ) Maldonado Caja 7. 1802-1803.

${ }^{98}$ AGN Uruguay ex Archivo General Administrativo (en adelante AGA) Maldonado 269.

${ }^{99}$ AGN Uruguay AJ Maldonado Caja 7. 1802-1803.
} 
Carlos buscando algún interesado. Esto motivó a José Machado de Araujo y Silva a postularse ofreciendo a 12 reales el novillo y 10 la res de vaca pero los cabildantes rechazaron su oferta. Finalmente, el 3 de marzo Francisco Aparicio, vecino de Maldonado, se hizo con el abasto para lo que quedaba del año 1812 y todo el 1813 pero con el precio de 14 reales el novillo y 12 la vaca ${ }^{100}$. En este caso los cabildantes prefirieron mantener el negocio para uno de los vecinos del lugar, aún a costa de un mayor precio de la res para el conjunto de los habitantes.

Los datos que tenemos de los remates de la villa de San Carlos son más dispersos pero los precios de la carne fueron similares. Al no haber cabildo el remate se llevaba a cabo por parte del comandante militar lo que eliminaba la posibilidad de ofrecer un donativo. El 20 de septiembre de 1789 José Francisco Acuña ganó el remate ofreciendo el novillo a 8 reales hasta fin de año y a 9 el año siguiente ${ }^{101}$. Francisco de los Santos, por su parte, consiguió el abasto para el año 1801 con la postura de vender el novillo a 9 reales y la vaca a $8^{102}$. Finalmente, Francisco Bustamante había obtenido el derecho a vender la carne, durante el año 1802, con el precio de 9 reales el novillo y 8 la res de vaca. Sin embargo las quejas de los vecinos porque el precio de la carne era superior al que se pagaba en la cercana ciudad de Maldonado obligaron a realizar nuevamente el remate que ganó Sebastián Amago con la postura de 8 reales el novillo y 6 la vaca ${ }^{103}$.

Esos mercados oficiales eran, sin duda, negocios apetecibles para determinados agentes, tal como demuestran las pujas en los remates. La magnitud de los abastos de carne acompañó al crecimiento demográfico de los pueblos y ciudades. De esta manera, en los años finales del siglo XVIII ya constituían una importante oportunidad de ganacia. Sin embargo, representaban un porcentaje pequeño del consumo total de carne fresca de los habitantes de la región, ya que el autoconsumo era muy significativo, y eran ínfimos con respecto a la cantidad total de animales sacrificados. Además, hay que considerar que una parte de las reses teminaba pudriéndose. Al respecto, es necesario tener en cuenta que la calidad de la carne era muy inferior, y ni hablar de las condiciones de conservación, a la que estamos acostumbrados en la actualidad ${ }^{104}$. Por

\footnotetext{
${ }^{100}$ AGN Uruguay AJ Maldonado Caja 11. 1811-1814.

${ }^{101}$ AGN Uruguay AJ Maldonado Caja 2. 1788-1790.

${ }^{102}$ AGN Uruguay AJ Maldonado Caja 6. 1800-1801.

${ }^{103}$ AGN Uruguay AJ Maldonado Caja 7. 1802-1803.

${ }^{104}$ Recordemos que el ganado vacuno fue modificado considerablemente en el siglo XIX con la introducción de especies provenientes de Inglaterra.
} 
ende, algunas partes debían ser poco apetecibles. En ese contexto, es lógico que en las expediciones corambreras, por ejemplo, se alimentasen exclusivamente con la lengua y el matambre dejando el resto. Existía, entonces, una cantidad enorme de carne fresca que se desperdiciaba, pudriéndose o sirviendo de alimento para las jaurías de perros cimarrones que poblaban la campaña.

\subsection{La producción de carnes saladas}

Ante el gran desperdicio de carne, era lógico que se intentaran distintos métodos para tratar de conservarla. Entre ellos se destacan el charque, la cecina, la carne en salmuera y el tasajo. El charque era carne secada al sol. Tenía la ventaja de no requerir sal pero no se conservaba bien en los climas húmedos. Por esa razón prácticamente no se fabricó en el Río de la Plata. Aunque a veces los funcionarios confundían los distintos tipos de carnes y registraban como charque al tasajo. La cecina, por su parte, consistía en charque envuelto en grasa y luego colocado en barricas, lo que además de no asegurar su conservación era muy costoso (Giberti, 1986: 26 y 56). Por lo que este método tampoco fue muy utilizado en la región. En cambio, se emplearon con más frecuencia otros que requerían del uso de $\mathrm{sal}^{105}$. Por un lado, la carne podía ser salada en una salmuera (sal disuelta en agua) y envasada en barriles. Para el tasajo, en cambio, la carne cortada en lonjas era puesta por breve tiempo en salmuera para, luego de escurrida, dejarla secar entre capas de sal por un período de cuarenta a cincuenta días. Durante ese tiempo la carne debía ser expuesta al sol diez veces para contribuir al proceso de desecación. Una vez terminado el proceso, la carne podía transportarse sin necesidad de ser colocada en ningún recipiente especial. El tasajo era de una calidad inferior y solamente se vendía para el consumo de los esclavos de Brasil y Cuba, con lo cual se relaciona con la aparición del saladero como establecimiento productivo, mientras que los otros métodos podían ser realizados en estancias o de manera doméstica (Ibíd.: 91).

\footnotetext{
${ }^{105}$ La sal actúa sobre la carne de dos maneras: "como cuerpo antiséptico, preservando la fibra muscular de los agentes alterantes y por otro lado interviene como un cuerpo higrométrico en alto grado, absorbiendo los líquidos capaces de precipitar su alteración" (Seoane, 1928: 139).
} 
Habitualmente se considera que el salado de carne comenzó con la instalación de los primeros saladeros. Sin embargo, existen indicios de una producción de carne seca y salada a menor escala en chacras y estancias. Las guías de alcabala de Maldonado ${ }^{106}$ revelan, por ejemplo, que entre 1782 y 1786 se trasladaron 216 arrobas de charque en 15 viajes realizados por distintos individuos. Además, en otros dos viajes los individuos llevaban "un poco" de charque, presumiblemente para consumo personal. Por su parte, José de Sosa en dos traslados realizados en 1786 llevaba entre sus mercancías una arroba de cecina en cada uno. En los años siguientes se registran varios envíos de los distintos tipos de carnes saladas $\mathrm{y}$, especialmente, de lenguas saladas en pequeñas cantidades y de manera intermitente, pero que en su conjunto conforman un total interesante. Entre 1783 y 1806 se enviaron a Montevideo 4.412 arrobas de carnes saladas y 9.749 unidades de lenguas saladas (Anexo 4. Cuadro A.7.). Además, entre los bienes transportados encontramos la presencia de otra forma de conservar la carne, en este caso chorizos. La elaboración de estos embutidos es interesante porque además de la utilización de sal y otros condimentos implicaba, también, el aprovechamiento de las tripas del ganado. No sabemos de que carne estaban rellenos los chorizos. Pero podría ser porcina o una mezcla de carnes de distintos tipos de ganado. Por el problema de su conservación, presumimos que se trataban de chorizos secos que se diferencian en su elaboración solamente por el uso de una mayor proporción de sal y el secado posterior. Entre los años 1782 y 1805 hemos identificado el envío de chorizos en 37 guías de salida de Maldonado. Es difícil determinar la cantidad que transportaban porque no existía una medida unificada. En algunos casos se lo medía en varas ${ }^{107}$ y a veces por docenas aunque sin indicar el tamaño ${ }^{108}$. Sin embargo, en su mayor parte se lo identificaba por el valor, es decir: tantos pesos de chorizos ${ }^{109}$.

Por otro lado, la información contenida en los libros manuales donde se asentaba la alcabala terrestre de Montevideo brinda datos que indican que en los años $1787 \mathrm{y}$ 1788 ingresaron a esa ciudad 480 quintales de tasajo, 1554 de cecina y 187,75 de carne salada, como se puede observar en el cuadro 9. El libro de 1784 no contiene datos de esos derivados vacunos y lamentablemente los correspondientes a los años 1785 y 1786 no se encuentran en el archivo. En 1788 la corona liberó de impuestos a los distintos

\footnotetext{
${ }^{106}$ AGN Libros auxiliares de alcabala de guías en Sala XIII, Maldonado: Cajas de 3288 a 3312

${ }^{107}$ Por ejemplo, el 7 de agosto de 1797 Blas Vidal envío a Montevideo 40 varas de chorizo.

${ }^{108}$ Por ejemplo, el 5 de abril de 1783 Antonio Chalar trasladó a Montevideo 3 docenas de chorizos.

${ }^{109}$ Por ejemplo, el 25 de noviembre de 1786 Juan Pascual Pla mandó a Montevideo 8 pesos de chorizos.
} 
tipos de carnes para fomentar su producción, con lo que a partir de esa fecha dejó de registrarse en los manuales auxiliares de la alcabala terrestre.

Cuadro 9. Ingreso de tasajo, cecina y carne salada a Montevideo 1787-1788

\begin{tabular}{|c|c|c|c|c|}
\hline Fecha & Introductor & Vendedor & Bien & Cantidad \\
\hline $27-3-1787$ & Trapani, Juan Camilo & & cecina & 100 \\
\hline $1-4-1787$ & Cucullu, Simon de & Castilla, Juan de & carne salada & 25 \\
\hline $1-4-1787$ & Cucullu, Simon de & Castilla, Juan de & cecina & 25 \\
\hline $18-4-1787$ & Rojas, Diego de & & cecina & 32 \\
\hline $20-4-1787$ & Rojas, Diego de & & cecina & 9 \\
\hline $26-4-1787$ & Baudrix, Jose & Trapani, Juan Camilo & cecina & 67 \\
\hline $30-4-1787$ & Baudrix, Jose & Artigas, Martin Jose de & cecina & 177 \\
\hline $3-5-1787$ & Trapani, Juan Camilo & & cecina & 45 \\
\hline $22-5-1787$ & Baudrix, Jose & Rojas, Diego de & cecina & 35 \\
\hline $6-6-1787$ & Escardo, Pedro & Diaz, Pedro & tasajo & 100 \\
\hline $6-6-1787$ & Escardo, Pedro & Diaz, Pedro & carne salada & 53 \\
\hline $2-7-1787$ & Escardo, Pedro & Gutierrez, Luis & tasajo & 260 \\
\hline $18-7-1787$ & Mariño, Ramon & & carne salada & 3 \\
\hline $20-7-1787$ & Escardo, Pedro y Ros, Juan & Trapani, Juan Camilo & cecina & 105 \\
\hline $4-9-1787$ & Laporta, Luis & Trapani, Juan Camilo & carne salada & 106,75 \\
\hline $4-9-1787$ & Trapani, Juan Camilo & & cecina & 185 \\
\hline $13-11-1787$ & Trapani, Juan Camilo & & cecina & 400 \\
\hline $23-11-1787$ & Calzada, Benito & Diaz, Pedro & cecina & 300 \\
\hline $12-12-1787$ & Trapani, Juan Camilo & & cecina & 70 \\
\hline $29-12-1787$ & Escardo, Pedro & Romero Frances, Juan & tasajo & 120 \\
\hline 7-4-1788 & Pelayo, Santiago & & cecina & 1 \\
\hline $9-4-1788$ & Sanchez, Gregorio & & cecina & 3 \\
\hline
\end{tabular}

Fuente: Elaboración propia a partir de AGN XIII 15-10-1 y 15-10-2. Cantidad en quintales.

La presencia de una producción a pequeña escala implica que existían individuos con experiencia en la elaboración de carnes saladas. Esa experiencia tenía sus efectos en la calidad del producto final elaborado. Durante el proceso de secado de la carne es necesario conocer el ritmo de secado y el momento en el que la carne está lista. El secado no debe ser muy rápido porque la carne puede tomar un color oscuro y volverse dura y la grasa tener un gusto desagradable y, por otro lado, si el proceso es demasiado lento el producto puede quedar húmedo y quedar así expuesto a los hongos y bacterías (Seoane, 1928: 177). Es decir, la existencia de individuos experimentados en 
la elaboración de carnes saladas pudo haber sido aprovechado por los dueños de los nuevos saladeros, evitando así posibles pérdidas que se hubiesen podido ocasionar en la producción durante los primeros años de actividad del establecimiento.

Los saladeros surgieron a fines del siglo XVIII en la costa norte del Río de la Plata. Los primeros tres comenzaron a funcionar antes de 1790 y estaban distribuidos a lo largo de la costa del Río de la Plata: el de Francisco Antonio Medina en la zona cercana a Colonia del Sacramento ${ }^{110}$, el de Juan Balbín de Vallejo en las proximidades de Montevideo y el de Miguel de O'Ryan en el área de Maldonado.

En los años siguientes existió una importante producción de carne salada en los alrededores de Montevideo donde se instalaron varios establecimientos. Con respecto al análisis de esta actividad económica en esa ciudad portuaria, Arturo Bentancur (1997: 46) propone dividir el período en tres etapas. Sitúa la primera entre los años 1787 y 1790 correspondiendo a los comienzos de la producción para el mercado externo. Durante esos años se remitieron poco más de veinte embarcaciones con destino a La Habana. A partir de 1791 se inicia la etapa de auge que, aún con las dificultades de la guerra, se extiende hasta 1804. Durante esta etapa se instalaron varios establecimientos y se abrieron nuevos mercados (Brasil, las costas del Pacífico americano y de África) que se sumaron así a las economías de plantación caribeñas. Por último, las vicisitudes de los años posteriores a 1805 determinaron la declinación de la salazón de carnes en la plaza de Montevideo.

Es necesario tener en cuenta que el saladero no implicó ningún cambio tecnológico pero la concentración de procesos en un mismo sitio y una mejor organización permitió un aprovechamiento más integral de cada animal y, al mismo tiempo, acelerar la producción. El establecimiento contaba como mínimo con un corral grande, uno más chico donde se mataba el ganado, un mecanismo para transportar el animal muerto, un lugar techado y de piso firme donde se extrae el cuero y se corta la carne y espacios para las tinas que extraían la grasa con agua hirviendo y para la carne que se estaba salando (Giberti, 1986: 89-91).

A pesar de esto la instalación de un saladero implicaba la inversión de un considerable capital inicial para la época. Sala de Tourón, Rodríguez y de la Torre (1967: 107) afirmaron que ese capital tenía dos orígenes: el comercio y la explotación

\footnotetext{
${ }^{110}$ Sobre la historia de este saladero, ver: Montoya (1984)
} 
del ganado. De hecho, Arturo Bentancur (1997) ha mostrado que por lo general se daban asociaciones entre comerciantes y estancieros, aportando los primeros el capital y la sal y los segundos el ganado vacuno.

Como es de suponer los saladeros dependían, principalmente, de dos insumos: la carne fresca y la sal. Como vimos, la carne era un bien abundante y barato en las campañas rioplatenses. De todas maneras, la magnitud de la demanda de la industria saladeril debe haber tenido un impacto considerable para la ganadería de cría de las áreas de Montevideo, Colonia y Maldonado. Moraes (2011: 204-205) estimó que para los años 1787-1796 esa demanda habría sido de aproximadamente 44.000 cabezas de ganado por año y durante 1798-1808 habría ascendido a las 60.000 anuales ${ }^{111}$, lo que representaría una magnitud similar al consumo de carne fresca de la población de Montevideo. Es decir, que la demanda de novillos se habría duplicado. Además, los grandes saladeros debían asegurarse una provisión regular de ganado lo que propició que, en algunos casos, se produjera una integración vertical incorporando a la empresa la producción ganadera (Ibíd.: 202).

Siendo la carne un bien tan abundante, el mayor inconveniente de la producción saladeril consistía en el abastecimiento adecuado de sal. La provisión de sal era uno de los cuellos de botella de esta industria. Giberti (1986: 56) consideraba que muchos intentos de salazón de carnes habían fracaso por la escasez de sal de buena calidad a precios bajos.

La sal provenía principalmente de las salinas situadas en territorio indígena y, en menor medida, de Córdoba. El hecho de que se situasen en un territorio fuera del dominio español implicaba que cada expedición en busca de sal debía, para tener éxito, pactar con las parcialidades indígenas ${ }^{112}$. En Montevideo, a partir de la década de 1780 , se logró una provisión más abundante de sal al incorporarse al mercado la sal de España y en la década siguiente la sal proveniente de Carmen de Patagones. Esos años son coincidentes con el auge de la producción saladeril en la zona.

\footnotetext{
${ }^{111}$ Ese sería el ganado necesario para producir un promedio anual de 35.645 quintales de carne salada durante el primer período y 51.020 en el siguiente.

${ }^{112}$ El estudio de Taruselli (2006) destaca la importancia económica de esas expediciones que tanto por el abastecimiento necesario para los participantes como por el intercambio que generaban con los indios tendía a transformarse en "una verdadera caravana comercial". El autor destaca también la importancia de la elección de un comandante con ascendencia entre los habitantes de la campaña y buena relación con los indios para el éxito de la empresa.
} 
Entre los precios que periódicamente fijaba el cabildo de Montevideo se encontraba el de la cuartilla de sal. La sal tenía distintos precios de acuerdo a su origen (Anexo 4 Cuadro A 11). En general, la sal proveniente de las Salinas y de Córdoba que llegaban a través de Buenos Aires tenía un costo mayor que la proveniente de España y de Patagones.

Para poder tener una idea de la evolución del precio de la sal en Montevideo hemos optado por elaborar un índice del mismo a partir de ponderar los precios de la sal de distinto origen, asignándole una proporción igual a cada uno. El resultado se ve reflejado en el gráfico 9. La serie correspondiente al índice del precio de sal se encuentra representada en el gráfico con la línea color celeste y con color rojo aparece la tendencia polinómica de esa serie. Tanto la serie como su tendencia muestran una disminución del precio de la sal que podemos atribuir al arribo al puerto de la sal que llegaba por vía marítima ${ }^{113}$. Es decir, la sal proveniente tanto de España como de Carmen de Patagones. Esta situación se confirma, también, por el hecho de que el precio de la sal aumentaba en los momentos durante los cuales los conflictos bélicos impedían esa provisión de sal por parte de las embarcaciones que surcaban el Atlántico. En este sentido, son muy claros los aumentos del precio de la sal durante las tres guerras con Inglaterra (1779-1783, 1796-1802 y 1804-1808).

En consecuencia, el período de auge de la producción de carnes saladas en Montevideo coincide con un momento en el que los precios de la sal eran relativamente bajos, lo que nos induce a pensar que la provisión de ese bien era abundante en esa plaza. Esa situación sin duda constituyo una de las ventajas de Montevideo con respecto a otras zonas del Río de la Plata para el establecimiento de los saladeros. Otros beneficios adicionales de esa ubicación era que al estar las embarcaciones ancladas en ese puerto el costo de transporte del tasajo hasta las bodegas era menor y que la oferta de ganado vacuno en el área estaba asegurada.

\footnotetext{
${ }^{113}$ El estudio sobre el precio de la sal en Buenos Aires que hizo Martín Cuesta (2007: 35-38) muestra también un descenso en el precio de la sal en la segunda mitad del siglo XVIII, especialmente durante los años finales.
} 
Gráfico 9. Índice del precio (en reales) de la cuartilla de sal en Montevideo 1762-1815

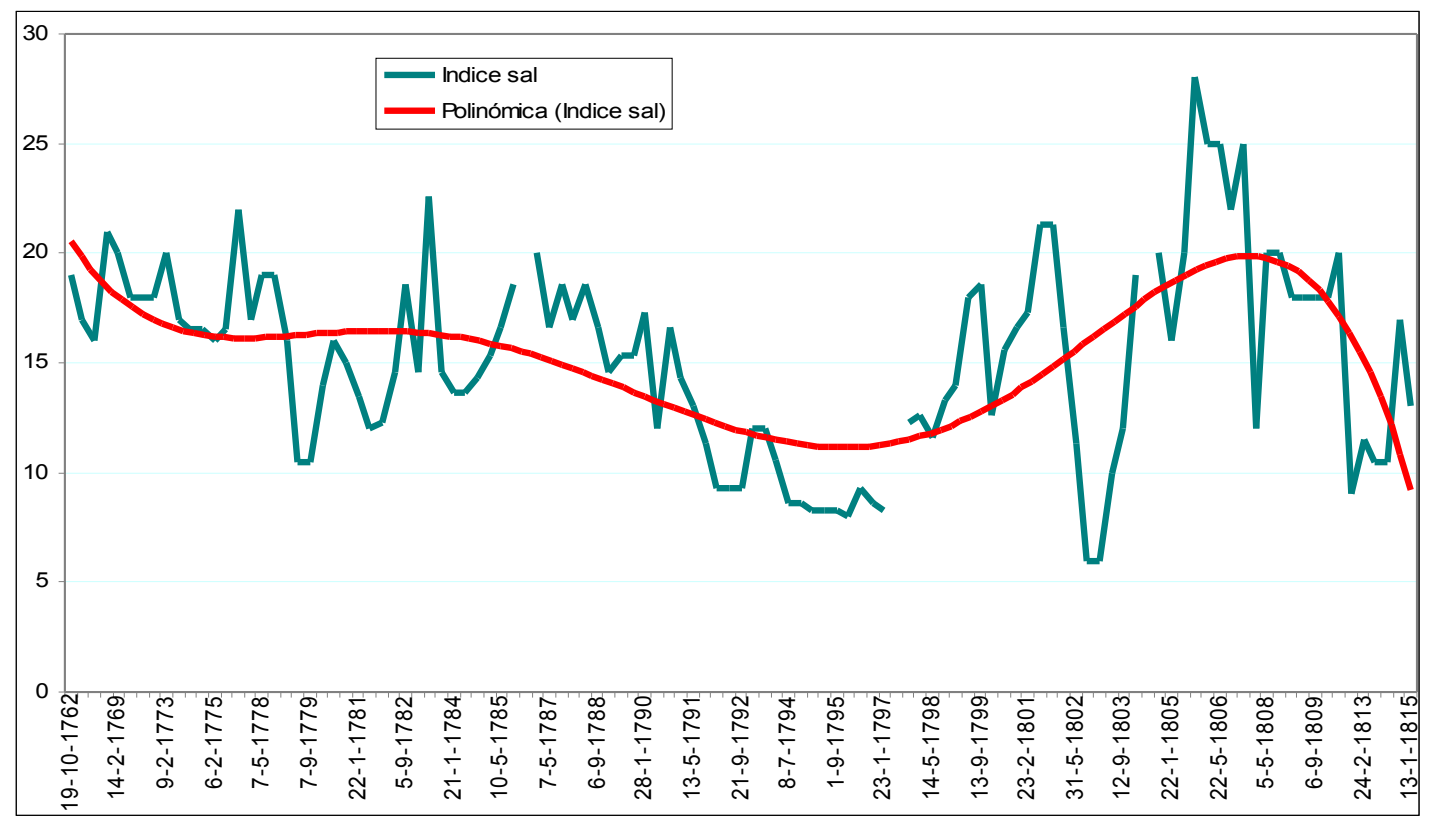

Fuente: Elaboración propia a partir de Acuerdos del cabildo de Montevideo

El otro cuello de botella para la producción saladeril estaba constituido por las características de la demanda. El principal mercado consumidor (Cuba) estaba a una distancia considerable y una vez ahí las carnes saladas rioplatenses sufrían la competencia de las producidas en la Capitanía General de Venezuela y, en menor medida, en Nueva España. En este sentido, los saladeros de Río Grande tenían una ventaja fundamental ya que tenían su mercado consumidor en el norte brasileño con el consecuente menor costo del flete.

Tanto la posibilidad de colocar lo producido en el mercado consumidor como el adecuado aprovisionamiento de sal dependían de las condiciones de navegación en el Atlántico. En este sentido, la guerras con Gran Bretaña (1796-1802 y 1804-1808) tuvieron un impacto significativo en la producción de carnes saladas, tal como se puede observar en el aumento del precio de la sal durante esos años (gráfico 9). Además, los sucesos posteriores a 1805, incluyendo las invasiones inglesas y el sitio terrestre a la ciudad de Montevideo en 1811, produjeron la decadencia de los saladeros montevideanos (Bentancur, 1997: 46) que debieron esperar un largo período de tiempo para poder resurgir. 
En síntesis, un balance de lo que conocemos hasta hoy nos indica que para una indagación más profunda sobre la producción de carne salada en el Río de la Plata es necesario investigar sobre varios puntos: estudiar la importación de sal, observar el desempeño del producto rioplatense en los mercados de consumo de Cuba y del norte brasilero, comparar las condiciones de producción de los saladeros en las distintas zonas de elaboración (Río de la Plata, Río Grande del Sur y los llanos venezolanos) y analizar las compañías formadas por los comerciantes y ganaderos para producir las carnes saladas. Todavía no disponemos de la información necesaria para cubrir esos aspectos. De todas maneras, realizarlo requiere un esfuerzo y una extensión que exceden las posibilidades de este apartado y requiere una investigación que se concentre exclusivamente en la producción y comercialización de la carne salada.

Mientras tanto el análisis efectuado en este capítulo nos permitió ver cómo tímidamente durante los años finales del siglo XVIII se comenzaba a aprovechar más integralmente cada cabeza de ganado sacrificada, lo que se puede observar tanto en el aprovechamiento del sebo y la grasa como de la carne del animal, ya sea para consumir fresca o para exportarla en forma de tasajo. Esta situación era propiciada por el crecimiento demográfico de la región y por las nuevas oportunidades que presentaba el comercio exterior. Implicaba también el avance de la ganadería de rodeo con la consiguiente mayor ocupación de tierras y el corrimiento de la frontera más leguas hacia el norte, alejándose cada vez más de las costas del Río de la Plata. 


\section{Capítulo 5}

\section{La apropiación de la tierra}

\section{Repartos, denuncias y mercado de tierras}

La apropiación de la tierra era el primer paso para poder explotar el ganado de manera legal. Durante el siglo XVIII existieron distintas maneras de acceder al usufructo legal de un terreno en el Río de la Plata. En primer lugar, la necesidad de poblar el territorio propició el reparto de tierras entre los primeros habitantes para el establecimiento de chacras y estancias. En segundo lugar, por razones similares gobernadores, comandantes militares, cabildos y otras autoridades tenían facultades para otorgar terrenos a quienes se los solicitasen. En tercer lugar, algunos ocupantes de hecho podían acceder a los trámites legales para obtener la propiedad de tierras realengas y conseguir así una ventaja sobre posibles competidores. Por último, a medida que avanzaba la ocupación cobraba mayor importancia las operaciones de compra-venta entre particulares ya que aunque todavía existía una gran disponibilidad de tierras, algunos sitios podían ser especialmente apetecibles por su ubicación, accidentes geográficos o mejoras hechas por su anterior propietario.

Además, de esas cuatro vías legales para acceder a la propiedad de la tierra existían diversas situaciones que implicaban la ocupación y el uso de los terrenos. Diferentes indicios permiten vislumbrar que la ocupación de hecho de las tierras estaba muy extendida, especialmente entre los pequeños productores. Por otro lado, existían distintos tipos de acuerdos o contratos entre algunos propietarios y los productores que iban desde la explotación de una parcela por parte de agregados y esclavos hasta el arrendamiento, ya sea por medio de un contrato escrito y protocolizado o por un acuerdo oral.

En una región de fronteras tan extensas, como el Río de la Plata del siglo XVIII, la tierra era un factor abundante. La expansión territorial y el crecimiento demográfico marcan, sin duda, la vitalidad de esa economía. Sin embargo, el acceso desigual a la 
propiedad legal de la tierra implicó también una restricción en la adquisición de los rincones más aptos para el desarrollo de la explotación ganadera y a las reservas de ganado cimarrón. Esa situación determinó que, en su mayor parte, los pequeños productores debieron dedicarse a la labranza mientras que se formaron distintos grupos de agentes vinculados a la explotación del ganado que pudieron acumular recursos económicos y posicionarse dentro de esa sociedad. En el capítulo 7 abordaremos en profundidad la formación de uno de esos grupos, probablemente el más importante a nivel regional, por lo menos en cuanto a la explotación del ganado cimarrón, cuyos integrantes residían en la ciudad de Montevideo. En este capítulo indagaremos acerca del acceso a la propiedad de la tierra, la importancia de las denuncias, la consecuente expansión hacia las tierras situadas al norte del río Negro y la conformación de un mercado de tierras en las áreas de Montevideo y Maldonado.

\subsection{Repartos y mercedes de tierras para chacras y estancias}

La fundación de Montevideo implicó el reparto de un solar, un terreno para chacra y otro para estancia a cada uno de los habitantes. De esta manera, entre $1727 \mathrm{y}$ 1730 se distribuyeron 84 chacras de 400, 300, 250 y $200 \operatorname{varas}^{114}$ y 20 suertes de estancias de 3.000 varas de frente y 1,5 legua $^{115}$ de fondo. Los pobladores recibían las tierras con la condición de no poder venderlas o enajenarlas por el término de 5 años (RAGA, 1885: 135-172). Con el correr de los años ese reparto inicial fue ampliado gracias a las tierras que iban cediendo las autoridades. Entre 1738 y 1774 los distintos gobernadores y el cabildo de Montevideo concedieron 76 mercedes de chacras y 150 de estancias (Pivel Devoto, 1964: 30-112).

Los gobernadores de Buenos Aires solamente concedieron 11 mercedes de estancias desde 1738 hasta que en 1751 perdieran esas facultades por la formación de la gobernación de Montevideo. La primera merced de tierras para establecer una estancia

\footnotetext{
${ }^{114}$ Tres pies formaban una cuadra. El pie del Río de la Plata representaba 0,288866 metros (Garavaglia, 2011: 29). Las suertes de chacras tenían, por lo general, 400 varas de frente por una legua de fondo (Pivel Devoto, 1964: 28). Desconocemos la razón por la que en la fundación de Montevideo se repartieron terrenos de menores dimensiones.

${ }^{115}$ Una legua representaba una superficie de 2.700 hectáreas. La suerte de 3.000 varas por legua y media de fondo también fue la extensión de las mercedes originarias en los pagos de Luján, Areco y Arrecifes situados en la campaña de Buenos Aires (Garavaglia, 2011: 28-29).
} 
fue la cesión del rincón de San José otorgado a Francisco de Alzaybar el 20 de abril de 1738 (Ibíd.: 49-51). Esa merced fue excepcional por su tamaño y fue la primera posesión de Alzaybar que, como veremos más adelante, logró acaparar importantes dimensiones de tierras y aseguró tener derechos sobre otras como retribución por su importante rol en la fundación de Montevideo y en su comercio durante las primeras décadas de existencia de la ciudad.

Otra de las mercedes importantes de esos primeros años esta relacionada con la instalación de la orden jesuita en la zona. En 1746 el gobernador de Buenos Aires concedió a la Compañía, con la conformidad del cabildo montevideano, un terreno para chacra de una legua cuadrada en el arroyo del Primer Canelón, un terreno para calera en el arroyo del Segundo Canelón y la rinconada que forman los ríos Santa Lucía Grande y Santa Lucía Chico para que formaran ahí su estancia.

Durante esas dos primeras décadas también se concedieron unas pocas mercedes de tierras para chacras. Solamente se dieron 8 terrenos, dos de ellos para la orden jesuita (el que ya mencionamos y otro otorgado en $1749^{116}$ ). Esto es el reflejo de las dificultades que tuvieron los pobladores para tomar un control efectivo de su territorio durante esos primeros años. La competencia con los portugueses y las constantes invasiones de los indios habían provocado incluso el abandono de algunas estancias ${ }^{117}$.

A partir de la segunda mitad del siglo XVIII las condiciones cambiaron. Entre 1752 y 1774 se concedieron todas las mercedes de chacras y estancias de las que tenemos registro dentro de la jurisdicción. En esos momentos, los vecinos pobladores hicieron uso de sus derechos y pidieron los terrenos que les correspondían para ellos y para sus hijos ${ }^{118}$. Sin duda, la derrota, prácticamente definitiva, de los indios minuanes en 1751 constituyó un importante aliciente para la formación de esos nuevos establecimientos rurales.

\footnotetext{
${ }^{116}$ Estaba ubicado en Arroyo del Miguelete, desde unas piedras nativas que sobresalían en ambas costas frente a la chacra que había sido de José Mitre, aguas abajo hasta un bañado, que comenzaba frente a la chacra de Juan de Morales y fue concedido porque la Compañía pretendía evantar un molino de agua, necesitaba ese terreno para cortar el agua y abrir asequias y conducirlas hasta el molino (Pivel Devoto, 1964: 31-32).

${ }^{117}$ En 1752, por ejemplo, Antonio Méndez recibió en merced, por parte del gobernador de Montevideo, una suerte de estancia entre el río Santa Lucía y el arroyo Tala que había abandonado debido a las irrupciones de los indios (Pivel Devoto, 1964: 58).

${ }^{118}$ El 28 de marzo de 1764, por ejemplo, Bartolomé Pérez recibió cuatro suertes de estancias situadas entre los arroyos Chamizo y Carreta Quemada para él y sus tres hijos (Ibíd.: 77).
} 
Por otro lado, fuera de la jurisdicción de Montevideo y en las zonas fronterizas, los comandantes militares tuvieron facultades para efectuar repartimientos de tierras. De esa manera, los comandantes de la villa de San Carlos, San José, Cerro Largo y del fuerte de Santa Teresa otorgaron extensiones de tierras con el fin de poblar esos territorios. Un caso especial fue el del ministro de la Real Hacienda de Maldonado, Pérez del Puerto, que desde 1782 también tuvo facultades para entregar tierra debido a que estaba encargado de las fundaciones de pueblos en el área. Sin embargo, tanto los comandantes como el ministro sólo podían concederlas en usufructo y no en propiedad $^{119}$ (Pivel Devoto, 1964: 27-28).

Esos repartos en zonas fronterizas formaron parte de la política de poblamiento y defensa de las fronteras que llevaron a cabo los funcionarios de la corona durante la segunda mitad del siglo XVIII. La cronología de las concesiones de tierras realizadas por los comandantes militares nos permite seguir la expansión territorial de la región.

En las décadas del 70 y 80 del siglo XVIII se suceden numerosas mercedes de tierras en Maldonado y San Carlos ${ }^{120}$. En cambio, en la década de 1790 y durante los primeros años del siglo XIX la mayor parte de los repartos de terrenos para chacras y estancias se efectuaron en las zonas cercanas al fuerte de Santa Teresa y a la guardia de Melo $^{121}$.

Las tierras concedidas siempre tenían acceso a una aguada, por lo general arroyos o ríos que hacían de frente del terreno. La figura 1 tomada del plano de fundación de Minas muestra a modo de ejemplo como se distribuyeron los terrenos en ese lugar a lo largo de los cursos de agua.

Las mediciones las llevaba a cabo un piloto tomando como punto de partida un accidente natural o un camino. A partir de ahí se utilizaba una cuerda, generalmente de cáñamo, que medía unas 100 varas. Se marcaba el punto hasta donde se había medido clavando palos o cañas. Además, se utilizaba una brújula que servía para mantener el rumbo (Garavaglia: 2011: 32-33).

\footnotetext{
${ }^{119}$ En 1793 Agustín de la Rosa, comandante de Santa Teresa, manifestó que concedía la merced de tierra a Miguel de los Santos "desde ahora hasta cuando los necesite el rey" (Ibíd.: 92-93).

${ }^{120}$ En esos años los comandantes concedieron terrenos, por ejemplo: a Antonio Machado y Bentos José Florido, Manuel Piris y Juan Correa Machado en 1775, a Tomás Aquino en 1777, a Manuel Lorenzo y Antonio Severino en 1778, José Pereira en 1780 y Manuel Sosa en 1782. AGN Uruguay, Archivo Judicial, Maldonado Caja 1 1765-1787.

${ }^{121}$ En 1793 el comandante de Santa Teresa concedió terrenos para estancias a: Miguel de los Santos, Cayetano de la Rosa, Ventura González y Santos Montiel. Entre 1795 y 1811 se otorgaron 25 mercedes de tierras para estancias en las cercanías de la guardia de Melo. (Ibíd.: 92-113)
} 
Figura 1. Plano de fundación de la villa de Concepción de Minas (1783)

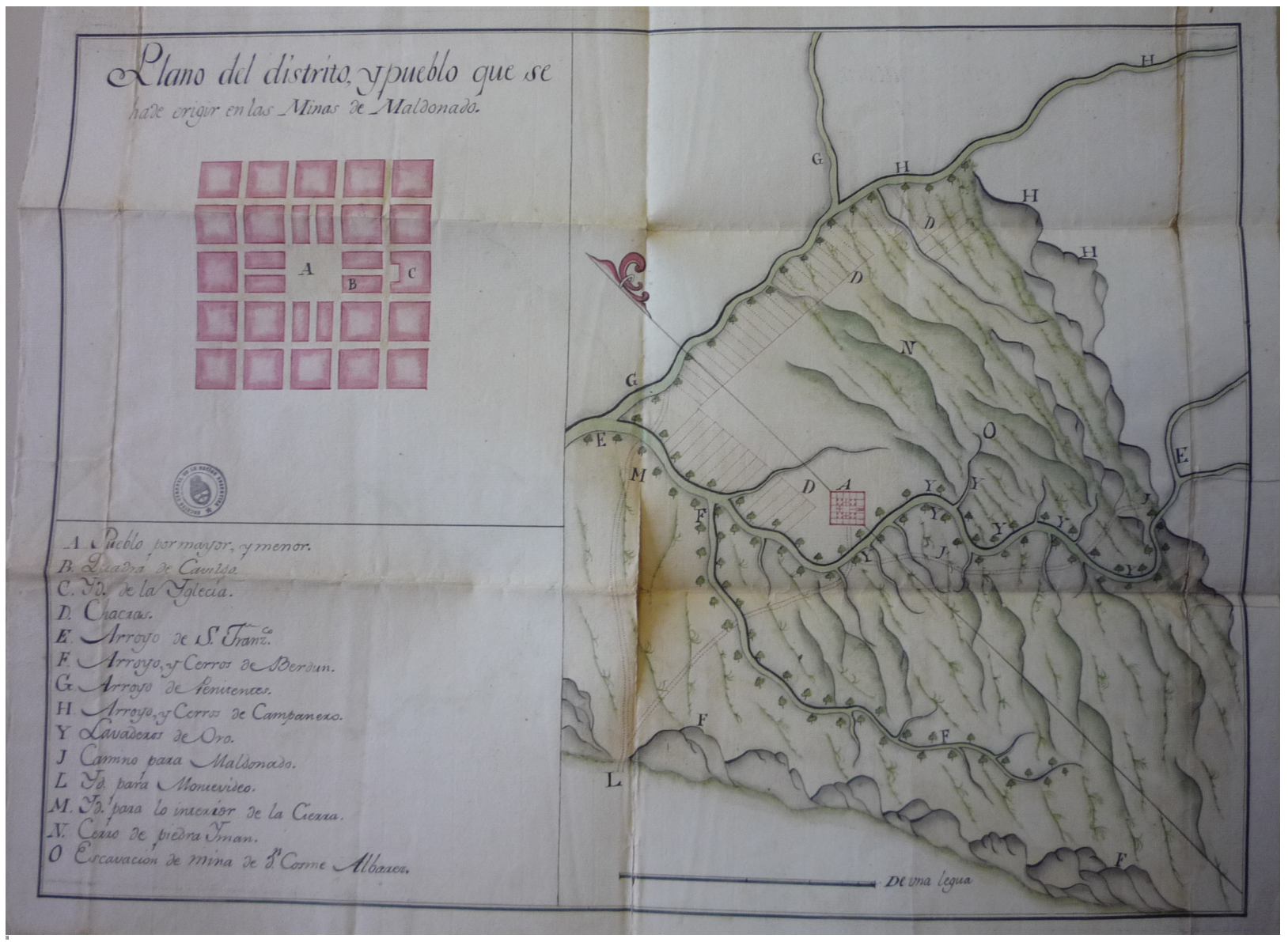

Fuente: AGN Sala IX 2-4-3

En ocasiones estas mensuras no eran exactas o la propiedad no era correctamente amojonada y se ocasionaban conflictos entre vecinos linderos. En 1735, por ejemplo, los chacareros de la otra banda del arroyo de los Migueletes solicitaron al cabildo de Montevideo que para terminar las disputas entre vecinos pasase la justicia con un piloto para delinear nuevamente las chacras porque en el reparto solamente se les había indicado el frente (RAGA, 1885: 387-388). 
5.2. Denuncias, ventas y composiciones de tierras realengas

Además de los repartos y concesiones de gobernadores y comandantes, los súbditos de la corona podían adquirir tierras realengas siguiendo los trámites indicados por la Real Instrucción de 1754. La Instrucción derogaba la Real Cédula de 1735 que exigía confirmación real. De esta manera, se buscaba evitar los gastos excesivos de los trámites al otro lado del Atlántico y sobre todo los que ocasionaban las gestiones en la corte. Estipulaba, además, que los ocupantes de hecho de terrenos realengos pudieran adquirirlos mediante una composición, es decir pagando una suma determinada, a diferencia de las denuncias nuevas en las que se debía rematar la propiedad en pública subasta.

Al igual que otras medidas relativas a la propiedad de la tierra en América y en el Río de la Plata (como el auto de la Real Hacienda de Buenos Aires de 1805), la Real Instrucción tenía como finalidad agilizar las gestiones para producir un aumento en la recaudación fiscal (Pivel Devoto, 1964: 118-119). En consecuencia, las prevenciones sobre las dimensiones de los terrenos fueron menores y algunos individuos pudieron obtener la propiedad de grandes extensiones de tierra. En realidad, en la mayor parte de los casos ni siquiera se preocuparon por finalizar las gestiones, conformándose con los beneficios que les proporcionó la ocupación de hecho de esos terrenos y la prioridad que les daba haber realizado la denuncia.

La persona interesada en adquirir la propiedad de un terreno realengo debía, en primer lugar, realizar la denuncia formal ante la autoridad competente indicando la ubicación, lindes y extensión del mismo. Luego, un juez certificaba la calidad de realengas de las tierras pretendidas, designaba al encargado de medirlas y a un tasador con conocimiento sobre la campaña y citaba a los vecinos linderos. Por último, se procedía al remate, con los pregones y demás gestiones previas (Ibíd.: 113).

De todas maneras, el bajo precio de la tierra en el Río de la Plata hizo que los trámites continuaran siendo muy onerosos. En ocasiones, los costos de mensura y tasación eran superiores a la valuación del terreno ${ }^{122}$ (Ibíd.: 199). En consecuencia, muchos interesados solamente realizaron la denuncia de terrenos que ya ocupaban de

\footnotetext{
${ }^{122}$ Por ejemplo, las costas de la mensura de la rinconada, situada entre los dos arroyos Yaguarón y la laguna hermosa, de dos y media leguas de frente y cuatro de fondo, denunciada en 1792 por José Francisco Azcue, fueron de 152 pesos y 4 reales mientras que el terreno había sido avaluado en 120 pesos (10 pesos la legua cuadrada) (Pivel Devoto, 1964: 290).
} 
hecho. La denuncia, por si sola, ya cumplía la función de otorgarles prioridad sobre otros posibles aspirantes (Ibíd.: 121).

A partir del año 1784 las ventas de terrenos realengos se vieron suspendidas hasta la resolución del expediente sobre el "arreglo de los campos". Luego de largos informes por parte de los funcionarios involucrados la conclusión se demoró hasta 1805 . La suspensión de los trámites para adquirir tierra realenga puede ser interpretada de manera contrastante. Julio Djenderedjian (2003: 172) sostiene que la suspensión de las ventas favoreció a los pequeños y medianos productores frente a los grandes productores ya que ayudó a mantener el statu quo en un momento en el cual la ganadería vivía una fuerte expansión del mercado externo. Sin embargo, a nuestro entender, la misma situación puede ser interpretada de manera opuesta. Los informes del expediente indican que las intenciones de las autoridades eran beneficiar a los pequeños y medianos productores con el fin de poblar las fronteras (Sala de Tourón, Rodríguez y de la Torre, 1968: 81-118). Pero la demora en la resolución benefició a los denunciantes de grandes extensiones de tierras realengas que, de esa manera, podían usufructuarlas sin tener que abonar su precio en un remate público o mediante la composición. Finalmente, cuando el auto de la Junta Superior de Real Audiencia de 1804 y el acuerdo de la Real Audiencia de 1805 resolvieron de manera definitiva el extenso expediente, los sucesos políticos y militares de los años siguientes impidieron la ejecución efectiva de las medidas que buscaban el establecimiento de poblaciones en la frontera con los territorios portugueses y concesiones de tierras a familias pobres (Pivel Devoto, 1964: 2-3).

Antes de la suspensión se vendieron algunas grandes extensiones dentro y fuera de la jurisdicción de Montevideo. Entre 1754 y 1782 pudieron finalizar los trámites para apropiarse de tierras realengas: José Villanueva Pico, Fernando Martínez de Haedo, María Francisca de Alzáybar, Melchor de Viana, Miguel Ignacio de la Cuadra y Bruno Muñoz (Ibíd.: 122).

Las gestiones podían demorarse por varios años. Melchor de Viana ocupó las tierras que iban desde la Cuchilla Grande hasta el río Yi entre los arroyos Mansevillagra y Maciel (indicadas con el número 14 en el mapa 7) en 1765 cuando realizó la denuncia ante el juez comisionado de tierras Florencio Antonio Moreiras. Sin embargo, la muerte del juez demoró los trámites y el terreno fue medido y tasado cinco años más tarde. 
Finalmente, el remate de las tierras se efectuó el 8 de abril de 1782 y el 27 de ese mismo mes Felipe Arguibel, como apoderado en Buenos Aires de Melchor de Viana, abonó 1.014 pesos y un real por el terreno más los impuestos correspondientes (Ibíd.: 143$145)$.

Algunas de esas ventas de tierras realengas sufrieron la oposición de los pobladores canalizadas a través del cabildo de Montevideo. En primer lugar, el cabildo se opuso en 1750 y 1751 a la compra que pretendía hacer José Villanueva Pico. Los cabildantes sostenían que el terreno era necesario para el procreo del ganado de la ciudad y que aún no se habían repartido las estancias entre los pobladores debido a que las invasiones de los indios había obligado a despoblar las que se habían establecido sobre el río Santa Lucía (Ibíd. 396-397). A pesar de los argumentos del cabildo montevideano, Villanueva Pico adquirió el terreno ${ }^{123}$ en el remate efectuado el 19 de febrero de 1752 y recibió la confirmación real de la propiedad del mismo el 34 de abril de 1754 (Ibíd.: 127-130).

Un par de décadas más tarde, el cabildo volvió a oponerse a una denuncia de tierras realegas. En este caso se trataba del intentó de Francisco de Alzaybar quien desde 1771 procuró adquirir una inmensa cantidad de tierras realengas. Esas pretensiones territoriales de Alzaybar se encuentran resaltadas con el número 2 en el mapa 6 que es ilustrativo de la extensión desmesurada de las mismas. El argumento del denunciante consistía en que el ganado esparcido por las campañas procedía de la estancia que había poblado con 36.000 cabezas de ganado vacuno en el rincón de San José en 1736. Afirmaba, en consecuencia, que debía tomar posesión de esos campos para evitar que los vecinos se adueñaran injustamente de esos ganados en las estancias que establecieron años más tarde (Ibíd.: 399).

Los regidores esgrimieron diferentes argumentos que no recibieron una buena acogida por parte de los funcionarios involucrados. La tenaz oposición del cabildo estaba vinculada con las pretensiones que algunos vecinos, como Miguel Ignacio de la Cuadra, tenían de adquirir parte de las tierras denunciadas ${ }^{124}$. La muerte de Francisco de

\footnotetext{
${ }^{123}$ La extensión del terreno era de 6 a 7 leguas de frente y 10 de fondo y estaba situado entre los ríos Solís Chico y Solís Grande desde la desembocadura en el Río de la Plata hasta el nacimiento en el potrero de Pan de Azúcar. El terreno está indicado con el número 6 en el mapa 6 y con el 16 en el mapa 7.

${ }^{124}$ La composición del cabildo en ese año es significativa al respecto. Esto es un primer indicio de una situación que trataremos en profundidad en el capítulo 8. Los agentes vinculados a la producción ganadera aparecen electos en el cabildo cada vez que surge un asunto que afecta sus intereses.
} 
Alzaybar, acaecida en 1775, frenó el trámite y esas tierras fueron finalmente denunciadas y ocupadas por varios de los vecinos de Montevideo.

Mapa 6. Denuncias de tierras en la jurisdicción de Montevideo, 1774

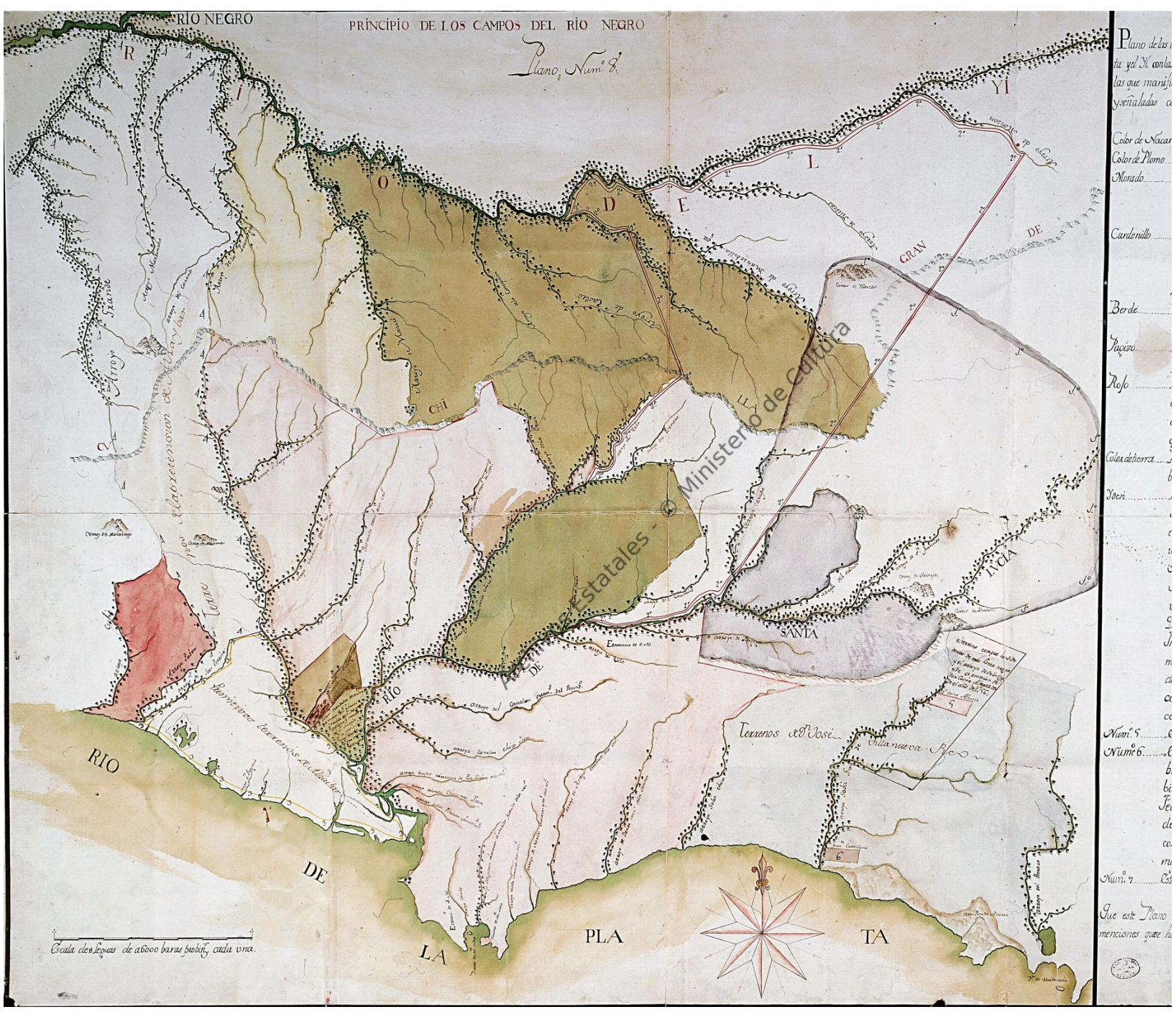

Fuente: AGI, Mapas y planos, Buenos Aires, 102. Disponible en línea: pares.mcu.es

El mapa 6 que acompañaba la carta del cabildo de Montevideo del 11 de noviembre de 1774 apelando las pretensiones de Francisco de Alzaybar es demostrativo de las dimensiones de algunas de las propiedades obtenidas y de los terrenos que los interesados pretendían adquirir ${ }^{125}$. La escala original del mapa es de 8 leguas cada 130

${ }^{125}$ El mapa lleva el nombre de "Plano de las tierras comprendidas entre el Río de la Plata y el Yi, marcándose en colores los terrenos que pretende cada uno de los que se expresan al margen". 
mm. Las referencias que lo acompañan indican que: con color nacar están representadas las estancias y chacras de los vecinos, con color plomo la propiedad de Villanueva Pico, con morado la de María Francisca de Alzáybar, con cardenillo el terreno comprado a las temporalidades por Juan Francisco García, en verde la propiedad de Melchor de Viana, con color papiro la de Miguel Ignacio de la Cuadra, en rojo las 11 suertes de estancia concedidas al entonces difunto Manuel Durán, con color tierra los primitivos terrenos de Francisco Alzaybar antes de que ampliara su denuncia y los que pretendía.

El cabildo se opuso, también a la compra en 1774 por parte de Juan Francisco García de Zúñiga de los bienes que habían pertenecido a la orden jesuita, a las denuncias de María Francisca de Alzaybar en 1778 y a la compra de terrenos realengos efectuada en 1780 por Bruno Muñoz ${ }^{126}$. En los tres casos los argumentos esgrimidos por el procurador del cabildo fueron similares y rondaban en torno a que las dimensiones de los terrenos podían permitir el establecimiento de centenares de vecinos y que los ganados dispersos pertenecían al común del vecindario (Ibíd.: 461-483).

Los mapas 7, 8 y 9 elaborados por Lucía Sala de Tourón, Julio Carlos Rodríguez y Nelson de la Torre (1968) permiten vislumbrar la situación con mayor claridad. Muestran las excesivas dimensiones de algunas de las denuncias, lo que nos invita a tener recaudos y a no interpretar esas denuncias como propiedades rurales sino que más bien tenían la finalidad de apropiarse del ganado cimarrón que habitaba esas tierras y explotarlo mediante las vaquerías. Tampoco hay que confundir las delimitaciones de las propiedades, aún las más pequeñas, con unidades de explotación ya que, como veremos en los casos de los agregados, en una misma estancia podían encontrarse varias unidades productivas.

En el mapa 8 podemos observar la ubicación geográfica de las denuncias de los principales productores de cueros que pudimos identificar para el período 1784-1797 (cuadros 7 y 8). A su vez, eso permite situar de manera aproximada los posibles focos corambreros o al menos una idea del lugar desde donde partían las vaquerías. Las referencias son las siguientes: 3 denuncias de la familia Alzaybar, 4 Juan Francisco García de Zúñiga, 6 Miguel Ignacio de la Cuadra, 7 Viana - Alzaybar, 8 y 38 Bruno Muñoz, 10 Fernando Martínez, 14 Melchor de Viana, 18 Manuel Vázquez de España,

${ }^{126}$ Bruno Muñoz adquirió las tierras situadas entre los arroyos Godoy, Tapes, Cebollatí, Tacuarí y el albardón o cuchilla que divide las aguas del río de la Plata y de la Laguna Mirim, que en conjunto medían de 38 a 40 leguas, por 2.125 pesos más 342 pesos y 7 reales de impuestos y costas y recibió la confirmación del título de propiedad el $1^{\circ}$ de marzo de 1780 (Ibíd.: 190-198). 
19 Claudio Márquez, 21 Francisco Rodríguez, posteriormente el mismo Rodríguez, Luis A. Gutiérrez y Melchor de Viana, 23 José Llorens y 26 familia Durán. Con letras se encuentran indicadas zonas que eran fuente de disputas por parte de distintos particulares. Así, con la letra A se indican tierras que eran reclamadas, al mismo tiempo, por Alzáibar y por de la Cuadra, con la B las disputadas entre Melchor de Viana y García de Zúñiga, con la $\mathrm{C}$ entre el mismo García de Zúñiga y María Francisca de Alzáibar, con la D entre la misma y Bruno Muñoz y con la $G$ tierras en las que se superponen la compra de Fernando Martínez de Haedo y las denuncias de Miguel Ignacio de la Cuadra y su suegro Manuel Durán (Ibíd.: 292-293). Como se puede observar, la mayor parte de esas tierras se encontraban por fuera de la jurisdicción de Montevideo, repartiendo el territorio situado entre los ríos Yi y Negro e incluso superando la barrera de este último para ingresar en lo que se había considerado como el espacio de pastoreo de los ganados misioneros.

En consecuencia, los mapas son indicativos de la expansión territorial hacia el norte de esta parte de la región Río de la Plata durante la segunda parte del siglo XVIII con la consiguiente apropiación por parte de particulares de las tierras que con anterioridad formaban parte del espacio misionero. La comparación con la frontera bonaerense, de expansión mucho mas modesta durante esos años, permite situar el crecimiento territorial de la región en este sector norte, lo que, a su vez, es revelador del dinamismo económico de esta zona.

Los mapas sirven, además, para situar las zonas donde los repartos de tierras configuraban una distribución de la propiedad caracterizada por las pequeñas y medianas dimensiones. Esas zonas están indicadas en el mapa 7 con el número 1 y se corresponden a las tierras circundantes a los poblados de Santo Domingo Soriano, Colonia de Sacramento, Montevideo, Maldonado y San Carlos y en el mapa 8 están indicadas con el número 2 y corresponden a los terrenos cercanos a, nuevamente, Maldonado y San Carlos y los nuevos repartos realizados en Rocha y en Melo.

También se distinguen claramente los rincones realengos que aparecen en el mapa 6 con el número 4, en el mapa 7 con el número 2 y en el mapa 8 con el número 68. Como se puede observar las estancias del rey tenían unas dimensiones más que considerables y se encontraban situadas en lugares estratégicos que les permitían abastecer adecuadamente a la tropa de transporte y alimento. 
Mapa 7. La propiedad de la tierra en la "Banda Oriental" en 1763

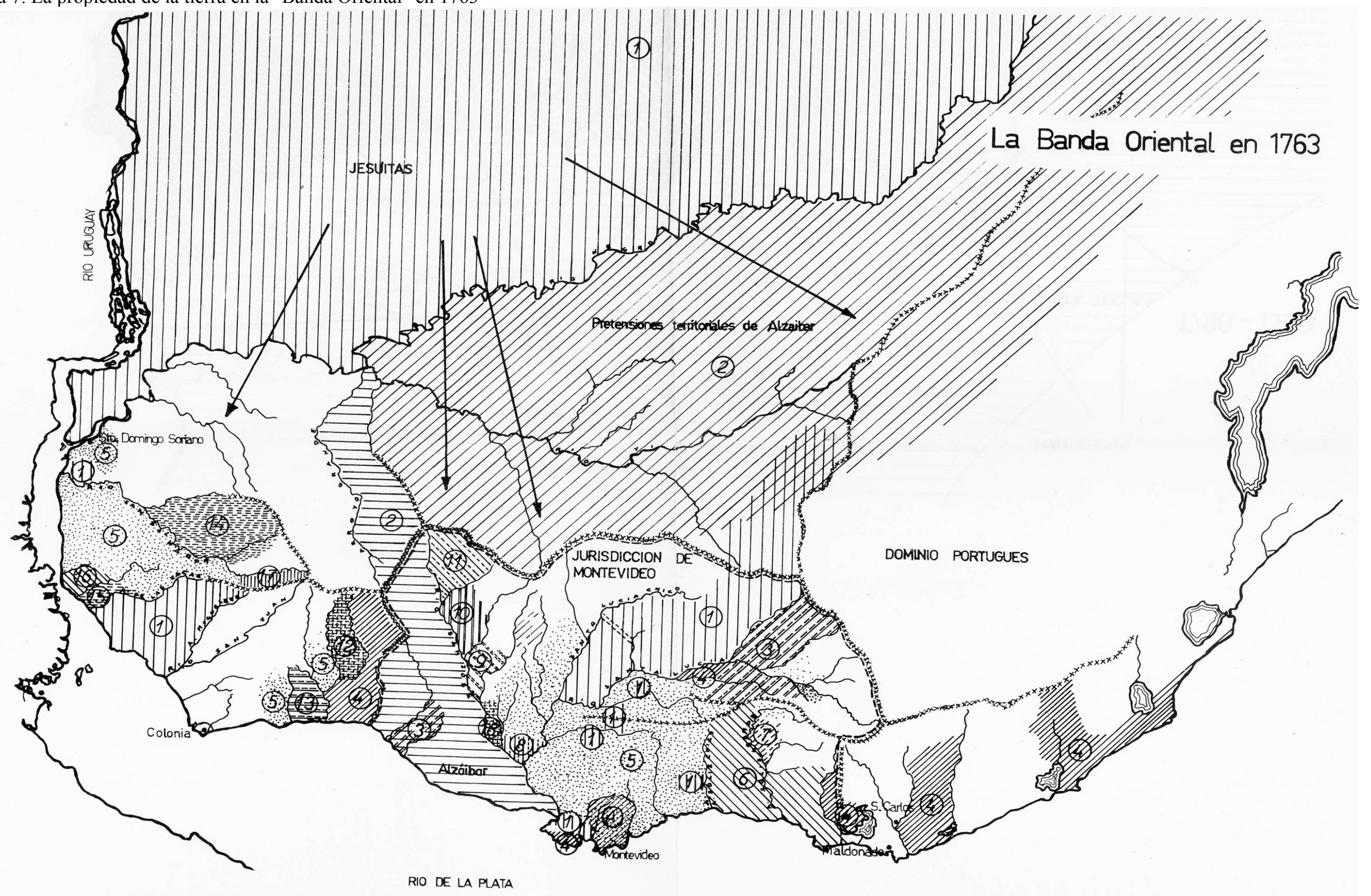

Fuente: Sala de Tourón, Rodríguez y de la Torre (1968) 
Mapa 8. La propiedad de la tierra en la "Banda Oriental" hacia 1780

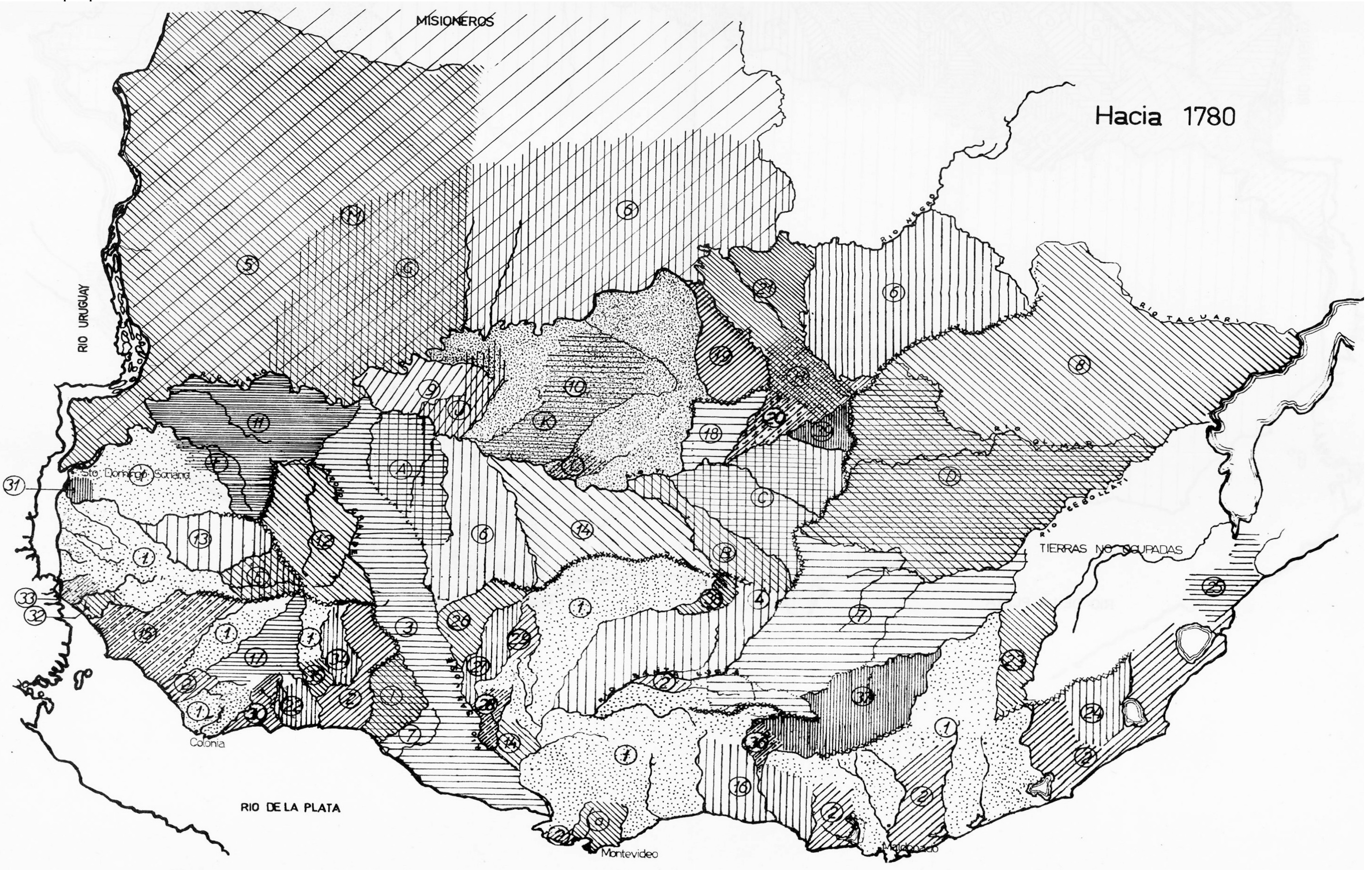

Fuente: Sala de Tourón, Rodríguez y de la Torre (1968) 
Mapa 9. Denuncias de tierras en la "Banda Oriental" entre 1790 y 1799

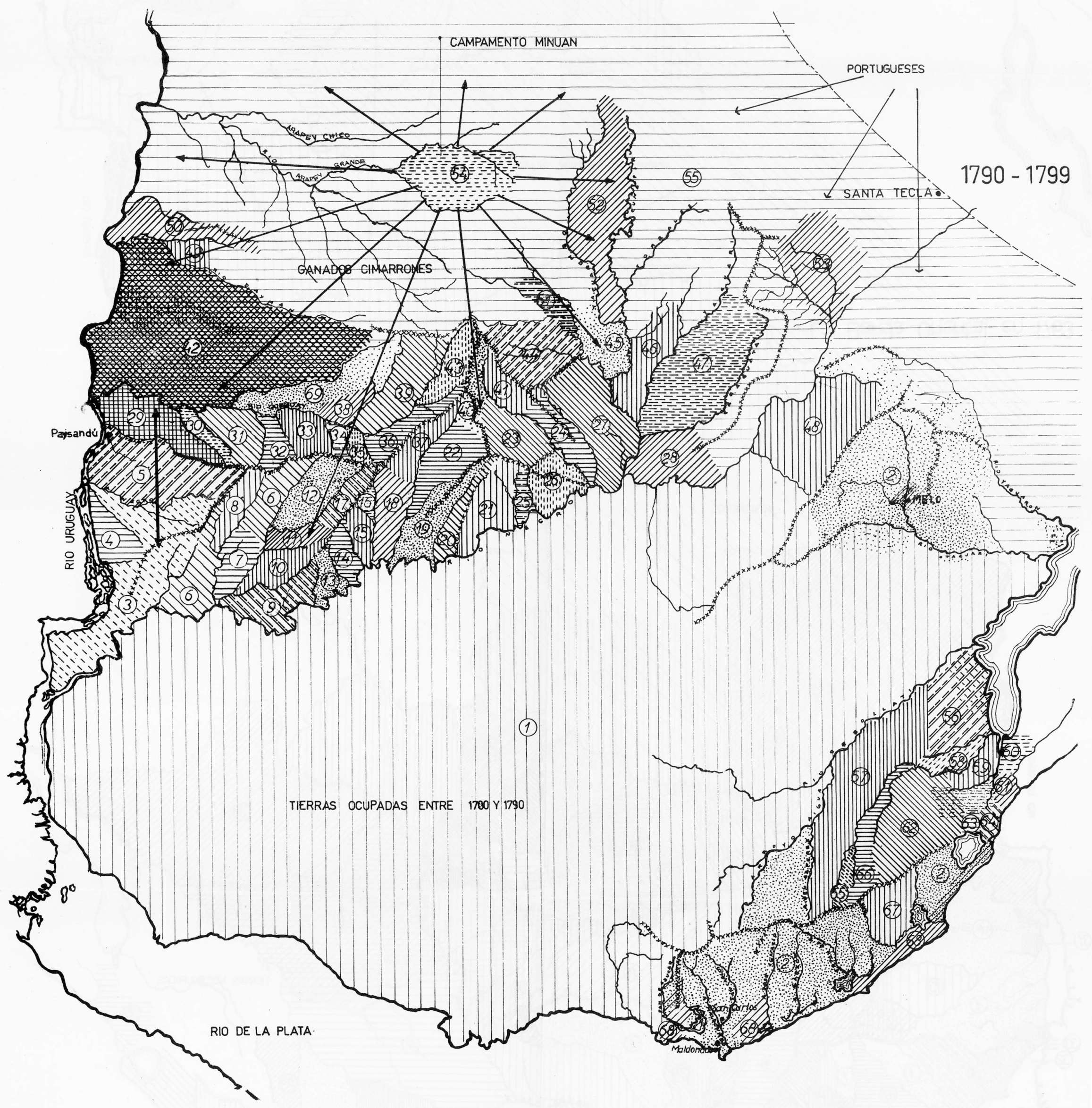

Fuente: Sala de Tourón, Rodríguez y de la Torre (1968) 
5.3. El mercado de tierras regional: compra-ventas de bienes inmuebles rurales

Al mismo tiempo que la región se expandía territorialmente con la ocupación de nuevas tierras, aumentaban los traspasos de la propiedad por medio de las operaciones de compra-venta entre particulares. La abundante disponibilidad de tierra aún no ocupada tuvo como consecuencia que la formación de ese mercado fuese lenta a través de todo el siglo XVIII.

Esa abundancia de la tierra determino que su precio se mantuviese bajo. De acuerdo al estudio de Garavaglia (1999: 291) sobre los precios en la campaña de Buenos Aires, el precio de la tierra compartió el comportamiento negativo del resto de los precios agropecuarios y en el año 1820 se pueden observar los mismos niveles de precios de 1750/1760. El autor considera al mercado de la tierra como imperfecto ya que no presenta todas las características de un mercado pero si se puede percibir cierta relación entre el precio de la tierra y el de los bienes generados por la producción agropecuaria. El valor de la tierra estaba influido por la ubicación, representada por la cercanía con respecto a Buenos Aires o la distancia con respecto a la frontera, y por la presencia de aguadas en el terreno. De esta manera, los precios promedios por varas en el período 1751/1815 variaron según la zona: desde 1,56 reales en Magdalena, 1,88 en Arrecifes, 2,09 en Areco, 2,13 en Luján y hasta los 2,23 para las estancias más cercanas a Buenos Aires (Ibíd.: 295-296).

María Inés Moraes (2011:227), por su parte, estudió el mercado de tierras de la jurisdicción de Montevideo. La autora sostiene que la mayor cantidad de ventas de chacras fue consecuencia del dinamismo agrícola que cobró el área que, a su vez, se debía al crecimiento demográfico de esos años. Esa situación se vio reflejada en un crecimiento de los precios de las chacras, a pesar de algunas caídas en 1764/1772 y luego de 1780. Por otro lado, Moraes afirma que existió una relación entre las ventas de estancias y la expansión de la frontera agraria ya que las operaciones disminuyeron luego de 1780. Es decir, existieron menos ventas de estancias porque había mayores posibilidades de ocupar tierras nuevas. Los precios de los terrenos para estancias cayeron en las décadas de 1760 y 1770, encontrando su punto mínimo en 1775, y luego tuvieron una leve recuperación llegando en 1787 a los precios iniciales. 
Más allá de este comportamiento de los precios, los datos de las operaciones de compra y venta de esos bienes inmuebles rurales permiten comprobar la lenta formación de un mercado regional a lo largo de todo el siglo XVIII. Hablamos de bienes inmuebles rurales porque en la mayor parte de las transacciones la tierra solamente era una parte de los bienes que se vendían y, en ocasiones, el ganado y los edificios de las estancias tenían más valor que el terreno ${ }^{127}$. En los gráficos 10 y 11 hemos agrupado los datos sobre ventas de chacras y estancias contenidos en los protocolos notariales de Buenos Aires trabajados por Eduardo Saguier (1993), en los protocolos notariales de Montevideo incluidos en la colección de documentos dirigida por Pivel Devoto (1964) y la información brindada por la alcabala de Maldonado ${ }^{128}$, que ya analizamos en otro estudio (Biangardi, 2013). Los gráficos permiten vislumbrar la lenta formación de un mercado de bienes inmuebles rurales a partir de la cantidad de operaciones anuales realizadas. La tendencia exponencial que trazamos en el gráfico 10 es demostrativa de que a pesar de ciertas fluctuaciones la cantidad de operaciones efectuadas no dejó de crecer durante todo el siglo XVIII.

El aumento en la cantidad de transacciones de las últimas dos décadas del siglo XVIII tiene varias razones. En primer lugar, la consolidación en la ocupación de nuevos espacios que queda claro en las transacciones registradas en la alcabala de Maldonado (ver Anexo 4 Cuadro A.12) y en las ventas de estancias situadas en las costas del río Negro. En segundo lugar, la puesta en venta de las tierras recibidas en merced o compradas a la corona en remates. Estas tierras son vendidas, especialmente, por personas que las recibieron como herencia de los primeros propietarios ${ }^{129}$. En tercer lugar, en los años finales del siglo se puede observar un proceso de subdivisión de esos terrenos que, sin duda, estaba vinculado con el corrimiento de las reservas de ganado

\footnotetext{
${ }^{127}$ En la mayor parte de los casos no se indica el valor de cada bien. Sin embargo, en algunas ocasiones la información es más detallada. El 20 de junio de 1763, por ejemplo, Juan de Achucarro compró la estancia que tenía Francisco Morales en Canelones. El comprador abonó 375 pesos por la tierra y 746 por el resto de los bienes que eran los siguientes: 600 cabezas de ganado vacuno pequeño a 6 reales cada uno, 1.050 ovejas a 2 reales, 114 yeguas a 2 reales, 9 caballos a 2 pesos, un hacha 1 peso y 4 reales, un corral 5 pesos y una marca de ganado 2 pesos (Ibíd.: 691). El 6 de marzo de 1798, para poner un ejemplo más tardío, Felipe Pérez compro dos suertes de estancia a los herederos de Antonio de Córdoba situada en el arroyo Chamizo. El comprador pagó 1503 pesos y 4 reales de los cuáles 750 correspondían al precio de la tierra y el resto (753 pesos y 4 reales) al valor de los ganados, ranchos y utensillos (Ibíd.: 725-726).

${ }^{128}$ En Maldonado no había escribanos durante el período analizado por eso utilizamos la información que nos brindan los libros auxiliares de la alcabala de ventas.

${ }^{129}$ En Montevideo hubo 36 operaciones de ventas de estancias que indican que los vendedores habían recibido la propiedad del inmueble por herencia, 13 fueron llevadas a cabo por albaceas, 12 por viudas y 2 en amoneda pública. Una situación similar se daba con las transacciones de chacras.
} 
cimarrón hacia el norte y la incorporación de esas tierras a la zona de producción de la ganadería de rodeo. Situación que implicó un reacomodamiento de las dimensiones de las propiedades.

Gráfico 10. Ventas de bienes inmuebles en la región Río de la Plata 1701-1810

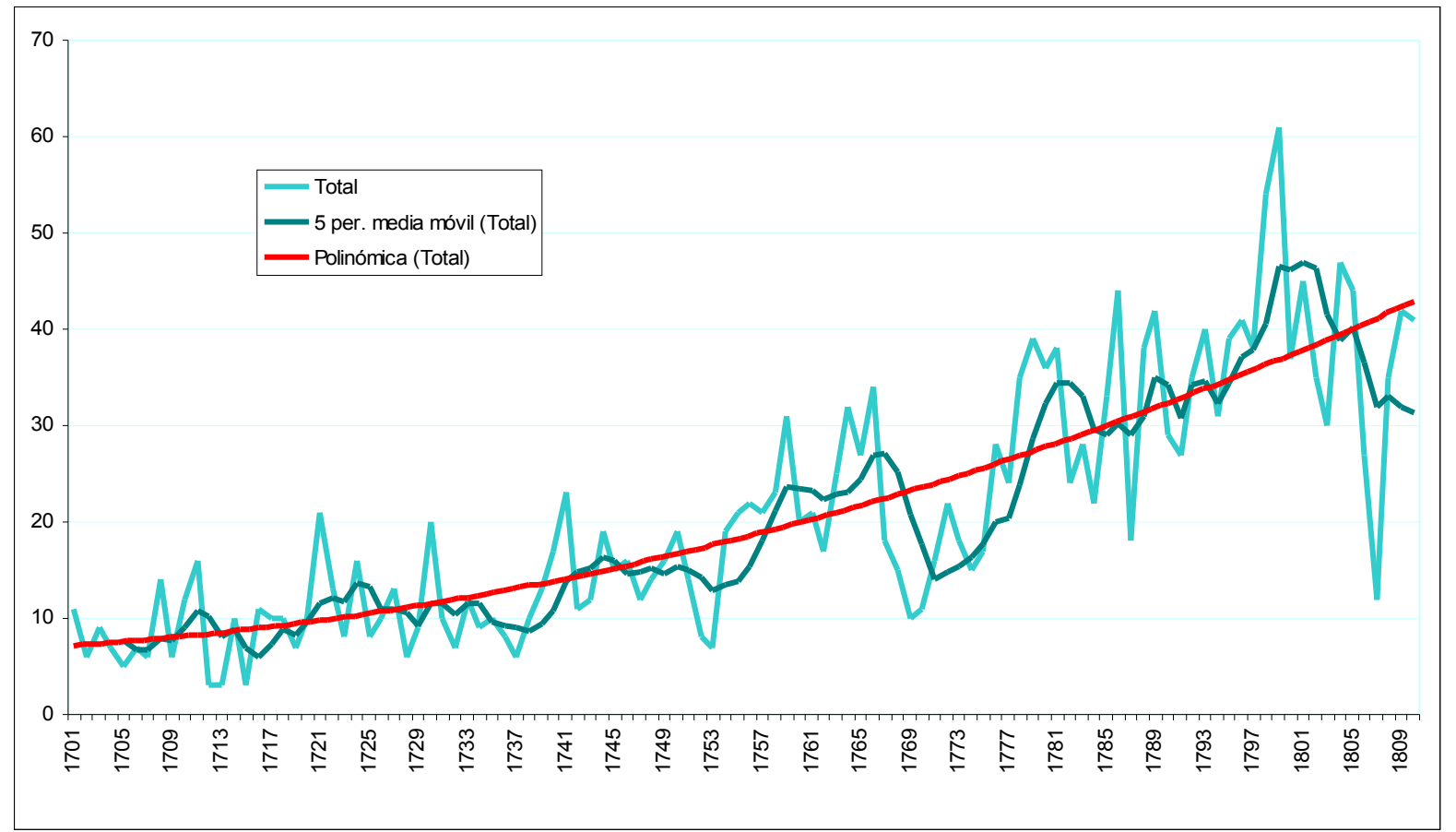

Fuente: Elaboración propia a partir de Saguier (1993: 69-71), Pivel Devoto (1964: 683685, 746-747) y AGN XIII Maldonado Legajos de 3288 a 3312

Un ejemplo claro de esta situación es el siguiente. El 7 de octubre de 1800 Benito López compró la estancia, situada entre los arroyos Gutiérrez y Olimar Grande, que Margarita Viana y Aguirre había heredado de su padre José Joaquín de Viana, primer gobernador de Montevideo. El comprador abonó 3.950 pesos por la misma. Luego Benito López vendió cinco porciones de ese mismo terreno por un total de 2.450 $\operatorname{pesos}^{130}$ y mantuvo una parte del mismo para su propio uso. Es decir, la propiedad original fue finalmente dividida en seis.

\footnotetext{
${ }^{130}$ En las 5 operaciones se aclara que el terreno vendido era parte del que Benito López había comprado a Margarita de Viana y Aguirre. No figuran las dimensiones de esos terrenos pero las fechas, compradores y montos son los siguientes: el 8 de octubre de 1800 a José Antonio Artigas por 850 pesos, el mismo día a José Ignacio Cardoso por 400 pesos, el 12 de febrero de 1801 a Gregorio Frías por 300 pesos, el 3 de diciembre de 1805 a Pedro José Guevara por 400 pesos y el 6 de junio de 1809 a María Pucharber, viuda de José Cardoso por 500 pesos (Ibíd.: 732-733, 735, 743-744).
} 
Gráfico 11. Ventas de bienes inmuebles rurales en Buenos Aires, Montevideo y Maldonado 1774-1806

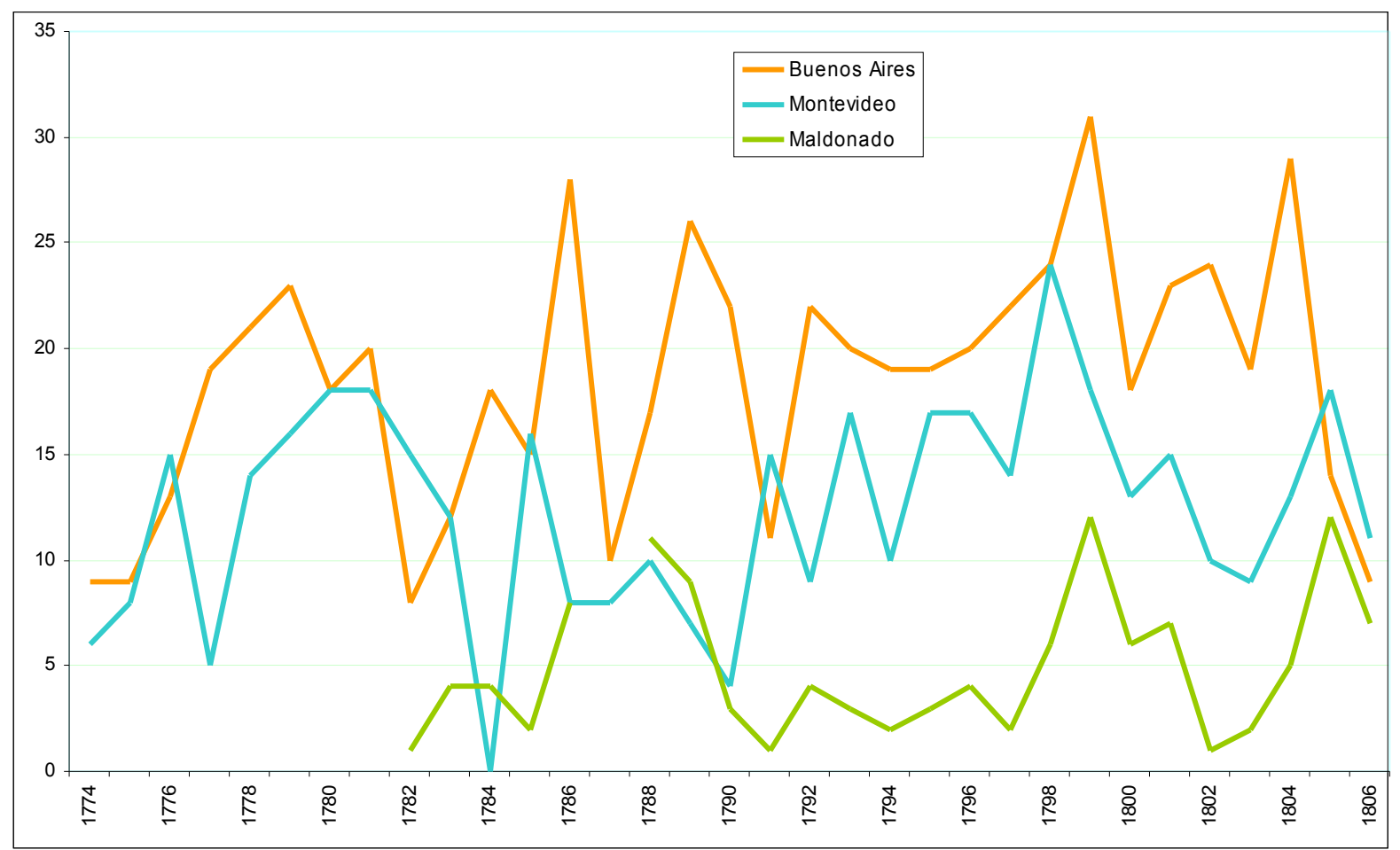

Fuente: Elaboración propia a partir de Saguier (1993: 69-71), Pivel Devoto (1964. 683$685,746-747)$ y AGN XIII Maldonado Legajos de 3288 a $3312^{131}$

El gráfico 11, por su parte, es indicativo de la existencia de un incipiente mercado regional que desde el punto de vista de las fluctuaciones en la cantidad de operaciones anuales efectuadas se muestra integrado. Es decir, que más allá de los precios por varas, que como vimos pueden variar de acuerdo a la ubicación, las compraventas de chacras y estancias estaban influidas por los mismos factores en las tres áreas analizadas ya que, si bien en alguna de las áreas las consecuencias se pudieron haber demorado un año más, las fluctuaciones son similares.

Principalmente esas fluctuaciones son un indicio más de la importancia que tenía el comercio ultramarino en la economía regional. Las interrupciones del tráfíco marítimo a causa de las guerras afectaban tanto a las estancias como a las chacras. La demanda de cueros dependía de la disponibilidad de espacio en las bodegas de los

\footnotetext{
${ }^{131}$ Hemos incluido dentro de las transacción que figuran como de Montevideo algunas ventas de estancias que se encuentran fuera de la jurisdicción de la ciudad ya que consideramos que el área, tal como la planteamos en la introducción, se expandió hacia las tierras situadas al norte de la misma sin que esa situación tuviera su correlato en la definición de los límites de la jurisdicción.
} 
barcos. La producción de frutas, cereales, hortalizas y de carne fresca se veía influida también por la demanda extra que generaban las tripulaciones, tanto en su estadía como por los alimentos que se llevaban para el viaje de retorno ${ }^{132}$. Además, también sufrían la injerencia de otros factores como las dificultades climáticas. Seguramente, las sequías, que en ciertos lugares pudieron ser muy prolongadas, llevaron a algunos productores a la necesidad de vender sus propiedades.

Jorge Gelman (1998: 86, 210-211), en su estudio sobre el área de Colonia de Sacramento y Santo Domingo Soriano, ha propuesto que en esos años de crisis se producía un proceso de polarización en la estructura productiva de la campaña. En esos años, los grandes estancieros podían aprovechar la disminución de la demanda para aumentar su stock de animales y esperar a la reanudación del comercio ultramarino una vez finalizada la coyuntura bélica. En cambio, los medianos productores se vieron en dificultades para sobrellevar la crisis y en algunos casos debieron vender sus tierras. De esa manera, para el autor el aumento en la participación de los grandes estancieros en la producción total de la zona se producía a costa de los medianos productores y no de los pequeños, aumentando así la polarización de la estructura agraria.

En este sentido, en los años de guerra (especialmente en 1776, 1796, 1798, 1799 y 1806) se produjeron mayores ventas de estancias en Montevideo (ver Anexo 4 cuadro A.11) lo que podría ser un indicio de la existencia del mismo proceso de polarización. Por otro lado, en muchas ocasiones los vendedores se desprenden de parte o de la totalidad de sus tierras que son compradas por sus vecinos linderos. En 29 de las ventas de estancias estudiadas se específica que las mismas lindaban con terrenos del comprador y en 22 con tierras del vendedor. De todas maneras, el mercado de tierras todavía se encontraba en formación y la cantidad de operaciones de compra-venta de bienes inmuebles rurales todavía era escasa. Esa situación parece bastante lógica en una región que todavía disponía de una amplia frontera abierta con la consiguiente abundancia en la oferta de tierras que aún no habían sido ocupadas.

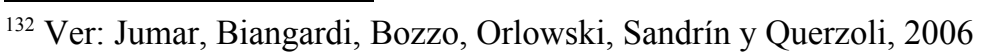


5.4. Arrendamientos de estancias y chacras

El arrendamiento de estancias y chacras constituía una vía alternativa para el acceso al usufructo de la tierra. Para algunos individuos el arrendamiento permitía emprender una actividad productiva a cambio de un pago anual sin que fuese necesaria la compra de la propiedad. El propietario, por su parte, obtenía una renta de un terreno que de otra manera podía permanecer ocioso y, al mismo tiempo, aseguraba su propiedad sobre el mismo evitando que sea ocupado por intrusos.

Aunque el arrendamiento, o al menos prácticas similares, parecen haber estado muy extendidos en el siglo XVIII rioplatense, solamente poseemos información sobre unos pocos de esos contratos. Lo más probable es que la mayor parte de esos acuerdos se hicieran de palabra, quizá también sujetos a determinadas costumbres, y en consecuencia no quedaban asentados en los protocolos notariales ${ }^{133}$.

Tenemos indicios de algunos de esos acuerdos que se hacían de manera oral en el área de Montevideo. Por ejemplo, en 1807 cuando José Joaquín de Viana arrendó su estancia en Vejiga a José Ramírez por el término de 8 años a cambio de 1.000 pesos anuales, el artículo cuarto del contrato estipulaba lo siguiente:

"Que las semillas del presente año, esto es lo que algunos labradores pagan al otorgante por razón de las sementeras que les permite hacer en los terrenos de la estancia, serán a favor del que otorga, pero no así en los restantes años del arrendamiento, en que deberán entenderse aquellos con el arrendatario Ramírez" (Pivel Devoto, 1964: 775)

En los protocolos notariales de Montevideo se pueden encontrar 29 contratos de arrendamientos ( 22 de estancias y 7 de chacras). Esos acuerdos duraban entre 2 y 8 años y estipulaban una retribución anual. Contenían, además, cláusulas que determinaban las condiciones en las que el arrendatario recibía la propiedad, que en algunos casos incluían un inventario de los bienes, y las condiciones en las que debía entregar la misma una vez concluido el arrendamiento.

\footnotetext{
${ }^{133}$ Raúl Fradkin (1995a y 1995b) ha estudiado los arrendamientos en la campaña de Buenos Aires durante el siglo XVIII. El autor destaca que la mayoría de los contratos eran verbales y que las normas sociales, entendidas como la "costumbre del pays" regían las condiciones según las cuales se efectuaban esos arrendamientos en los diferentes lugares de la campaña. Un ejemplo de arrendamiento se puede observar en el estudio de caso analizado por Gabriela Gressores (1996).
} 
Así, por ejemplo, en el contrato mediante el cual Lorenzo Soler y Nicolás Fernández Miranda daban en arrendamiento tres suertes de estancias en el río Santa Lucía a Francisco Godar se especificaba que el arrendatario debía dejar a favor de los propietarios todos los ranchos y corrales que levantara y las labranzas que efectuara (Ibíd.: 777).

En algunas ocasiones el contrato estipulaba que en vez de un pago monetario anual, el arrendatario debía entregar al propietario la mitad del procreo anual en el caso de las estancias o del producto de los frutales en el de las chacras. En esas ocasiones era usual que el propietario se hiciera cargo de la mitad de los gastos de la explotación. Ese era el caso del acuerdo llevado a cabo en 1787 entre Miguel y Felipe Pírez para explotar una estancia de dos leguas de frente y 3 de fondo situada en la Cuchilla de Carapé. En cuanto a las chacras podemos mencionar el arrendamiento de 1793 que estipulaba que la fruta debía repartirse en partes iguales entre el propietario, Miguel de Otermin, y el arrendatario José Pacheco, quien además tenía que plantar 300 frutales por año y proporcionar al propietario semillas de trigo, maíz y porotos. (Ibíd.: 778-779)

Un caso especial de arrendamiento fue el de la estancia perteneciente a la ciudad $^{134}$. En 1783 Juan Miguel Laguna, cura vicario de Canelones, la arrendó por el plazo de tres años abonando 200 pesos anuales (AECM, 1942: 66-68).. Luego en 1788, Fernando Crespo y Valdés obtuvo el derecho a explotar la estancia situada en el pago del Pintado ofreciendo, en remate público, el pago de 370 pesos anuales. El contrato estipulaba un período de 5 años y, al finalizar el contrato, logró extenderlo por otros 5 años aunque, llamativamente, ganando el remate con una postura en la que ofreció pagar menos de la mitad (150 pesos cada año) que en el período anterior. Al finalizar el contrato, Crespo y Valdés debía entregar 660 cabezas de ganado vacuno ya que había recibido esa cantidad al inicio del mismo. (Ibíd.: 778, 780)

Por último, queremos destacar que en estos contratos también podemos encontrar indicios del proceso de subdivisión de las tierras y del cambio en los agentes vinculados a la producción ganadera iniciado en los años finales del siglo XVIII, que ya

\footnotetext{
${ }^{134}$ El cabildo de Montevideo tomó la desición de arrendar la estancia que pertenecía a la ciudad luego de las dificultades que ocasionó la administración directa de la misma. En 1772 el capataz de la estancia acusó ante el cabildo a Francisco Hernández de entrar a la misma de llevarse el ganado (RAGA, 1918: 327-328), lo que generó un juicio que término con la condena de Rodríguez obligandólo a emprender la restitución del ganado (AJ Caja 24. Expediente 20. Autos criminales obrados contra Francisco Hernándezsobre extracción de ganado de la estancia del común de esta ciudad).. El 18 de agosto de 1775 los cabildantes se quejaban del "ningún fruto y poco adelantamiento" de la estancia (RAGA, 1920: 179180).
} 
planteamos al analizar las operaciones de compra-venta. Ya hemos mencionado a José Joaquín de Viana, que figura en el cuadro 7 como uno de los mayores productores de esos años, quien en los primeros años del siglo XIX, al parecer volcado en ese entonces a la carrera militar ${ }^{135}$ y residente en Buenos Aires, no continuó con la explotación directa de las tierras heredadas por su padre y prefirió darlas en arrendamiento. En 1802 suscribió un contrato de arrendamiento para ceder dos rincones de estancia a José Ramírez y compañía a cambio de 300 pesos al año por el término de 8 años. El 25 de agosto de 1807 firmó un nuevo contrato, al que ya referimos más arriba, por el que recibía 1.000 pesos anuales a pagar por tercios cada cuatro meses con lo que se aseguraba una renta considerable. (Ibíd.: 771-776)

Por su parte, Martina Gómez, esposa de Fernando Martínez (otro de los productores indicados en los cuadros 7 y 8), efectuó en 1795 ocho contratos de arrendamientos mediante los cuales cedió la explotación de sus tierras. Es probable que esa cantidad se deba a que eligieron subdividir las propiedades para darlas en arriendo ya que algunos terrenos lindaban entre si. Todos los acuerdos tenían un plazo corto (de dos años) y en su conjunto brindaban una renta de 550 pesos al año. Estos contratos de arrendamientos confirman la impresión general, que ya tratamos más arriba, de una transformación de las condiciones estructurales de la produción en los años de transición de un siglo a otro, en los cuales la retirada de las reservas de ganado cimarrón hacia el norte del territorio y la consecuente expansión de la ganadería de rodeo obligaban a que las estancias tuvieran dimensiones más acordes a la nueva situación. Al mismo tiempo, esas modificaciones traían aparejados un cambio en los agentes que llevaban a cabo esa actividad productiva.

La apropiación de la tierra era un paso fundamental para iniciar la explotación del ganado. Sin embargo, la tierra por si sola no puede producir bienes. Para eso era necesario disponer de una cantidad suficiente de mano de obra lo que, como veremos en el próximo capítulo, constituía una dificultad considerable en la región; ya que si la tierra era un factor que abundaba, en el caso de los trabajadores parecía plantearse una situación completamente diferente.

\footnotetext{
${ }^{135}$ En 1802 detentaba el cargo de Subteniente de Infantería de Buenos Aires
} 


\section{Capítulo 6}

\section{Entre la libertad y la esclavitud \\ La mano de obra: asalariados, esclavos y agregados}

El mayor problema para la producción ganadera de la época fue, sin duda, la escasez de mano de obra. Las grandes extensiones de las praderas rioplatenses tenían una baja densidad demográfica que se acentuaba a medida que se alejaban de las ciudades portuarias. Los trabajadores disponían, además, de varias fuentes de empleo alternativas al trabajo en las estancias. Los peones tenían, de esta manera, un importante poder de negociación para discutir el monto y la forma del pago que recibían por su trabajo. En consecuencia, los salarios constituían el gasto más significativo en el presupuesto de las estancias rioplatenses, que en algunos casos podía representar el 81,4 $\%$ de los egresos del establecimiento (Amaral, 1987: 256). En ese contexto, los estancieros recurrieron a fuentes alternativas de mano de obra. Los que poseían capital pudieron comprar esclavos que constituyeron el núcleo de trabajadores permanentes de la estancia. Por otro lado, muchos propietarios permitieron que un número variable de personas, que se las denominaba como agregados, se asentaran en sus tierras para tener a mano una fuente de mano de obra relativamente estable.

En este capítulo haremos un balance del debate historiográfico en torno a la utilización de los distintos tipos de mano de obra en las campañas de la jurisdicción de Buenos Aires cuyas conclusiones pueden hacerse extensivas a otras áreas de la región. Al mismo tiempo, recurriremos al padrón de 1772-1773 de la jurisdicción de Montevideo y a los de Maldonado de 1781 y 1798 para tener un panorama inicial de la disponibilidad de mano de obra en las áreas que estamos analizando. Además, recurriremos a los libros auxiliares de la alcabala para obtener información sobre operaciones de compra-venta de esclavos que nos brinden indicios sobre el dinamismo del mercado de ese tipo de mano de obra. 


\subsection{Los trabajadores asalariados}

Los trabajadores asalariados rurales en el Río de la Plata del siglo XVIII se caracterizaron, generalmente, por una importante movilidad geográfica y por su inestabilidad en el empleo. Las quejas de los estancieros por la escasez de mano de obra y la imposibilidad de retener a los trabajadores fueron constantes durante todo el período. Los intentos de coaccionar legalmente a los peones para sujetarlos al empleo fracasaron constantemente y la reiteración de los bandos de gobernadores y acuerdos de los cabildos sobre la papeleta de conchabo y demás medidas son más que reveladoras de su ineficacia (Mayo, 2004: 101-103) ${ }^{136}$.

La coacción legal fracasó porque las condiciones estructurales del espacio rural rioplatense hacían imposible su aplicación efectiva. La movilidad geográfica de los trabajadores era muy importante y las alternativas laborales eran variadas. En diferentes momentos del año un trabajador podía emplearse en las vaquerías al norte del río Negro, luego conchabarse temporalmente en una estancia, recoger la cosecha en las chacras cercanas a algún centro poblacional e incluso aprovechar las oportunidades laborales que generaba la presencia de navíos en el complejo portuario rioplatense ${ }^{137}$. Además, disponían de otras opciones. Podían dedicarse a las faenas ilegales valiéndose de los circuitos clandestinos de comercialización de cueros o aprovechar la abundancia relativa de tierras para asentarse e iniciar una pequeña explotación agropecuaria. También existía la posibilidad de ocuparse talando los montes de la región para producir leña y carbón $^{138}$ o vivir de la pesca en el estuario ${ }^{139}$.

Ricardo Salvatore y Jonathan Brown (1987) plantearon que los trabajadores rurales tenían determinados hábitos laborales y que su reticencia a emplearse por períodos largos podría interpretarse como una resistencia al cambio cultural que

${ }^{136}$ En Montevideo el intento de efectuar la coacción legal se dio desde temprano. El 3 de febrero de 1742 el cabildo acordó dictar un bando contra los vagabundos para prender al que no fuera conchabado (RAGA), 1886: 57-58).

${ }^{137}$ Sobre la demanda de trabajadores que generaba el complejo portuario rioplatense ver: Jumar, Biangardi, Bozzo, Orlowski, Sandrín y Querzoli, 2006.

${ }^{138}$ Pierre Gautreau (2006) ha demostrado la importancia de la explotación de los montes en la época que estamos analizando. El autor pudo identificar la existencia de leñadores y carboneros, así como algunas empresas dedicadas a esta actividad que contrataban varios peones.

${ }^{139}$ Hay varios indicios de que la pesca era una actividad significativa en la región. Por ejemplo, a partir de los datos contenidos en las guías de alcabala de Maldonado hemos podido determinar que entre 1782 y 1806 se enviaron a Montevideo 24.534 corbinas (Biangardi, 2013). 
representaba el proceso de proletarización que querían imponer los propietarios. Eso explicaría porque los peones, en la mayor parte de los casos, dejaban el empleo luego de cobrar el primer pago. En consecuencia, existía una gran movilidad de los trabajadores y un cambio constante en el plantel de los trabajadores temporarios de las estancias. En contraste, Jorge Gelman (1989) sostuvo que había una marcada estacionalidad en el empleo debido a que los mismos trabajadores debían ocuparse de levantar la cosecha de trigo. En este sentido, como ya vimos, plantea la importancia de un sector de campesinos que recurren regularmente al mercado de trabajo para complementar la economía familiar.

Carlos Mayo (2004: 115), por su parte, indagó acerca de las razones por las que se conchababan en las estancias esos individuos que podían acceder directamente a los medios necesarios para subsistir. En ese sentido, argumentó que el incentivo residía en acceder a ciertos bienes de consumo (yerba, tabaco, ropa). Para obtener esas mercancías en las pulperías de la zona los habitantes rurales debían obtener dinero trabajando en las estancias, vendiendo sus excedentes (si es que los tenían) o recurriendo a los circuitos clandestinos de cueros. Es decir, que un individuo podía ingresar al mercado de trabajo para satisfacer una necesidad de consumo y luego, una vez satisfecha esa necesidad, retirarse del mercado y mantenerse el resto del tiempo en una economía autosubsistencia.

De todas maneras, no hay acuerdo entre los autores sobre las causas de la inestabilidad del mercado de trabajo en las estancias. En general fluctúan entre destacar la restricción en la demanda, por la estacionalidad de las tareas en la estancia (Amaral, 1987), o en la oferta, por la resistencia de los asalariados (Salvatore y Brown, 1993) (Mayo, 2004) que ya observamos. La impresión que deja esa importante producción historiográfica es que se daba una combinación de todos los factores planteados. Uno de los problemas principales es que la fuente habitualmente utilizada (la contabilidad de las estancias) no permite determinar si los peones abandonaban los establecimientos por su decisión o por la del propietario (Mayo, 2004: 106).

Los argumentos esgrimidos por los historiadores se refieren principalmente al trabajo en las estancias. Sin embargo, entre las vaquerías para hacer corambre y las estancias de rodeos existían grandes diferencias tanto en las características del trabajo como en la forma del salario. En los capítulos anteriores, siguiendo los argumentos de 
María Inés Moraes (2011), remarcamos ya la importancia de las vaquerías para la producción de cueros de la región. El peso de esta actividad económica es un indicio de que las vaquerías de corambre implicaban una alternativa laboral importante para los trabajadores rurales.

En las vaquerías la forma predominante era el salario a destajo. La remuneración dependía de la función de cada trabajador dentro de la expedición. Así, el vaquero recibía una suma mayor que los peones o el barraquero. Entre 1772 y 1775, el vaquero o desjarretador obtenía medio real por animal y el peón desollador dos reales por cueros, pero en su faena, ya descrita en el capítulo 2, cada vaquero podía encargarse de una cantidad de animales muy superior a la de cada desollador (Pérez, 1996: 152). Los peones encargados del sebo o los que cuidaban los caballos podía recibir una remuneración mensual pero eran una minoría dentro de los trabajadores de la vaquería.

En cambio, en las estancias los peones recibían el salario por jornadas, con excepción de los capataces que, por lo general, lo percibían mensualmente. Realizaban tareas variadas, algunas permanentes y otras temporales, como el pastoreo de los animales, la yerra, doma de potros, construcción de corrales y mantenimiento de los edificios, faenas de cueros, esquila de ovejas y el resto de las actividades que diariamente se realizaban en las estancias.

Los peones recibían su salario en dinero y en especie, por lo general textiles, en proporciones variables según el poder de negociación de los peones (Mayo, 2004: 130). Los trabajadores pretendían cobrar la mayor parte posible en moneda, mientras que los propietarios intentaban que aceptaran mercancías. Cuando los estancieros daban textiles $\mathrm{y}$ otros bienes a los peones los valuaban por encima de su precio de mercado consiguiendo así una ganancia extra. Esta operación lograba, de hecho, disminuir el costo laboral del establecimiento que como vimos era, por lejos, el egreso más importante. Por ejemplo, Jorge Gelman (1996: 79-80) ha mostrado que la estancia de las Vacas, situada al norte de Colonia de Sacramento ${ }^{140}$, pagó los salarios correspondientes a los años 1792-1794 en un 59,9\% en productos y el resto en plata. Además, la contabilidad de la estancia demuestra que los administradores estipulaban el valor de esos bienes a un precio superior al del mercado, a veces con una diferencia de $100 \%$. De

\footnotetext{
${ }^{140}$ La estancia de las Vacas era propiedad de la Hermandad de la Caridad de Buenos Aires, tenía unas 40 leguas de superficie y sus límites eran: el Río de la Plata, el arroyo de la Vacas, el río San Juan y los montes de Migueletes (Gelman, 1996: 61-62).
} 
esta manera, esa diferencia entre el precio al que habían comprado esas mercancías y el precio que le asignaban a esos mismos bienes al entregárselos a los peones redundaban en una ganancia para la institución que funcionaba, de hecho, como una reducción del costo salarial. Para los estancieros esto era uno de los mecanismos fundamentales para aumentar su tasa de ganancia, recordemos que los salarios constituían, por lejos, el gasto más importante de las estancias.

En líneas generales, los salarios que recibían los trabajadores empleados en las vaquerías eran mayores que los de los peones conchabados en las estancias. Osvaldo Pérez (1996: 179) indica como otro beneficio adicional que los trabajadores empleados en las expediciones para faenar cueros podían regular el ritmo de producción. Por otro lado, el peón que realizaba su labor en un establecimiento rural tenía un techo para dormir, un simple rancho pero aún así muy superior a los toldos que se organizaban durante las vaquerías, y una mejor alimentación.

La escasez de mano de obra, el alto costo de los asalariados y su inestabilidad en el empleo hacía natural que los productores buscarán fuentes alternativas de mano de obra. Los esclavos de origen africanos eran una opción viable en el mercantilizado Río de la Plata y los estancieros que tenían el capital necesario para adquirirlos no dudaron en hacerlo.

\subsection{La mano de obra esclava}

Los establecimientos productivos rioplatenses del siglo XVIII disponían de mano de obra esclava, al mismo tiempo que recurrían al empleo de trabajadores asalariados. Como no podía ser de otra manera, los historiadores han debatido sobre la utilización que las estancias hacían de cada tipo de mano de obra. La discusión giró, entonces, en torno a la complementariedad o al carácter sustitutivo de los esclavos con respecto a los peones libres y a las razones que llevaban a los propietarios a adquirir mano de obra esclava.

A partir de la contabilidad de la estancia de Clemente López Osorio situada en el pago de Magdalena, Samuel Amaral (1987: 272-274) realizó una comparación entre el costo y la productividad de un peón libre con la de un esclavo. Apoyado en esos 
cálculos, Amaral sostiene que el esclavo resultaba más barato para trabajos permanentes (el $71 \%$ de lo que costaba un peón). Sin embargo, la productividad diaria de los peones era superior a la de los esclavos (2,88 y 2,34 respectivamente). En consecuencia, ambos tipos de mano de obra resultaban complementarios, siendo conveniente para el estanciero disponer de esclavos para las tareas permanentes y contratar peones para los trabajos temporarios.

Carlos Mayo (2004: 136-138) consideraba, en cambio, que esclavos y asalariados constituían tipos de mano de obra sustitutivas y no complementarias. Basaba su argumentación en la opinión de los contemporáneos y en que, según su modo de ver, los estancieros no podrían haber realizado los cálculos que hizo Amaral. Los administradores de estancias que cita el autor indicaban que sus razones para utilizar mano de obra esclava consistían, principalmente, en disminuir los pagos salariales y evitar las indisciplinas, habituales por parte de los asalariados. Los esclavos formaban el núcleo de trabajadores de la estancia tanto para las tareas permanentes como para las estacionales. Los peones asalariados eran contratados para cubrir la demanda sobrante de mano de obra que se producía por las fluctuaciones de la producción.

En nuestra opinión, Carlos Mayo generaliza a partir de la administración de las estancias que eran propiedad de ordenes religiosas. Es probable que sus objetivos y sus prácticas empresariales difirieran de las de los laicos. Una distinción importante es que las ordenes religiosas, en general, disponían de más capital para la compra de esclavos. Por otro lado, el hecho de que los estancieros no pudieran realizar los cálculos hechos por Amaral no invalida la veracidad de esos datos $\mathrm{y}$, además, es probable que la experiencia en la gestión de sus establecimientos les indicara la forma en que obtenían mayores ganancias. Por esta razón nos parece más lógica la idea de la complementariedad entre esclavos y peones libres. Aún cuando en algunas ocasiones los peones se desempeñarán en tareas permanentes o los esclavos en trabajos estacionales.

Los estancieros no cubrían sus necesidades de mano de obra solamente con esclavos por varios motivos. En primer lugar, no siempre disponían del capital para comprarlos. Por otro lado, un plantel muy numeroso de esclavos podía constituir un gasto muy elevado en momentos en que la demanda disminuyera drásticamente, como cuando el comercio ultramarino se veía interrumpido por la guerra. Por último, existía el 
riesgo de perder la inversión por la muerte o la huída del esclavo, o simplemente porque se enfermaba y no podía trabajar (Gelman, 1998: 191).

De todas maneras, para los propietarios de grandes estancias la mano de obra esclava era el mejor recurso para conformar un núcleo permanente de trabajadores. Julio Djenderedjian (2003: 276) considera que si el mercado de compra-venta de esclavos era lo suficientemente dinámico, la mano de obra esclava no era más inelástica que la mano de obra libre. Es decir que de la misma manera que en los momentos de menor demanda era posible despedir a los peones (si no se iban por sus propios medios), se podía disminuir el plantel de esclavos vendiendo algunos de ellos y en cuando repuntaba la necesidad de brazos para producir se compraban nuevos esclavos. Esto podía tener el problema de que el precio de los esclavos disminuyese cuando los estancieros iban a vender los esclavos sobrantes y aumentase cuando intentaran comprar los esclavos que necesitaban cuando repuntaba la demanda de cueros. Pero esa diferencia podía compensarse con el ahorro en los gastos de mantenimiento de una mano de obra que se hubiese estado ociosa.

Como ya vimos, la demanda de cueros fluctuaba y en los momentos en que había una caída abrupta, habitualmente motivada por la interrupción del tráfico marítimo por una guerra, los estancieros podían suspender la matanza de animales y aprovechar para aumentar el stock de de ganado de sus establecimientos (Gelman, 1998: 150). Ante la disminución de sus ingresos y la reducción de la cantidad de mano de obra necesaria es lógico que los estancieros despidieran a gran parte de sus peones para reducir los costos. Sin embargo, un esclavo era al mismo tiempo mano de obra y una mercancía. Vender un esclavo podía ser una forma de conseguir dinero en un momento de crisis de la actividad pero también implicaba descapitalizar parte de la empresa. Tanto adquirir como desprenderse de la mano de obra esclava dependían de la disponibilidad de dinero de los estancieros y del dinamismo del mercado de compra venta de esclavo.

En el Río de la Plata no se propició la reproducción de la mano de obra esclava y, por lo tanto, la oferta dependía totalmente de los vaivenes del arribo de esa mercancía al complejo portuario. Alex Boruki (2011: 85) ha estudiado el comercio esclavista hacia el Río de la Plata entre los años 1777 y 1812. Durante todo el período ingresaron un total de 70.000 esclavos africanos. En base a esos datos el autor considera que el arribo 
de esclavos constituyó el acontecimiento demográfico más importante para la región después de su colonización. En este sentido, podemos pensar que existía una oferta de mano de obra esclava significativa disponible para los estancieros tuvieran el capital necesario. De todas maneras, es importante reparar en varias cuestiones. En primer lugar, el Río de la Plata era la puerta de ingreso a los amplios circuitos comerciales que fluían hacia el interior y, por ende, una gran parte de esos esclavos solamente pasaron por la región. En segundo lugar, el ingreso no fue constante y dependía de factores políticos y comerciales. Boruki (Ídem: 88) distingue tres períodos en el comercio de esclavos. Durante el primero, que sitúa entre 1777 y 1791, solamente hubo arribos importantes en dos años (1782 y 1788). Luego entre 1792 y 1806 existió un incremento constante, seguido luego por una declinación del comercio esclavista. Es decir, que la oferta fue fluctuando. Por último, la mayor parte de los esclavos provenían de Brasil y sus arribos aumentaban en los períodos de guerra entre España e Inglaterra, presentando un comportamiento contrario al comercio con Europa. En consecuencia, en los momentos en los cuales los estancieros deberían desprenderse de parte de sus esclavos se encuentran con un mercado en el que la oferta de esa mercancía era abundante con lo que, a primera vista, no parecería un buen negocio.

De todas maneras, más allá de las cifras de importación de esclavos, la dinámica del mercado interno de esa mercancía tan particular se percibe mejor en el análisis de las operaciones de compra-venta que nos podrían indicar si los esclavos pasaban de mano en mano. Con ese objetivo relevamos la información sobre esas operaciones que existe en los libros auxiliares donde se asentaban los pagos de la alcabala terrestre de Maldonado. Creemos que la cantidad de operaciones de compra-venta de esclavos en el área de Maldonado reflejadas en el cuadros 10 es indicativa del dinamismo de ese mercado y, por lo tanto, parece plausible que existiera esa flexibilidad en el uso de mano de obra esclava. Al menos los propietarios que disponían del capital suficiente podían adquirir y vender esclavos con relativa facilidad. Aunque habría que ver si las fluctuaciones de los precios de los esclavos producto de la abundancia de la mercancía en ciertos momentos, como ya mencionamos, no redituaba en una pérdida de capital para los estancieros que decidieran desprenderse de parte de su plantel de esclavos.

Los libros de alcabala de ventas de la Real Hacienda de Maldonado ofrecen información sobre 1.075 compra-ventas de esclavos en 24 años (cuadro 10). Como era 
de esperarse, estas transacciones presentan un comportamiento contrario a las de tierras, aumentando en los años de importante tráfico ultramarino y disminuyendo cuando llegaban menos embarcaciones al Río de la Plata. Aunque en el comercio de esclavos no era tan importante la cantidad de navíos que llegaban al puerto sino más bien su procedencia. Por otro lado, el área de Maldonado tenía, como ya vimos, una conexión terrestre muy importante con los territorios de Río Grande y, por lo tanto, gran parte de los esclavos tenían esa procedencia. Entre 1782 y 1786, 79 de los 131 esclavos vendidos están registrados como "primera venta, introducido de los dominios de Portugal". Del resto de los esclavos no conocemos su procedencia.

Cuadro 10. Venta de esclavos en el área de Maldonado, 1782-1806

\begin{tabular}{|c|c|}
\hline Año & Cantidad \\
\hline 1782 & 62 \\
\hline 1783 & 9 \\
\hline 1784 & 14 \\
\hline 1785 & 26 \\
\hline 1786 & 20 \\
\hline 1787 & s/d \\
\hline 1788 & 37 \\
\hline 1789 & 24 \\
\hline 1790 & 55 \\
\hline 1791 & 115 \\
\hline 1792 & 51 \\
\hline 1793 & 35 \\
\hline 1794 & 47 \\
\hline 1795 & 36 \\
\hline 1796 & 56 \\
\hline 1797 & 26 \\
\hline 1798 & 39 \\
\hline 1799 & 52 \\
\hline 1800 & 46 \\
\hline 1801 & 55 \\
\hline 1802 & 113 \\
\hline 1803 & 76 \\
\hline 1804 & 33 \\
\hline 1805 & 40 \\
\hline 1806 & 8 \\
\hline Total & 1075 \\
\hline
\end{tabular}

Fuente: Elaboración propia a partir de libros auxiliares de alcabala de ventas AGN Sala XIII Maldonado legajos de 3288 a 3312 
En general, no sabemos el destino que tuvieron esos esclavos. La mayoría pueden haber ido a engrosar la mano de obra rural, pero debemos también considerar la posibilidad de que fueran destinados al trabajo doméstico o a alguna actividad artesanal. Solamente contamos con 5 transacciones que indican que fueron hechas en la estancia del comprador y una que se registró como efectuada "en el campo". Eso no significa que fueran las únicas operaciones realizadas en el ámbito rural sino que se declaraban de esa manera para no mencionar el nombre del vendedor alegando que no lo conocían, lo que podría ser el indicio de algún tipo de contrabando que de esa manera quedaba blanqueado. Sin embargo, aunque desconocemos el destino que tuvieron esos esclavos, la cantidad de transacciones nos inducen a pensar que constituían una alternativa de mano de obra accesible para los dueños de las explotaciones rurales, siempre y cuando tuvieran el caudal necesario para efectuar la compra.

De todas maneras, la posibilidad de disponer de mano de obra esclava y de poder venderlos en épocas de crisis para volver a comprar cuando la demanda de cueros crecía se restringía a un pequeño grupo de grandes estancieros que disponían del capital necesario. Por eso por lo general los productores pecuarios intentaron recurrir a otros tipos de mano de obra.

\subsection{Los agregados}

Otra opción para los propietarios de conseguir una fuente alternativa de mano de obra eran los agregados. Bajo esa categoría se incluían una variedad de situaciones pero básicamente consistía en individuos o grupos familiares a los que el estanciero permitía asentarse en sus tierras a cambio de prestaciones laborales. Carlos Mayo (2004: 73-80) afirmaba que el agregado era un caso de colonato. Los propietarios compensaban a sus trabajadores con el usufructo de una porción de terreno o aceptaban a los ocupantes a cambio de que trabajasen para él. De esta manera, lograban transformar un factor abundante, la tierra, por otro que escaseaba, el trabajo.

La agregación era una relación informal a la que se llegaba por un acuerdo oral y que estaba regida por la costumbre. Esta situación era ciertamente precaria e implicaba riesgos para ambas partes. En ocasiones el estanciero intentaba desalojar de sus tierras a 
los ocupantes. En otros casos, el agregado podía retirarse del lugar luego de recoger su cosecha sin haber prestado ningún servicio al estanciero.

La presencia de agregados, tanto como la de otros ocupantes de hecho en distintas porciones de tierra, nos advierte que no debemos confundir las denuncias, o las propiedades adquiridas por medio de transacciones o mercedes reales, con unidades productivas. Es claro que en cada caso se trata de complejos compuestos por unidades productivas de diversos tamaños.

El carácter oral y la precariedad de la agregación dificultan su estudio ya que las fuentes que dan cuenta de esa relación son escasas limitándose a los pocos padrones elaborados en esos años y algunos juicios que muestran la intención de los propietarios de desalojar a los ocupantes de sus tierras. Es decir, por un lado los padrones nos muestran un fotografía de un momento determinado que solamente nos dice la condición de los habitantes de las estancias y, por el otro, por lo general los juicios nos muestran el final de la relación cuando a los estancieros ya no les conviene mantener a esos agregados dentro de los límites de sus propiedades. En consecuencia, ninguna de las fuentes nos muestra con claridad las características de esa relación.

Como resaltó Carlos Mayo (2004: 76, 113), la agregación aparece como un producto del ciclo de vida de los habitantes de la campaña. Los padrones de las campañas rioplatenses permiten ver que los peones asalariados son, en su mayoría, hombres jóvenes y solteros. En cambio, los agregados y los pequeños productores tiene en promedio más edad y un porcentaje mayor de ellos estaban casados.

El padrón de Aldecoa nos permite vislumbrar esa situación para la jurisdicción de Montevideo en los años 1772-1773 ${ }^{141}$. El gráfico 12 muestra la estructura de las edades de agregados y peones para poder realizar una comparación. Observamos que los peones son en general más jóvenes que los agregados, esto es muy claro en las franjas etarias que representan a los jóvenes solteros entre los 15 y los 24 años. Además, el promedio de edad era de 30 y 34 años respectivamente. Sin embargo, también constatamos que hay peones que nunca lograban acceder a la ocupación de un terreno por una relación de agregación.

\footnotetext{
${ }^{141}$ El padrón fue elaborado por el teniente Aldecoa entre los años 1772 y 1773 . Tiene la ventaja con respecto a otros padrones y censos que fue efectuado por una sola persona lo que hace que en toda la fuente haya un criterio uniforme. Por otro lado, como el objetivo era recopilar información para la organización de milicias prácticamente no incluye información sobre la edad de las mujeres, niños menores de edad y esclavos.
} 
Gráfico 12. Estructura etaria de agregados y peones en la jurisdicción de Montevideo, $1772-1773$

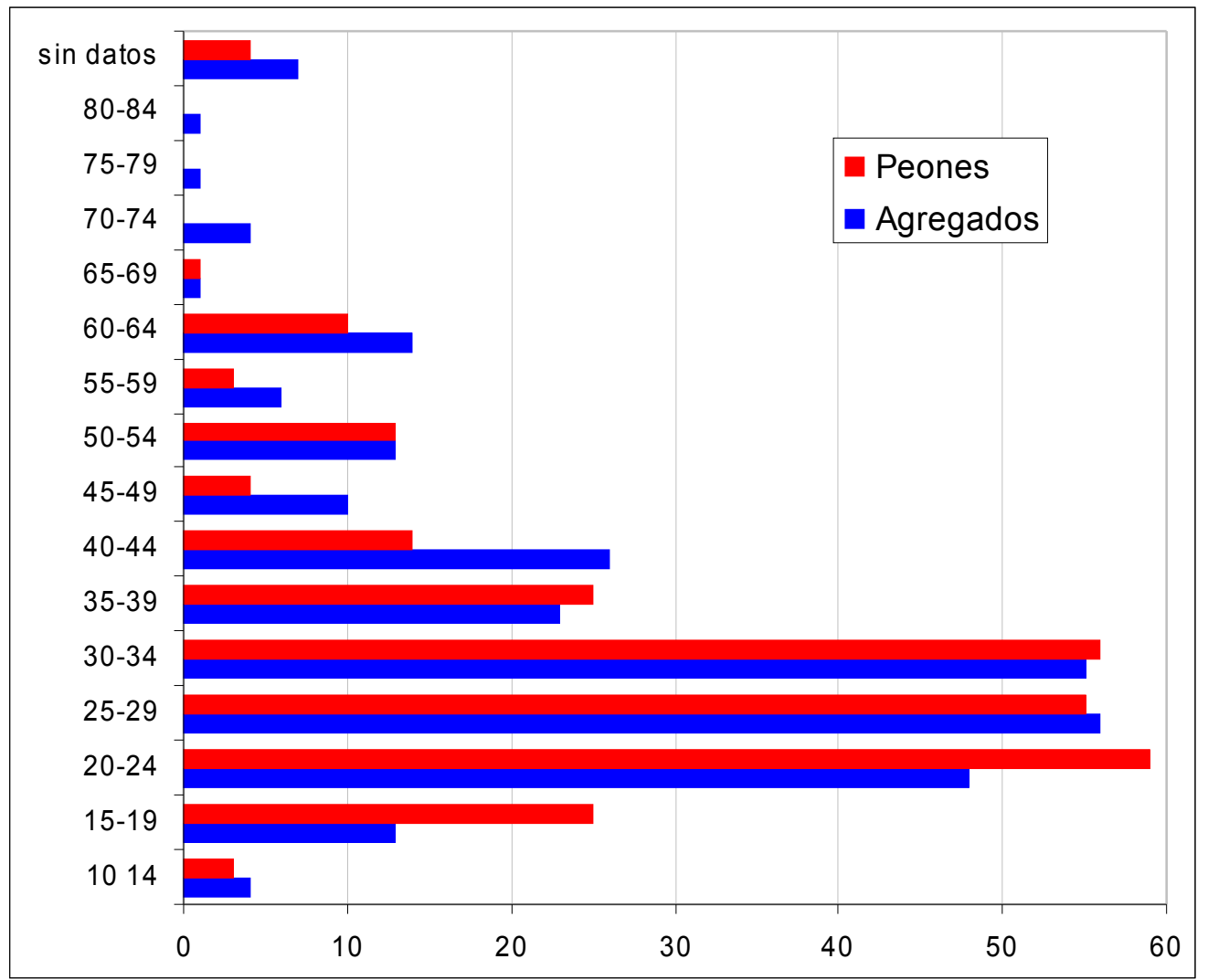

Fuente: Elaboración propia a partir de Apolant (1966: 50-123)

No todos los peones tenían la posibilidad de agregarse por varios motivos. En primer lugar porque dependía de la voluntad de los propietarios que no siempre estaban dispuesto a tolerar que ocupen parte de sus tierras. En segundo lugar, si la agregación estaba vinculada con la formación de familias dependía del mercado matrimonial. La cantidad de mujeres en la campaña determinaba necesariamente que muchos peones permanecerían solteros durante toda su vida. Por último, existía una relación entre el origen étnico de los peones y el acceso que podían tener a formar una familia y agregarse. Los cuadros 11 y 12 indican la cantidad de peones y agregados que había en las chacras y estancias de la jurisdicción de Montevideo en 1772-1773 y la caracterización étnica que les asignó el encargado de confeccionar el padrón. 
Cuadro 11. Agregados y peones en las estancias de la jurisdicción de Montevideo 17721773, cantidad y distinción por grupo étnico

\begin{tabular}{|l|r|r|l|r|}
\cline { 2 - 5 } \multicolumn{1}{c|}{} & \multicolumn{2}{l|}{ Agregados } & \multicolumn{2}{l|}{ Peones } \\
\hline & Cantidad & Porcentaje & Cantidad & Porcentaje \\
\hline Blanco & 150 & $86,70 \%$ & 115 & $58,10 \%$ \\
Mulato & 8 & $4,65 \%$ & 8 & $4,00 \%$ \\
Indio & 13 & $7,50 \%$ & 74 & $37,40 \%$ \\
Mestizo & 2 & $1,15 \%$ & 1 & $0,50 \%$ \\
\hline Total & 173 & $100,00 \%$ & 198 & $100,00 \%$ \\
\hline
\end{tabular}

Fuente: Elaboración propia a partir de Apolant (1966: 50-123)

Cuadro 12. Agregados y peones en las chacras de la jurisdicción de Montevideo 17721773, cantidad y distinción por grupo étnico

\begin{tabular}{|l|r|r|l|r|}
\cline { 2 - 5 } \multicolumn{1}{c|}{} & \multicolumn{2}{l|}{ Agregados } & \multicolumn{2}{l|}{ Peones } \\
\hline & Cantidad & Porcentaje & Cantidad & Porcentaje \\
\hline Blanco & 100 & $90,90 \%$ & 58 & $78,40 \%$ \\
Mulato & 3 & $2,70 \%$ & 4 & $5,40 \%$ \\
Indio & 7 & $6,40 \%$ & 10 & $13,50 \%$ \\
Negro libre & 0 & $0 \%$ & 1 & $1,35 \%$ \\
Mestizo & 0 & $0 \%$ & 1 & $1,35 \%$ \\
\hline Total & 110 & $100,00 \%$ & 74 & $100,00 \%$ \\
\hline
\end{tabular}

Fuente: Elaboración propia a partir de Apolant (1966: 50-123)

En las chacras y, en mayor medida, en las estancias la proporción de individuos caracterizados como blancos era superior entre los agregados que entre los peones. Es probable que esa diferencia se debiera a dos situaciones que serían indicios de una discriminación étnica. Por un lado, los blancos, especialmente los inmigrantes europeos, se encontraban en una posición favorable dentro del mercado matrimonial y, por ende, tenían menos dificultades para casarse y formar una familia. Por otro lado, la agregación era una especie de contrato oral, un acuerdo informal entre el propietario y el agregado. En este sentido, era necesario un cierto grado de confianza entre las partes y podemos conjeturar que muchos de los estancieros se sentían más dispuestos a aceptar que personas, que al igual que ellos, eran identificadas como blancos se asentaran en sus tierras y se resistían cuando pretendían hacerlo mulatos, negros libres o indios. Es 
probable que también haya influido en esto el paisanaje. Es decir, que el mismo origen (vasco, catalán, gallego, etc.) brindarse una mayor confianza derivada de compartir unas mismas pautas culturales y eso ayudase al establecer una relación de agregación.

Por último, podemos ver que en las estancias había casi tantos agregados como peones (173 y 194 respectivamente). En consecuencia, es posible afirmar que en la campaña montevideana, al menos en 1772-1773, la agregación era una situación ampliamente extendida que permitía duplicar la cantidad de mano de obra libre disponible para los estancieros del área.

En síntesis, existían diferentes tipos de mano obra involucradas en la producción de los cueros y otros derivados vacunos. Es difícil determinar si la cantidad de trabajadores disponibles era suficiente. Sin embargo, las quejas de los propietarios al respecto al parecer estaban más vinculadas con la imposibilidad de controlar y disciplinar a la mano de obra libre y a los altos costos de los salarios que a una escasez real de trabajadores.

Por otro lado, la movilidad de la mano de obra que entraba y salía del mercado de trabajo y las relaciones informales con los agregados, más algunas partidas de changadores que circulaban por la campaña implicaban que los estancieros tuviesen también dificultades para mantener el control sobre su ganado y que los corambreros no pudiesen restringir el acceso al ganado cimarrón, que pretendían apropiarse, por parte de otros competidores. El capítulo siguiente trata sobre los distintos intentos de efectuar ese control y de restringir, de esa manera, el acceso al ganado vacuno para privilegiar a un grupo de agentes económicos. 


\section{Capítulo 7}

\section{Conflictos por la propiedad del ganado}

Las condiciones en las que se efectuaban la producción de cueros y la ganadería de rodeo en el siglo XVIII generaban dificultades para implantar de manera efectiva la propiedad privada del ganado. La ausencia de alambrados, la inexactitud de los límites de las propiedades y el desplazamiento del ganado, especialmente acentuado en momentos de sequías, producían conflictos entre estancieros. Al mismo tiempo, las partidas de cuatreros abundaban por toda la campaña y los bienes que producían encontraban una buena recepción en los pulperos rurales. Por otra parte, la explotación del ganado orejano tornaba casi imposible distinguir entre las faenas de cueros legales y las clandestinas.

En ese contexto se realizaron acciones colectivas por parte de los productores para asegurarse la propiedad del ganado y reprimir las faenas clandestinas. A través del cabildo de Montevideo los agentes vinculados a la producción de cueros enfrentaron judicialmente a la administración de los pueblos misioneros por la propiedad de las reservas de ganado cimarrón que poblaban las tierras adyacentes a los ríos Yi y Negro. Los cabildantes buscaron, además, controlar las faenas registrando el ingreso de cueros y efectuando embargos en los casos que lo creyeron necesario.

Los corambreros y los estancieros también recurrieron a la instancia judicial, de manera individual o grupal, para combatir el cuatrerismo y el abigeato denunciando a pulperos y peones de explotaciones cercanas. El reconocimiento mutuo de sus marcas en los cueros incautados era fundamental en estos casos y muestra el interés común en hacer respetar la propiedad del ganado.

Por último, el estado virreinal mostró también cierto interés por controlar las faenas de cueros y efectuó una actividad represiva para lograrlo. La mayor parte de esa actividad resultó ser espasmódica concentrándose en breves períodos de tiempo. Esto fue un indicio de los cambios políticos que imprimían los virreyes que se iban 
sucediendo y se debía, también, a la distinta intensidad de las faenas en los momentos de auge del tráfico marítimo y su consecuente disminución cuando éste se interrumpía.

\subsection{Litigios por la propiedad de reservas de ganado cimarrón}

Luego de la fundación de Montevideo sus habitantes debieron enfrentar distintos conflictos para asegurarse la explotación del ganado que se hallaba en las tierras comprendidas en la jurisdicción que se les había asignado. Durante las primeras cuatro décadas de existencia del nuevo poblado sus habitantes debieron enfrentar la competencia de portugueses, indios y de españoles residentes en Buenos Aires que incursionaban en su territorio para hacer recogidas de ganado o faenas de corambre. Como veremos en detalle más adelante, Montevideo fue consolidando su territorio de manera paulatina a partir del debilitamiento de sus competidores y, al mismo tiempo, de su constante crecimiento demográfico. A medida que fueron consolidando ese territorio inicial los habitantes de Montevideo comenzaron a ocupar tierras situadas fuera de los límites de su jurisdicción, extendiéndose hacia el norte, en lo que había sido parte del espacio pastoril misionero y a explotar las reservas de ganado que allí existían.

Esa situación llevo a un inevitable conflicto con los administradores de los pueblos misioneros. Los autodenominados hacendados montevideanos entablaron, entonces, un pleito con los administradores de los pueblos misioneros por la propiedad del ganado existente en la rinconada formada entre los ríos Yi y Negro. Luego de la expulsión de los jesuitas la administración de las misiones pasó a manos laicas. En ese contexto, las autoridades de Yapeyú y la administración general de las misiones llevaron a cabo contratos con particulares para la producción de cueros y para ejercer la vigilancia dentro del espacio misionero. Sabemos que entre 1773 y 1775 las faenas y el control de ese espacio geográfico estuvo a cargo de Cristóbal Castro Callorda. En 1779 se realizó un contrato con Domingo Igarzábal que, entre otras cláusulas, estipulaba que debía llegar a un acuerdo con los hacendados montevideanos para resolver las posibles disputas sobre la propiedad del ganado. Igarzábal trabajó en conjunto con Lorenzo Figueredo que había sido contratado por las autoridades de Yapeyú para controlar la zona entre los ríos Yi y Negro. En 1781 Antonio Pereira reemplazó a Figueredo en la 
función de patrullar el área. Entre las funciones de Pereira también se encontraban las de hacer faenas de cueros (Moraes, 2011: 253-254).

Como era de esperarse, los conflictos con los hacendados montevideanos no tardaron en llegar. El detonante fue el intento que Lazcano, administrador general de los pueblos misioneros, efectuó en 1781 de establecer un veedor que controlara los cueros que ingresaban por el portón de la ciudad para detectar los que pertenecían a las misiones. En esta instancia, el Cabildo de Montevideo contestó desconociendo que los ganados situados al norte del río Yi pertenecieran a los misioneros, realizó juntas de hacendados y designó apoderados para que llevaran adelante el pleito ante las autoridades (Sala de Tourón, de la Torre y Rodríguez, 1968: 57). Los argumentos de los cabildantes eran los usuales en todos los juicios sobre derechos sobre ganado cimarrón o alzado. Generalmente se recurría a enunciar cuál había sido el origen de los animales y, al mismo tiempo, se brindaban datos que indicaban la manera en la que el ganado podría haber migrado. En consecuencia, según el cabildo, el ganado vacuno provenía de las estancias de los vecinos de Montevideo ya que no podría haber cruzado los ríos desde el norte ${ }^{142}$. Sin embargo, el reclamo no tuvo eco ya que tanto el virrey Vértiz como el superintendente Sanz estaban de acuerdo con el argumento de la administración de los pueblos misioneros.

La situación cambió de manera brusca con la llegada del virrey Loreto en 1784. Éste sostuvo una política firme contra las faenas clandestinas, intentó combatir el contrabando y, especialmente, se mostró contrario a los intereses de los administradores misioneros y sus socios. El nuevo virrey suspendió las vaquerías de los pueblos misioneros, prohibió cualquier faena de ganado cimarrón, ordenó el embargo de toda la corambre que había sido realizada por Igarzábal y Pereira y, simultáneamente, destituyó a Antonio Pereira de su cargo de comandante, designando en su lugar a Félix de la Rosa (Moraes: 254 y 273). Además, Loreto entabló una disputa con el superintendente Francisco de Paula Sanz que duró hasta 1788, cuando la superintendencia dejó de existir y el virrey absorbió las funciones que correspondían al cargo desaparecido.

Al debilitar a sus principales competidores en la explotación de las reservas de ganado cimarrón, el virrey Loreto favoreció de hecho a los hacendados montevideanos (Sala de Tourón, de la Torre y Rodríguez, 1968: 58; Moraes, 2011: 276). Ante la nueva

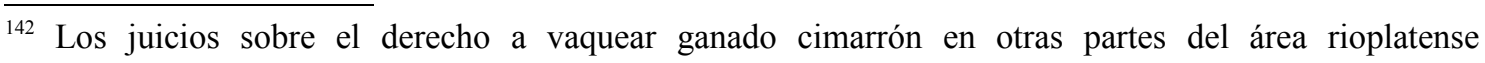
comenzaron en el siglo XVII. Ver: Barriera, 2010. 
situación, el Cabildo de Montevideo reanudó el pleito por la propiedad del ganado. El 28 de junio se realizó un cabildo abierto donde los "vecinos hacendados" se obligaban a pagar los gastos y nombraban a ocho de los hacendados para que señalaran apoderados en la ciudad y en Buenos Aires y para que "se junten para tratar y deliberar lo que mas conviniese a los vecinos hacendados"143. Lo que podemos considerar como una junta de hacendados realizada en el contexto del cabildo, recurriendo a la figura de un cabildo abierto. Esa reunión constituyó un antecedente a la que en 1791 dejó constituido el Gremio de Hacendados (Sala de Tourón, de la Torre y Rodríguez, 1968: 126) ${ }^{144}$.

En los años siguientes no hubo litigios colectivos, seguramente se suspendieron por la tramitación del expediente conocido como "arreglo de los campos", tal como sucedió con las denuncias de tierras. A pesar de esto los hacendados montevideanos retomaron su actividad corporativa con mayor intensidad luego que finalizó el gobierno del marqués de Loreto. En 1791 realizaron una junta de hacendados que nombró apoderados para que los representaran en todos los asuntos que eran de su interés. Por otro lado, reafirmaron sus intenciones de controlar la circulación de productos pecuarios. Ese mismo año varios hacendados presentaron una querella contra el pulpero Antonio Rodríguez del pago del Pintado por abigeato ${ }^{145}$. En la querella, además de denunciar el delito cometido, reclamaban que se reconocieran los cueros en el portón de la ciudad como medio para evitar las faenas clandestinas. El año anterior Juan Francisco García de Zúñiga, electo regidor alférez real del cabildo de Montevideo, pretendió reflotar una petición que los hacendados habían realizado en $1786^{146}$. Pero no tuvo éxito porque se encontró con la oposición del alcalde de primer voto que lo recusó declarando que:

\footnotetext{
${ }^{143}$ Las ocho personas designadas fueron: Tomás de Estrada, Juan Antonio Haedo, Domingo Bauza, José Más de Ayala, Juan Balbín Vallejo, Juan Romero, Francisco Sierra y (nuevamente) Miguel Ignacio de la Quadra. Según las firmas que constan en el acuerdo, ratificaron el acuerdo 78 vecinos, además de los 7 regidores de ese año (AECM, 1942: 74-81).

${ }^{144}$ Analizando el caso de Buenos Aires, Fernando Jumar y Javier Kraselsky (2007: 10) consideran que las nuevas corporaciones surgieron porque el cabildo no podía asumir la representación de todos los intereses locales.

${ }^{145}$ Querella contra Antonio Rodriguez alias el Maturrango por Miguel de la Quadra, Melchor de Viana, Manuel Duran y Juan José Seco por aceptar cueros robados en su pulpería. AGN Uruguay, Archivo Judicial, Montevideo Civil 1 Caja 97 Año 1791.

${ }^{146}$ Esa petición coincide con la ausencia de relaciones de ingresos de cueros, sebo y grasa durante cuatro meses de ese año, lo que reafirma nuestra presunción de que se debía a la presión que ejercían los vecinos en contra de ese control por parte del aparato burocrática virreinal.
} 
"En este Cavildo y sobre su mesa se halla un espediente firmado a instancia de algunos Vecinos de esta ciudad, en que esta firmado como parte el Señor Regidor Alferez Real., por el cual solicitaron por maio de 86 que por este Cavildo se dispusiese que los vecinos criadores alternatibamte. tubiesen autoridad para registrar é intervenir en todas las instrucciones de cueros sebo grasa \&.a cuia instancia, que aun está pendiente, hicieron por medio del Sindico Procurador general, en que nadie tiene mas interes que dicho Señor Regidor por sea el vecino que tiene mas ganados, como es publico y notorio; y aqui está de manifiesto el interes que muebe a decir denulidad de la contestacion al oficio que puntualmente trataba delo mismo que ya el citado Sor. Regidor tiene pretendido como parte, en cuia parte pretendia ser tambien Juez solicitando contestar por si aun oficio en que. se trata de su propio y particular interes" (AECM, 1942: 357)

A pesar de haber sido infructuoso, el intento muestra, sin embargo, que existía una continuidad y coherencia en el accionar de los hacendados. La junta de hacendados de 1791 que nombró como apoderados a Juan Francisco García de Zúñiga, José Cardoso y Manuel Pérez, va a confirmar ese camino. Directa o indirectamente la política del virrey Loreto con respecto a la explotación del ganado y el control de la circulación fue propicia para que los hacendados montevideanos se consoliden como grupo social.

7.2. Embargos de cueros del estado virreinal

El gobierno del virrey Loreto con su política respecto a las faenas misioneras dio inicio a una nueva etapa en cuanto a los decomisos de cueros en la "Banda Oriental". Esos años vivieron una actividada de las fuerzas represivas del aparato burocrático virreinal en los campos del norte de la región que implicó un aumento exponencial en la cantidad de cueros embargados, en los changadores apresados en la campaña por realizar faenas clandestinas y en la amplitud del espacio que quedaba bajo vigilancia.

Desde junio de 1784, cuando había entrado en funciones el nuevo comandante de campaña Féliz de la Rosa, hasta marzo del año siguiente fueron decomisados 66.117 cueros. De los cuales: 45.800 correspondían a las vaquerías misioneras ${ }^{147}, 15.989$ a distintos decomisos realizados por Félix de la Rosa, 595 habían sido embargados por el comandante del fuerte de Santa Tecla, 3.578 por las partidas de resguardo y 155 por el coronel Reseguín en los pagos de Santa Lucía y Pintado ${ }^{148}$.

${ }^{147} 26.394$ faenados por Antonio Pereira y 19.406 por Domingo Igarzábal.
${ }^{148}$ AGN Argentina, Sala IX 2-4-4. 
En cuanto a los presos, otra relación enviada al virrey el 12 de junio del mismo año muestra que mientras Antonio Pereira había remitido a Montevideo solamente 17 presos durante los años en los que estuvo a cargo de la vigilancia de la campaña, luego de su destitución fueron apresadas 93 personas $^{149}$. Es interesante destacar que en la mayor parte de los casos se trata de hombres solteros, muchos de ellos son identificados como changadores y que algunos eran indios o mulatos ${ }^{150}$. Antonio Pereira, que formaba parte de los apresados, logró fugarse en una embarcación rumbo a España para volver años más tarde libre de culpa y cargo, perdón real mediante, para transformarse en un gran hacendado, que incluso llegó a ser uno de los apoderados del gremio ${ }^{151}$.

Los decomisos de cueros a particulares realizados por Félix de la Rosa continuaron durante todo 1785. De junio a diciembre de ese año efectuó otros 10 embargos, la mayor parte en campos situados al norte del Río Negro, remitiendo a Montevideo un total de 5.547 cueros $^{152}$. Cuando llegaban a la ciudad los cueros enviados por el comandante de campaña eran rematados en subasta pública. De noviembre de 1784 a diciembre del año siguiente tuvieron lugar ocho remates en los cuales el precio de los cueros osciló entre los 15 reales y los 19 reales y medio la pesada de 41 libras de los cueros que se encontraban en buen estado ${ }^{153}$. En el cuadro 13 se dan los detalles de esos remates junto a los tres que había llevado a cabo el cabildo durante los primeros meses de 1784, que veremos más adelante.

En los años siguientes la intensidad del control sobre la circulación de cueros volvió a disminuir de manera considerable. María Inés Moraes (2011: 266) indica que entre los años 1786 y 1804 solamente se efectuaron 29 decomisos de cueros. Es interesante destacar que 24 de esos embargos tuvieron lugar en los años 1794, $1795 \mathrm{y}$ $1796^{154}$. Lo que revela el carácter espasmódico que tenían las políticas represivas contra el contrabando y las faenas clandestinas de cueros. Una comparación entre esos años y los de 1784-1785, que estamos estudiando en esta ocasión, podría ser revelador de los

\footnotetext{
14954 fueron apresados por Félix de la Rosa, 15 por su segundo el Teniente de Infantería Francisco Lucero y 24 por las partidas de resguardo.

${ }^{150}$ AGN Argentina, Sala IX 2-4-5.

${ }^{151}$ De hecho, fue uno de los apoderados nombrados por la Junta de Hacendados de 1802 (Sala de Tourón, de la Torre y Rodríguez, 1767: 128).

152 Según la relación que presentó Luis Antonio Gutiérrez, depositario de los cueros, el 8 de junio de 1786. AGN Argentina, Sala IX 2-5-1.

${ }^{153}$ AGN Argentina, Sala IX 2-5-2.

15413 en 1794,4 en 1795 y 7 en 1796.
} 
motivos por los que tenían lugar esas políticas y de las razones por las que estas no podían perdurar en el tiempo.

Cuadro 13. Remates de cueros en Montevideo 1784-1785

\begin{tabular}{|c|c|c|c|c|}
\hline Fecha & $\begin{array}{c}\text { Cantidad } \\
\text { de } \\
\text { cueros }\end{array}$ & Comprador & $\begin{array}{l}\text { Precio en reales } \\
\text { (en buen estado)* }\end{array}$ & $\begin{array}{l}\text { Precio en reales } \\
\text { (apolillados) }^{*}\end{array}$ \\
\hline $24 / 2 / 1784$ & 152 & Francisco Antonio Maciel & 15,5 & \\
\hline $27 / 3 / 1784$ & 129 & Francisco Rodríguez & 15,5 & \\
\hline $31 / 3 / 1784$ & 74 & Francisco Rodríguez & 15,5 & \\
\hline $9 / 11 / 1784$ & 2487 & Manuel Diago & 18,5 & 11 \\
\hline $13 / 11 / 1784$ & 3386 & Manuel Diago & 19 & 12 \\
\hline $15 / 12 / 1784$ & 3224 & Sebastián Roso & 19,5 & 12,5 \\
\hline $5 / 2 / 1785$ & 780 & Bernardo Suárez & 18,75 & 12 \\
\hline 9/4/1785 & 1046 & Manuel Diago & 16,75 & 11,5 \\
\hline 2/10/1785 & 1015 & Manuel Diago & 15 & 8 \\
\hline 12/11/1785 & 1452 & Sebastián Roso & 15 & 8,5 \\
\hline 24/12/1785 & 1537 & Manuel Diago & 15,5 & 11,75 \\
\hline
\end{tabular}

*Precio por pesada de 41 libras

Fuente: Elaboración propia a partir de AGN Uruguay, Archivo Judicial, Montevideo Civil 1 Caja 64 Año 1784 y AGN Argentina, Sala IX 2-5-2

Sin embargo, a pesar de haber sido breve, la actividad represiva desplegada durante los primeros meses del gobierno del virrey Loreto tuvo importantes consecuencias. En primer lugar, la suspensión de las faenas misioneras y la represión de las partidas clandestinas de changadores tuvo como consecuencia una importante disminución en el total de los cueros exportados por la región Río de la Plata dentro del sistema legal español, que se mantuvo hasta 1790 y en particular desde Montevideo(ver gráfico 3). Es decir, durante todo el mandato del marqués de Loreto como virrey (17841790). Ese descenso solamente es comparable a los que tuvieron lugar durante las guerras con Inglaterra (1779-1783 y 1796-1801), únicos años en los que la exportación fue menor al medio millón de cueros.

Moraes (2011: 260) considera que otra consecuencia de la política de Loreto consistió en "un crecimiento imparable de ese mercado invisible que era el entablado con los portugueses". Afirma que, según los informes del lado español, hasta la década de 1780 y la crisis del sistema misionero los campos situados al norte de río Negro 
mostraban "cierto orden". Aunque la historiografía brasileña muestra que ese mercado existía $^{155}$, al no estar registrado en nuestras fuentes es difícil medir su magnitud. Además, dadas las distancias existentes, y sus correspondientes costos de transportes, es más probable que se tratase de extracciones de ganado en pie que de cueros faenados en la región. En este sentido, dado que se extraía ganado cimarrón en una frontera en disputa entre dos imperios solamente puede ser considerado como contrabando desde el punto de vista de los funcionarios borbónicos o del de los intereses de los agentes económicos asentados en el Río de la Plata.

La política represiva de Loreto tuvo, además, otra consecuencia. Ayudó a que los hacendados montevideanos se consoliden como grupo social ya que debilitó a sus competidores en el acceso a los recursos. Sin los faenadores misioneros ni los changadores particulares los agentes económicos asentados en Montevideo tuvieron libre disponibilidad de las reservas de ganado cimarrón. Al haber realizado sus denuncias de tierras realengas antes de la suspensión eran los únicos que podían eludir las restricciones a la explotación de esos animales al denunciarlos como alzados de sus estancias. De esta manera, en los años siguientes los hacendados montevideanos efectuaron un proceso de avance sobre tierras y ganados que antes formaban parte del espacio misionero (Moraes, 2011: 271).

7.3. Acciones de los estancieros y corambreros por el control de las faenas y para reprimir el abigeato

Salvando las breves coyunturas en las que la estructura burocrática virreinal se ocupaba de patrullar la campaña para evitar las faenas de ganado clandestinas, la mayor parte del tiempo eran los propios estancieros y corambreros los que se ocupaban de controlarlas, lo que podían efectuar de distintas maneras. En primer lugar, utilizando el poder jurisdiccional del cabildo para, por ejemplo, realizar embargos y tomar medidas para asegurar que el stock de animales existentes en el territorio no disminuyera. En segundo lugar, cada uno de los estancieros y corambreros vigilaba su propio ganado, o el que consideraba como propio, evitando su extracción por parte de algún otro

\footnotetext{
${ }^{155}$ Ver: Gil, 2002.
} 
interesado de apropiarse de ese bien y en el caso de no poder impedirlo recurrían a la acción judicial para conseguir su devolución o, al menos, un resarcimiento. En tercer lugar, la instancia judicial también podía ser utilizada para reprimir conductas de los pobladores de la campaña que desde el punto de vista de los hacendados sobrepasaban el límite de lo tolerable, ya sea en cuanto a la actividad de faeneros clandestinos o de individuos que recurrían al abigeato para sobrevivir.

Veremos algunos ejemplos de cada una de estas maneras de controlar las faenas. Además de brindar una idea de cómo algunos agentes económicos buscaban asegurarse la apropiación del ganado, esos expedientes también revelan la trama de relaciones sociales que se daba en las poco pobladas campañas rioplatenses durante esos años.

7.3.1. Por el control de las faenas: embargos de cueros realizados por el cabildo de Montevideo en 1784

Con respecto a la primera forma que identificamos, es habitual observar que en los acuerdos de los cabildos rioplatenses se tomaban medidas contra las faenas de vacas para evitar la disminución del stock de ganado de la jurisdicción pero estás medidas, generalmente, no se traducían en acciones concretas. Sin embargo, el cabildo de Montevideo, por acuerdo del 29 de enero de 1784, determinó efectuar el reconocimiento de los cueros que eran trasladados en carros para hacer cumplir las prohibiciones de matar vacas (AECM, 1942: 64). Como consecuencia de esta decisión los regidores efectuaron algunos decomisos de cueros en los meses siguientes. Ese control realizado por los cabildantes se efectuaba en el nivel de la circulación y en teoría se restringía al territorio comprendido dentro de los límites de la jurisdicción del Cabildo, aunque en la práctica solía trascenderlo.

En el acuerdo del 29 de enero los cabildantes de Montevideo acordaron realizar el reconocimiento de los cueros que se introdujeran en la ciudad debido a que tenían noticias de las continuas matanzas de vacas que se realizaban a pesar de las repetidas prohibiciones dictaminadas por el ayuntamiento. Los cueros decomisados serían rematados y lo recaudado se repartiría en tres partes: una para la Real Cámara, otra para 
el aprehensor y la última para la reparación del Cabildo y el aumento de sus propios (AECM, 1942: 62).

El 9 de febrero el fiel ejecutor del Cabildo, Luis Antonio Gutiérrez, realizó el decomiso de 287 cueros de toro y novillo y 273 de vaca que eran transportados en 7 carretas del rey que provenían de San José ${ }^{156}$. Para el reconocimiento de los cueros recurrió a Miguel Ignacio de la Quadra y al comisionado del Pago de Chamiso, José Fernández, quienes determinaron que los cueros no eran de matadero ni de estancia sino que habían sido faenados por tropa de desolladores en la misma campaña. Además 85 de esos cueros (47 de vaca y 38 de toro y novillo) tenían marcas, muchas de ellas conocidas por los observadores.

El mismo día del embargo se presentó José de Alagón, vecino de Colonia de Sacramento afirmando que había comprado los cueros a hacendados establecidos de su ciudad y que en esa jurisdicción no existía ninguna orden que impidiera la matanza de vacas para el consumo de sus propios dueños. Luego con el objetivo de obtener algún lucro se había trasladado a Montevideo con la correspondiente licencia que presentaba. En otro escrito reafirmaba que los cueros los había conducido desde Colonia en las carretas de Juan Peralta, y no del rey, que allí no había prohibición y que los había comprado a los vecinos de aquel distrito como quedaba acreditado por la certificación competente. Además sostenía:

"Que los cueros sean echos de faenas y no en matadero ni estancia como dicen (...), no es razon que perjudique el legitimo derecho que yo tengo de ello, por la adquisicion lisita, que tuve con la compra, y cuia acredite con documentos competentes para obtener la licencia de transportarlos (...)

...los ganados se transmigran de unos campos a otros, y este motivo contribuie tanto para que en mas remotas distancias se allen ganados de esta jurisdiccion quanto para que en las estancias de ella se marquen ganados de otra, que despues vuelvan a su querencia."

Con lo cual ponía en duda la legitimidad de la propiedad indicada por las marcas y veladamente denunciaba que los estancieros marcaban todos los ganados que se hallaban en sus establecimientos incluyendo los que no les pertenecían. Ante la persistencia del embargo, José de Alagón pidió una certificación del decomiso para

${ }^{156}$ Expediente formado sobre ciento cincuenta y dos cueros embargados a Dn Josef Alagon por el Rexidor Fiel Ejecutor Dn Luis Antonio Gutierrez. AGN Uruguay, Archivo Judicial, Montevideo Civil 1 Caja 64 Año 1784. 
poder reclamar a los individuos que se los habían vendido. Finalmente, se remataron 152 cueros de vaca como "faenados a contravención", pesaban en total 3.900 libras y fueron comprados por Francisco Antonio Maciel a 15 reales y medio por pesada (de 41 libras). Los que estaban marcados fueron presuntamente devueltos a sus dueños.

En este punto es necesario remarcar que las personas involucradas en el decomiso no eran jueces imparciales. Miguel Ignacio de la Quadra y Luis Antonio Gutiérrez eran parte de los agentes vinculados a la explotación del ganado cimarrón que residían en Montevideo. Ambos habían hecho denuncias de tierras de gran extensión más allá de los límites de la jurisdicción de la ciudad en los territorios antes pertenecientes al espacio misionero, como puede verse en el mapa 8. Como a varios de los autodenominados hacendados montevideanos, esas denuncias les permitían establecer lo que Osvaldo Pérez denominó estancia de alzados (Pérez, 1996: 166). Como ya mencionamos en el capítulo 2, esas estancias eran grandes extensiones lindantes o cercanas a tierras realengas que contaban con unos pocos animales mansos pero que, sobre todo, se dedicaban a explotar las reservas de ganado cercanas a la propiedad. Las denuncias de tierras y el registro de marcas permitía a los hacendados "legalizar" la explotación del ganado cimarrón recurriendo al argumento de que consistía en ganado de su propiedad que se había alzado. En consecuencia, los hacendados montevideanos se preocuparon por establecer controles sobre la circulación ya que tendía a asegurarles una cierta preeminencia en la explotación del ganado cimarrón en perjuicio de los posibles changadores (Sala de Tourón, de la Torre y Rodríguez, 1967: 11).

Los días 20 y 28 de febrero el fiel ejecutor realizó dos nuevos decomisos. En el primero embargó 38 cueros que contenían marcas de diferentes vecinos cuando estaban por ingresar por el portón conducidos por el carretillero Juan Ruiz. El supuesto dueño, Pedro Maciel Paraguay, se ausentó cuando vio que se efectuó la aprehensión y nadie se presentó reclamando los cueros. En el segundo se incautaron 91 cueros de vaca en la pulpería que Diego García tenía en su casa de El Cordón. Los 129 cueros se remataron juntos el 20 de marzo a favor de Francisco Rodríguez que pagó 140 pesos y 7 y medio reales por las 3027 libras que pesaron los cueros a 15 y medio reales por pesada de 41 $\operatorname{libras}^{157}$.

${ }^{157}$ Expediente formado sobre ciento veinte y nueve cueros embargados por el Rexidor Fiel Ejecutor Dn Luis Antonio Gutierrez. AGN Uruguay, Archivo Judicial, Montevideo Civil 1 Caja 64 Año 1784. 
Mientras tanto el 15 de marzo el juez comisionado del partido de Las Piedras, José Fernández de Cáceres, decomisó cuatro carros, uno de los cuales transportaba solamente cueros de vaca ${ }^{158}$. El comisionado ignoraba quién era el dueño debido a que los peones no conocían su nombre y

“...conociendo por su vaja esfera por ser Indios desde luego lo ignorarian, no hizo mas pesquisa sobre este particular entendiendo que el Dueño de dichos cueros se le presentaría lo que no se verificó...”

La declaración de dos de los peones es indicativa de por qué no sabían su nombre y nos da una idea de cómo podían conchabarse para un trabajo. José Molina contaba que:

"...en el Arroyo de la Virgen estaban los carros (...) parados por falta de un peon y presentandole un hombre que le salió al encuentro que si queria conchavarse (...) y dadole seis pesos vino picando el carro pero que ni conoce quien le conchavó ni menos sabe de donde venian dichos carros..."

Rodríguez, otro de los peones, declaró que:

“...vio en las inmediaciones de la Capilla de Pintado unos carros cargados de cueros en rodeo y llegandose a ellos (...) preguntó a los que estaban sentado inmediatos al fuego que si faltaba algun peon para ayudar a picar aquellos carros a lo que le contestó uno de ellos el mas bien portado y quien a su parece serian los cueros quieres conchabarte [subrayado en el original] (...) el dueño de los carros y los cueros no lo conoce”

Un mes más tarde, Francisco de los Ángeles Muñoz, alcalde de segundo voto, declaró que el comandante de los campos de los ríos Yí y Negro (nuestro ya conocido Antonio Pereira) le pidió que le entregue los cueros, carros y peones para proceder contra ellos porque esos cueros habían sido faenados "en los campos de su pertenencia" 159 . Es decir, el comandante reclamaba su derecho a juzgar sobre las faenas realizadas en el territorio a su cargo. Ante el pedido, el alcalde mandó que se devuelvan los cueros "Para obviar disputas, y disenciones como es publico las hemos tenido", con

\footnotetext{
${ }^{158}$ Expediente formado sobre setenta y dos cueros que ha decomisado Josef Fernandez de Caceres Juez Comisionado de Las Piedras. AGN Uruguay, Archivo Judicial, Montevideo Civil 1 Caja 64 Año 1784.

${ }^{159}$ Hay que tener en cuenta que este episodio tuvo lugar con anterioridad a que el virrey Loreto suspendiera las faenas misioneras.
} 
excepción de los 74 de vaca que se remataron de la manera habitual ${ }^{160}$. Este hecho es ilustrativo de cómo los cabildantes de Montevideo al trascender los límites de su jurisdicción chocaban con el accionar de otras autoridades.

\subsubsection{Conflictos entre vecinos por extracción de ganados}

Estancieros y corambreros también recurrían al recurso judicial, cuya primera instancia era el cabildo, para evitar las extracciones de ganado de las tierras que habían adquirido. En general, se trataba de situaciones de conflictos entre vecinos que se acusaban de no respetar los límites de sus propiedades o de sustracciones de ganado de la estancia contigua. Sin embargo, también existieron ocasiones en que el propietario recurría al alcalde de primer voto para que se le reconociese la propiedad de un terreno para poder desalojar a las partidas que se hallaban faenando en esas tierras.

Tanto estos tipos de juicios como los que buscaban combatir el abigeato existen en escasa cantidad para la época. No se daban con frecuencia porque lo más común era que los conflictos se resolviesen de manera verbal con o sin presencia del juez comisionado en el lugar. En los expedientes que pudimos revisar hay indicios de resoluciones de conflictos anteriores que no llegaron a la instancia judicial formal ${ }^{161}$. También es probable que existiera cierta tolerancia con algunas de estas prácticas que se daban en la campaña y que solamente llegaban a juicio algunos casos que por sus características sobrepasaban esos límites.

Un caso paradigmático de los conflictos que se solían dar entre vecinos se encuentra representado en la demanda impuesta por Francisco Sequeira contra Salvador Pérez en $1773^{162}$. La causa se encuentra caratulada por el delito de abigeato aunque rápidamente se puede observar que el asunto no es tan simple. El 8 de diciembre de ese año el demandante envió un escrito al alcalde de primer voto de Montevideo

\footnotetext{
${ }^{160}$ Los cueros pesaron un total de 1712 libras y la subasta favoreció nuevamente a Francisco Rodríguez a 15 reales y medio la pesada de 41 libras.

${ }^{161}$ Por ejemplo, en la demanda que José Fernández, capataz de Juan Ángel Llanos interpuso contra Gregorio Pereira en 1777, el acusado en su declaración admitió que el mismo año había sido demandado por “juicio verbal” por José Cardoso por la extracción de 25 yeguas. AGN Uruguay AJ, Montevideo Civil 11777 Caja 39 Expediente 16. Demanda puesta por José Fernández capataz de Juan Angel Llanos contra Gregorio Pereira y Fulano Brito sobre extracción de 300 cabezas de ganado.

162 AGN Uruguay AJ Montevideo Civil 11773 Caja 28 Expediente 38. Querella puesta por Francisco Pereira contra Salvador Peres. Por abigeato.
} 
denunciando que el acusado había ingresado a su estancia de la costa de San José, junto a sus hijos y peones, para luego arrear todo el ganado que pudo conducir, llevarlo hasta su estancia, marcarlo con su marca y, finalmente, matar a todos los toros y novillos que halló aptos. Lo interesante es que Sequeira admite en su presentación que hasta ese momento no había marcado el ganado y que lo mantenía orejano con lo que su propiedad sobre el mismo es difícil de probar.

Como era de esperarse, Salvador Pérez contestó afirmando que las acusaciones eran falsas y que, al formularlas, Sequeira lo estaba injuriando. Esto era algo característico de los conflictos entre vecinos. El demandado siempre hacía hincapié en que la denuncia mancillaba su honor. Esa respuesta está relacionada a la posición social equivalente entre ambos contendientes y por eso esas situaciones no se repiten en los juicios por abigeato cuando un estanciero acusaba a un arrimado o a un peón.

Finalmente, luego de varias actuaciones, el alcalde de segundo voto dictó sentencia el 16 del diciembre de 1774 obligando a Sequeira a pagar los costos procesales y reconviniendo a ambos contendiente por no mantener ni una buena convivencia entre vecinos y ni el recato que era acorde a su lugar en la sociedad. Por eso les brinda una guía sobre cómo gestionar el ganado en cada estancia y qué hacer en caso de que el ganado de uno pase a la propiedad del otro, al mismo tiempo que los conmina a un "callamiento perdurable" sobre la causa.

Por otro lado, la querella presentada por Miguel Ignacio de la Cuadra en $1778^{163}$ es representativa de la manera en que un nuevo propietario podía recurrir a la justicia para imponer su derecho sobre la tierra adquirida y conseguir desplazar a los faenadores que realizaban su actividad dentro de la misma. El denunciante había adquirido varios terrenos en esos años, algunos realengos adquiridos por composición ${ }^{164} \mathrm{y}$ otros por compra a particulares ${ }^{165}$. La mayor parte del expediente está conformado por los papeles que presentó de la Cuadra confirmando su propiedad sobre las tierras. Logrando que el Alguacil Mayor, Ramón de Cáceres, desalojara la partida de faenadores y embargase los

${ }^{163}$ AGN Uruguay AJ Montevideo Civil 11778 Caja 40. Querella seguida por Miguel Ignacio de la Quadra contra el vaquero Guaycuru por haberlo hallado faenando en sus ganados y terrenos que de su legitimidad se comprenden aquí los títulos por lo que se ve en este cuerpo.

${ }^{164}$ Miguel Ignacio de la Cuadra había denunciado y luego comprado las tierras realengas situadas entre los arroyos Maciel y Porongos, frente al río Yi, con 4 a 5 leguas de frente y 6 a 7 leguas de fondo (Pivel Devoto, 1964: 147-152).

${ }^{165}$ En ese mismo año, de la Cuadra había comprado una estancia ubicada en el arroyo Cagancha a Hermenegildo Laguna por 180 pesos (Ibíd.: 700). 
cueros que ya habían hecho ${ }^{166}$ a pesar de que los prácticos determinaron que el terreno se hallaba fuera de la jurisdicción de Montevideo. Con lo cual nos encontramos con otro antecedente del accionar de los cabildantes montevideanos trasendiendo los límites de su territorio.

Podemos ver otro ejemplo de este tipo de situaciones en el juicio emprendido en el cabildo de Maldonado en 1787 entre Jorge de Olivera y Soto y Ramón del Puerto. El expediente que comenzó por sustracción de ganado en una estancia del valle de Aiguá, o "de Iguada" como aparece mencionado en las actuaciones, terminó resolviéndose en otro juicio paralelo sobre la propiedad de las tierras. El eje del conflicto parece haber sido nuevamente la compra reciente del terreno. Ramón del Puerto acreditó en el juicio haber comprado la estancia a José Ferradel en $1784^{167}$, aunque el pago de la alcabala aparece registrado en 1786. La medición de los terrenos avaló la posición de del Puerto y obtuvo una sentencia a su favor. ${ }^{168}$

\subsubsection{Unos pocos juicios por abigeato: en busca de un castigo ejemplar}

Las características de la ganadería extensiva de esos años y la consecuente dificultad que tenían estancieros y corambreros para controlar a los hombres y al ganado en la campaña harían suponer que el abigeato debería haber sido un epidemia incontrolable durante esos años. Las quejas de los hacendados sobre la anarquía que reinaba en los campos parecerían confirmarlo. Sin embargo, el archivo judicial muestra una reducida cantidad de juicios por esa causa.

Es probable que esto se deba a varias cuestiones relacionadas. Por un lado, la mayor parte de los conflictos puede haberse resuelto de manera oral y, de esta manera, no quedaron registros de ellos en nuestras fuentes. Los pocos juicios que se realizaron muestran que la instancia judicial tenía costos muy altos para el delito que se buscaba combatir. Algunas causas directamente se abandonaron porque los demandantes

\footnotetext{
${ }^{166}$ El 22 de agosto de 1778 se embargaron 100 cueros de toro que estaban en una pila y 74 en la estaca, una chusa, una media luna, dos hachas, 15 cuchillos, 54 caballos y dos yeguas y luego retirándose dos leguas del puesto de de la Cuadra se encontró un carro viejo con otros 80 cueros que también embargó.

${ }^{167}$ Este a su vez había recibido las tierras por concesión del comandante militar de la Villa de San Carlos en 1778 .

${ }^{168}$ AGN Uruguay, Archivo Judicial, Maldonado Civil 11787 Caja 1 Expediente 25. Jorge de Olivera y Soto sobre sustracciones de su ganado y Expediente 26. Jorge de Olivera y Soto contra Ramón del Puerto sobre tierras.
} 
prefirieron no hacerse cargo de las costas procesales ${ }^{169}$ y siempre intentaban que dentro del castigo se incluyera que el acusado se hiciera cargo de los mismos.

En 1785, por ejemplo, seis individuos fueron apresados y se embargaron 16 cueros con marcas de distintos propietarios. Luego de cinco meses en prisión los acusados fueron liberados ya que según el juicio del fiscal de la causa solamente había "levísimos" indicios contra José Domingo Giles porque había hecho algunos cueros sin poseer ganado propio. Sin embargo, el mencionado, que era el dueño de la casa donde se produjo la detención, fue condenado a pagar las costas, que ascendían a la no despreciable suma de 52 pesos y 4 reales, como castigo por permitir en su casa gente sin ocupación honesta conocida ${ }^{170}$.

En 1792 los hacendados desistieron de la querella que habían mantenido desde el año anterior contra el pulpero Antonio Rodríguez por abigeato siempre y cuando éste se comprometiese a pagar tanto todos los costos procesales, que en esta causa eran muy elevados ${ }^{171}$, así como también abonar lo correspondiente por los cueros marcados que se le habían embargado y con la condición de que mudase a otro partido ${ }^{172}$.

En otras ocasiones los propietarios se conformaban con el tiempo que los acusados fueron mantenidos en la cárcel como castigo suficiente. Es probable que esto también sea un reflejo de que no siempre era fácil hacer cumplir las sentencias o los acuerdos entre partes que implicaban un resarcimiento para el propietario. En 1777 Juan Ángel Llanos, capitán de milicias, llegó a un convenio en el juicio que seguía contra Gregorio Pereira y Fulano Brito quienes habían sustraído 300 reses de ganado de su estancia. Llanos acordó dar por finalizado el pleito, siempre y cuando se le entregaran las reses y cueros embargados y que Pereira pagase los costos del proceso. Sin embargo, el expediente continua con varias cartas del capitán de milicias, que se repiten durante siete años, donde reclama constantemente que los depositarios de los bienes se niegan a

\footnotetext{
${ }^{169}$ Ese parece ser el caso de Ventura Correa en su demanda contra el mulato Salvador Servin. AGN Uruguay, Archivo Judicial, Montevideo Civil 11780 Caja 48 Expediente 89. Causa criminal seguida contra el mulato paraguay Salvador Servin por el delito de abigeato.

${ }^{170}$ AGN Uruguay, Archivo Judicial, Montevideo Civil 11785 Caja 69 Expediente 54. Causa criminal formada contra seis individuos por decirse faenaban cueros furtivamente en las estancias de esta jurisdicción.

${ }^{171}$ La cuenta presentada por el alguacil mayor Ramón de Cáceres de las diligencias que había realizado ya alcanzaba los 169 pesos.

172 AGN Uruguay, Archivo Judicial, Montevideo Civil 11791 Caja 97 Expediente 6. Querella contra Antonio Rodríguez alias el Maturrango por Miguel de la Quadra, Melchor de Viana, Manuel Duran y Juan José Seco por aceptar cueros robados en su pulpería.
} 
entregarlos y que no se conoce el paradero de Pereira para hacerle pagar los gastos. Es decir que Llanos nunca se vio resarcido de la pérdida de su ganado. ${ }^{173}$

Por otro lado, no siempre era posible comprobar el delito de abigeato. En 1779 Juan Miguel Gómez fue detenido por haber muerto una vaca y una ternera que había retirado de la estancia del Maestre de Campo de Caballería Manuel Domínguez. Gómez declaró que el ganado era suyo y que por eso fue a buscarlo a la estancia contigua para lo que intentó pedir el permiso del capataz. También denunció el atropelló que sufrió por parte del juez comisionado que lo había apresado. El cual se había apresurado a embargarle los bienes, vendiendo dos de sus caballos. Sin embargo, ningún testigo pudo certificar de quién era la propiedad del ganado. Finalmente, trascurrido menos de un mes de la detención del acusado se presentó Manuel Domínguez diciendo que se había valido del juez comisionado porque él mismo no podía ser juez de la causa, que se sentía satisfecho de los perjuicios recibidos y que por la suma pobreza de Juan Miguel Gómez y de la carga de mucha familia que tenía, en atención a la caridad era conveniente ponerlo libertad. ${ }^{174}$

Sin embargo, no todos los acusados eran tratados con tantas consideraciones. Cuando el acusado era extranjero o indio la situación era diferente. En esos casos los denunciantes solían reclamar un castigo que funcionara como ejemplo y escarmiento para el resto de los habitantes de la campaña $\mathrm{y}$, en esos casos, los jueces dictaban sentencias de cumplimiento efectivo, comúnmente un determinado tiempo de trabajo en las reales obras.

En agosto de 1776 el juez comisionado José Garrido condujo preso desde la campaña a Juan de Aguilar, natural de la isla de Malta, por haber muerto un buey que pertenecía a Esteban de Otero, alias el cautivo. El delito había sido corroborado porque hallaron la cabeza del buey, junto a otras osamentas, oculta en un pozo de agua de la chacra del maltés. El acusado se defendió diciendo que, en realidad, el buey había sido muerto por el mulato José Roque, a quién califico como gauderio, que vive sin conchabarse con persona alguna, y que por esa misma razón ignoraba su paradero.

\footnotetext{
${ }^{173}$ AGN Uruguay, Archivo Judicial, Montevideo Civil 11777 Caja 39 Expediente 16. Demanda puesta por José Fernández capataz de Juan Angel Llanos contra Gregorio Pereira y Fulano Brito sobre extracción de 300 cabezas de ganado.

${ }^{174}$ AGN Uruguay, Archivo Judicial, Montevideo Civil 11779 Caja 45 Expediente 87. Diligencia actuada contra las personas de Juan Miguel Gomez, Miguel Cabrera y Agustín Moreno. Por abigeato. Los otros dos acusados eran indios a los que querían mandar a las reales obras pero no aparecen implicados en la causa, más allá de figurar sus nombres en la carátula.
} 
Según Aguilar, el mulato había quedado al cuidando del rancho mientras él "iba a correr baguales a la sierra" y que en el intermedio el mulato había dado muerte al animal. Sin embargo, el alcalde de primer voto no creyó las explicaciones del acusado y dos meses después de su apresamiento lo condenó a seis meses de trabajo en las reales obras, a ración y sin sueldo, y cumplido ese tiempo a ser desterrado a Buenos Aires sin poder retornar a Montevideo, de lo contrario pasaría seis años de trabajo en las reales obras bajo las mismas condiciones. ${ }^{175}$

En 1790 Juan Esteban Durán presentó una demanda contra José Dionisio, alias Gualeguay, natural de "los paranás", por efectuar faenas furtivas en la estancia de su difunto hermano Ventura, al que representaba como albacea de sus bienes. En su presentación Durán pidió que se aplicara un castigo que sirviese "a otros de escarmiento". Luego de permanecer seis meses en la prisión, Gualeguay fue enviado, por orden del gobernador, a trabajar por cuenta del rey en las matanzas de ganado que se estaban realizando en las "Islas Baulinas"176. 177

Es posible que estas condenas, además de funcionar como un elemento aleccionador, estuviesen relacionadas con que los acusados eran individuos que estaban por fuera de la trama de relaciones sociales del lugar. Por eso los declarantes siempre se cuidaban de caracterizar a los acusados como gauchos, gauderios o vagos $^{178}$ para resaltar que no tenían arraigo en el lugar ya que no estaban conchabados a ningún patrón ni eran parte de los habitantes de la zona.

El 9 de marzo de 1785 Juan Antonio Bustillos declaró en la causa que se llevaba contra José Giles y otros individuos por abigeato y se ocupó de mencionar como gauchos a las personas que no conocía y diferenciarlos, de esa manera. De los que sí conocía a quienes identificó como labradores de la manera siguiente:

"Que ya havia requerido al dueño de la casa donde los aprehendieron, que para que consentia en ella aquella gente gaucha con cuia expresion recombino a dho dueño de casa qe se llama Josef Giles (...), y à Domingo, è Ignacio Gorosito qe estos dos ultimos sabe llegaron del Sauce la

\footnotetext{
${ }^{175}$ AGN Uruguay, Archivo Judicial, Montevideo Civil 11776 Caja 37 Expediente 37. Causa criminal contra un individuo de nación maltes por el delito de abigeato.

${ }^{176}$ Creemos que se trata de la Isla Paulino situada actualmente en el partido de Berisso, provincia de Buenos Aires.

${ }^{177}$ AGN Uruguay AJ Montevideo Civil 11790 Caja 95 Expediente 35. Demanda de Juan Esteban Duran como albacea de su hermano Ventura contra un tal Gualeguai y Félix Pedroso por faenas de cueros furtivas en la estancia de dicho finado.

${ }^{178}$ Sobre la etimología y el uso de estos términos ver: Coni (1945) y Assunçao (1963).
} 
noche que los aprehendieron, y que no los conoce por de mala nota, y que à su vecino lo ha visto que hase sus sementeras" $" 179$

En la misma causa, la declaración de José Estebán Durán también hace mención a los gauchos vinculándolos con uno de los típicos vicios que se les adjudicaban, el juego:

"que tambien le consta por haverlo visto que en su casa consentia muchos gauchos y que el regular exercicio de estos es jugar por ser aficionado igualmente el dueño de casa à ello..."180

Por supuesto, estas menciones que remiten a una visión tradicional del gaucho pueden ser nada más que una estrategia judicial pero lo importante es que plantean una división entre los individuos conocidos y con lazos con la comunidad y los otros, definidos como vagos o gauchos. En cambio, en los juicios las personas asentadas aparentan aceptar las relaciones establecidas en el lugar y, por lo tanto, declaman que se resisten a participar de las faenas y circuitos de comercialización clandestinos del cuero. Por ejemplo, en el juicio ya mencionado que siguió Juan Esteban Durán contra el indio Gualeguay, Juan Antonio Quereguis declaró que estando en su casa situada en Chamizo en tierras de la estancia del finado Dn Ventura Durán, llego “a boca de la noche" un tal Gualeguay, quien llamándolo aparte le dijo como en secreto si quería comprar 6 cueros, le dijo que tenía marcas del finado, entonces él "le reconvino que como queria que el estando en aquellas tierras a favor fuese comprador y consentidor de lo robado en la propia hacienda, anda vèr à otro que te los compre". ${ }^{181}$

En consecuencia, hay indicios para creer que los estancieros y corambreros podían resguardar su propiedad sobre el ganado por medio de las relaciones sociales que establecían con los pobladores de la campaña. En este sentido, encontramos una resignificación de las relaciones que se daban entre los arrimados y los propietarios. No sólo se planteaba una tolerancia en la ocupación de la tierra para aumentar la disponibilidad de mano de obra, como vimos en el capítulo anterior. También el hecho

\footnotetext{
${ }^{179}$ AGN Uruguay, Archivo Judicial, Montevideo Civil 11785 Caja 69 Expediente 54. Causa criminal formada contra seis individuos por decirse faenaban cueros furtivamente en las estancias de esta jurisdicción.

${ }^{180}$ Ibíd.

${ }^{181}$ AGN Uruguay AJ Montevideo Civil 11790 Caja 95 Expediente 35. Demanda de Juan Esteban Duran como albacea de su hermano Ventura contra un tal Gualeguai y Félix Pedroso por faenas de cueros furtivas en la estancia de dicho finado.
} 
de que existieran habitantes en los lindes de sus terrenos permitían un mejor control de su ganado mediante este tipo de relaciones que parecen tener algunas reminiscencias paternalistas. Sin embargo, esto puede haberse sido solamente un pequeño resguardo que no impidió la existencia de faenas clandestinas de cueros. Pero, sin duda, la magnitud de esos robos no implicó una reducción excesiva de las ganancias de los hacendados. Su supervivencia como agentes económicos no se vio amenazada por estas extracciones de parte de su stock ganadero más allá de las quejas que elevaron a las distintas autoridades. En cambio, el costo de reprimir esa faenas siempre fue superior a las pérdidas que les ocasionaban esas prácticas como quedó demostrado tanto por la espasmódica actividad del aparato burocrático virreinal o de los cabildos al respecto como por la escasa utilización de la instancia judicial para resolver esos conflictos por parte de los estancieros y corambreros. 


\section{Capítulo 8}

\section{Los corambreros montevideanos}

Luego de analizar el proceso de apropiación de la tierra y las disputas legales que buscaban asegurar la explotación del ganado en beneficio de un grupo de agentes, en este capítulo realizaremos un esbozo de estudio prosopográfico o biografía grupal de los agentes que hemos denominado corambreros montevideanos. De esta manera, podremos completar un panorama de ese conjunto reducido de personas que gracias a las denuncias de grandes extensiones de tierras podían explotar las reservas de ganado cimarrón y dar salida a los cueros producidos por medio de los circuitos legales de comercialización.

Como cualquier otra metodología, la prosopografía no está exenta de críticas ${ }^{182}$. Sin embargo, entre los abordajes posibles parece el más adecuado para estudiar un grupo de agentes dedicados a una actividad económica productiva. Otras herramientas metodológicas, como la reconstrucción de redes de vínculos personales, pueden ser más adecuadas para el estudio de las actividades comerciales ${ }^{183}$.

Para el Río de la Plata disponemos de dos trabajos que realizan este tipo de estudios y que hemos tomado como modelo. La investigación de Susan Socolow (1988) sobre los comerciantes mayoristas de la capital virreinal y el artículo de Carlos Mayo (1991) sobre los estancieros de la campaña de Buenos Aires. Por otro lado, aunque no es un trabajo prosopográfico, el estudio de Bernd Schröter (1999) de la capa social alta de Montevideo durante el siglo XVIII es otra referencia obligada.

En este caso, dadas las características de la actividad económica que define el grupo de agentes analizados, la producción de cueros a partir de la explotación del

${ }^{182}$ Por ejemplo, Christian Büschges (1999: 12-13) considera que la limitación más importante de estos estudios consiste en que solamente analizan una dimensión de las relaciones sociales, es decir, la económica. También considera como otra dificultad el hecho de concentrarse en un grupo específico ya que entiende que se debe investigar todo lo que elige denominar como capa social alta. Sin embargo, a nuestro entender estás críticas confirman lo adecuado de nuestra elección ya que nuestro objetivo es estudiar a un grupo determinado por ciertas condiciones económicas.

${ }^{183}$ Para estudios de redes aplicadas al espacio rioplatense ver los trabajos de Zacarías Moutoukías (1995b, 2000). 
ganado cimarrón, el primer elemento que se destaca es el período de tiempo breve de actuación de estos agentes. Ese accionar, dependiendo de cada uno de los agentes, comenzó aproximadamente en la década de 1760 y finalizó, paulatinamente, durante la década de 1790, especialmente en los últimos años del siglo. En ese momento, el agotamiento de las reservas de ganado cimarrón en el área dio paso a transformaciones en el sistema productivo que determinaron que el desplazamiento de esa actividad económica por la ganadería de rodeo que era llevada a cabo por otro tipo de agente económico, los estancieros, que no forma parte del análisis que se realiza en este capítulo.

En las páginas que siguen estudiaremos el proceso de conformación del grupo de agentes económicos que denominamos corambreros montevideanos. Es decir, en qué momento se asentaron en Montevideo y de qué manera pudieron acceder a la explotación legal del ganado cimarrón. En la mayoría de los casos las denuncias de tierras realengas fueron la herramienta fundamental para el inicio de la actividad de estos agentes. Luego, analizaremos la manera en que durante la década de 1780 se produjo una recomposición del grupo de agentes, cuando se incorporaron algunos individuos. El instrumento principal mediante el cual se daba ese ingreso fueron las alianzas matrimoniales. Este proceso fue coincidente con la suspensión de las faenas corambreras de la administración de los pueblos misioneros y de la posibilidad de denunciar tierras realengas, medida que se extendió durante toda la tramitación del expediente conocido como de "arreglo de los campos". Por último, veremos cómo en los años finales de la década de 1790 se procedió al fraccionamiento de las tierras antes denunciadas para arrendamiento o venta, en muchos casos como producto de testamentarias que siguieron al fallecimiento de algunos de los corambreros. Ese fraccionamiento de las grandes propiedades es un indicio más de la expansión de la ganadería de rodeo ante el agotamiento de las reservas de ganado cimarrón en esas zonas. Por lo tanto, se puede observar la desaparición de esos agentes debido a la transformación de las condiciones estructurales del área estudiada.

Por otro lado, este proceso coincidió con la aparición en Montevideo de nuevos agentes económicos vinculados a las nuevas oportunidades comerciales que se abrieron a partir de las medidas liberalizadoras tomadas por la corona luego de 1791, tal como plantean los trabajos de Bentancur (1997) y Schöter (1999). Lo que seguramente 
contribuyó a disminuir la posición preponderante que ocupaban los pocos corambreros que quedaban o de los grandes estancieros del momento, algunos de los cuales contaban con un pasado ligado a la organización de vaquerías.

8.1. Proceso de conformación del grupo de agentes económicos. Las denuncias de tierras.

La primera persona que se dedicó a la producción masiva de cueros para exportación en Montevideo fue Francisco de Alzaybar. Si bien la amplitud de sus intereses comerciales nos impide considerarlo meramente como un corambrero y tampoco podemos calificarlo como montevideano ${ }^{184}$ constituye, sin embargo, el antecedente más importante de los agentes económicos que denominamos corambreros montevideanos.

Francisco de Alzaybar comenzó su relación con la región en 1724 cuando firmó el primero de sus contratos con la Corona para enviar al Río de la Plata cuatro navíos de 1.000 toneladas en el plazo de cuatro años. Dos años después llevó a cabo un nuevo acuerdo por el que se comprometió a trasladar a los pobladores canarios destinados a la fundación de Montevideo (Jumar, 2000: 189). Lógicamente una parte importante de la carga de retorno de esos viajes estaba constituida por cueros.

Años más tarde, Alzaybar pudo dedicarse directamente a la producción de ese bien en tierras cercanas a la ciudad. De esta manera, eliminaba intermediarios lo que seguramente aumento sus ganancias. En 1738 recibió por merced el terreno correspondiente al rincón de San José que tenía una extensión de 100.000 hectáreas. Al parecer, Alzaybar ya ocupaba esas tierras desde 1735 (Pérez, 1996: 170). Más adelante, afirmaba que había poblado el rincón con 36.000 cabezas de ganado. Sin embargo, una estimación más realista efectuada por el cabildo de Montevideo, en 1742, afirmaba que el naviero español poseía 12.000 cabezas de ganado, lo que era indicativo de su importancia ya que, según la opinión de los regidores, todo resto del vecindario solamente sumaba unas 4.000 cabezas de ganado (RAGA, 1886:68). Como vimos en el capítulo 4, en los primeros años de la década de 1770, Alzaybar denunció una gran

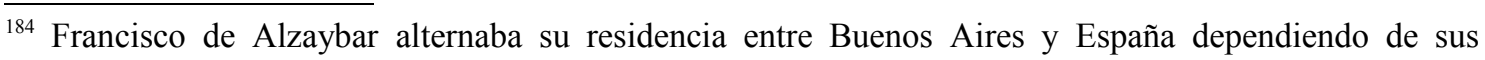
asuntos comerciales. 
extensión de tierras argumentando que los ganados que allí había eran animales alzados de su estancia y que, por lo tanto, los vecinos de Montevideo, que habían poblado sus estancias posteriormente, se apropiaban de ese ganado que originalmente le pertenecía. Como era de esperarse, la denuncia sufrió la resistencia de los vecinos representados por el cabildo. Finalmente, el trámite quedó en suspenso por la muerte de Francisco de Alzaybar acaecida en 1775.

El núcleo de los primeros corambreros estuvo dado por la red de relaciones de Alzaybar que incluía a algunos de los pobladores de la ciudad. Este grupo se formó en las décadas de $1750 \mathrm{y}$, especialmente, en la de 1760 y todavía se los encuentra económicamente activos en los años finales del siglo XVIII. Los principales instrumentos para que estos individuos se iniciaran en la producción corambrera, al mismo tiempo que se insertaban en la sociedad montevideana, eran el casamiento y las denuncias de tierras.

María Francisca de Alzaybar era sobrina de Francisco de Alzaybar. Ignoramos en que año arribo al Río de la Plata, pero ya estaba en Montevideo en 1755 cuando se casó con el primer gobernador de Montevideo, José Joaquín de Viana, con quién tuvo 5 hijos (2 varones y 3 mujeres) de los que hablaremos en el apartado siguiente al analizar la recomposición del grupo de agentes (Apolant, 1966b: 414-416).

Mientras su esposo se dedicó a la carrera militar y burocrática, María Francisca de Alzaybar efectuó una importante producción de cueros a partir de la explotación del ganado cimarrón en las extensas tierras que fue acumulando, sin desestimar ocasionalmente el recurso de faenar también las cabezas vacunas que se encontraban en los terrenos lindantes. En el mismo año de su casamiento recibió en merced el rincón que formaban los arroyos Luis Pereira y Pavón que tenía fondo hacia el Río de la Plata y el frente del terreno entre las nacientes de los arroyos (Pivel Devoto, 1964: 63). Esa estancia fue poblada con las 6.000 cabezas de ganado vacuno y 1.000 yeguas que había recibido como dote de parte de su tío Francisco de Alzaybar ${ }^{185}$. Trece años más tarde, en 1768, María Francisca adquirió, por composición, las tierras realengas que se situaban entre el río Santa Lucía y el arroyo Casupá. El terreno, por el cual solamente debió abonar 150 pesos más 8 pesos, 6 reales y 25 maravedíes por el real derecho de media

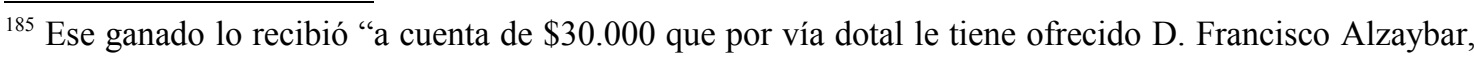
su tío" según declaró en su testamento José Joaquín de Viana. El testamento se encuentra íntegramente transcrito en: Azarola Gil, 1926: 59-61. 
anata. Tenía una extensión de 6 leguas de frente por 10 leguas de fondo ${ }^{186}$ (Ibíd: 152155). Por último, en 1774 , cuando ya era viuda ${ }^{187}$, aumentó su patrimonio territorial con la incorporación de una nueva estancia ubicada en el arroyo Las Piedras. Esta vez la forma de adquisición fue la compra a los herederos de Juan Delgado Melilla y Agustina de Saa. El establecimiento poseía 3.800 varas de frente y 7.200 varas de fondo. El precio de la venta fue elevado para la época alcanzando los 1.168 pesos y 7 reales ya que además del valor de la tierra incluía las edificaciones, árboles y animales existentes en el establecimiento ${ }^{188}$ (Íbid: 694-695).

Al redactar su testamento en 1773, José Joaquín de Viana declaraba que en sus dos estancias, que disponían de la mano de obra permanente de 11 esclavos, poseía de 60 a 70 mil cabezas de ganado vacuno, más de 200 caballos y 11 carros con su boyada correspondiente (Azarola Gil, 1926: 60). Aún en la década de 1780 cuando, como veremos, ya había repartido parte de sus actividades entre sus yernos y uno de sus hijos, María Francisca de Alzaybar era todavía una de las mayores productoras de cueros de la región. Tal como se puede observar en el cuadro 6 (ver capítulo 2), en los 54 meses de los que tenemos datos entre septiembre de 1784 y marzo de 1790 introdujo 19.723 cueros, lo que representa una media de más de 4.000 cueros por año. Recordemos que un estanciero importante podía llegar a producir 1.000 cueros anuales si poseía un stock de animales sujetos a rodeo superior a los 5.000 animales, con lo que una media de más de 4.000 cueros anuales producidos no son una cantidad para nada desdeñable. En la década siguiente, María Francisca de Alzaybar firmó un convenio con Juan Balbín de Vallejo quien se hizo cargo de administrar sus establecimientos. Finalmente, "La Mariscala", como se la denominaba por el cargo militar de su difunto marido, falleció en 1803 cuando ya rondaba los 70 años de edad (Apolant, 1966b: 417).

Otro integrante destacado del grupo de corambreros montevideanos también estaba relacionado con el primer gobernador de la jurisdicción y con la red de relaciones

\footnotetext{
${ }^{186}$ En el censo que realizó el cabildo en 1769 aparecen esas dos estancias, que eran contiguas, como pertenecientes a María Francisca de Alzaybar de la manera siguiente: “448 Estancia de Da. María Francisca de Alzáybar en Casupá, Santa Lucía, arroyo del metal, conocido por el del soldado. 449 Estancia de (...) en el río Santa Lucía, su fondo a la Cuchilla que divide Solís Grande, por lindero con las tierras de Verdún" (Apolant, 1966a: 114).

${ }^{187}$ José Joaquín de Viana falleció en Buenos Aires en 1773.

${ }^{188} \mathrm{El}$ inventario de la tasación con sus cantidades y precios correspondientes es el siguiente: 3.000 varas de frente a 2,5 r c/u, los ranchos viejos $20 \mathrm{p}, 89$ árboles de manzano a $3 \mathrm{r} \mathrm{c} / \mathrm{u}, 10$ higueritas a $1 \mathrm{r} \mathrm{c} / \mathrm{u}, 3$ trozos de palo $4 \mathrm{r}, 3$ bancos chicos a $2 \mathrm{r} \mathrm{c} / \mathrm{u}$, un corral viejo y otros palos $4 \mathrm{p}, 155$ yeguas a $2 \mathrm{r} \mathrm{c} / \mathrm{u}, 71$ potros a $6 \mathrm{r}$ c/u, 10 caballos mancos a $10 \mathrm{r}$ c/u, 2 caballos sanos a $4 \mathrm{p} \mathrm{c} / \mathrm{u}, 70$ vacas a $4 \mathrm{r} \mathrm{c} / \mathrm{u}$.
} 
de Francisco de Alzaybar. Melchor de Viana, primo de José Joaquín de Viana, se instaló en Montevideo en la década de 1750. En 1759 contrajo matrimonio con María Antonia de Achucarro, hija de Juan de Achucarro ${ }^{189}$ (Ídem: 508). Ambos contrayentes tenían mucho para aportar al enlace matrimonial. El esposo aportaba su parentesco cercano con el reciente gobernador de la plaza y la esposa contaba con su condición de hija de uno pobladores, con los consecuentes privilegios para acceder a la propiedad de la tierra, y con una dote superior a los $14.000 \operatorname{pesos}^{190}$.

En las décadas siguientes Melchor de Viana consiguió apropiarse de considerables extensiones de tierras realengas por lo mecanismos de denuncia, tasación y remate (ver capítulo 4). Esas tierras se sumaron a las que recibió por herencia de su mujer luego de la muerte de Juan de Achucarro en $1768^{191}$ y de Dominga Camejo en 1772 , de cuyas testamentarias fue albaceas ${ }^{192}$.

En 1764 Melchor de Viana recibió en merced una suerte de estancia que lindaba con la de Juan de Achucarro ${ }^{193}$ y que estaba situada frente al arroyo Cagancha (Pivel Devoto, 1964: 77). Al año siguiente, ocupó y denunció un terreno realengo de dimensiones considerables ${ }^{194}$ situado entre el río Yí, el Albardón o Cuchilla Grande y los arroyos Mansevillagra y Maciel, que lindaban por el norte con el río Yi, por el sur con la Cuchilla Grande que divide las aguas vertientes que van a parar al río Santa Lucía Chico y con terrenos que ya había comprado (Ídem: 143-145). Como ya mencionamos en el capítulo 4, los trámites de la adquisición de este terreno se demoraron varios años. La tasación se efectuó en 1770 y el remate fue realizado en 1782. Por último, la

\footnotetext{
${ }^{189}$ En la tasación que efectuó el cabildo de Montevideo en 1751 Juan de Achucarro era el segundo vecino con mayor patrimonio después de Francisco de Alzaybar. Sus bienes consistían de 8.000 pesos entre casas, sitios, molino y atahona, 4 esclavos valuados en 700 pesos, 1.800 cabezas de ganado vacuno a 2 pesos cada una y 600 ovejas a 3 reales cada una lo que hacía un patrimonio total de 12.725 pesos (Apolant, 1966a: 8). Además, Juan de Achucarro aparece en los acuerdos del cabildo de Montevideo actuando como apoderado de Francisco de Alzaybar en 1742 (RAGA, 1886: 69).

${ }^{190}$ Esa suma es la que María Antonia de Achucarro declaró haber aportado a su casamiento con Melchor de Viana al momento de redactar su testamento en 1823 (Azarola Gil, 1926: 95).

${ }^{191}$ En 1768, año de su fallecimiento, dio poder para testar a su mujer, Dominga Camejo, y a su yerno Melchor de Viana (Apolant, 1966b: 208).

${ }^{192}$ De ocho hijos que había tenido Dominga Camejo solamente le sobrevivieron dos. María Antonia, casada con Melchor de Viana, y María Isidora, quien en 1775, cuando apenas tenía 15 años, se casó con José Francisco de Sostoa, que era oficial de la Caja Real de Montevideo (Ídem: 209). Es lógico suponer que Melchor de Viana administraba los bienes y que se encargó tanto de arreglar el matrimonio como de suministrar la dote de María Isidora.

${ }^{193}$ Ese mismo año Juan de Achucarro había recibido 6 suertes de estancia situadas entre el río San José y el arroyo Cagancha, cuyo frente comenzaba desde el lindero de la de Antonio Varela aguas arriba y sus fondos al terreno donde mantenía su ganado el vicario de Montevideo (Pivel Devoto, 1964: 77).

194 Tenía una extensión 13 leguas y 1200 varas, 11 leguas y 600 varas, 18 leguas y 1500 varas y 12,5 leguas y 500 varas.
} 
adquisición se completó cuando Felipe Arguibel, que actuó como su apoderado en Buenos Aires, abonó 1.014 pesos y un real por el terreno más los impuestos correspondientes. Por otro lado, en 1772 denunció las tierras que habían pertenecido al cura vicario de Montevideo, Nicolás Barrales, quien se las había legado con la única condición de que con ellas fundase dos capellanías ${ }^{195}$. Según la denuncia hecha por Melchor de Viana este terreno medía 3,5 leguas de frente y 1,5 de fondo y se situaban entre el río San José, el Santa Lucía Grande y el Camino Real, que lindaba por el norte con las tierras de Francisco Rodríguez Cardoso y de Josefa Balague, por el oeste con las de Antonio Varela y de los herederos de Juan de Achucarro, es decir el mismo ${ }^{196}$ (Ídem: 145-146). Finalmente, adquirió una estancia de 700 varas, situada en el arroyo Mereles, por compra a Pascuala Sacristán, viuda de Esteban de Ledesma, que la había recibido por merced (Ídem: 173-178).

En 1793, cuando ya tenía 62 años ${ }^{197}$, Melchor de Viana vendió su estancia situada entre el río San José y el Santa Lucía Grande a uno de los nuevos estancieros de esa época, Joaquín de Chopitea, por la considerable suma de 7.000 pesos (Ídem: 716). Hasta ese momento, Melchor de Viana fue uno de los mayores productores de cueros del área. Los datos registrados en el censo de 1769 indican que en esos momentos disponía entre sus dos estancias de 45.000 cabezas de ganado vacuno, 1.000 ovinos, 20 yeguas y 20 caballos y disponía de una fuerza laboral compuesta por 20 esclavos y 23 peones (Apolant, 1966a: 113). Es decir, considerando una tasa de reproducción promedio del $20 \%$ durante esos años podía producir 9.000 cueros anuales suponiendo que ese ganado declarado estuviese sujeto a rodeo. Aunque eso era poco probable ya que todavía en 1788 Melchor de Viana defendía que el ganado no sujeto a rodeo se reproducía en mayor cantidad (Pérez, 1996: 168-169). Ya en la segunda mitad de la década de 1780 la cantidad de cueros que faenaba parece haber sufrido una merma, por lo menos si nos atenemos a los 2.915 que aparecen en el cuadro 6 (ver capítulo 2 ).

${ }^{195}$ El 10 de diciembre de 1772 Melchor de Viana fundó las capellanías y eligió a los dos novicios. Como Barrales lo había autorizado a cambiar el asiento del capital, Viana gravó otra estancia y una casa, ambas de su propiedad. (Barrán, 1998: 54)

${ }^{196}$ Existió otra denuncia y compra de tierras realengas vinculada a Melchor de Viana. En 1778 Bruno Muñoz denunció un terreno inmenso de una superficie de 38 a 40 leguas entre los arroyos Godoy, Tapes, Cebollatí, Tacuarí y el albardón o cuchilla que divide las aguas del río de la Plata y de la Laguna Miní. Como resultado del remate en 1780 debió abonar 2.125 pesos más 342 pesos y 7 reales de impuestos y costas (Ídem: 190-198). Al parecer, Muñoz había hecho la denuncia en nombre de Melchor de Viana pero después busco quedarse con las tierras lo que tuvo como consecuencia un largo pleito que terminó con un reparto de las mismas entre los interesados (Sala de Tourón, Rodríguez y de la Torre, 1968: 30-31).

${ }^{197}$ Melchor de Viana falleció 3 años más tarde, el 4 de febrero de 1796 (Apolant, 1966b: 508). 
Miguel Ignacio de la Cuadra fue otro de los corambreros que se insertó en la sociedad montevideana a partir de su casamiento con una de las hijas de los pobladores más importantes. El 27 de mayo de 1761 tuvo lugar su casamiento con Inés Durán, hija de Manuel Durán ${ }^{198}$ y de María del Cristo Pérez (Apolant, 1966b: 560). Dos años más tarde recibió tres suertes de estancia en merced por parte del gobernador de Montevideo con la obligación de poblar esas tierras con 10.000 cabezas de ganado ${ }^{199}$. Efectivamente, en el censo de 1769 esas estancias situadas entre los ríos San José y San Gregorio disponían de un stock de animales compuesto por 16.000 cabezas de ganado vacuno, 25 yeguas, 30 caballos, 500 ovinos y 100 cerdos (Apolant, 1966a: 113). Durante ese mismo año denunció un terreno realengo de grandes dimensiones (de 4 a 5 leguas de frente y de 6 a 7 leguas de fondo) situado entre los arroyos Maciel y Porongos, frente al río Yi cuyo remate se efectuó recién en $1779^{200}$ (Pivel Devoto, 1964: 147-152). Los 8.172 cueros que sabemos que trasladó hasta Montevideo según figura en el cuadro 6 lo posicionaban aún en la segunda mitad de la década de 1780 entre los mayores productores de corambre de la región. En la década siguiente la que aparece entre los grandes productores es su esposa, Inés Durán, con 1.184 cueros marcados y 5.174 cueros orejanos (ver cuadro 7) lo que probablemente haya sido una estrategia familiar por la sucesión de los bienes de su madre María del Cristo Pérez fallecida en $1790^{201}$.

Juan Francisco García de Zúñiga constituye un caso particular dentro de este primer núcleo de corambreros de Montevideo. Comerciante de la ciudad de Buenos Aires, comenzó su actividad económica en Montevideo a fines de la década de 1760. Su

${ }^{198}$ En la tasación hecha por el cabildo de Montevideo en 1751 Manuel Duran figura como uno de los pobladores con mayor patrimonio. Sus bienes fueron valuados por un total de 6.262 pesos de la manera siguiente: por casa y sitio 1.500 pesos, cuatro esclavos y una esclava 1.000 pesos, una chacra 150 pesos, por 1.700 cabezas de ganado vacuno a 2 pesos cada una 3.400 pesos, por 200 yeguas a 4 reales cada una 100 pesos y por 300 ovejas a 3 reales 112 pesos (Apolant, 1966a: 11). Manuel Duran se casó en 1739 con María del Cristo Pérez, con quien tuvo, 7 hijos y falleció en 1765 (Apolant, 1966b: 198). En virtud de los privilegios acordados a los pobladores de Montevideo Manuel Durán recibió 6 suertes de estancias entre 1753 y 1764 para él mismo y para sus hijos (Pivel Devoto, 1964: 59-60, 71-72, 77-78).

${ }^{199}$ En 1768 aumentó las dimensiones de su propiedad adquiriendo una suerte de estancia por 281 pesos y dos reales. Esas tierras situadas en el río San José había pertenecido a Benito Algarañas y fueron vendidas por su albacea Domingo Guerrero (Pivel Devoto, 1964: 692-693).

${ }^{200}$ En 1778 volvió a realizar una denuncia de tierras realengas aunque esta vez de una extensión aún mayor (12 leguas de frente y 20 de fondo) situadas en el paraje Tacuarembó Grande y Chico con el Yaguary y el Caraguatá, con frente al sur sobre el río Negro, fondos hacia la Cuchilla Grande que lindaban por el oeste con el Tacuarembó chico y al este con el río Negro (Pivel Devoto, 1964: 242-255). De todas maneras, Sala de Tourón, Rodríguez y de la Torre (1968: 71) afirman que esta denuncia no fue efectiva ya que Miguel Ignacio de la Cuadra nunca ocupó esas tierras, ni tampoco su cuñado Manuel Durán que aparentemente iba a ser el beneficiado.

${ }^{201}$ El 15 de abril de 1790 dio poder para testar a su hija Inés Durán y su fallecimiento se produjo cuatro días más tarde (Apolant, 1966b: 199). 
accionafr como un gran productor de corambre se inició a partir del momento en que compró la mayor parte de las estancias que habían pertenecido a los jesuitas por la considerable suma de 29.000 pesos. Aunque al parecer nunca abonó realmente el precio de esas tierras. De acuerdo a lo que indican Sala de Tourón, Rodríguez y de la Torre (1768: 31), luego de su muerte en 1815, los herederos solamente disponían de las mensuras como prueba de sus derechos sobre esos terrenos. Luego de la adquisición de los bienes de los jesuitas, Juan Francisco García pudo aumentar las tierras que le pertenecían mediante otras compras ${ }^{202}$.

Todos los datos que podemos recabar, provenientes tanto de fuentes cuantitativas como cualitativas, coinciden en el hecho de que Juan Francisco García era uno de los mayores, sino el mayor productor de la región en las décadas de $1780 \mathrm{y}$ 1790. Por un lado, los 24.147 cueros del cuadro 6 y 25.600 del cuadro 7 (ver capítulo 2) que hacen una producción anual superior a los 5.300 y 4.700 cueros respectivamente, lo que implicaba tener como mínimo un stock de animales cercano a los 26.500 cabezas de ganado vacuno. Por otro lado, en 1790 el Alcalde de primer voto del cabildo de Montevideo afirmaba que era público y notorio que Juan Francisco García era el vecino que era propietario de la mayor cantidad de ganado (AECM, 1942b:357).

En febrero de 1780 el cabildo de Montevideo contestando un oficio del gobernador que prohibía la matanza de vacas, mencionaba a Melchor de Viana, Juan Francisco García, María Francisca de Alzaybar, María del Cristo Pérez y Miguel Ignacio de la Cuadra como los poderosos hacendados que a pesar de ser los que podían pagar más peones se contentaban con mantener unos pequeños rodeos por lo que pedían obligar a los tres primeros a mantener rodeos de 10 a 12 mil cabezas y a los otros dos de 4 a 5 mil como solución del abastecimiento de carnes de la jurisdicción y a los desordenes de la campaña ya que todos los cueros de toros que no estuviesen marcados podrían ser decomisados (AECM, 1942a: 241-249). Los planes de los cabildantes de ese año no se llevaron a cabo, como pudimos comprobar por la cantidad de cueros orejanos que ingresaron a Montevideo entre 1791 y 1797. Lo que sí sucedió durante la década de 1780 fue una ampliación del grupo de corambreros montevideanos por una

\footnotetext{
${ }^{202}$ Juan Francisco García de Zúñiga compró las siguientes estancias: en 1768 a Bruno Múñoz de una extensión de 3,5 leguas de frente y fondo correspondiente por 1.000 pesos; en 1785 a Francisco Antonio Maciel por 4.225 pesos una estancia en el río Negro con ranchos, corrales y demás utensillos, 8 esclavos, 6.000 cabezas de ganado, 300 yeguas, 50 caballos, 50 bueyes y 6 carros; y en 1804 a Josefa Morales por 1.000 pesos una extensión de 2.000 varas de frente y una legua de fondo en el arroyo Colorado (Pivel Devoto, 1966: 697, 706 y 736).
} 
recomposición que se dio por la incorporación de nuevos integrantes ya sea por el inicio de la actividad económica de algunos de los hijos o por ingreso a la sociedad montevideana de inmigrantes que se vincularon a los antiguos corambreros mediante el casamiento con sus hijas.

8.2. Recomposición del grupo de agentes económicos. El casamiento como forma privilegiada de acceder a los derechos de explotación sobre el ganado.

En la década de 1780 se produjo un proceso de recomposición del grupo de agentes económicos caracterizado por la incorporación de nuevos integrantes. Esto fue producto de la conjunción de varias situaciones. Por un lado, al mismo tiempo que la reanudación del tráfico marítimo abría una nueva expansión de la producción de cueros, la política del "arreglo de los campos" emprendida por el virrey Loreto a partir de 1784, suspendió las denuncias de tierras dejando a los enlaces matrimoniales como el instrumento exclusivo para que los nuevos miembros del grupo pudieran acceder a las explotación legal de las reservas de ganado cimarrón. Por otro lado, el ciclo de vida de los antiguos corambreros implicó que por esta época parte de su actividad económica fuese emprendida por algunos de sus hijos.

Manuel Solsona, por ejemplo, no necesitó efectuar ninguna denuncia de tierras ni comprar estancias para transformarse en uno de los mayores productores de cueros del área, tal como lo muestran los 21.056 cueros que tenemos registrados como ingresados por él entre 1784 y 1797 (cuadros 6 y 7). A partir de 1780 se encontró con que podía disponer de las tierras que habían pertenecido a Francisco Alzaybar, de las que hizo uso al menos hasta 1798 cuando las estancias fueron rematas en subasta pública y compradas por Miguel Ignacio de la Cuadra por 24.500 pesos $^{203}$ (Pivel Devoto, 1964: 725).

La herencia de Francisco de Alzaybar llegó a manos de Manuel Solsona de la manera siguiente. Francisco de Alzaybar, que como vimos falleció en 1773, nombró

\footnotetext{
${ }^{203}$ Las tres estancias que se vendieron eran las denominadas como la Grande, la Barra y la Bolsa. Se vendieron con todos sus ganados y demás utensillos. De la Cuadra se obligaba a pagar el $5 \%$ al contado, el principal y los réditos en 3 años y a hipotecar en garantía, todos sus bienes muebles y raíces, especialmente las 3 estancias citadas. El remate había sido aprobado por la Real Hacienda (Pivel Devoto, 1964: 725).
} 
como su heredero universal y albacea a su hermano Martín. Por su parte, Martín de Alzaybar murió en 1780 dejando como heredera a su sobrina Gabriela de Alzaybar, hermana de María Francisca, quien se había casado con Manuel Solsona en 1775 (Apolant, 1966b: 418).

Otros de los nuevos corambreros montevideanos de la década del 1780 se iniciaron en la actividad luego de sus enlaces matrimoniales con las hijas de María Francisca de Alzaybar. Las fechas de esos casamientos (ver figura 2) son coincidentes con la reactivación del comercio luego de la guerra con Inglaterra que hacía apetecible la producción de cueros y con la política de arreglo de los campos emprendida por Loreto que suspendió las faenas misioneras e impidió efectuar nuevas denuncias de tierras.

Figura 2. Descendencia de José Joaquín de Viana y María Francisca de Alzaybar

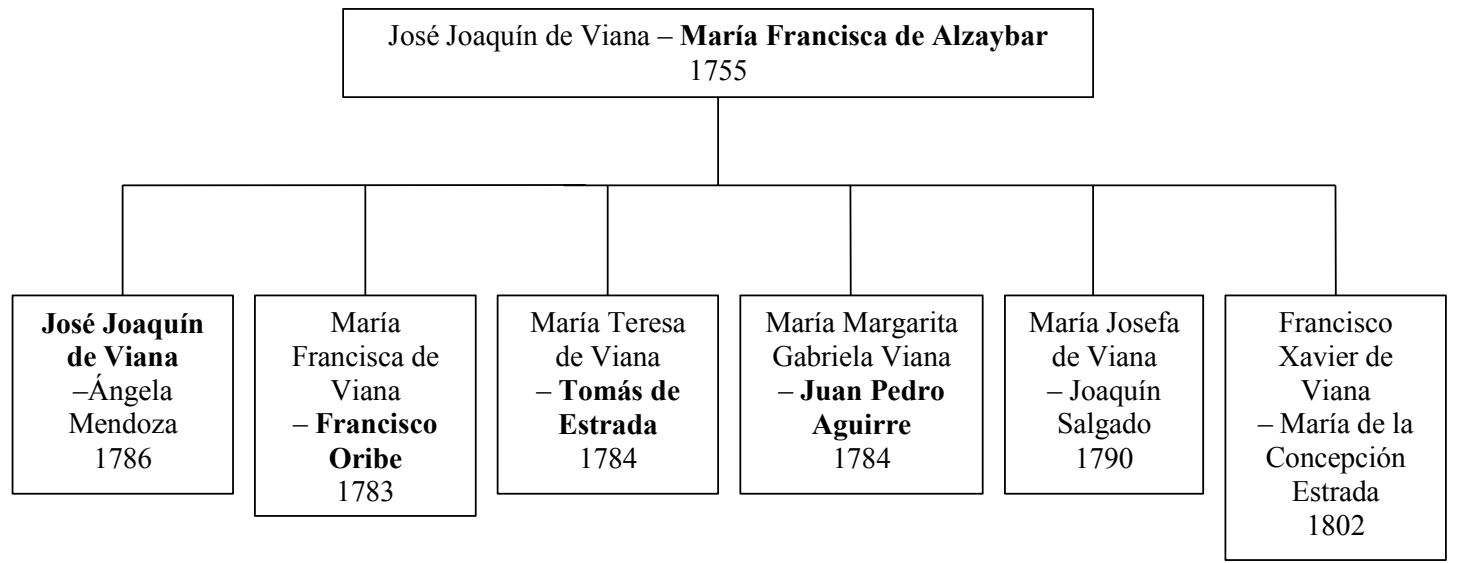

Fuente: Elaboración propia a partir de Apolant (1966b: 415)

En 1784 sucede un incidente revelador de la magnitud que cobró el acopio de cueros en Montevideo durante el momento de la reactivación del tráfico marítimo al finalizar la guerra con Inglaterra. El Alguacil Mayor de Montevideo le pidió a Juan Pedro Aguirre fianza por los cueros que se encontraban en su barraca ya que no había podido “dar razón de qué campos y ganados proceden”. De la inspección surge que, en ese momento, había 18.200 cueros pertenecientes a diferentes sujetos que habían sido 
desembarcados del navío San Miguel y Ánimas, ya que no había podido iniciar su navegación hacia Cádiz ${ }^{204}$, otros 2.966 de propiedad de Domingo Igarzabal ${ }^{205}$ y 1.000 que Aguirre había comprado a Igarzabal. ${ }^{206}$.

El episodio muestra las relaciones que Aguirre mantenía con los administradores misioneros y las dificultades que le trajo la política emprendida por Loreto, especialmente en cuanto a la suspensión de las faenas de corambre misioneras y al control sobre la circulación de los cueros. Al igual que otros inmigrantes encontró la solución en la vinculación con una de las familias arraigadas en Montevideo. Ese mismo año contrajo matrimonio con María Margarita Gabriela de Viana, una de las hijas de María Francisca de Alzaybar. De esta manera pudo sortear esos problemas y acceder a la explotación legal del ganado. A partir de ese momento Juan Pedro Aguirre se transformó en un activo productor de cueros, como atestiguan los 3.479 cueros que el cuadro 6 y los 19.705 del cuadro 7, abandonando paulatinamente la actividad comercial.

De la misma manera, Francisco Oribe contrajo matrimonio en 1783 con María Francisca Viana y, lo mismo hizo, Tomás Estrada con María Teresa Viana en 1784, ambas hijas de María Francisca de Alzaybar (Imagen 1). Los dos aparecen en los años siguientes como productores de cueros, así como también uno de los hijos de "la Mariscala", José Joaquín de Viana, como se puede observar en los cuadros antes mencionados.

8.3. Desaparición de los corambreros montevideanos como grupo de agentes económicos ante las transformaciones productivas del espacio económico.

El agotamiento de las reservas de ganado cimarrón en el área de Montevideo y el consecuente avance de la ganadería de rodeo coincidió en los últimos años del siglo XVIII y los primeros del XIX con la desaparición de los corambreros montevideanos.

\footnotetext{
${ }^{204}$ La fragata San Miguel y Ánimas a cargo del capitán Pedro Paulo de Lima finalmente pudo emprender viaje con destino a Cádiz el 20 de diciembre de ese mismo año. AGN Montevideo 1784 IX 2-4-3

${ }^{205}$ Comerciante de Buenos Aires a cargo de la Administración de las Misiones y, por lo tanto, de las faenas que se realizaban de la otra banda del Río Negro.

${ }^{206}$ El caso se resolvió, finalmente, luego de que Agustín Casimiro de Aguirre, en representación de su primo, presentó (en Buenos Aires) una denuncia por agravios contra el funcionario y se dictaminó que no debía dar fianza debido a que "por bien notorios principios de derechos no están obligados a darlas los que poseen bienes raízes (sic) de competente valor, como se verifica por notoriedad en Don Juan Pedro de Aguirre" por lo que debían devolvérsele los cueros. AGN Tribunales Leg. 82 Exp. 1, IX 36-5-5
} 
Los que quedaron debieron transformar sus establecimientos productivos o dejar su lugar a nuevos productores. Ese proceso puede observarse en el fraccionamiento de las grandes extensiones de tierra, ya sea por venta o arrendamiento, que llevaron a cabo los herederos de los antiguos corambreros.

Melchor de Viana, por ejemplo, falleció en 1796. Como vimos, tres años antes había vendido una de sus estancias más importantes a Joaquín de Chopitea. Entre 1796 y 1803 su viuda y albacea, María Antonia de Achucarro, vendió el resto de sus establecimientos en seis operaciones ${ }^{207}$ y ninguno de sus hijos y yernos parece haberse dedicado a la producción corambrera ${ }^{208}$.

Los hijos y yernos de María Francisca de Alzaybar, por su parte, también se fueron desvinculando de la producción durante esos años vendiendo o arrendando las tierras que habían recibido por herencia. En 1795 Tomás de Estrada y su esposa María Teresa de Viana se desprendieron de las tierras que habían recibido en dos ventas efectuadas en distintos momentos del año ${ }^{209}$. Por su parte, María Margarita Gabriela de Viana, en esos momentos ya viuda de Juan Pedro de Aguirre, vendió parte de sus estancias en cuatro operaciones efectuadas entre 1798 y $1802^{210}$. En 1799 Francisco

\footnotetext{
${ }^{207}$ En 1796 vendió una estancia situada desde el Yerbal Grande hasta el Yerbal Chico, con fondos a la Cuchilla de Dionisio a Salvador Quintana por 500 pesos. El 4 de enero de 1799 efectuó dos ventas. Un terreno de 2 leguas de frente y 5,5 de fondo en las puntas del arroyo Yerbal Grande hasta donde hace barra con los Yerbalitos y las caídas de la Cuchilla Dionisio, fondo hasta la Cuchilla Grande a Salvador Quintana por 1.200 pesos y otro de 4 leguas de frente y 5 de fondo ubicado entre la Cuchilla Ladrones y el arroyo Avestriz Chico cerca del río Olimar a Ramón de Lago por 550 pesos. El 22 de enero de ese mismo año vendió a Joaquín de Chopitea una estancia, denominada "La Calera de San José" que se extendía entre los arroyos San José y Cagancha, con ganado vacuno, caballar y ovejuno y algunas edificaciones por 3.074 pesos y 2,5 reales. En 1800 realizó otra operación de venta por un terreno de 2,5 leguas de frente y 3 de fondo en las puntas de la Cañada y Cuchilla del difunto Dionisio que compró Francisco Medina por 600 pesos. Por último, en 1803 José Tomás Guevara le compró una suerte de estancia en el arroyo Mataojo por 700 pesos. (Pivel Devoto, 1964: 721, 728-729, 733 y 735)

${ }^{208}$ Melchor de Viana y María Antonia de Achucarro tuvieron 8 hijos (6 mujeres y 2 varones). La mayor parte de sus hijas se casaron integrantes de la Real Armada y sus dos hijos varones siguieron la carrera militar (Apolant, 1966b: 508-509) lo que revela una tipo de estrategia familiar que contrasta con la llevada a cabo por María Francisca de Alzaybar.

${ }^{209}$ El 3 de junio de 1795 Tomás Estrada y su esposa vendieron un rincón de estancia situado entre los ríos Luis Pereira y Pavón por 1.800 pesos que María Teresa de Viana había recibido por donación de su madre. El 3 de diciembre de ese mismo año Juan Ignacio Martínez les compró un terreno de 3 leguas de frente y 10 de fondo ubicado frente al río Santa Lucía, fondo a la Isla de Milán, al este el arroyo del Soldado y al oeste el arroyo Gaitán por 3.000 pesos que María Teresa había recibido como herencia de su padre. (Pivel Devoto, 1966: 719-720)

${ }^{210}$ En 1798 vendió a Martín José Artigas una estancia entre los arroyos Casuá y Soldado, frente al río Santa Lucía por 3.000 pesos. En 1799 un terreno de estancia a Javier de Echenique ubicado entre arroyos Olimar Grande y Las Pavas por 2.000 pesos. Al año siguiente otro terreno de estancia situado entre los arroyos Gutíerrez y Olimar Grande por 3.950 pesos a Benito López. Por último, el 28 de abril de 1802 Agustín de Abreu y Orta le compró una estancia que se extendía desde las vertientes del río Yi hasta los arroyos Cordobés y Sauce o Malvajar por 9.000 pesos. (Ídem: 726, 730, 732 y 734)
} 
Oribe y su esposa también vendieron sus estancias ${ }^{211}$. Francisco Javier de Viana hizo lo propio vendiendo sus tierras en tres oportunidades ${ }^{212}$. Por último, José Joaquín de Viana vendió una parte de sus tierras y dio en arriendo otras, especialmente en los primeros años del siglo $\mathrm{XIX}^{213}$.

Miguel Ignacio de la Cuadra e Inés Durán constituyen un caso particular ya que no tuvieron hijos, por lo tanto a la muerte de ésta en $1805^{214}$ sus bienes fueron heredados por sus hermanos y sobrinos. Su sobrino y albaceas Juan José Durán, hijo de Manuel Durán y Luisa Pagola ${ }^{215}$, vendió una parte de esas tierras en 1809 y 1810 a José Fernández y Manuel Royano respectivamente ${ }^{216}$.

Fernando Martínez es otro ejemplo de un productor que se fue retirando de la actividad paulatinamente vendiendo y arrendando sus tierras. En la década de 1780 se desprendió de parte de sus tierras en cuatro ventas, tres de ellas efectuadas en los años 1788 y $1789^{217}$. Esto podría explicar la disminución de su producción de cueros que

\footnotetext{
${ }^{211}$ Francisco de Oribe y su esposa María Francisca de Viana vendieron tres rincones de estancia (el que formaba el arroyo Godoy con el Barriga Negra y Polancos; el limitado por los arroyos Molles y Godoy; y el que llaman de Pirarajá, entre el arroyo de este nombre y el Godoy) con ganado, ranchos, poblaciones y útiles a Juan Francisco Martínez Moldes por 6.000 pesos. Los dos primeros rincones los habían recibido por herencia y el otro lo habían comprado. (Ídem: 731)

${ }^{212}$ En 1794 vendió a Juan José Brid un terreno de estancia que se extendía desde la Cuchilla que divide las aguas del Río de la Plata a la Laguna Miní, siguiendo el arroyo Polanco, hasta el de Barriga Negra, y al sur de éste hasta la Cuchilla del río Santa Lucía por 2.000 pesos. El 15 de septiembre de 1801 efectuó otra venta de un terreno de estancia entre los arroyos Tapes, Igua y Marmarajá con el ganado respectivo que adquirió Juan José Seco por 8.000 pesos. Por último, en 1809 vendió a Joaquín de Maguna una estancia ubicada entre los arroyos Gutíerrez y Pirarajá con frente a la Cuchilla Yerbal Chico y fondos al Cebollatí por 3.000 pesos. (Ídem: 717, 733-734 y 743)

${ }^{213}$ Las ventas realizadas por José Joaquín de Viana son las siguientes: en 1787 un terreno de 3 leguas de frente y 6 de fondo en el paraje Barriga Negra, entre los arroyos Los Tapes y Barriga Negra, a Esteban Artigas por 400 pesos; en 1791 una estancia entre los arroyos Barriga Negra y Tapes, desde sus nacientes en la Cuchilla hasta los fondos del río Cebollatí a Juan José Seco por 2.500 pesos: en 1806 media legua de frente y 1,5 de fondo en la costa del río Santa Lucía arriba a Fermín Ibargoyen por 350 pesos; y en 1808 una estancia de 6 leguas, 3.400 varas de frente y 3 leguas 5.400 varas de fondo entre los arroyos Verdún, Santa Lucía y la Cuchilla que divide las aguas al Solís Grande y al nominado arroyo Santa Lucía con ganado vacuno, caballar, lanar, poblaciones y dos esclavos a José Ramírez Pérez por 7.000 pesos. Los contratos de arriendo habían sido establecidos con José Ramírez en 1802 y 1807. En el primero se arrendaban dos rincones entre la Cuchilla Grande con aguas vertientes de esta a Olimar Chico y a Godoy durante ocho años por 300 pesos anuales. El segundo arriendo se hizo sobre una estancia ubicada en Vejiga también otros ocho años por la suma de 1.000 pesos anuales. (Ídem: 708-709, 712, 740-741 y 771 776)

${ }^{214}$ Miguel Ignacio de la Cuadra había fallecido dos años antes.

${ }^{215}$ Juan José Durán también había sido albacea de su padre muerto en 1803 (Apolant, 1966b: 518).

${ }^{216}$ El 22 de marzo de 1809 vendió tres suertes de estancias contiguas ubicadas en las nacientes del río Maciel a José Fernández por 600 pesos y el 21 de noviembre de 1810 unos terrenos de estancia entre los arroyos Cordobés y Pablo Páez a Manuel Royano por 400 pesos (Pivel Devoto, 1964: 742 y 746).

${ }^{217}$ El 4 de octubre de 1781 vendió a Francisco Maciel unos terrenos entre los arroyos Chileno y Carpintería, desde su nacimiento en la Cuchilla Grande hasta su desagüe en el río Negro, el que sirve por lindero norte, así como por el sur la Cuchilla Grande por 600 pesos dobles. En 1788 un terreno de estancia entre los arroyos Molles y Minas a Hermenegildo Laguna por 800 pesos. En 1789 dos terrenos
} 
observamos comparando los datos de los cuadro 6 y 7. En 1795 su esposa Martina Goméz efectuó en su nombre ocho contratos de arrendamientos de estancias ${ }^{218}$. Finalmente, el 5 de mayo de 1809 Fernando Martínez vendió un rincón de estancia ubicado entre entre el arroyo Yi y Maestre de Campo a Juan Francisco Solorzano por 1.000 pesos (Pivel Devoto, 1964: 743).

Estos no son más que algunos indicios del proceso de cambio en la estructura productiva y de la recomposición de los agentes productivos que sufrió el área durante el cambio de siglo. El tiempo de los corambreros montevideanos había pasado. Luego de más de tres décadas de explotación, las reservas de ganado cimarrón cercanas se agotaron y las vaquerías se mudaron a tierras situadas muchos kilómetros al norte del río Negro y fueron llevadas a cabo por nuevos agentes, de los que no tratamos aquí pero que pueden ser objeto de futuras investigaciones. En el área cercana se dio el proceso natural que llevó al triunfo definitivo de la ganadería de rodeo. Eso implicó una disminución en el tamaño de los establecimientos, lo que se condice con el fraccionamiento de las antiguas propiedades que observamos en este apartado. Los antiguos corambreros que no se habían desprendido de sus tierras sufrieron los avatares de los nuevos moviemientos políticos ${ }^{219}$. El siglo XIX será el momento de la guerra primero y más tarde, luego de la posterior recomposición del stock de ganado, de la hegemonía económica y política de los grandes estancieros. Lo que nos remite

de estancia, uno entre los arroyos Villasboas y Tejera desde sus nacientes hasta el desagüe en el río Yi a José Antonio Arrube por 500 pesos y otro en las puntas del arroyo Tejera a Juan Medina también por 500 pesos. (Ídem: 703-704 y 710-711)

${ }^{218}$ Todos los contratos se hicieron por el plazo de dos años y son los siguientes: a José Olivera un terreno de estancia de 1,5 legua de frente y 4,5 de fondo entre los arroyos Mollecitos y Talita por 200 pesos anuales; a Pedro Casavalle un terreno de estancia de una legua de frente y 3,5 de fondo entre el arroyo Caballero y el río Yi por 60 pesos al año; a Andrés Fleitas, vecino de la jurisdicción del río Negro, una estancia en el arroyo Carpintería, en inmediaciones, del río Negro por 25 pesos anuales; a Manuel Cejas un terreno de estancia de 1 legua de frente y 2 de fondo en la terreno de estancia de 1 legua de frente y 2 de fondo por 50 pesos al año; a Diego González, vecino de la villa de Nuestra Señora de Guadalupe, un terreno de 8 cuadras entre los arroyos Villasboas y Caballero por 20 pesos anuales; a Juan Gómez una suerte de estancia en las puntas del arroyo Las Conchas contra la Cuchilla Grande por 50 pesos anuales; a Francisco Blanco un terreno de estancia de media legua de frente y 1 de fondo en la Horqueta del Caballero, entre los arroyos Caballero y Tabares a 45 pesos por año; y, por último, a Domingo Queirúa un terreno llamado el Rincón de las Conchas 100 pesos al año. (Ídem: 780-782)

${ }^{219}$ Podemos ver un ejemplo de esta situación en el testamento que redactó en Montevideo el 27 de agosto de 1823 María Antonia de Achucarro, viuda de Melchor de Viana, en el cual declaró que “...durante los sitios que sufrió esta plaza por las tropas de Buenos Aires, sacaron estas y las orientales, de dichas estancias (que casi absolutamente destruyeron) todos los ganados vacunos que tenían de rodeo, las manadas de yeguas mansas, y crías que había de caballos, cuyas haciendas, por su considerable número, componían la mayor parte de nuestros bienes; y finalmente que D. José Artigas me despojó durante su gobierno de la mayor y principal parte de los terrenos en que se hallaban las referidas estancias, y los repartió entre varios sujetos, que sin otro título hasta hoy los ocupan..." (Azarola Gil, 1926:96). 
nuevamente a la vinculación entre la explotación del ganado y las relaciones de poder que se establecían en la sociedad y cómo estas se enmarcaban dentro del sistema político, primero dentro de la monarquía española y luego en los distintos estados que surgieron en las tierras rioplatenses. 


\section{Capítulo 9}

\section{Las relaciones de poder en Montevideo y Maldonado}

A fines del siglo XVIII la corona española aún estaba lejos de convertirse en una monarquía absoluta. Después de casi cien años de intentos de llevar a cabo un reformismo centralizador por parte de los borbones poco había cambiado en la estructura política de sus dominios en Europa y América. En realidad, el sistema político estaba conformado por un conjunto de corporaciones y poderes territoriales que entablaban negociaciones con la corona y que conformaban lo que se puede denominar como monarquía compuesta o monarquía policéntrica ${ }^{220}$.

En la América hispana las unidades territoriales estaban conformadas en torno a los cabildos. Esta institución permitía al sector dominante local controlar los recursos del territorio y, al mismo tiempo, negociar con las autoridades que representaban a la corona. Federica Morelli (2005: 32) sostiene que las reformas borbónicas reforzaron el poder de las corporaciones urbanas y, por ende, también la composición plural de la monarquía.

La política de poblamiento emprendida por la corona en las fronteras del Río de la Plata creó nuevos cabildos en la región durante el siglo XVIII. Julio Djenderedjian (2008) sostiene que esas institucionales ayudaron a la conformación de espacios de poder locales. Como ya vimos, también afirma que ese acceso a los instrumentos de poder era un elemento clave en la gestión empresarial, en tanto implicaba permisos para el acceso a la tierra o el manejo de tropas milicianas que podían ayudar a controlar la mano de obra, además de generar lazos de lealtades y solidaridades, especialmente a través de los beneficios del fuero militar (Djenderedjian, 2003: 295-296).

En este capítulo indagaremos sobre el accionar de corambreros y estancieros en los cabildos de Montevideo y de Maldonado a partir del análisis de los resultados de las

${ }^{220}$ Para un análisis de la monarquía española como una monarquía compuesta ver: Russell y Gallego (1996) y para una caracterización como una monarquía policéntrica ver: Cardim, Herzog, Ruiz Ibáñez y Gaetano (2012). 
elecciones de los regidores, de los temas tratados en las sesiones y de los acuerdos alcanzados. A partir de ese estudio podremos observar que en un primer momento la actividad principal de un cabildo consistía en la consolidación territorial, lo que implicaba, además, asegurar su dominio sobre los recursos de ese espacio, en este caso la tierra y, sobre todo, el ganado. En el caso de Montevideo se pudo ver además que una vez conseguido ese objetivo la presencia de los autodenominados hacendados se torno esporádica. De esta manera, planteamos que estos agentes buscaban ser electos como regidores solamente en los momentos en que era necesario negociar asuntos que concernían a sus intereses económicos. Sin embargo, en los años finales de la década de 1780 y especialmente en la de 1790, el crecimiento urbano y la expansión comercial tuvieron como consecuencia que el cabildo dejase de presentarse como un vehículo eficaz para canalizar los intereses de esos agentes económicos que buscaron otras vías para lograr sus cometidos.

Por otro lado, las autoridades incentivaron la aparición de corporaciones ligadas a determinadas actividades económicas en un proceso que Javier Kraselsky (2010) denominó como centralización corporativa. Ello llevo a la reuniones de juntas de comerciantes y hacendados por separado y a la creación del consulado en Buenos Aires que estuvo integrado por ambas categorías socio ocupacionales desde 1797. El surgimiento de esas nuevas corporaciones estuvo ligado, en parte, al hecho de que los cabildos ya no representaban eficazmente los intereses de los individuos vinculados a esas actividades. Por eso en este capítulo también analizaremos la conformación y el accionar del gremio de hacendados en la jurisdicción de Montevideo.

Por último, el cabildo de Maldonado se presenta como caso ejemplar de las instituciones creadas en toda la región Río de la Plata como correlato de la política de poblamiento de la corona en estas zonas de frontera. Así podremos analizar el lugar que ocupaban los agentes económicos, vinculados a la explotación del ganado vacuno, en estos nuevos espacios de poder. 
9.1. Años iniciales del cabildo de Montevideo: el proceso de consolidación de un territorio

El cabildo de Montevideo comenzó su actividad en 1730, pocos años después de la fundación de la ciudad, y se mantuvo sesionando hasta bien entrado el siglo XIX. Sin embargo, en esta ocasión estudiaremos su desempeño solamente hasta 1807 para no extendernos con los pormenores de la crisis posterior del sistema político de lamonarquía.

Podemos dividir el accionar del cabildo durante la época que analizamos en dos períodos. El primero se extiende desde su creación en 1730 hasta 1784. Esta etapa se caracterizó por una lenta consolidación del territorio que había sido asignado como jurisdicción de la ciudad ${ }^{221}$. En el proceso de imponer su control sobre los recursos de ese espacio el cabildo de Montevideo debió imponerse frente al accionar de otros competidores por el usufructo de las tierras y, especialmente, del ganado.

A su vez, este primer período podría dividirse en dos momentos. Antes de 1751 existía una actitud defensiva incentivada por la preocupación que generaban las incursiones de los indios, que en los acuerdos están identificados como minuanes. En esos primeros años son recurrentes las menciones a las incursiones de los indios minuanes en los acuerdos del cabildo de Montevideo. El 4 de noviembre de 1730 se informaba que los indios minuanes habían invadido las estancias de los vecinos (RAGA, 1885: 279-281). El 27 de febrero de 1732 se realizan gestiones para entablar la paz con los indios minuanes, con ese objetivo efectuó una reunión con el cacique Tacu que se presentó junto a otros 19 indios (Ibíd.: 311-313). La paz acordada parece haber durado hasta 1742 cuando los vecinos se quejan nuevamente de los daños ocasionados a las estancias por parte de los indios minuanes (RAGA, 1886: 72-74). El 12 de julio de

${ }^{221}$ El territorio de la jurisdicción se puede ver delineado en el mapa 7 (ver capítulo 4). De acuerdo a lo indicado por el comisionado Pedro Millán el 24 de diciembre de 1726 en el Libro Padrón elaborado durante la fundación de la ciudad los límites de la jurisdicción eran: "desde la boca que llaman del arroyo de Jofré, siguiendo la Costa del Río de la Plata hasta el Puerto de Montevideo, y desde él siguiendo la Costa de la Mar hasta Topar con las Sierras de Maldonado a detener de Frente este Territorio; y por mojon de ella el Cerro que llaman de Pan de Azúcar, y de fondo hasta las Cabezadas de los Ríos San José y Santa Lucía que van a Rematar a un Albardón que sirbe de Camino a los faeneros de Corambre, y atraviesa la Tierra desde la misma Sierra y parage que llaman de Cebollatí, y viene a rematar este dicho albardon, a los Cerros que llama Guejonmi y divide las Vertientes de los dichos Ríos San José y Santa Lucía, a esta parte del Sur, y las que corren aun la parte del Norte y componen el Río de Yy, y corren a los Campos del Río negro, y con esta Seña del dicho albardon que divide las bertientes a Norte y Sur, y ha de servir de mojón por la parte del fondo queda deslindado el Término y jurisdicción..." (RAGA, 1885: 100-101). 
1745 los vecinos vuelven a quejarse por los daños que experimentaban los vecinos en sus ganados y acuerdan dar cuenta del asunto al Gobernador y Capitán General para que mande que los indios minuanes se retiren de la jurisdicción para evitar entrar en guerra con ellos (Ibíd.: 175-176). Luego se vuelven a reiterar las mismas quejas el 20 de junio de 1746, el 5 de mayo de 1749 y el 18 de febrero de 1750 (Ídem: 203, 264 y 288).

La victoria sobre los minuanes en 1751 y la creación de la gobernación de Montevideo marcan el inicio de una nueva etapa caracterizada por la paulatina desaparición de los competidores. A la disminución de la amenaza de incursiones de los indios le siguió la expulsión de los portugueses de Colonia de Sacramento en $1777^{222}$. Sin embargo, la crisis del sistema misionero desbarató al último y más importante de los competidores por el ganado cimarrón ya que su desaparición implico que los montevideanos tuvieran abierto un espacio de expansión hacia el norte que ya habían ido ocupando paulatinamente, lo que causo las disputas legales que veremos en el apartado siguiente $^{223}$. El espacio pastoril misionero tuvo un lento proceso de descomposición que se manifestó primero en las consecuencias que trajo el resultado de la guerra guaranítica $(1754-1756)^{224}$, luego en la expulsión definitiva de los jesuitas en

${ }^{222}$ En varios acuerdos del cabildo se hace mención a la presencia de tropas compuestas por portugueses dentro de la jurisdicción de Montevideo. La primera fue el 19 de abril de 1730 cuando el alcalde provincial vio dos tropas de portugueses, una en la costa de Yi y otra en el paraje donde se habían quemado las carretas de Monzón (RAGA, 1885: 237-238). Los cabildantes informaron también que el 4 de octubre de 1734 los portugueses habían arriado las vacas, caballos y hasta los bueyes lo que implicó que muchos vecinos se vieran impedidos de realizan sus labranzas (Ibíd.: 368-369). El 25 de febrero de 1738 el alcalde de la Santa Hermandad pide que se le proporcionen una partida de 15 vecinos y 15 soldados, o en su defecto 30 vecinos, para recorrer la campaña. El argumento que esgrime es que algunos changadores se habían pasado a los portugueses llevándose caballadas para hacer corambre y correr vacas (Ibíd.: 447)

${ }^{223}$ En los acuerdos también se ve reflejada la competencia con los jesuitas por el ganado. El 20 de diciembre de 1731 el alcalde de la Santa Hermandad encontró una tropa de indios tapes que estaban recogiendo ganado vacuno con licencia del padre superior de la orden jesuita (RAGA, 1885: 303). El 24 de noviembre de 1733 el Alcalde Provincial informa nuevamente que los indios de los jesuitas estaban recogiendo vacas en la jurisdicción (Ibíd.: 349-350). El 15 de diciembre de 1735 se reiteran las quejas por las incursiones de los indios tapes de los jesuitas (Ibíd.: 399). El 3 de octubre de1757 menciona la necesidad de que las haciendas de los vecinos están guardadas por las entradas de los indios tapes por lo que se recogen 192 pesos y 4 reales como producto de las contribuciones de los vecinos para hacer dos fuertes, uno en Santa Lucía chico y otro en el Arroyo de Cazupa (RAGA, 1886: 492-494). El 12 de noviembre de 1761 se reiteran las quejas los robos de ganado que genera la presencia de indios Tapes pero, en esta ocasión, se habla de que están ubicados en Las Tunas, sobre la costa del río Negro, lo que revela que ya en ese año los montevideanos han extendido sus actividades hasta esas tierras (RAGA, 1887: 229-232).

${ }^{224}$ Podemos ver una manifestación de las consecuencias de esa guerra en lo acaecido durante el año 1762 cuando un grupo de indios minuanes al mando del cacique Cumandat se presentan ante el gobernador y el cabildo para llegar a un acuerdo de paz que les permita asentarse dentro de la jurisdicción de Montevideo. De acuerdo a la declaración del cacique se habían ido de las misiones porque, al no haber ayudado en la guerra a los jesuitas, estaban "al desabrigo" y por eso buscaban amparo sometiéndose al gobierno montevideano (RAGA, 1887: 288-293). 
1767 y, por último, en la suspensión de las faenas de cueros que llevaban a cabo los administradores laicos de las misiones en 1784.

El período siguiente se caracterizó por el hecho de que el cabildo perdió la capacidad de representar los intereses de aquellos que querían asegurarse la explotación del ganado. Al igual que el anterior, también es posible dividir este período en dos etapas. Los primeros años de 1784 a 1790 pueden ser considerados como de transición. Como veremos, las sesiones de año 1790 presentan el último intento de los vecinos hacendados de utilizar al cabildo como un instrumento para defender sus intereses. Al año siguiente se produce la aparición del gremio de hacendados de la jurisdicción que asumió esa representación. Desde ese año hasta la invasión inglesa de 1807 el cabildo, además de ocuparse de los asuntos urbanos, representa las preocupaciones de la plaza comercial, que en esa época vivía una rápida expansión al calor de las medidas liberalizadoras otorgadas por la corona.

\subsection{Presencia y accionar de los vecinos hacendados en el cabildo de Montevideo}

Al defender la exclusividad de la explotación del ganado por encima de los intentos de otros competidores, el cabildo de Montevideo aparece, durante todo el primer período, representando los intereses de los agentes vinculados a la explotación de ese recurso que se autodenominaban como vecinos hacendados. Como ya vimos en los capítulos anteriores, desde el punto de vista del análisis económico dentro de la denominación hacendado se confundían distintos tipos de agentes, sin embargo en el plano social podemos ver que esos individuos se conjugaban dentro de un mismo grupo para defender un interés común. Esta situación era especialmente clara en algunas ocasiones, como en el cabildo abierto realizado en 1784.

El 28 de junio de 1784 tuvo lugar un cabildo abierto en Montevideo que convocó a los vecinos hacendados. El objetivo de la reunión era que los convocados decidiesen si se comprometían a pagar los gastos que ocasionaba el pleito que seguían en Buenos Aires por el derecho a los ganados que decían eran "prófugos y dispersos de sus haciendas" y que se hallaban en los campos situados entre el río Yi y el río Negro. Con ese fin se eligieron ocho individuos para que, junto al síndico procurador del 
cabildo, nombrasen nuevos apoderados en Montevideo y Buenos Aires y revocasen los poderes a los anteriores y decidieran sobre cualquier otra diligencia sobre el asunto. Las ocho personas elegidas fueron: Tomás Estrada 225 , Juan Antonio de Haedo, Domingo Bauzá, José Más de Ayala, Juan Balbín Vallejo, Juan Romero, Francisco Sierra y Miguel Ignacio de la Cuadra (AECM, 1942: 76-81). El acuerdo se cerró con la firma de un total de 83 vecinos (ver Anexo 3). Es decir, de la reunión participaron los que en esta tesis caracterizamos como corambreros y, también, un gran número de estancieros. En la práctica la reunión funcionó como una junta de hacendados por lo que la consideramos como un antecedente de las juntas que se efectuaron en 1791 y 1802, que analizaremos en el apartado siguiente.

Sin embargo, la presencia de los grandes productores de cueros en el cabildo no fue permanente sino, más bien, esporádica. La compulsa entre las elecciones y los acuerdos alcanzados deja la impresión de que estos agentes buscaban ocupar un cargo en el cabildo solamente cuando se debía tratar asuntos que concernían a sus intereses. Un ejemplo paradigmático es la composición del cabildo en el año 1773 cuando, como ya vimos en el capítulo 4, la institución se opuso a la denuncia de tierras realengas efectuadas por Francisco de Alzaybar. Ese año habían sido electos nuestros ya conocidos: Bruno Muñoz como alcalde de primer voto, Miguel Ignacio de la Cuadra como alcalde de segundo voto, Francisco Martínez como alférez real y Juan Esteban Duran como alcalde provincial ${ }^{226}$. Otro ejemplo es la presencia de Francisco García de Zúñiga como regidor en 1790 para tratar el asunto que veremos a continuación. Probablemente el hecho de que la explotación de ganado involucrara a una parte tan importante de la población ${ }^{227}$ impedía, por lo general, que el cabildo dictaminara medidas contrarias a sus intereses por lo que los grandes corambreros y estancieros no necesitaban estar ahí de manera permanente.

Finalmente, en la década de 1790 el cabildo dejó de ser el mejor canal para representar los intereses de los vecinos hacendados. Los acuerdos del cabildo de Montevideo de enero de 1790 son indicativos de que los hacendados tenían dificultades

\footnotetext{
${ }^{225}$ Tomás Estrada actuó en esta reunión como apoderado de María Francisca de Alzaybar y de Gabriela de Alzaybar.

${ }^{226}$ El resto de los cargos fueron electos de la manera siguiente: Antonio Camejo como Fiel Ejecutor, Francisco de Lores como depositario general, Antonio de la Torre como alcalde de la santa hermandad y Cosme Álvarez como procurador general. Todos los cabildantes desde 1730 hasta 1808 en Anexo 4.

${ }^{227}$ Como vimos en el capítulo 1, en la década de 1780 podemos asegurar que al menos un cuarto de la población producía o compraba cueros, sebo y/o grasa antes de que estos ingresaran a la ciudad. Con lo que el porcentaje pudo haber sido mayor.
} 
para hacer prevalecer sus intenciones en esa institución. El 18 de enero Francisco García de Zúñiga, alférez real electo para ese año, solicitó unos oficios que el gobernador había enviado en diciembre del año anterior los que, según él, no habían sido contestados todavía y debían ser contestados por los cabildantes actuales, y no por los del año anterior. Sin embargo, ocho días más tarde, el 26 de enero, se demostró que los ofícios habían sido contestados pero Juan Francisco García de Zúñiga intentó demostrar que la contestación estaba viciada de nulidad. El asunto se retoma al día siguiente cuando se aclaran las razones por las que interesa tanto la contestación de uno de esos oficios. Ese día el alcalde de primer voto, Juan Ellauri, pide que el alferez real se retire porque se va a tratar un asunto que atañe al interés particular de ese regidor. El alcalde de primer voto mostró, entonces, que el alférez solamente quería anular el oficio que propone que un regidor y dos vecinos controlen las introducciones de cueros y grasa por el portón de la ciudad. Al respecto, en el cabildo se encontraba un expediente que contenía una solicitud presentada en mayo de 1786 firmada por varios vecinos, entre los que se contaba Juan Francisco García de Zúñiga, en la que pedían que el cabildo dispusiese que los vecinos criadores, de manera alternada, tuviesen autoridad para registrar e intervenir en todas las introducciones de cueros y grasa ${ }^{228}$. Por lo tanto, el alférez pretendía ser juez y parte por lo que no podía intervenir en el asunto ya que era por todos sabido que era el que más interés tenía por ser el vecino que tenía más ganado. Finalmente, el día 30 de enero el alcalde de segundo voto pidió la salida del alcalde de primer voto y del alférez real, el cabildo entonces ratificó la nulidad de la contestación del oficio y remite las instancias al gobernador (AECM, 1942: 348-359). En consecuencia, si bien la contestación fue anulada estos acontecimientos dejan en claro las dificultades que encontraban los hacendados para lograr sus cometidos. Especialmente si tenemos en cuenta la solicitud que habían realizado en 1786 y que el cabildo cuatro años más tarde todavía no había resuelto a su favor. En consecuencia, al año siguiente los hacendados comenzaron un proceso de organización corporativa que intentó suplir la pérdida de eficacia del cabildo como institución privilegiada para canalizar sus intereses sectoriales.

\footnotetext{
${ }^{228}$ Significativamente no disponemos de los informes mensuales de las introducciones de cueros de esos meses de 1786 lo que brinda un dato a favor de la hipótesis que esgrimimos en el capítulo 1 sobre que esas ausencias podrían reflejar las presiones de los productores sobre el gobernador para evitar que las autoridades controlen la circulación de los bienes pecuarios.
} 


\subsection{Constitución y desempeño del Gremio de Hacendados en Montevideo}

La pérdida de eficacia del cabildo como institución para la defensa de los intereses de los hacendados se dio en Montevideo de manera similar a lo sucedido en Buenos Aires. Los hacendados se reunieron en juntas y nombraron apoderados que gestionaran peticiones y demandas ante las autoridades virreinales en defensa de esos intereses.

La formación de corporaciones que representaban a diferentes categorías socioprofesionales en el Río de la Plata ha sido interpretada por Javier Kraselsky (2010) como una redefinición de los vínculos entre los actores locales y la corona en un proceso que denomina como centralización corporativa. En ese contexto, se percibe una declinación de los cabildos como instituciones que ocupadas de canalizar los intereses de comerciantes y hacendados, que se dieron una organización corporativa, primero informalmente mediante el accionar de las juntas y luego de manera más institucionalizada a partir de la creación de los gremios de hacendados y del Consulado de Buenos Aires en $1794^{229}$.

En Buenos Aires los hacendados se reunían en Juntas para tratar sus asuntos y elegir apoderados desde $1775^{230}$. En Montevideo, en cambio, la primera junta de hacendados realizada por fuera del Cabildo se produjo recién en 1791. Esta junta que dio origen al gremio se efectuó con la presencia de 30 individuos que eligieron como apoderado a Juan Francisco García de Zúñiga, José Cardoso y Manuel Pérez. Lucía Sala de Tourón, Nelson de la Torre y Juan Carlos Rodríguez (1967: 126-128) consideran que las gestiones de esos apoderados, así como también las del cabildo, fueron eficaces en los asuntos en los cuales las autoridades tenían capacidad para resolverlos. Para los autores la creación en 1797 del Cuerpo de Blandengues fue un ejemplo de ello.

\footnotetext{
${ }^{229}$ El Consulado fue creado en 1794 como una corporación mercantil. Sin embargo, por medio de la Real Orden de 31 de marzo de 1797 se produjo la integración de los hacendados a la institución, de manera similar a lo que ocurría en otras ciudades hispanoamericanas en la misma época. Kraselsky (2010: 214215) considera que esa integración solamente se dio en el plano formal ya que los hacendados no participaron de las elecciones a los cargos consulares y, por lo tanto, no eligieron representantes propios. De esta manera, el autor infiere que “...habría habido un acuerdo tácito respecto a que los hacendados no participarían en los cargos consulares tal como estaba previsto en la Real Orden; pero igualmente habrían ejercido un poder de presión con sus demandas".

${ }^{230}$ Para un análisis de esas juntas ver: (Fradkin, 1986) y (Azcuy Ameghino, 2002).
} 
La conformación del Gremio de Hacendados de Montevideo se produjo dentro de un contexto muy particular. Por un lado, se enmarca en la política favorable a los hacendados emprendida por el virrey Arredondo quien dio curso al pedido del cabildo de Buenos Aires solicitando la instauración de la Hermandad de la Mesta en su jurisdicción $^{231}$ y el Bando del 12 de septiembre de 1791 que intentaba regular el comercio de $\operatorname{cueros}^{232}$. Entre las disposiciones que estipulaba el Bando se incluían la necesidad del reconocimiento de los cueros por parte del apoderado de los hacendados y la posibilidad de embargar toda la partida por un solo cuero fuera de regla ${ }^{233}$. Por otro lado, en el contexto local durante el año anterior Juan Francisco García de Zúñiga había sufrido la oposición dentro del cabildo de Montevideo con respecto al asunto del reconocimiento de los cueros en la ciudad.

Estas medidas eran recurrentes en los momentos de auge de las exportaciones de cueros. En esos momentos, las autoridades se preocupaban por las faenas clandestinas de cueros e intentaban controlar su circulación. Al mismo tiempo, los hacendados buscaban asegurar el cumplimiento de esas medidas para hacer prevalecer su privilegio en la explotación del ganado. Las interrupciones del comercio ultramarino debidas a las guerras reducían la presión sobre el stock de ganado y, por ende, el accionar corporativo de los productores ganaderos disminuía.

En este sentido, es sintomático que el nuevo período de paz propiciara la reunión de una nueva junta de los hacendados de Montevideo en 1802. En esa ocasión se eligieron como apoderados a Antonio Pereira, Miguel Zamora, Juan Francisco Martínez, Manuel Pérez y Lorenzo Ulibarri. Esta nueva junta es reveladora de la recomposición de los agentes económicos vinculados a la producción de cueros en Montevideo durante esos años así como de la expansión de la ganadería de rodeo. Sin embargo, los objetivos continuaban siendo prácticamente los mismos. Entre ellos se destaca la necesidad de establecer reconocedores para evitar la venta de cueros robados. Se intenta, además, promover disposiciones para evitar las vaquerías de los guaraníes al

\footnotetext{
${ }^{231}$ Finalmente, la Hermandad de la Mesta no fue creada en el Río de la Plata. Lucio Mir (1999: 23) considera que las autoridades no aprobaron la conformación de la Mesta por temor a que "...se estructurara una organización con excesiva autonomía con respecto de los poderes públicos...".

${ }^{232}$ El bando y las repercusiones que generó se pueden ver en el expediente que en 1797 se generó con motivo de la suspensión del reconocimiento de los cueros en Montevideo que se encuentra publicado en Barba (1955).

${ }^{233}$ Este bando encontró la oposición de los comerciantes cargadores de Buenos Aires. Ver. Kraselsky, 2010: 168-175.
} 
norte del río Negro lo que revela la superación de los límites jurisdiccionales por parte de esos agentes (Sala de Tourón, de la Torre y Rodríguez, 1967: 128-129).

La actuación de los apoderados motivó que dos años más tarde surgiera una oposición dentro del gremio. La finalización del expediente sobre el "arreglo de los campos", a partir del acuerdo de la Real Audiencia, llevó a que el virrey Sobremonte dictara disposiciones para organizar una expedición al cargo de Francisco Javier de Viana para fundar pueblos y dos guardias en la frontera con los territorios lusitanos. Los apoderados del gremio de hacendados de Montevideo se comprometieron a financiar esa expedición, para eso tomaron prestados quince mil pesos que debían ser devueltos con los fondos del gremio al cabo de tres años ${ }^{234}$. La financiación de la expedición por parte del gremio encontró la oposición de los hacendados ${ }^{235}$. Un grupo de hacendados pidieron la reunión de una nueva junta ${ }^{236}$. Los apoderados buscaron evitar la convocatoria hasta después de la salida de la expedición, llegando incluso al extremo de que uno de los apoderados, Miguel Zamora, huyó a Buenos Aires con el libro de acuerdos del gremio donde fue arrestado y obligado a retornar a Montevideo. La reunión se llevó a cabo el 16 de diciembre de 1805 con la participación de los cinco apoderados y otros 83 hacendados. En vez de nombrar nuevos apoderados la junta decidió modificar la forma de agremiación. De esta manera, se resolvió organizar una Junta Económica Directiva del Cuerpo General de Hacendados de la Campaña compuesta por 13 miembros ${ }^{237}$. Al mismo tiempo, rechazaron abonar el donativo que tenía como finalidad financiar la expedición de Viana. Es decir, prevaleció la postura de los opositores, en contra de la voluntad del virrey. Finalmente, el virrey disolvió el Gremio de Hacendados de Montevideo, y por lo tanto a la Junta Económica Directiva recién nombrada, y ordenó al gobernador y al cabildo de Montevideo para que obligasen a los hacendados a abonar la contribución a la que los apoderados anteriores se habían comprometido (Pivel Devoto, 1952: 80-95). Es difícil evaluar las consecuencias de esta

\footnotetext{
${ }^{234}$ Los quince mil pesos iban a estar destinados a financiar 60 carretas con sus bueyes que se utilizarían para construir un cuartel general en Ibicuy y dos guardias en la frontera (Pivel Devoto, 1952: 87).

${ }^{235}$ Argumentaban que el fondo del gremio tenía otros destinos previstos (ayuda económica para algún hacendado con inconvenientes, matanzas de perros cimarrones y yeguas baguales, costear los tramites de expedientes y solicitudes) y, por lo tanto, no se podía financiar la expedición con el mismo (Ibíd.: 95).

${ }^{236}$ Los peticionantes fueron: Juan Francisco de Zúñiga, Juan de Vargas, Felipe Pérez, Juan Balbin de Vallejo, Juan de Chopitea, Francisco Sierra, Luis Antonio Gutiérre y Mateo Gallego (Ibíd.: 83).

${ }^{237}$ Los miembros designados fueron: Juan Francisco de Zúñiga, Juan Jacinto Vargas, Agustín Abreu, Joaquín de Chopitea, Juan Ignacio Martínez, Juan Balbín Vallejo, Francisco Sierra, Mateo Gallego, Bernardo Súarez, Lorenzo Larrauri, Juan Durán, Pedro Vidal y Pedro Pérez (Ibíd.: 92-93).
} 
disputa, especialmente por la cercanía en el tiempo con la invasión de los ingleses al Río de la Plata y los sucesos posteriores. Sin embargo, es posible enmarcarla dentro de la crisis general del sistema político de la monarquía española en esos primeros años del siglo XIX.

9.4. Accionar de los estancieros en el cabildo de Maldonado

El cabildo de Maldonado es un ejemplo típico de los cabildos creados a partir de la política de poblamiento de fines del siglo XVIII emprendida por los funcionarios borbónicos en el Río de la Plata. La institución fue creada en 1784, aunque realmente no entró en funcionamiento hasta 1786 cuando el virrey confirmó, finalmente, a los regidores electos dos años antes. Como en el caso de Montevideo, la primera tarea que debieron emprender los cabildantes fue la de consolidar su dominio sobre un territorio.

Debido a lo tardío de su fundación no tuvo que luchar contra competidores, como fue el caso de Montevideo. Sin embargo, el cabildo de Maldonado sí tuvo que hacer prevalecer sus dominios sobre otras autoridades de la monarquía borbónica. Todo cabildo nuevo significaba un recorte de la jurisdicción de otro cabildo o de algún comandante militar. En este caso, la jurisdicción del cabildo de Maldonado no recortó la del cabildo de Montevideo sino que comenzaba donde ésta terminaba (en el cerro Pan de Azúcar). Significó, sin embargo, que el comandante de Maldonado no tuviera más jurisdicción sobre las causas judiciales ${ }^{238}$. Además, la creación del cabildo dio inicio a una disputa con el comandante militar de la villa de San Carlos por la delimitación de las la jurisdicción de cada autoridad.

El conflicto comenzó en 1786 cuando el comandante ordenó al juez comisionado por la ciudad de Maldonado, residente en el pago de Rocha, Miguel Antonio Zalayeta que devolviese el ganado que había embargado a Antonio Huertas, vecino de Maldonado ${ }^{239}$. Dos años más tarde, el cabildo de Maldonado consultaba al virrey sobre la extensión de su jurisdicción para determinar si se extendía hasta los

\footnotetext{
${ }^{238}$ El 20 de marzo de 1786 el superintendente Francisco de Paula Sanz envió una carta acompañando un oficio que ordenaba al comandante militar que se desprenda de las causas de justicia y policía que se negaba a delegar a los cabildantes. AGN Uruguay Ex AGA Maldonado 269.

${ }^{239}$ Carta del cabildo al comandante de la villa de San Carlos fechada el 20 de septiembre de 1786. AGN Uruguay Ex AGA Maldonado 289.
} 
arroyos de Garzón, Rocha y Don Carlos o solamente hasta José Ignacio ${ }^{240}$. Por su parte, Manuel Serrano, comandante en ese momento de la villa de San Carlos, opinaba que su jurisdicción comprendía: la villa de San Carlos y los partidos de José Ignacio, Garzón, Rocha, Chafalote, valle "de Igua" y Mataojo "de esta banda" del arroyo Maldonado, tal como había sido desde la creación de esa comandancia en $1763^{241}$. En 1791 afirmaba, además, que el virrey había declarado a la justicia ordinaria de la villa y sus partidos independiente de la de Maldonado ${ }^{242}$. La disputa no tuvo, sin embargo, una resolución definitiva hasta 1799 cuando el virrey dispuso que esos partidos fueran parte de la jurisdicción de San Carlos ${ }^{243}$.

Recordemos que la extensión de la jurisdicción implicaba la posibilidad de juzgar en las causas civiles y criminales y, por lo tanto, controlar a las personas y los recursos económicos. Esas disputas llegaban a puntos de alta conflictividad cuando fallecían sin testar personas con importantes bienes, como fue el caso de la muerte de José Llorens ${ }^{244}$ en $1791^{245}$. Además, como ya mencionamos, en la zona no había escribanos públicos y se hacían escrituras con las autoridades o vecinos como testigos, lo cual implicaba también la posibilidad de legalizar la posesión, la transferencia de tierras o esclavos y los testamentos.

A pesar de su reducida jurisdicción, el cabildo permitió a los estancieros y comerciantes de Maldonado canalizar sus quejas y negociar a nivel regional con las autoridades asentadas en Montevideo y Buenos Aires. En noviembre de 1792, por ejemplo, el Cabildo intercedió ante el gobernador de Montevideo para que se dejara de cobrar, a los hacendados y comerciantes que debían llevar sus productos a ese puerto ${ }^{246}$, el impuesto que tenía como fin recaudar fondos para la construcción de la iglesia matriz

\footnotetext{
${ }^{240}$ Carta del cabildo al virrey del 11 de agosto de 1788. AGN Sala IX Maldonado 3-7-5.

${ }^{241}$ AGN Uruguay Archivo Judicial Maldonado Caja 2. Documento $\mathrm{n}^{\mathrm{o}} 31$.

${ }^{242}$ Carta del comandante de San Carlos dirigida al cabildo de Maldonado con fecha del día 13 de octubre de 1791. AGN Uruguay Ex AGA Maldonado 289.

${ }^{243}$ Fajardo Terán (1953), 233.

${ }^{244}$ José Llorens era una gran estanciero, ya tuvimos oportunidad de mencionarlo en el apartado 2.1 del capítulo 2 y aparece en el cuadro 6 como uno de los principales productores de cueros del período 17841790.

${ }^{245}$ José Llorens era vecino de Maldonado pero murió en su estancia situada entre India Muerta y el Alférez. Expediente por el fallecimiento de José Llorens. AGN Uruguay, Archivo Judicial, Maldonado Caja 3 1791-1793. En carta del 21 de noviembre de ese año Olaguier de Feliú da orden al comandante de la villa de San Carlos para que suspenda todo procedimiento en la testamentaria de José Llorens AGN Uruguay Maldonado 270.

${ }^{246}$ Recordemos que el puerto de Maldonado no estaba habilitado para el comercio ultramarino.
} 
de Montevideo ${ }^{247}$. Esta capacidad de negociación se ve especialmente reflejada en los primeros años del siglo XIX. En diferentes instancias las fuerzas que se disputaban el control del territorio (la gobernación de Montevideo, la junta de Buenos Aires, el movimiento artigista y luego el ejército portugués) debieron negociar con los cabildantes, lo que sin duda es revelador de su posición dominante dentro del espacio de poder local.

Especialmente, luego de 1810 el Cabildo se constituyó en un ámbito de negociación con los distintos movimientos políticos que se alternaron en el dominio del área. De esta manera, los vecinos consiguieron que se dé curso favorable a reclamos que llevaban varios años. En septiembre de 1810, obtuvieron del Gobernador de Montevideo la explotación de la isla de Lobos como parte de los propios del Cabildo ${ }^{248}$. Por otro lado, la Junta de Gobierno de Buenos Aires habilitó el puerto para el comercio ultramarino $^{249}$. Así los cabildantes de Maldonado pasaban del reconocimiento de un gobierno a otro. El primero de enero de 1811 se reunieron para reconocer al gobierno de las Cortes instaladas en la Isla de León. El 3 de septiembre, en cambio, los cabildantes y la mayor parte de los vecinos de la ciudad se reunieron para elegir diputado para el Congreso General expresando lo siguiente:

“...dijeron que por quanto esta reconocida y jurada en esta ciudad la Excelentisima. Junta de la Capital de Buenos Ayres como Representante de los derechos de Nuestro Augusto Soberano el Señor Don Fernando septimo (que Dios guarde) y no haviendose dado cumplimiento a lo dispuesto por aquel superior govierno por lo que respecta al nombramiento de diputado con arreglo a las instrucciones que recivio este Cavildo a causa del trastorno que sufrio esta ciudad por el govierno de Montevideo, y haviendo variado las circunstancias con motivo de la entrada de las tropas Patrioticas en este pueblo en cuio acto se reconocio y juro nuevamente aquel superior govierno en esta virtud y haviendo convocado por esquelas la parte principal y mas sana de esta ciudad y su jurisdiccion se procedio a la eleccion del diputado que por parte de esta ciudad debe asistir a la Capital para la celebracion del congreso..." 250

${ }^{247}$ Carta del cabildo al gobernador de Montevideo del 2 de noviembre de 1792. Ante la contestación del gobernador suspendiendo la contribución, los cabildantes convocaron el 23 de noviembre de ese mismo año a los vecinos hacendados para ver si aceptaban pagar la misma contribución pero para hacer un fondo para la iglesia de Maldonado. AGN Uruguay, Ex AGA, Maldonado 269.

${ }^{248} \mathrm{La}$ administración de la isla de Lobos quedó a cargo del alcalde de ese año, Antonio Jesús de la Fuente, por el término de tres años a partir de 1811. Una vez deducidos los gastos, las ganancias debían dividirse en tres partes y media. Una para el arrendatario, dos para la iglesia y la otra mitad debía, a su vez, dividirse en dos: una mitad para cubrir las deudas que habían quedado de la extinguida Real Compañía Marítima y la otra a un fondo para construir la casa capitular. Acuerdo del cabildo de Maldonado del 22 de septiembre de 1810. AGN Uruguay, Ex AGA, Maldonado 289.

${ }^{249}$ Carta de Rafael Pérez del Puerto a la Junta fechada el 24 de julio de 1810 agradeciendo la habilitación del puerto. AGN Uruguay, Ex AGA, Ibíd.

${ }^{250}$ Acuerdo del cabildo de Maldonado del 3 de septiembre de 1811. AGN Uruguay, Ex AGA, Ibíd. 
Se eligió para diputado al cura vicario de la ciudad Gavino Fresco, que antes había sido electo para tener la misma función en las Cortes. Finalmente, en diciembre de ese mismo año, conocemos la presencia de tropas del ejército portugués en la ciudad porque la elección de los cargos del Cabildo para el año siguiente debió realizarse en la sala de la casa del alcalde debido a que la casa capitular (o mejor dicho la casa que se alquilaba para tal fin) estaba ocupada por oficiales de esas armas ${ }^{251}$.

Es decir, a pesar de lo reducido de su jurisdicción y de tratarse de estancieros con menos recursos que en el caso de Montevideo, es evidente que su posición de dominio dentro del espacio de poder local les brindaba un importante poder de negociación, tanto dentro del sistema político de la monarquía borbónica como en la arena de conflictos que le sucedió en la región en las primeras décadas del siglo XIX.

${ }^{251}$ Acuerdos del cabildo de Maldonado de 10 y 30 de diciembre de 1811. AGN Uruguay, Ex AGA, Ibíd. De noviembre de 1811 a marzo del año siguiente 3.000 hombres del ejército portugués estuvieron acampando en Maldonado. Díaz de Guerra (1988), 313. 


\section{Conclusiones}

En síntesis, a lo largo del texto se pudo observar de qué manera se encuentran relacionadas la expansión territorial, la producción ganadera y la conformación de grupos de agentes dedicados a esa actividad productiva con el establecimiento de relaciones de poder en la región Río de la Plata durante fines del siglo XVIII, en este caso en las áreas de Montevideo y Maldonado. Es decir, que es posible afirmar que existía una conexión entre la estructura productiva y la estructura de las relaciones de poder establecidas en la región.

Antes de sumergirnos en las implicancias de estas afirmaciones realizaremos un balance de la investigación presentada en el texto. Tal como el lector a esta altura ya apreció, este trabajo, a pesar de centrar su atención en la producción ganadera, no se limitó a hacer una investigación de historia económica del tema. Esto se debió a la convicción de que la economía es inseparable de otros aspectos de la realidad social. Es decir, solamente en la mente del científico pueden existir la economía, la política o la cultura como esferas separadas. Pero esta distinción analítica solamente se justifica por la necesidad de aislar elementos para resolver un problema planteado por el observador. En este caso, consideramos que era necesario analizar aspectos políticos y sociales para tener una visión completa del tema tratado, aún asumiendo el riesgo de tener que abordar distintas conceptualizaciones planteadas para disciplinas que se pretenden separadas; como la historia económica, la historia política y la historia social. En este sentido, si bien hemos optado por utilizar el concepto de agente económico, caracterizándolos como corambreros, estancieros, etc., también utilizamos el de grupo social para analizar su accionar político-social aceptando la autodenominación de hacendados que estos se daban, por entender que es reveladora de las intenciones y objetivos que tenían y, por lo tanto, útil para nuestro estudio.

El punto de vista adoptado permitió, además, revelar la manera en que las instituciones brindaban instrumentos que permitían el control de los recursos económicos haciendo, así, fundamental la participación de los agentes en el sistema 
político de la monarquía. Este sistema que podríamos caracterizar de monarquía policéntrica se basaba en la negociación constante y en el hecho de que los diversos centros de poder disfrutaban de cierta autonomía, que variaba en cada caso. En consecuencia, la formación de espacios de poder local se veía incentivada y reforzada por las instituciones creadas por el afán reformista Borbón del siglo XVIII, especialmente fuerte en zonas fronterizas como lo era el Río de la Plata. De esta manera, los grupos dominantes podían consolidar su posición dentro de esos espacios de poder local gracias a los instrumentos institucionales que les brindaba la monarquía, asegurando, así, su dominio territorial sobre las personas y los recursos económicos, al mismo tiempo que participaban del sistema político en su conjunto. En consecuencia, a lo largo del texto pudimos observar a los agentes utilizando los cabildos para emprender acciones colectivas contra competidores por la apropiación del ganado, usando la instancia judicial para dirimir conflictos por la propiedad del mismo recurso entre agentes o para disciplinar a los habitantes de la campaña, efectuar embargos para controlar la circulación, negociar con gobernadores y virreyes a partir de su actividad corporativa en las juntas de hacendados o simplemente realizar denuncias de tierras realengas para conseguir de esa manera privilegios en la explotación del ganado.

Ese paulatino control sobre los recursos económicos y las personas implicaba el proceso de consolidación de un territorio. Es decir, que el accionar de los agentes que estudiamos tenía una territorialidad. El espacio en el que desarrollaban sus actividades económicas dependía de su capacidad de movilizar recursos (por ejemplo, disponer de carros y de dinero para pagar los salarios de vaqueros y peones) y de controlar bienes y personas para lo cual, como ya vimos, podían apoyarse en las instituciones políticas y, de esa manera, asegurarse, por ejemplo, la explotación del ganado cimarrón en un paraje determinado sin la interferencia de changadores independientes o trabajando para otro corambrero.

En este sentido, realizamos un recorte geográfico de nuestro objeto de estudio acorde a esa situación. En primer lugar, partimos de la noción región Río de la Plata elaborada por Fernando Jumar ${ }^{252}$. Como vimos, esta delimitación se basa en el espacio económico conformado por los flujos de circulación interna y tiene como núcleo

\footnotetext{
${ }^{252}$ Además de lo que planteamos en el cuerpo del texto, la región Río de la Plata brinda un marco de análisis que permite desprendernos de los anacronismos propios de las historias nacionales que pretenden recortar los espacios geográficos de manera acorde a estados que surgieron muchos años después.
} 
regional al complejo portuario rioplatense. Tomando la clasificación de los espacios económicos planteada por Perroux, Jumar caracteriza a ese espacio económico como homogéneo. Esa clasificación se basa en varios puntos, entre ellos que el medio ambiente natural en el que está inserto forma parte de un mismo ecosistema y que la producción se distribuía de manera pareja a lo largo de ese espacio ${ }^{253}$, lo quedo claramente reflejado en el repaso bibliográfico efectuado en la introducción. Ahora bien, la región Río de la Plata planteaba dos inconvenientes para este trabajo. Por un lado, posee unas dimensiones que la hacen casi imposible de abarcar en su totalidad en un sólo estudio, especialmente cuando se intenta indagar sobre la producción ganadera. Por otro, la delimitación de este espacio económico no coincide en sus dimensiones con un territorio determinado, tal como era el caso del espacio económico peruano postulado por Assadourian (1982) y el Virreinato del Perú. En el Río de la Plata, en cambio, coexistían distintas jurisdicciones legales a partir de las cuales diversas instituciones (cabildos, la gobernación de Montevideo y comandancias militares) fueron consolidando sus respectivos territorios, lo que, como vimos, podía tardar varios años por la presencia de indios insumisos, portugueses o por conflictos entre autoridades de la propia monarquía. Los agentes económicos dedicados a la explotación del ganado vacuno necesitaban apoyarse en la capacidad de esas instituciones para dominar y controlar a los recursos y a las personas dentro de ese espacio. Esto determinaba una territorialidad de su accionar o, para decirlo de otra manera, de su capacidad de agencia. En consecuencia, para estudiar la explotación del ganado propusimos dividir la región en áreas. Dentro de esa división escogimos indagar sobre las áreas de Montevideo y Maldonado ya que el análisis bibliográfico inicial había mostrado que la frontera norte de la región era la zona donde, durante la segundad mitad del siglo XVIII, se había situado la mayor expansión territorial y, por lo tanto, la producción ganadera más dinámica, indicando, al mismo tiempo, un crecimiento económico por incorporación de factores.

Una vez escogido el espacio geográfico a considerar, era necesario determinar el marco temporal al que se iba a referir el análisis. En líneas generales el trabajo se

\footnotetext{
${ }^{253}$ Esto significa que no es un espacio polarizado. No hay una producción que genere un arrastre y provoque la espacialización de otras, ni tampoco grandes ciudades que puedan ejercer la misma función de atracción como en el caso del espacio económico peruano descrito por Carlos S. Assadourian. En todo caso, esta región podría haber funcionado como un polo de un espacio mayor como podría ser un espacio económico rioplatense, como parece plantear en algunos casos Fernando Jumar.
} 
encuadró dentro de la segunda mitad del siglo XVIII. Los cortes cronológicos tradicionales indicarían indagar en el período 1778-1810. Sin embargo, el cuarto de siglo anterior a la creación del virreinato es fundamental para entender la expansión territorial de la región y el dinamismo que tomó en ese momento la frontera norte. Especialmente, si tenemos en cuenta que en 1751 se da simultáneamente la derrota de los indios minuanes, la creación de la gobernación de Montevideo y se funda Maldonado; y que la guerra guaranítica (1754-1756) y la expulsión de los jesuitas de 1767 aceleró la desarticulación del espacio pastoril misionero liberando las reservas de ganado cimarrón para su explotación con vías de hacer corambre destinada al comercio ultramarino. Por otro lado, tomamos como punto límite del análisis la invasión de los ingleses por considerar que marca el comienzo de los sucesos que implicaron la manifestación de la crisis del sistema político de la monarquía en el Río de la Plata y que dislocaron las condiciones en que se explotaba el ganado vacuno especialmente en las áreas de las que nos ocupamos.

A pesar de esto, dada la variedad de temas abarcados a lo largo de los capítulos mantuvimos cierta flexibilidad al respecto para poder, así, extendernos un poco más atrás en el tiempo e incluso en algunos casos extendernos unos años más del límite impuesto. Por eso para analizar la apropiación de la tierra en la jurisdicción de Montevideo o el accionar de ese cabildo y la consolidación de su territorio retrocedimos hasta la década del 1730 y para ejemplificar de qué manera los grupos con poder local podían negociar nos extendimos en el caso de Maldonado hasta 1811. O incluso en ciertos casos como en el estudio de la circulación de los bienes pecuarios en el área de Montevideo redujimos el período a 1784-1797 abarcando solamente el tiempo de paz que se produjo entre las dos guerras que sostuvo España con Inglaterra. Esta reducción fue dictada por las fuentes pero también permitió estudiar ese momento en el cual los flujos eran más intensos, ya que lo permitía la regularidad del comercio ultramarino.

Luego de un primer capítulo donde se efectuó un balance historiográfico de los estudios sobre la producción agropecuaria, las fronteras y las relaciones de poder que se entablaban en esos espacios, la exposición de los resultados de esta investigación comenzó, de hecho, con la presentación de ese estudio sobre la circulación de productos pecuarios dentro de las áreas elegidas, que efectuamos en el segundo capítulo,. A partir de la información recabada se construyeron series de los ingresos de esos bienes a la 
ciudad de Montevideo. Ante la ausencia de otras fuentes, los datos aportados por la circulación se revelan como el mejor indicador para el estudio de la producción, al mismo tiempo que permiten analizar las características del sistema de comercialización de los bienes producidos. De esta manera, pudimos identificar un período de crecimiento de la producción del área de Montevideo durante 1784-1790 que fue seguido por otro de estancamiento en los años siguientes (1791-1797). Ante esa situación planteamos la hipótesis de que en ese momento el área habría llegado al máximo de su capacidad productiva, para las condiciones de la época, y que la zona expansiva se había trasladado más al norte. También que, dados los menores costes de transporte, los bienes producidos en esa nueva zona se trasladaron de manera fluvial hacia Buenos Aires, lo que es coincidente con el aumento de los embarques en ese puerto que evidencian los datos aportados por Maximiliano Camarda. Al mismo tiempo, el paulatino agotamiento del ganado cimarrón implicó un proceso de avance de la ganadería de rodeo en el área de Montevideo.

También pudimos ver la importancia que tenían esas reservas de ganado al diferenciar entre cueros marcados y orejanos. De este modo, pudimos comprender que la marcada estacionalidad de los ingresos se debía más la actividad de las vaquerías que a la incidencia de la ganadería de rodeo; mientras que por otras series pudimos ver que el caso del sebo y la grasa es exactamente al contrario. Tal como ya había destacado María Inés Moraes, y analizamos de forma pormenorizada en el capítulo 2, estas dos formas de explotar el ganado vacuno eran disimiles en todos los aspectos posibles (es decir, en sus agentes, formas de contratación de la mano de obra, estacionalidad, objetivos y ubicación geográfica de la producción) a pesar de que el producto final fuera el mismo y que su origen se podía confundir en el momento de la circulación.

Por otro lado, al identificar el origen de los bienes que ingresaban observamos la existencia de un sistema de comercialización similar al descubierto por Jorge Gelman para el área de Colonia y Santo Domingo Soriano. Así comprobamos prácticamente la mitad de la producción era llevada hasta el mercado montevideano por los propios productores y el resto por comerciantes que recorrían la campaña, o tenían una pulpería en algún pago rural, comprando los excedentes de las explotaciones productivas más pequeñas. 
Finalmente, las series que reflejan los envíos de Maldonado a Montevideo, al abordar un período de mayor extensión (1783-1806) nos permitieron, además de mostrar el crecimiento de la producción del área, evaluar los efectos que tenían sobre la producción de derivados vacunos la interrupciones del comercio ultramarino generadas por las guerras europeas.

Los capítulos 3 y 4 tenían, por su parte, el objetivo de complementar ese análisis indagando en algunos temas referentes a las diferentes formas que se utilizaban para explotar el ganado vacuno, de las condiciones de comercialización de los bienes producidos, los mercados de consumo de los derivados vacunos y con respecto a los agentes vinculados a esas actividades.

En primer lugar, analizamos todos los aspectos que diferenciaban a las vaquerías para hacer corambre de la ganadería de rodeo. Tal como vimos, el objetivo de la primera era solamente extraer el cuero de los vacunos, el sebo y la grasa, descartando la carne. En la ganadería en cambio se criaba el ganado para conseguir novillos para proveer de carne al consumo de la población; aunque, obviamente, también se aprovechaba el resto del animal. Esto también tenía que ver con la ubicación geográfica de cada una de esas actividades, ya que las vaquerías se efectuaban en zonas alejadas de poblaciones estables por lo que la carne fresca no podría ser trasladada en buen estado y con que las características del vacuno, por su diferente grado de domesticación, hacía menos apetecible su carne para el consumo. También diferían en la mano de obra utilizada. Así, mientras en las vaquerías predominaba el salario, especialmente a destajo; en las estancias, en cambio, los salarios de peones se estipulaban por jornadas y se recurría también a otros tipos de mano de obra, como los esclavos y los agregados. Por otro lado, destacamos que dentro de la ganadería existieron otros tipos de establecimientos productivos además de la clásica estancia de rodeo: otros dos tipos de estancias, las misioneras y las del rey, que tenían características y ubicaciones geográficas distintas a las de rodeo $\mathrm{y}$, por otro lado, los mataderos y saladeros que dependían de la provisión de cabezas de ganado por parte de la ganadería pero que no por eso dejan de ser lugares donde se producía cueros, sebo, grasa y carne, ya sea fresca o salada.

En segundo lugar, a lo planteado anteriormente sobre el sistema de comercialización de los productos pecuarios, añadimos un estudio sobre la presencia y 
distribución de las pulperías a lo largo de la campaña. Tomando como ejemplo el área de Maldonado y partiendo de los datos contenidos en las composturas de pulperías pudimos estudiar cómo se distribuían entre los poblados y pagos del área y la permanencia en el tiempo de esos establecimientos comerciales. De esta manera, pudimos comprobar que si bien la cantidad total de establecimientos en el área era importante, estos se concentraban especialmente en los pueblos y ciudades y en la cercanía del fuerte de Santa Teresa, siendo escasos e intermitentes en los pagos de la campaña. En consecuencia, siguiendo el planteo de Gelman de que la presencia de competencia entre varios pulperos impedía la explotación mercantil de los pequeños productores, concluimos que en el área de Maldonado estos se encontraban expuestos a las condiciones que los pocos comerciantes que se afincaban o pasaban por esos pagos les impusieran para colocar su producción en el mercado. En cambio, los medianos y grandes productores que disponía de los medios para llevar los bienes producidos hasta los pueblos de la zona o, mejor todavía, hasta Montevideo, obtenían, de ese modo, mejores condiciones para hacerlo, lo que implicaba una ventaja considerable que justificaba el costo del transporte de las mercancías.

Por último, luego de plasmar todos los aspectos referentes a las condiciones de producción y al sistema de comercialización de los bienes pecuarios, procedimos a efectuar una caracterización de los agentes involucrados en esas actividades. Por un lado, diferenciamos a los comerciantes por su permanencia en un lugar o por su itinerancia $\mathrm{y}$, especialmente, por las diferencias en su giro. A modo de ejemplo presentamos un cuadro que muestra los mayores introductores a Montevideo de bienes pecuarios comprados en la campaña para el período 1784-1790 a partir de los datos que nos brinda la fuente analizada en el primer capítulo. Por otro lado, en el caso de los productores era necesario diferenciar los que participaban en cada una de las formas de explotar el ganado vacuno. De esta manera, definimos como corambreros a los agentes dedicados a las vaquerías y como productores ganaderos a los dedicados a la cría de ganado. Descartamos explícitamente la categoría de hacendado porque tiene el defecto de confundir a ambos agentes en uno sólo; aunque, como ya mencionamos, creemos que tiene cierta utilidad desde el punto de vista de la historia social como indicativa de los intereses de un grupo social. A su vez, dentro de los productores ganaderos adoptamos la distinción propuesta por Gelman entre estancieros y campesinos. Finalmente, a partir 
de los datos de ingresos a Montevideo entre 1784 y 1797 identificamos cierta concentración en la producción corambrera que mostramos en dos cuadros que reflejan las cantidades de cueros que trasladaron los productores más importantes del período.

En el capítulo 4 analizamos la producción y el destino de los otros derivados vacunos: la grasa, el sebo y la carne, ya sea tanto fresca como salada. Elegimos hacerlo aparte porque cada caso tiene sus particularidades tanto en la instancia de producción como en cuanto al consumo. Todos estos bienes se producían en su mayor parte dentro del ámbito de la ganadería de rodeo, aunque en las vaquerías también se extraía el sebo y la grasa del ganado. La grasa y el sebo eran bienes exportables y, además, tenían un importante consumo interno, como también habíamos destacado para los cueros. Sin embargo, la importancia del consumo interno parece ser mayor todavía para los primeros porque la proporción consumida era mayor que la exportada, mientras que en el caso de los cueros se daba de manera inversa. El sebo y la grasa eran consumidos en distintas formas en la iluminación, higiene y alimentación por lo que constituía un elemento fundamental de la vida cotidiana de los pobladores rioplatenses. Sin embargo, como vimos, la disponibilidad este bien no era constante. La producción fluctuaba no sólo porque dependía de la cantidad de animales sacrificados, sino también porque las condiciones climáticas determinaban la cantidad de materia grasa que contenía cada res.

El caso de la carne fresca era diferente ya que las condiciones técnicas de la época la transformaban en una mercancía de exclusivo consumo interno. En el Río de la Plata la carne era una mercancía abundante y barata por lo que su consumo per cápita era muy importante. Se trataba en su mayor parte de autoconsumo pero, de todos modos, los abastos de pueblos y ciudades y de los destacamentos militares podían constituir apetecibles oportunidades de negocios, especialmente en los años finales del siglo XVIII cuando el crecimiento poblacional había transformado a las ciudades en mercados de cierta consideración.

La carne salada, por otro lado, presentaba la situación opuesta, ya que la mayor parte de la demanda estaba conformada por mercados externos al Río de la Plata. Si bien se ha hecho mucho hincapié en el surgimiento de los saladeros como nuevos establecimientos productivos, en contraste en esta tesis destacamos la importancia de la producción doméstica de carne salada. Por otro lado, los saladeros del siglo XVIII no implicaron la incorporación de ningún avance tecnológico, aunque sí una concentración 
de procesos y una organización que incentivaron un aprovechamiento más integral de cada animal sacrificado. También indicamos los inconvenientes que encontraba en esos momentos este rubro productivo rioplatense: la distancia del principal centro consumidor (la economía de plantación cubana), la competencia de otros centros productivos (principalmente, Río Grande y los llanos venezolanos) y, especialmente, la dependencia del abastecimiento marítimo de sal que, como vimos, tenía una incidencia fundamental en la evolución del precio de este insumo indispensable. Por último, consideramos que, aún con sus limitaciones, la presencia de los saladeros constituyó un impulso importante para la expansión de la ganadería de rodeo por la considerable ampliación de la demanda de novillos, tal como ya había destacado María Inés Moraes .

Una vez finalizado el análisis de las condiciones de producción y comercialización de cada uno de los bienes pecuarios, dedicamos los capítulos 5 y 6 a estudiar la manera en que los agentes se apropiaron de los factores productivos. Dado que, por lo general, la ganadería extensiva posee una bajo nivel de inversión de capital concentramos nuestra atención en la tierra y el trabajo.

La tierra era un factor abundante en las praderas rioplatenses. La reciente ocupación de las áreas de Montevideo y Maldonado, y la consecuente baja densidad poblacional, provocaban esa situación lo que, necesariamente, repercutía en un nivel bajo del precio de la misma. En las zonas fronterizas la tenencia legal de la tierra cobraba importancia porque implicaba conseguir la preeminencia en la explotación del ganado que poblaba esos campos. Durante el período que analizamos existieron distintas formas de apropiación de la tierra, que analizamos con detenimiento en el capítulo 5. En primer lugar, en el marco de la política de poblamiento emprendida por la corona, los gobernadores y comandantes militares de las áreas estudiadas repartieron terrenos para chacras y estancias entre los vecinos pobladores. En segundo lugar, algunas personas denunciaron tierras realengas, en ocasiones grandes extensiones, iniciando largos trámites que a veces terminaban en la composición o la adquisición mediante subasta pública. En tercer lugar, a medida que aumentaba la ocupación del espacio, algunas tierras se tornaban apetecibles, ya sea por su particular ubicación, por la presencia de aguadas o porque sus dueños habían invertido en edificios o plantado arboledas. En consecuencia, con el correr de los años fue creciendo la cantidad de operaciones de compra-venta de chacras y estancias formándose lentamente un mercado 
de tierras. Comprobamos ese proceso siguiendo la cantidad total de transacciones de inmuebles rurales de la región durante todo el siglo XVIII y la primera década del XIX. Al mismo tiempo, comparando cómo evolucionaban año a año la cantidad de operaciones de las áreas de Montevideo y Maldonado con las de la campaña de Buenos Aires, vimos que ese mercado regional tenía un cierto grado de integración en las últimas décadas del siglo XVIII que estaba dado, principalmente, por la influencia del mercado externo y de las condiciones climáticas. Indagamos, además, sobre la posibilidad de la existencia de un proceso de polarización de las propiedades rurales, que había descubierto Gelman para Colonia y Santo Domingo Soriano, especialmente importante en los momentos de interrupción del comercio ultramarino. Finalmente, analizamos algunos contratos de arrendamientos de chacras y estancias que se conservaron por escrito. Aunque esta forma de acceder al usufructo de la tierra estaba muy extendida en las campañas rioplatenses, generalmente se trataba de acuerdos orales, basados en la confianza y regulados por la costumbre. En consecuencia, debemos resignarnos ante la imposibilidad de cuantificar este fenómeno y conformarnos con conocer algunos ejemplos de esa clase de contratos.

El capítulo 6, por su parte, trata sobre el problema de la utilización de diferentes tipos mano de obra en las actividades económicas de la campaña. La baja densidad poblacional, la movilidad de los habitantes y las alternativas laborales determinaban que la mano de obra asalariada fuera, desde el punto de vista de los estancieros, escasa e inestable. Este era un problema muy acuciante para estos agentes económicos ya que los salarios podían representar, de acuerdo a los datos de Samuel Amaral, cerca del $80 \%$ de los costos del establecimiento productivo. De esta manera, en las estancias se recurría a complementar la mano de obra asalariada con otros tipos de mano de obra. Por un lado, los estancieros que disponían del capital necesario podían comprar esclavos con lo que conseguían un plantel de trabajadores estables, que en los momentos de mayor actividad se completaba contratando peones asalariados. Para comprobar la disponibilidad de este tipo de mano de obra efectuamos un sondeo en los libros de alcabala de ventas, tomando como ejemplo el caso de Maldonado. De esta manera, exploramos la idea planteada por Julio Djenderedjian de que un mercado de esclavos dinámico podía hacer que este tipo de mano de obra se tornase tan flexible como la asalariada, ante la posibilidad de vender y comprar según las necesidades laborales de su establecimiento. Por otro lado, los 
estancieros solían permitir que algunas familias se asentaran en sus tierras generando así una relación de agregación. De esta manera, aumentaba la disponibilidad de mano de obra al mismo tiempo que aseguraba el reconocimiento de su propiedad sobre los terrenos ocupados. A partir de los datos contenidos en el padrón de Aldecoa, pudimos observar que los agregados estaban presentes en una proporción similar a la de los peones asalariados en la campaña de la jurisdicción de Montevideo en 1772-1773. Al mismo tiempo, efectuamos una comparación de la estructura etaria de peones y agregados que aportó información que apoya la idea de Carlos Mayo de que la agregación era parte del ciclo de vida de los peones $y$, también, que esa posibilidad se encontraba restringida por el origen y el color de la piel de esos trabajadores.

En las vaquerías, en cambio, únicamente se utilizaba mano de obra asalariada, predominaba la especialización y el salario a destajo. Además, los salarios parecen haber sido mayores a los que cobraban los peones en las estancias y los trabajadores disponían de mayor libertad, regulando el ritmo laboral. Aunque, como vimos, la alimentación, la seguridad y las comodidades para dormir eran mejores en las estancias lo que podía compensar un salario menor.

Una vez conseguida la posesión de la tierra y obtenida la mano de obra necesaria, era posible explotar el ganado vacuno. Sin embargo, la ausencia de alambrados, la movilidad de la población y de los animales y la competencia entre agentes tornaban problemático asegurar, y sostener en el tiempo, la propiedad sobre ganado. Teniendo en cuenta esa situación, en el capítulo 7 estudiamos acciones colectivas e individuales que efectuaron los agentes para reforzar su propiedad sobre el ganado vacuno y, también, damos cuenta de la, esporádica pero no por eso menos importante, actividad represiva emprendida por el estado virreinal con el objetivo controlar las faenas de cueros. Entonces, en primer lugar analizamos el litigio que enfrentó a los autodenominados hacendados montevideanos contra la administración de los pueblos misioneros por la propiedad del ganado cimarrón situado entre los ríos Yi y Negro. En segundo lugar, estudiamos la actividad represiva del estado virreinal que definimos como esporádica ya que, en general, se concentró en los momentos de auge de las faenas de cueros que coincidían con momentos de recomposición del comercio ultramarino. En consecuencia, concentramos nuestra atención en los años 1784-1785 cuando los decomisos de cueros en la "Banda Oriental" cobraron una intensidad 
inusitada como reflejo de la política emprendida por el virrey Loreto que, como vimos, incluyó también la suspensión de las faenas misioneras. Por último, dimos cuenta de las acciones colectivas e individuales de estancieros y corambreros que buscaban controlar las faenas y combatir la práctica del abigeato. Dentro de estas, analizamos tres tipos de situaciones: los embargos de cueros efectuados por el cabildo de Montevideo en 1784, conflictos entre vecinos estancieros y juicios por abigeato. Estos ejemplos mostraron que la instancia judicial era poco utilizada porque era muy costosa, muchos conflictos se solucionaban de forma oral, el disciplinamiento social se regía por la costumbre y debido a que existía una tolerancia con estas prácticas que se mantenía siempre y cuando se mantuvieran dentro de ciertos limites. En consecuencia, los juicios revelan situaciones anormales en las que se buscaba un castigo ejemplar.

Por otro lado, en el capítulo 8 realizamos una primera aproximación a un estudio prosopográfico de los agentes económicos dedicados a la explotación del ganado cimarrón que en el capítulo 3 definimos como corambreros. Primero analizamos el proceso de conformación del grupo de agentes, que se extendió, especialmente, durante las décadas de 1760 y 1770 y que tuvo como herramienta fundamental las denuncias de tierras realengas como medio de iniciar la explotación del ganado cimarrón. Luego identificamos un momento de recomposición del grupo durante la década de 1780 que se dio principalmente por la incorporación de nuevos miembros mediante alianzas matrimoniales, coincidiendo temporalmente con que la suspensión de las denuncias de tierras realengas había cerrado la otra posibilidad de ingreso. Por último, estudiamos la extinción de este agente económico en el área de Montevideo en los años finales del siglo XVIII y los iniciales del XIX. Comprobamos esta situación en el fraccionamiento de las tierras para su venta o arrendamiento. La desaparición de los corambreros montevideanos se dio por la combinación de varios factores. Por un lado, como vimos en el capítulo 2, se agotaron las reservas de ganado cimarrón del área trasladando las vaquerías a espacios situados más al norte. Esto tuvo el correlato lógico de la expansión la ganadería de rodeo en el área. Por otro lado, muchos de los individuos que producían cueros desde la década de 1760 llegaron al final de sus vidas y sus herederos, ante los cambios en la estructura productiva, decidieron desprenderse de esas grandes extensiones de tierras y dedicarse a otras actividades. Otros corambreros pudieron haberse transformado en grandes estancieros y, en cambio, los que no supieron 
adaptarse a los cambios sufrieron los embates de los cambios políticos de los comienzos del siglo XIX, perdiendo sus tierras y ganados.

Finalmente, en el capítulo 9 vimos el accionar de estancieros y corambreros dentro del sistema político de la monarquía a través de su participación en espacios institucionales, en los casos de los cabildos de Montevideo y Maldonado, y como corporación en el gremio de hacendados. De esta manera, pudimos observar que en un principio la principal preocupación pasaba por la consolidación territorial en un proceso que podía durar varios años y que implicaba conseguir el control de los recursos económicos de ese espacio geográfico que, en este caso, definimos como un área de la región Río de la Plata. Luego de asegurado ese territorio, la participación de los autodenominados hacendados se tornó esporádica, es decir, que solamente participaban del cabildo en los momentos en que era necesario negociar asuntos que concernían a sus intereses económicos. Por otro lado, en torno a la década de 1790 el cabildo de Montevideo parece haber dejado de ser el vehículo más eficaz para representar los intereses de los hacendados que, aprovechando el contexto, buscaron nuevas maneras de canalizar esos intereses a través de la conformación del gremio de hacendados que, como vimos, tampoco estuvo exento de conflictos. Por último, el caso del cabildo de Maldonado nos permitió ver un ejemplo de las instituciones creadas tardíamente, por la política de poblamiento llevada a cabo por la burocracia borbónica, que estimularon la creación de nuevos espacios de poder dentro de la región. La conformación de estos espacios junto a esas nuevas herramientas institucionales fueron aprovechados por los grupos dominantes para consolidar su posición en el área y su capacidad de negociación a nivel regional.

De esta manera, observamos un fraccionamiento de la región en varios espacios políticos interrelacionados que anticipan las divisiones que se dieron al momento de la formación de estados durante el siglo XIX. Es decir, consideramos que este análisis que relaciona el control de los recursos económicos para la explotación del ganado con los espacios políticos a partir de la conformación de una territorialidad, es revelador de la estructura de las relaciones de poder dentro de la región Río de la Plata que tuvo consecuencias por un largo período de tiempo.

En este sentido, si bien el contenido de esta tesis, junto a los últimos avances de la historiografía sobre el Río de la Plata durante el siglo XVIII, es suficiente para 
sostener estas afirmaciones, aún quedan algunos puntos que deben ser estudiados para resolver interrogantes o profundizar ciertos temas. Entonces, un balance que sirva a modo de guía para las investigaciones futuras sería el siguiente. En primer lugar, es necesario estudiar la continuidad de la explotación del ganado cimarrón en la nueva frontera norte e indagar sobre la aparición de los nuevos agentes. En segundo lugar, se podría profundizar el estudio de los todos los agentes económicos involucrados, su evolución en el tiempo y su desempeño en la vida social y política. En tercer lugar, sería muy útil investigar sobre la producción saladeril incorporando el mercado consumidor, las producciones competidoras y el desempeño económico de los establecimientos. Seguramente recabar la información para efectuarlo requiere sumergirse en los archivos de varios países (al menos los de Cuba, Venezuela, Brasil, Uruguay y Argentina). Por último, es necesario enmarcar el análisis en una visión de más largo plazo de la producción ganadera rioplatense en su conjunto. Un corte cronológico posible para efectuarlo puede ser c.1760-c.1840 teniendo en cuenta el período de predominio del vacuno extensivo, cuyo objetivo es la venta del cuero y paulatinamente también la producción de carne salada. Además, esta periodización permite dar cuenta de los cambios en la demanda externa, ya que abarca el período de la primera revolución industrial antes de que los cambios de la segunda revolución impusieran el auge de la ganadería ovina que desplazó por un breve tiempo al vacuno de su largo predominio en las praderas rioplatenses.

Ahora bien, más allá de esta agenda de investigación, esta tesis contiene aportes que, en conjunto con otras investigaciones recientes, permiten realizar una serie de afirmaciones que pueden matizar la visión actualmente dominante sobre la estructura productiva en el Río de la Plata a finales del siglo XVIII y sus consecuencias políticas y sociales. Particularmente, un recorte del espacio geográfico a estudiar que no se límite a la campaña de Buenos Aires permite sostener que la explotación del ganado con el objetivo de obtener cueros vacunos para la exportación tiene un lugar central en la estructura productiva de la región.

Por otro lado, las actividades económicas vinculadas a la explotación del ganado vacuno se realizaban con cierta autonomía respecto del comercio de la región. Esto tiene varias consecuencias. En primer lugar, tal como afirma Djenderejian (2003, 420) la ganadería presentaba una posibilidad de acumulación independiente de los lazos con la 
capital virreinal, lo que, junto a los numerosos cabildos y comandancias que había en la región, brindaba la base material para la creación de espacios de poder local autónomos. En segundo lugar, esto implica que la premisa de que el capital mercantil dominaba al capital productivo no es aplicable a la economía rioplatense en esa época y, por ende, los argumentos sobre la subordinación de los estancieros/hacendados con respecto a los comerciantes, que se plantean como una consecuencia lógica de esa premisa, no se sostienen.

Por último, si bien resaltamos la necesidad que tenían los agentes vinculados a la explotación del ganado para establecer relaciones de poder para asegurar su control sobre los factores productivos de esto no se desprende una imagen en la que resurjan las ideas del latifundio y la dependencia personal como clave para entender la realidad social de las praderas rioplatenses en el siglo XVIII. Esta interpretación provenía del error de intentar aplicar conceptos y herramientas elaboradas para explicar la historia europea y de otras partes más pobladas de la América hispánica al Río de la Plata, lo que solamente fue posible por una defectuosa crítica de las fuentes disponibles.

Es decir, el conocimiento acumulado puede permitir dejar atrás los debates que surcaron el campo académico rioplatense en el siglo pasado. De esta manera, es posible tener una perspectiva de la realidad económico-social y política del mundo rural de la región Río de la Plata a fines del siglo XVIII más acorde a los aportes de los estudios actuales y que encaja mejor con los análisis que abordan la economía, las manifestaciones políticas y los procesos de formaciones estatales de la primera mitad del siglo XIX.

En consecuencia, analizar la estructura productiva, las relaciones de poder y la constitución de territorios en el Río de la Plata durante el siglo XVIII permite observar características estructurales que sobrevivieron a la desaparición del sistema político de la monarquía española y sobre las que necesariamente se construyeron los nuevos movimientos políticos de comienzos del siglo XIX.

La imagen final resultante del mundo rural de fines del siglo XVIII en las praderas rioplatenses puede ser diferente a la planteada por las principales corrientes historiográficas del siglo pasado. Ni una avanzada de frontera poblada por farmers dominados, a través del mercado, por los comerciantes de las grandes ciudades, ni un mundo de terratenientes que sometían a sus agregados con cargas personales, ni 
tampoco un desierto surcado por gauchos changadores y contrabandistas; sino una realidad compleja y cambiante que se vivía numerosas transformaciones al calor de la expansión territorial, el crecimiento económico y los impulsos económicos provenientes del mercado externo irradiados desde las ciudades portuarias. 


\section{Anexos}

Anexo 1. Mapas

Mapa A.1. Esquema de la zonificación morfo-hidrológica del Río de la Plata

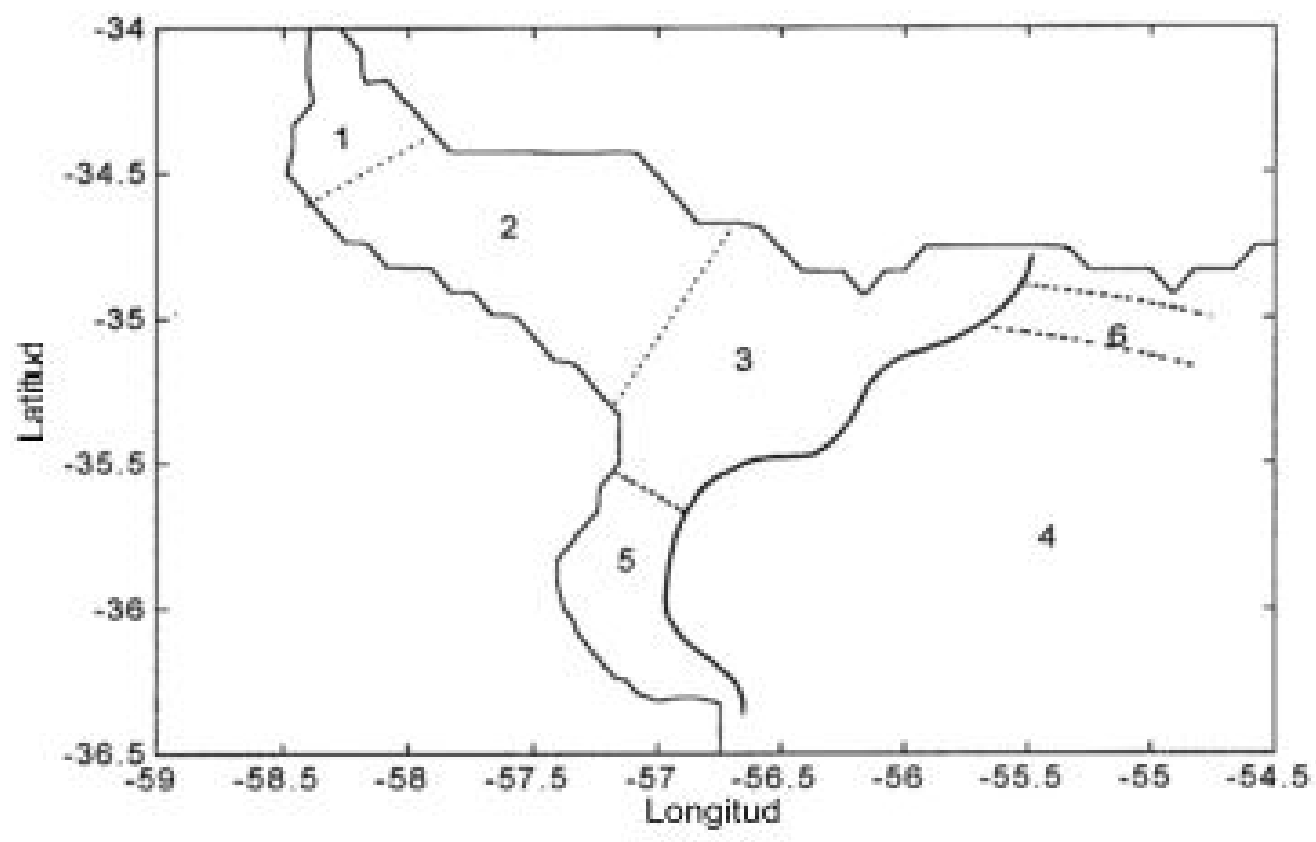

Figura 2.3 - Esquema de la zonación morfo-hidrológica del sistema del Rio de la Plata (de Nagy, 1989), 1= cuencas del Delta del Rio Paraná. 2 = rio mareal.

3= transición estuarina. 4a región exterior o marina (arenas relictas). 5= Bahía de Samborombón. 6= Canal Oriental Exterior.

Fuente: Nagy, Martínez, Caffero, Pedrosa, Forbes, Perdomo y López Laborde (1998: 22) 
Mapa A.2. Áreas de la zona fluvial del Río de la Plata

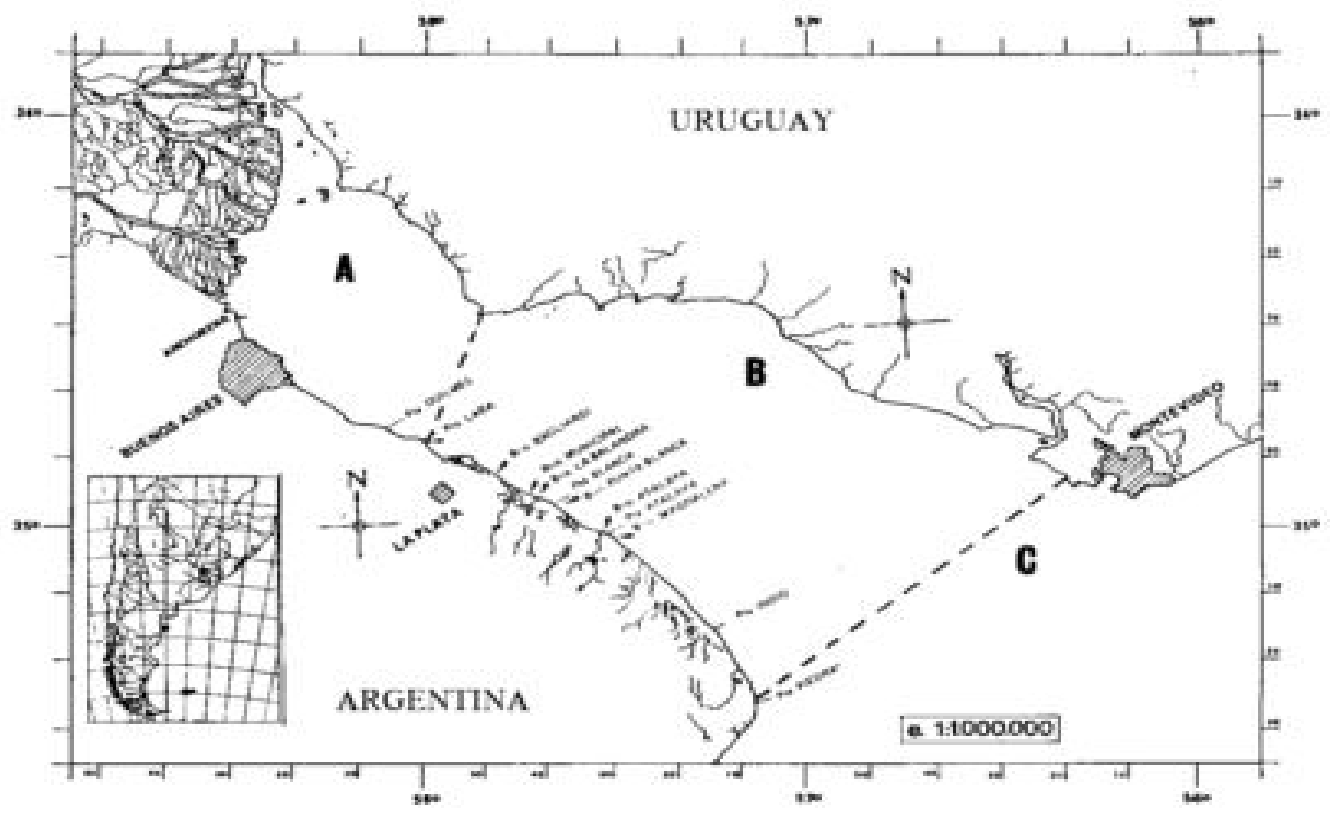

Figura 5.1 - Río de la Plata (Zona fluvial).

A: Zona fluvial interna; B: Zona fluvial media; C: Zona fluvial marina (Modificado de Darrigran y Rioja, 1988).

Fuente: Masello y Menafara (1998: 120) 
Mapa A. 3. Salinidad del Río de la Plata en invierno

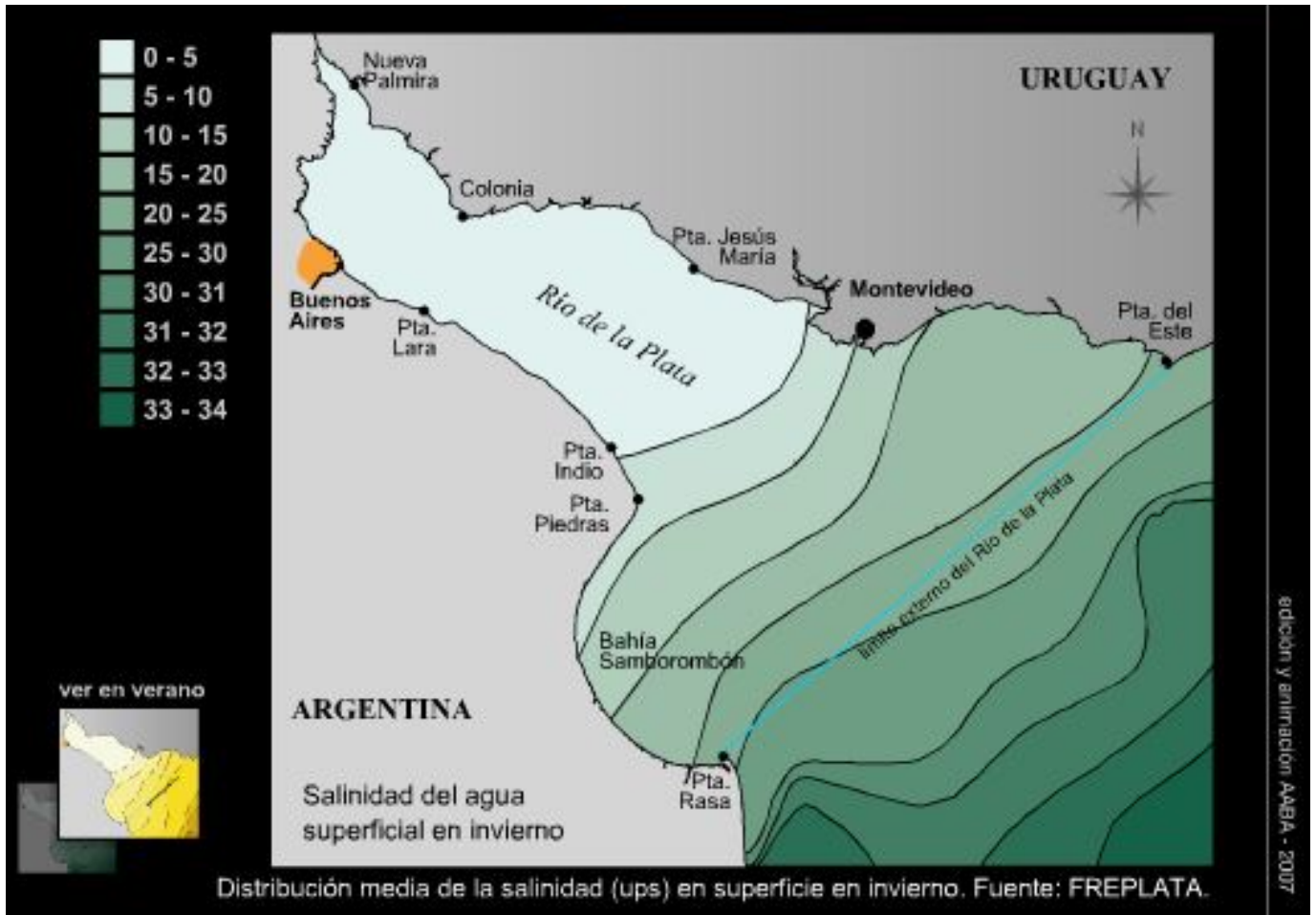

Fuente: Atlas Ambiental de Buenos Aires

Mapa A. 4. Mapa de salinidad del Río de la Plata en verano

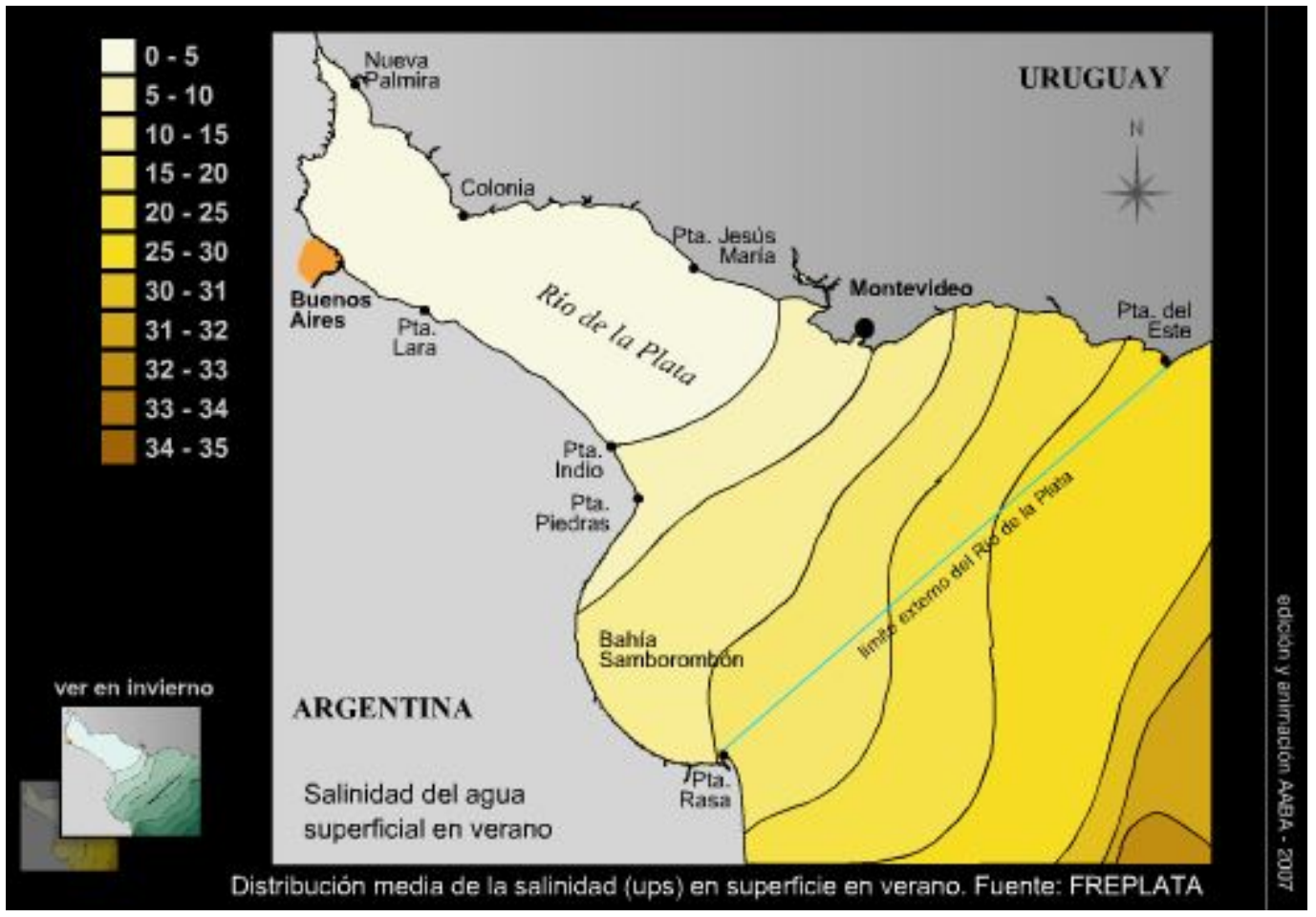

Fuente: Ibíd. 
Mapa A. 5. Batimetría del Río de la Plata

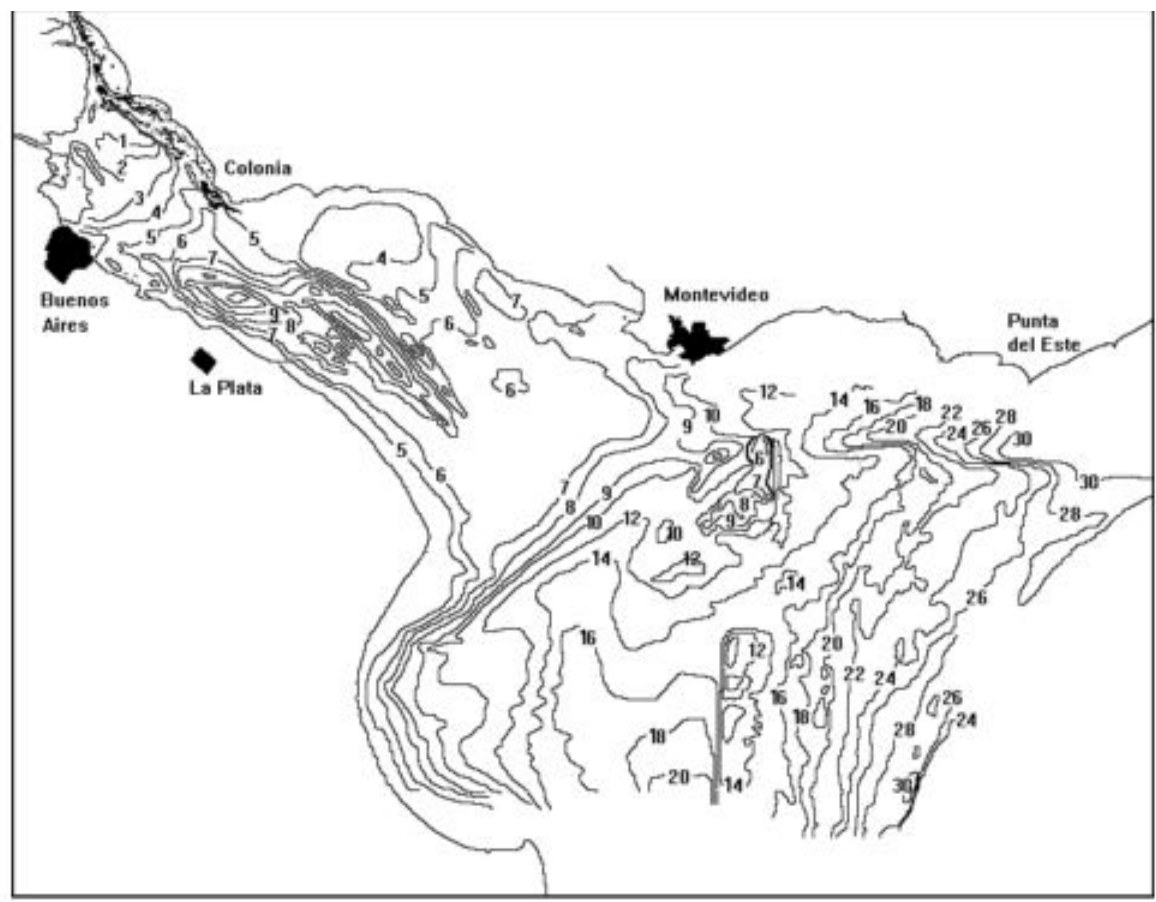

Ficura 1.3-Eatimetria del Rio de la Ptata (ischatas a intervalos de un metro). (De: Cavalotto, 1987; Parker \& López Labonde, 1990).

Fuente: (López Laborde: 8) 
Mapa A. 6. Mapa de zonificación del Delta del Paraná

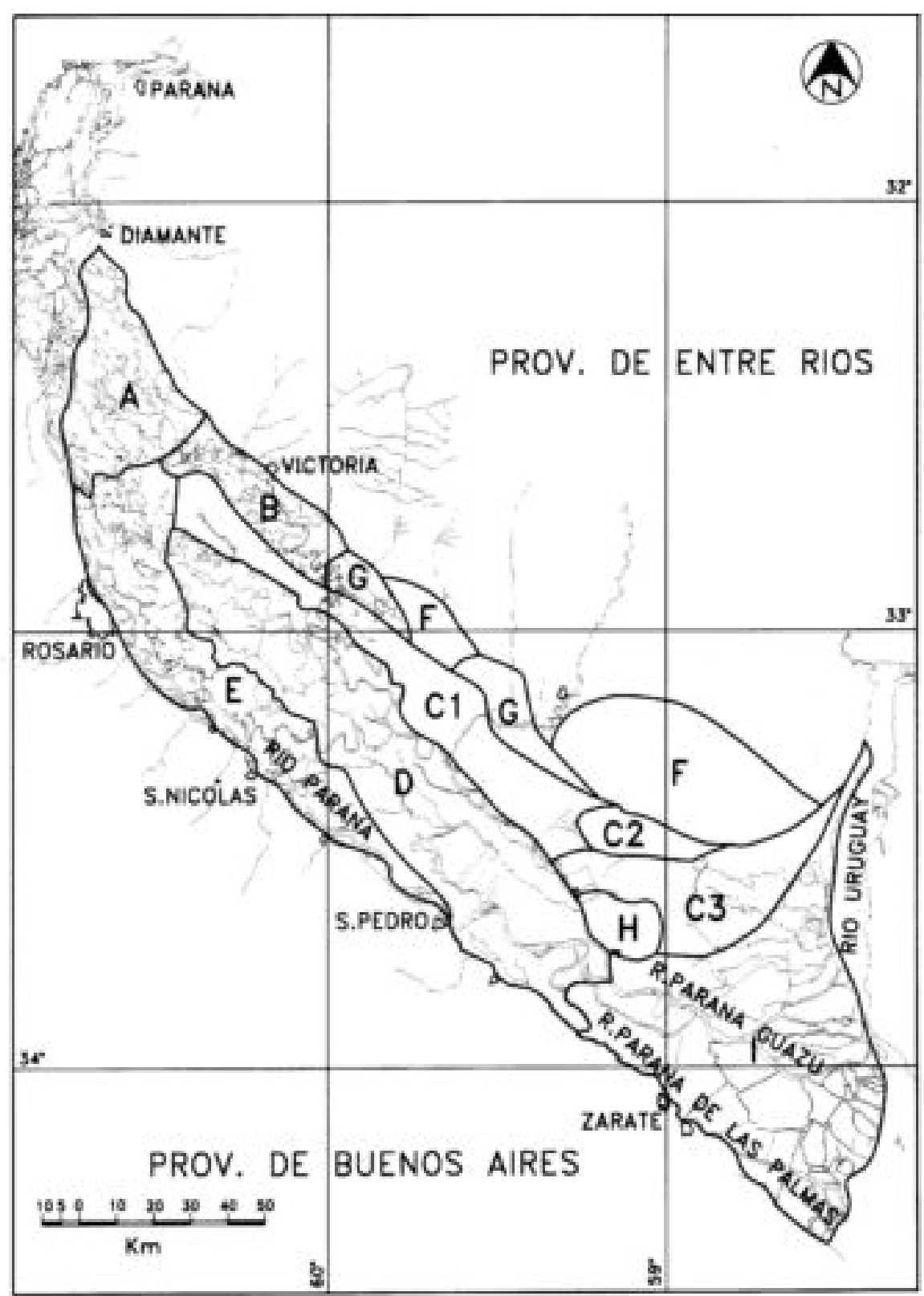

Fig. 2: Zonificación de la región del Delta del Rio Paranâ.

Unionoes: A. Bosques, praderas y lagunas de llanura de meandros; B. Isletas de praderas de albardones bajos; $\mathrm{C}$. Praderas de cordones y depresiones; $\mathrm{C}$. Praderas con isletes de bosque de cordones y depresiones; C. Bosques, praderas y arroyos de cordones y depresiones; D. Praderas de antigua llanura de 'mareas; E. Bosques y praderas de las islas de cauce y fajas de meandros del rio Parana; F. Praderas y sabanas de la antigua llanura litoral; G. Arbustales de antiguos deltas; H. Praderas de la isla de lbicuy; I. Pajonales y bosques del Bajo Delta.

Fuente: Malvárez (1999: 37) 
Mapa A. 7. Detalle del mapa 3

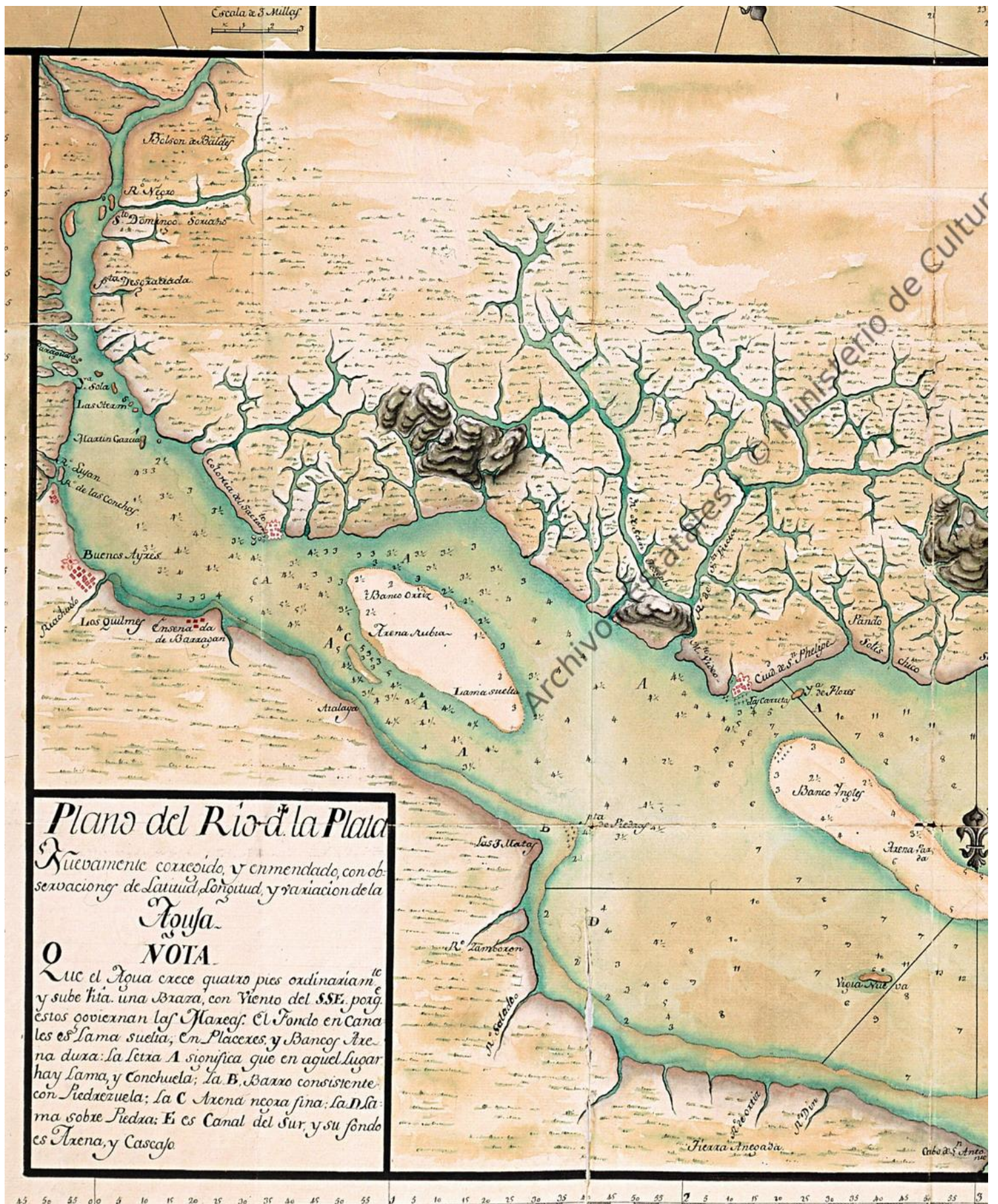

Fuente: Archivo General de Indias, Mapas y planos, Buenos Aires, 92B. Disponible en línea: pares.mcu.es 


\section{Anexo 2. Cuadros}

Cuadro A. 1. Cantidad de cueros exportados por la región Río de la Plata por quinqueños, 1699-1798.

\begin{tabular}{|r|r|}
\hline Período & Cantidad \\
\hline $1699-03$ & 23.070 \\
$1704-08$ & 51.418 \\
$1709-13$ & 104.836 \\
$1714-18$ & 164.173 \\
$1719-23$ & 248.551 \\
$1724-28$ & 483.043 \\
$1729-33$ & 495.576 \\
$1734-38$ & 91.051 \\
$1739-43$ & 31.859 \\
$1744-48$ & 158.532 \\
$1749-53$ & 267.765 \\
$1754-58$ & 265.151 \\
$1759-63$ & 274.258 \\
$1764-68$ & 340.260 \\
$1769-73$ & 705.591 \\
$1774-78$ & 1.330 .838 \\
$1779-83$ & 1.962 .729 \\
$1784-88$ & 2.076 .299 \\
$1789-93$ & 2.979 .904 \\
$1794-98$ & 2.482 .844 \\
\hline
\end{tabular}

Fuente: Elaboración propia a partir de Jumar (2008) para 1699-1778 y Camarda (2014) para 1779-1798 
Cuadro A. 2. Cantidad de cueros exportados desde Buenos Aires y Montevideo 17791799

\begin{tabular}{|r|r|r|r|}
\hline Año & Buenos Aires & Montevideo & \multicolumn{1}{|c|}{ Total } \\
\hline 1779 & 240.409 & 195.140 & 435.549 \\
1780 & 73.784 & 176.592 & 250.376 \\
1781 & 35.111 & 54.421 & 89.532 \\
1782 & 60.491 & 88.007 & 148.498 \\
1783 & 484.060 & 554.714 & 1.038 .774 \\
1784 & 361.742 & 301.176 & 662.918 \\
1785 & 192.505 & 122.761 & 315.266 \\
1786 & 284.077 & 86.614 & 370.691 \\
1787 & 232.069 & 121.099 & 353.168 \\
1788 & 228.157 & 146.399 & 374.556 \\
1789 & 226.515 & 173.070 & 399.585 \\
1790 & 279.030 & 342.334 & 621.364 \\
1791 & 237.539 & 216.674 & 454.213 \\
1792 & 530.322 & 346.041 & 876.363 \\
1793 & 390.252 & 238.127 & 628.379 \\
1794 & 432.685 & 311.579 & 744.264 \\
1795 & 239.037 & 266.728 & 505.765 \\
1796 & 531.903 & 347.335 & 879.238 \\
1797 & 125.303 & 89.552 & 214.855 \\
1798 & 21.000 & 117.722 & 138.722 \\
1799 & 298.194 & 118.545 & 416.739 \\
\hline Total & 5.504 .185 & 4.414 .630 & 9.918 .815 \\
\hline
\end{tabular}

Fuente: Camarda (2014) 
Cuadro A. 3. Ingreso de carros cargados de cueros, noviembre de 1784

\begin{tabular}{|c|c|c|c|c|}
\hline Fecha & Introductor & Carros & Cueros & Promedio \\
\hline $2-11-1784$ & Pérez, José & 3 & 240 & 80 \\
\hline $2-11-1784$ & Ramírez, Manuel & 8 & 680 & 85 \\
\hline $2-11-1784$ & García, Juan Francisco & 6 & 480 & 80 \\
\hline $2-11-1784$ & Gutiérrez, Luis & 1 & 50 & 50 \\
\hline $3-11-1784$ & Medio, Juan & 11 & 946 & 86 \\
\hline $3-11-1784$ & Maldonado, Manuel & 2 & 140 & 70 \\
\hline $6-11-1784$ & Buguen, Ramón & 8 & 640 & 80 \\
\hline $6-11-1784$ & Díaz, Juan & 2 & 160 & 80 \\
\hline $6-11-1784$ & González, Cayetano & 2 & 110 & 55 \\
\hline $6-11-1784$ & Monasterio, Antonio & 2 & 130 & 65 \\
\hline $6-11-1784$ & Melo, Juan Francisco & 7 & 630 & 90 \\
\hline $6-11-1784$ & Hernández, Juan & 1 & 42 & 42 \\
\hline $9-11-1784$ & Quadra, Miguel Ignacio de la & 6 & 500 & 83,3 \\
\hline $9-11-1784$ & Ibarra, Lorenzo & 9 & 778 & 86,4 \\
\hline $9-11-1784$ & Cruz, Juan Esteban & 8 & 640 & 80 \\
\hline 10-11-1784 & Antón, Miguel & 2 & 180 & 90 \\
\hline 10-11-1784 & Ramírez, Manuel & 8 & 610 & 76,2 \\
\hline 10-11-1784 & Fernández, Andrés & 7 & 599 & 85,5 \\
\hline 10-11-1784 & Ibáñez, Juan & 5 & 350 & 70 \\
\hline $11-11-1784$ & González, Manuel & 8 & 678 & 84,7 \\
\hline $11-11-1784$ & Monasterio, Antonio & 1 & 77 & 77 \\
\hline $11-11-1784$ & Balbín, Juan & 2 & 90 & 45 \\
\hline $11-11-1784$ & Maciel, Francisco & 4 & 320 & 80 \\
\hline $12-11-1784$ & Ferrer, Pedro & 2 & 160 & 80 \\
\hline $12-11-1784$ & Maciel, Francisco & 4 & 280 & 70 \\
\hline $12-11-1784$ & Estreyte, José & 1 & 80 & 80 \\
\hline 12-11-1784 & Sánchez, Juan & 1 & 82 & 82 \\
\hline $15-11-1784$ & Barrio, Domingo & 1 & 26 & 26 \\
\hline $15-11-1784$ & Lorenzo, Manuel & 1 & 14 & 14 \\
\hline $15-11-1784$ & Alzaybar, Maria Francisca & 5 & 277 & 55,4 \\
\hline $16-11-1784$ & García, Juan Francisco & 6 & 500 & 83,3 \\
\hline $16-11-1784$ & Pérez, Felipe & 1 & 80 & 80 \\
\hline $16-11-1784$ & Nieto, Manuel & 14 & 1180 & 84,2 \\
\hline 18-11-1784 & Nieto, Manuel & 6 & 602 & 100,3 \\
\hline 18-11-1784 & Vidal, Pedro & 7 & 637 & 91 \\
\hline 19-11-1784 & Nieto, Manuel & 12 & 1040 & 86,6 \\
\hline $20-11-1784$ & Viana, Melchor & 2 & 160 & 80 \\
\hline $20-11-1784$ & Cabral, Francisco & 1 & 69 & 69 \\
\hline $20-11-1784$ & Cabral, Luciano & 8 & 882 & 110,2 \\
\hline 22-11-1784 & Ferrer, Pedro & 3 & 246 & 82 \\
\hline 22-11-1784 & Mancebo, José & 1 & 26 & 26 \\
\hline $22-11-1784$ & Goloriz, Antonio & 9 & 739 & 82,1 \\
\hline $22-11-1784$ & Vidal, Pedro & 2 & 183 & 91,5 \\
\hline $22-11-1784$ & Llorens, José & 11 & 660 & 60 \\
\hline 23-11-1784 & Viana, Melchor & 2 & 160 & 80 \\
\hline 23-11-1784 & cabo de la partida de Santa Tecla & 1 & 60 & 60 \\
\hline 24-11-1784 & Nieto, Manuel & 9 & 774 & 86 \\
\hline $25-11-1784$ & Trapani, Juan & 7 & 560 & 80 \\
\hline
\end{tabular}




\begin{tabular}{|l|l|r|r|r|}
$26-11-1784$ & Viana, Melchor & 1 & 80 & 80 \\
$26-11-1784$ & Núñez, José & 3 & 300 & 100 \\
$26-11-1784$ & Trapani, Juan & 4 & 315 & 78,7 \\
$27-11-1784$ & Trapani, Juan & 4 & 320 & 80 \\
$27-11-1784$ & Nieto, Manuel & 3 & 270 & 90 \\
$27-11-1784$ & Rodríguez, Bernardo & 1 & 59 & 59 \\
$29-11-1784$ & Acosta, Joaquín y Ferrer, Pedro & 6 & 480 & 80 \\
$29-11-1784$ & Aguilera, José & 2 & 130 & 65 \\
$29-11-1784$ & Nieto, Manuel & 12 & 1040 & 86,6 \\
$29-11-1784$ & Torre, Antonio de la & 1 & 80 & 80 \\
$29-11-1784$ & Arosegui, Ignacio & 1 & 80 & 80 \\
$29-11-1784$ & Pérez, Manuel & 2 & 160 & 80 \\
\hline & Totales & $\mathbf{2 7 0}$ & $\mathbf{2 1 8 6 1}$ & \\
\cline { 2 - 3 } & Promedio general & 80,96 & \multicolumn{2}{|c}{} \\
\cline { 2 - 3 } & Mediana & 80 & \multicolumn{2}{|c}{} \\
\cline { 2 - 4 }
\end{tabular}

Fuente: Elaboración propia a partir de AGN IX 2-4-3

Cuadro A. 4. Destino de los cueros introducidos en noviembre de 1784

\begin{tabular}{|l|r|}
\hline Lugar & Cueros \\
\hline Hueco de Juan Pedro & 8822 \\
Hueco de Luis Gutiérrez & 7748 \\
Hueco de Andreu & 2864 \\
Hueco de José de Silba & 1290 \\
Hueco de Marcos Pérez & 1021 \\
Hueco del Oficial Real & 1018 \\
Miguel I. de la Quadra, su hueco & 500 \\
José Pérez, su hueco & 240 \\
Frente la casa de Luis León & 160 \\
Hueco de Lorenzo Ulibarri & 160 \\
Hueco de Juan Fernández & 116 \\
Juan Balbín, su hueco & 90 \\
Antonio de la Torre, su hueco & 80 \\
Hueco de Ramón Gimeno & 80 \\
Hueco de Sebastián Roso & 77 \\
Casa de Ventura Rodríguez & 42 \\
La Plaza & 40 \\
\hline
\end{tabular}

Fuente: Elaboración propia a partir de AGN IX 2-4-3 
Cuadro A. 5. Totales mensuales de cueros, sebo y grasa introducidos a Montevideo de septiembre de 1784 a marzo de 1790

\begin{tabular}{|c|c|c|c|c|}
\hline Año & Mes & Cantidad & Sebo & Grasa \\
\hline \multirow[t]{4}{*}{1784} & Sep & 17452 & & \\
\hline & Oct & 14079 & & \\
\hline & Nov & 24978 & & \\
\hline & Dic & & & \\
\hline \multirow[t]{11}{*}{1785} & Ene & 20054 & \multirow{12}{*}{385} & \multirow{11}{*}{171} \\
\hline & Feb & 4183 & & \\
\hline & Mar & 4835 & & \\
\hline & Abr & 3945 & & \\
\hline & May & 2193 & & \\
\hline & Jun & 3725 & & \\
\hline & Jul & 6000 & & \\
\hline & Ago & 3299 & & \\
\hline & Sep & & & \\
\hline & Oct & & & \\
\hline & Nov & & & \\
\hline \multirow{11}{*}{1786} & $\begin{array}{l}\text { Dic } \\
\text { Ene }\end{array}$ & & & \\
\hline & Feb & 4298 & 1055 & 222 \\
\hline & Mar & 5503 & 992 & 863 \\
\hline & $\mathrm{Abr}$ & & & \\
\hline & May & & & \\
\hline & Jun & & & \\
\hline & Jul & & & \\
\hline & $\begin{array}{l}\text { Ago } \\
\text { Sep }\end{array}$ & $\begin{array}{l}8615 \\
5207\end{array}$ & $\begin{array}{r}1697 \\
923\end{array}$ & $\begin{array}{l}397 \\
180\end{array}$ \\
\hline & Oct & 7971 & 1169 & 212 \\
\hline & Nov & 7903 & 1478 & 116 \\
\hline & Dic & 8247 & 2261 & 673 \\
\hline \multirow[t]{12}{*}{1787} & Ene & 7167 & 1744 & 642 \\
\hline & Feb & 4337 & 2095 & 733 \\
\hline & Mar & 5297 & 5778 & 1199 \\
\hline & Abr & 5739 & 3730 & 453 \\
\hline & May & 6921 & 3279 & 379 \\
\hline & Jun & 3050 & 1514 & 225 \\
\hline & Jul & 5556 & 1528 & 182 \\
\hline & Ago & & & \\
\hline & Sep & & & \\
\hline & Oct & 13911 & 1181 & 222 \\
\hline & Nov & & & \\
\hline & Dic & 7300 & 1579 & 413 \\
\hline \multirow[t]{5}{*}{1788} & Ene & 7253 & 2035 & 283 \\
\hline & Feb & 3982 & 1794 & 1103 \\
\hline & Mar & 7090 & 2228 & 1500 \\
\hline & Abr & 7136 & 4013 & 1048 \\
\hline & May & 4664 & 2554 & 833 \\
\hline
\end{tabular}




\begin{tabular}{|l|l|r|r|r|} 
& Jun & 5239 & 2718 & 1208 \\
& Jul & 5359 & 1755 & 406 \\
& Ago & 7141 & 3193 & 821 \\
Sep & 15873 & 3732 & 1201 \\
& Oct & 13924 & 2896 & 458 \\
& Nov & 17666 & 4471 & 589 \\
& Dic & 17816 & 4671 & 151 \\
\hline 1789 & Ene & 13545 & 3796 & 408 \\
& Feb & 15258 & 3116 & 666 \\
& Mar & 19362 & 3639 & 1169 \\
& Abr & 18533 & 5688 & 393 \\
& May & 11814 & 2844 & 148 \\
& Jun & 8906 & 1162 & 177 \\
& Jul & 9061 & 3223 & 383 \\
& Ago & 12452 & 1646 & 404 \\
& Sep & 12342 & 1411 & 730 \\
& Oct & 20379 & 2120 & 364 \\
& Nov & 20797 & 1110 & 214 \\
& Dic & 20786 & 1682 & 85 \\
\hline 1790 & Ene & 23397 & 1267 & 26 \\
& Feb & 16129 & 946 & 184 \\
& Mar & 14819 & 1430 & 734 \\
\hline
\end{tabular}

Fuente: Elaboración propia a partir de AGN IX: 2-4-3, 2-4-4, 2-4-5, 2-4-6, 2-5-1, 2-5-2, 2-5-3, 2-5-4, 2-5$5,2-5-6,2-6-1,2-6-2,2-6-3,2-6-4,2-6-5,2-6-6$ y 2-6-7. 
Cuadro A. 6. Introducciones de cueros y sebo pertenecientes a los diezmos

\begin{tabular}{|l|l|r|r|}
\hline Fecha & Introductor & Cueros & Sebo \\
\hline $22-9-1784$ & Bustillos, Juan Antonio & 290 & \\
$25-9-1784$ & Bustillos, Juan Antonio & 250 & \\
$27-9-1784$ & Bustillos, Juan Antonio & 300 & \\
\hline $1-12-1787$ & Bustillos, Juan Antonio & 90 & \\
$7-12-1787$ & Bustillos, Juan Antonio & 280 & \\
\hline $19-9-1788$ & Vicente, Antonio & 160 & \\
$24-10-1788$ & San Vicente, Antonio & 150 & \\
$12-11-1788$ & San Vicente, Antonio & & 120 \\
$17-12-1788$ & San Vicente, Antonio & 100 & \\
\hline $28-1-1789$ & San Vicente, Antonio & 240 & \\
$6-4-1789$ & Bustillos, Juan Antonio & 480 & \\
$24-4-1789$ & Bustillos, Juan Antonio & 790 & \\
$30-5-1789$ & Hidalgo, José & 160 & \\
$12-6-1789$ & San Vicente, Antonio & 320 & \\
$25-6-1789$ & Hidalgo, José Antonio & 640 & \\
$13-7-1789$ & Fachani, Nicolás & 160 & \\
$23-7-1789$ & Bustillos, Juan Antonio & 240 & \\
$22-9-1789$ & San Vicente, Antonio & 170 & \\
$28-9-1789$ & Fachani, Antonio & 164 & \\
$28-9-1789$ & Rodríguez, Gregorio & 70 & \\
$7-10-1789$ & Bustillos, Juan Antonio & 400 & \\
$9-10-1789$ & San Vicente, Antonio & 200 & \\
$7-11-1789$ & San Vicente, Antonio & 160 & \\
$7-11-1789$ & San Vicente, Antonio & 150 & \\
$27-11-1789$ & Rodríguez, Gregorio & 60 & \\
$23-12-1789$ & Lebral, Antonio & 120 & \\
$28-12-1789$ & Hidalgo, José Antonio & 480 & \\
\hline $16-1-1790$ & Bustillos, Juan Antonio & 270 & \\
\hline & Totales & $\mathbf{6 8 9 4}$ & $\mathbf{1 2 0}$ \\
\hline
\end{tabular}

Fuente: Elaboración propia a partir de AGN IX: 2-4-3, 2-4-4, 2-4-5, 2-4-6, 2-5-1, 2-5-2, 2-5-3, 2-5-4, 2-5$5,2-5-6,2-6-1,2-6-2,2-6-3,2-6-4,2-6-5,2-6-6$ y $2-6-7$. Cueros en unidades y sebo en arrobas. 
Cuadro A. 7. Ingreso de cueros marcados y orejanos a Montevideo 1791-1797

\begin{tabular}{|c|c|c|c|c|}
\hline Año & Mes & $\begin{array}{l}\text { Cueros } \\
\text { Marcados }\end{array}$ & $\begin{array}{l}\text { Cueros } \\
\text { orejanos }\end{array}$ & Total \\
\hline \multirow[t]{4}{*}{1791} & Sep & 7.132 & 3.102 & 10.234 \\
\hline & Oct & 15.276 & 6.583 & 21.859 \\
\hline & Nov & 14.004 & 14.918 & 28.922 \\
\hline & Dic & 17.265 & 18.284 & 35.549 \\
\hline \multirow[t]{12}{*}{1792} & Ene & 5.151 & 9.989 & 15.140 \\
\hline & Feb & 8.629 & 7.354 & 15.983 \\
\hline & Mar & 16.775 & 14.510 & 31.285 \\
\hline & Abr & 6.425 & 2.047 & 8.472 \\
\hline & May & 12.118 & 0 & 12.118 \\
\hline & Jun & 14.482 & 0 & 14.482 \\
\hline & Jul & 12.353 & 0 & 12.353 \\
\hline & Ago & 21.092 & 0 & 21.092 \\
\hline & Sep & 17.338 & 0 & 17.338 \\
\hline & Oct & 15.976 & 5.809 & 21.785 \\
\hline & Nov & 11.019 & 21.586 & 32.605 \\
\hline & Dic & 13.105 & 24.642 & 37.747 \\
\hline \multirow[t]{12}{*}{1793} & Ene & 9.309 & 16.765 & 26.074 \\
\hline & Feb & 6.807 & 7.388 & 14.195 \\
\hline & Mar & 8.499 & 9.553 & 18.052 \\
\hline & $\mathrm{Abr}$ & 4.092 & 13.168 & 17.260 \\
\hline & May & 8.458 & 9.188 & 17.646 \\
\hline & Jun & 4.934 & 8.242 & 13.176 \\
\hline & Jul & 3.328 & 9.751 & 13.071 \\
\hline & Ago & 4.811 & 6.628 & 11.439 \\
\hline & Sep & 6.242 & 5.997 & 12.239 \\
\hline & Oct & 12.403 & 19.042 & 31.445 \\
\hline & Nov & 7.626 & 15.459 & 23.085 \\
\hline & Dic & 7.653 & 21.715 & 28.715 \\
\hline \multirow[t]{12}{*}{1794} & Ene & 9.001 & 9.722 & 18.723 \\
\hline & Feb & 8.500 & 8.217 & 16.717 \\
\hline & Mar & 9.232 & 9.835 & 19.067 \\
\hline & $\mathrm{Abr}$ & 13.922 & 6.038 & 19.960 \\
\hline & May & 8.599 & 5.751 & 14.350 \\
\hline & Jun & 8.183 & 6.078 & 14.261 \\
\hline & Jul & 7.064 & 3.832 & 10.896 \\
\hline & Ago & 9.926 & 7.101 & 17.027 \\
\hline & Sep & 7.862 & 7.102 & 14.964 \\
\hline & Oct & 8.001 & 9.669 & 17.670 \\
\hline & Nov & 13.930 & 13.754 & 27.684 \\
\hline & Dic & 18.847 & 22.487 & 41.304 \\
\hline \multirow[t]{6}{*}{1795} & Ene & 9.525 & 12.568 & 22.093 \\
\hline & Feb & 11.860 & 6.673 & 18.533 \\
\hline & Mar & 12.913 & 5.560 & 18.473 \\
\hline & $\mathrm{Abr}$ & 12.656 & 4.374 & 17.030 \\
\hline & May & 8.722 & 4.277 & 12.999 \\
\hline & Jun & 7.828 & 5.714 & 13.542 \\
\hline
\end{tabular}




$\begin{array}{rlrrr} & \text { Jul } & 7.328 & 6.920 & 14.248 \\ & \text { Ago } & 13.329 & 6.516 & 19.845 \\ \text { Sep } & 5.741 & 11.017 & 16.758 \\ & \text { Oct } & 10.977 & 11.923 & 22.900 \\ \text { Nov } & 17.175 & 25.381 & 42.556 \\ \text { Dic } & 11.264 & 14.413 & 25.677 \\ 1796 \text { Ene } & 13.185 & 12.450 & 25.635 \\ & \text { Feb } & 19.482 & 8.629 & 28.111 \\ & \text { Mar } & 11.127 & 3.580 & 14.707 \\ & \text { Abr } & 8.999 & 7.051 & 16.050 \\ \text { May } & 14.011 & 5.007 & 19.018 \\ & \text { Jun } & 11.894 & 5.823 & 17.717 \\ & \text { Jul } & 5.968 & 4.662 & 10.630 \\ & \text { Ago } & 14.693 & 3.199 & 17.892 \\ \text { Sep } & 19.309 & 7.355 & 26.664 \\ & \text { Oct } & 17.870 & 6.360 & 24.230 \\ \text { Nov } & 17.777 & 18.955 & 36.732 \\ \text { Dic } & 12.472 & 5.543 & 18.015 \\ 1797 & \text { Ene } & 2.504 & 4.202 & 6.706 \\ & \text { Feb } & 4.232 & 1.642 & 5.874 \\ & & \text { Total } & 1.308 .619\end{array}$

Fuente: AGN IX 3-2-5 
Cuadro A. 8. Envíos de derivados vacunos de Maldonado a Montevideo, 1782-1806

\begin{tabular}{|c|c|c|c|c|c|}
\hline & $\begin{array}{c}\text { Cuero } \\
\text { vacuno }\end{array}$ & Sebo & Grasa & $\begin{array}{c}\text { Carne } \\
\text { salada }\end{array}$ & $\begin{array}{c}\text { Lengua } \\
\text { salada }\end{array}$ \\
\hline Año & Unidad & Arroba & Arroba & Arroba & Unidad \\
\hline 1782 & 0 & 22 & 230 & 0 & 0 \\
\hline 1783 & 10.567 & 237 & 528,5 & 60 & 0 \\
\hline 1784 & 10.589 & 534 & 981,5 & 37 & 0 \\
\hline 1785 & 6.831 & 789,5 & 950,5 & 140 & 0 \\
\hline 1786 & 5.674 & 862 & 730,5 & 0 & 0 \\
\hline 1787 & s/d & s/d & s/d & s/d & s/d \\
\hline 1788 & 13.694 & 2.788 & 1.139 & 786 & 64 \\
\hline 1789 & 19.600 & $3.840,50$ & 1.502 & 78 & 172 \\
\hline 1790 & 25.576 & 2.479 & 1.161 & 124 & 86 \\
\hline 1791 & 29.359 & 2.019 & 818 & 140 & 108 \\
\hline 1792 & 31.518 & 2.837 & 661,5 & 29 & 300 \\
\hline 1793 & 21.699 & 889 & 571 & 0 & 18 \\
\hline 1794 & 32.521 & $1.911,50$ & 660 & 164 & 312 \\
\hline 1795 & 33.178 & 6.645 & 2.186 & 8 & 0 \\
\hline 1796 & 38.368 & 6.872 & 1.423 & 643 & 456 \\
\hline 1797 & 10.589 & 838 & 114 & 1.778 & 1.110 \\
\hline 1798 & 19.796 & 2.163 & 203 & 152 & 583 \\
\hline 1799 & 17.350 & 3.762 & 272 & 105 & 324 \\
\hline 1800 & 11.289 & 1.605 & 107 & 0 & 0 \\
\hline 1801 & 5.481 & 658 & 46 & 0 & 0 \\
\hline 1802 & 64.994 & 9.852 & 42 & 30 & 216 \\
\hline 1803 & 53.447 & 11.182 & 295 & 0 & 4.296 \\
\hline 1804 & 74.430 & 14.688 & 276 & 28 & 768 \\
\hline 1805 & 25.315 & 6.412 & 153 & 110 & 636 \\
\hline 1806 & 16.311 & 5.033 & 173 & 0 & 300 \\
\hline Total & 578.176 & $88.918,5$ & $15.223,5$ & 4.412 & 9.749 \\
\hline
\end{tabular}

Fuente: Elaboración propia a partir de AGN Libros auxiliares de alcabala de guías en Sala XIII, Maldonado: Cajas de 3288 a 3312 
Cuadro A. 9. Introducciones de Manuel Campana a Montevideo 1787-1788

\begin{tabular}{|c|c|c|c|}
\hline Fecha & Bien & Cantidad & Valor \\
\hline $16-7-1787$ & $\begin{array}{l}\text { Cueros } \\
\text { sebo derretido } \\
\text { sebo en rama } \\
\text { Grasa } \\
\text { Gallina } \\
\end{array}$ & $\begin{array}{r}108 \\
30 \text { arrobas } \\
50 \text { arrobas } \\
3 \text { arrobas } \\
100 \\
\end{array}$ & 189 \\
\hline $10-8-1787$ & $\begin{array}{l}\text { Cueros } \\
\text { Grasa } \\
\text { Gallina }\end{array}$ & $\begin{array}{r}50 \\
2 \text { arrobas } \\
60 \\
\end{array}$ & 68 \\
\hline $17-10-1787$ & $\begin{array}{l}\text { Cueros } \\
\text { sebo en rama } \\
\text { Tocino } \\
\text { Queso } \\
\text { Gallina } \\
\text { Pollo } \\
\end{array}$ & $\begin{array}{r}122 \\
6 \text { arrobas } \\
12 \text { lonjas } \\
40 \\
50 \\
22 \\
\end{array}$ & 152 \\
\hline $26-1-1788$ & $\begin{array}{l}\text { Cueros } \\
\text { Sebo } \\
\text { Grasa } \\
\text { Mantequilla } \\
\text { Gallina } \\
\text { Queso } \\
\end{array}$ & $\begin{array}{r}60 \\
3 \text { cuarterolas } \\
3 \text { barriles } \\
12 \\
4 \\
60 \\
\end{array}$ & 161 \\
\hline $\begin{array}{l}12-3-1788 \\
12-3-1788 \\
12-3-1788 \\
12-3-1788 \\
12-3-1788 \\
\end{array}$ & $\begin{array}{l}\text { Cueros } \\
\text { Sebo } \\
\text { Sebo } \\
\text { Grasa } \\
\text { Huevo } \\
\end{array}$ & $\begin{array}{r}90 \\
2 \text { cuarterolas } \\
4 \text { barriles } \\
5 \text { barriles } \\
1 \text { barril }\end{array}$ & 123,4 \\
\hline $14-5-1788$ & $\begin{array}{l}\text { Cueros } \\
\text { sebo en rama }\end{array}$ & $\begin{array}{r}120 \\
70 \\
\end{array}$ & 141,2 \\
\hline
\end{tabular}

Fuente: Elaboración propia a partir de AGN XIII 15-9-4, 15-10-1, 15-10-2 y 15-10-6. Valor en pesos. 
Cuadro A.10. Sebo introducido en Montevideo por Francisco de Alba, 1789-1790

\begin{tabular}{|c|l|c|}
\hline Fecha & \multicolumn{1}{|c|}{ Proveedor } & Sebo \\
\hline $8-5-1789$ & Juan Jose Seco & 30 \\
$23-5-1789$ & Juan Jose Seco & 50 \\
$4-6-1789$ & Juan Jose Seco & 40 \\
$22-6-1789$ & Juan Jose Seco & 20 \\
$3-7-1789$ & Manuel Perez & 60 \\
$7-8-1789$ & Juan Jose Seco & 20 \\
$11-8-1789$ & Juan Jose Seco & 20 \\
$20-8-1789$ & Juan Jose Seco & 20 \\
$1-9-1789$ & Juan Jose Seco & 20 \\
$9-9-1789$ & Francisco Oribe & 20 \\
$11-9-1789$ & Antonio Almedo & 20 \\
$16-9-1789$ & Juan Jose Seco & 20 \\
$30-9-1789$ & Juan Jose Seco & 30 \\
$27-10-1789$ & Juan Jose Seco & 50 \\
$30-10-1789$ & Francisco Oribe & 20 \\
$20-11-1789$ & Juan Jose Seco & 60 \\
$1-12-1789$ & Juan Jose Seco & 100 \\
$28-12-1789$ & Juan Ignacio Martinez & 100 \\
$15-1-1790$ & Juan Jose Seco & 25 \\
$29-1-1790$ & Juan Jose Seco & 100 \\
$12-2-1790$ & Juan Jose Seco & 100 \\
$25-2-1790$ & Juan Jose Seco & 50 \\
$12-3-1790$ & Bernardo Lacumbe & 40 \\
$29-3-1790$ & Juan Jose Seco & 50 \\
\hline & Total & 1065 \\
\hline
\end{tabular}

Cuadro A.11. Sebo introducido en Montevideo por Custodio García, 1789-1790

\begin{tabular}{|c|l|c|}
\hline Fecha & \multicolumn{1}{|c|}{ Proveedor } & Sebo \\
\hline $15-9-1789$ & Manuel Perez & 50 \\
$12-10-1789$ & Juan Jose Seco & 25 \\
23-10-1789 & Juan Jose Seco & 30 \\
$7-11-1789$ & Juan Jose Seco & 40 \\
$19-11-1789$ & Juan Jose Seco & 40 \\
5-12-1789 & Juan Jose Seco & 40 \\
$18-12-1789$ & Manuel Perez & 60 \\
$16-1-1790$ & Manuel Perez & 40 \\
$28-1-1790$ & Feliciano Jimenez & 50 \\
$10-2-1790$ & Juan Jose Seco & 40 \\
\hline & Total & 415 \\
\hline
\end{tabular}


Cuadro A. 12. Precio de la cuartilla de sal en reales en Montevideo 1762-1815

\begin{tabular}{|c|c|c|c|c|}
\hline Fecha & Salinas & Córdoba & España & Patagones \\
\hline $19-10-1762$ & 26 & 12 & & \\
\hline $7-2-1764$ & 22 & 12 & & \\
\hline $12-1-1767$ & 22 & 14 & & \\
\hline $12-2-1768$ & 24 & 18 & & \\
\hline $14-2-1769$ & 24 & 16 & & \\
\hline $28-3-1770$ & 20 & 16 & & \\
\hline $8-2-1771$ & 20 & 16 & & \\
\hline $17-2-1772$ & 20 & 16 & & \\
\hline $9-2-1773$ & 24 & 16 & & \\
\hline 24-1-1774 & 22 & 12 & & \\
\hline $6-6-1774$ & 21 & 12 & & \\
\hline $1-9-1774$ & 21 & 12 & & \\
\hline $6-2-1775$ & 20 & 12 & & \\
\hline $17-1-1776$ & 21 & 12 & & \\
\hline $25-1-1777$ & 30 & 14 & & \\
\hline $23-1-1778$ & 22 & 12 & & \\
\hline $7-5-1778$ & 26 & 12 & & \\
\hline $4-9-1778$ & 26 & 12 & & \\
\hline $10-2-1779$ & 20 & 12 & & \\
\hline $10-5-1779$ & 16 & 5 & & \\
\hline $7-9-1779$ & 16 & 5 & & \\
\hline $30-1-1780$ & 16 & 12 & & \\
\hline $18-5-1780$ & 20 & 12 & & \\
\hline $9-9-1780$ & 20 & 10 & & \\
\hline $22-1-1781$ & 18 & 9 & & \\
\hline $9-5-1781$ & 20 & 10 & 6 & \\
\hline $17-9-1781$ & 20 & 10 & 7 & \\
\hline $12-1-1782$ & 24 & 12 & 8 & \\
\hline $5-9-1782$ & 24 & 12 & 20 & \\
\hline $11-2-1783$ & 24 & 12 & 8 & \\
\hline $6-5-1783$ & 32 & 24 & 12 & \\
\hline $4-9-1783$ & 24 & 12 & 8 & \\
\hline $21-1-1784$ & 24 & 12 & 5 & \\
\hline $8-5-1784$ & 24 & 12 & 5 & \\
\hline $7-9-1784$ & 24 & 12 & 7 & \\
\hline $26-1-1785$ & 24 & 12 & 10 & \\
\hline $10-5-1785$ & 24 & 16 & 10 & \\
\hline $9-9-1785$ & 24 & 16 & 16 & \\
\hline $26-1-1786$ & & & & \\
\hline $16-1-1787$ & 24 & 16 & & \\
\hline
\end{tabular}




\begin{tabular}{|c|c|c|c|c|}
\hline $7-5-1787$ & 24 & 16 & 10 & \\
\hline $1-9-1787$ & 24 & 16 & 16 & \\
\hline $22-1-1788$ & 20 & & 14 & \\
\hline $19-5-1788$ & 22 & 18 & 16 & \\
\hline $6-9-1788$ & 20 & 16 & 14 & \\
\hline $23-1-1789$ & 20 & 12 & 12 & \\
\hline $5-5-1789$ & 20 & 12 & 14 & \\
\hline $14-9-1789$ & 20 & 12 & 14 & \\
\hline $28-1-1790$ & 26 & 12 & 14 & \\
\hline $18-5-1790$ & 18 & & 6 & \\
\hline $13-9-1790$ & 24 & 12 & 14 & \\
\hline $10-1-1791$ & 20 & 11 & 12 & \\
\hline $13-5-1791$ & 20 & 9 & 10 & \\
\hline $10-9-1791$ & 20 & 7 & 8 & \\
\hline $31-1-1792$ & 18 & & 4 & 6 \\
\hline $19-5-1792$ & 18 & & 4 & 6 \\
\hline $21-9-1792$ & 18 & & 4 & 6 \\
\hline $27-7-1793$ & 18 & & 8 & 10 \\
\hline $10-10-1793$ & 18 & & 8 & 10 \\
\hline $5-2-1794$ & 18 & & 6 & 8 \\
\hline 8-7-1794 & 16 & & 4 & 6 \\
\hline 29-10-1794 & 16 & & 4 & 6 \\
\hline $14-1-1795$ & 16 & & 4 & 5 \\
\hline $12-5-1795$ & 16 & & 4 & 5 \\
\hline $1-9-1795$ & 16 & & 4 & 5 \\
\hline $29-1-1796$ & 16 & & 3,5 & 4,5 \\
\hline $14-5-1796$ & 16 & & 4 & 8 \\
\hline $13-9-1796$ & 16 & & 4 & 6 \\
\hline $23-1-1797$ & 13 & & 4 & 5 \\
\hline $19-6-1797$ & & & & \\
\hline $4-9-1797$ & 17 & & 7,5 & 12,5 \\
\hline $22-1-1798$ & 18 & & 8 & 12 \\
\hline $14-5-1798$ & 18 & & 7 & 10 \\
\hline $10-9-1798$ & 18 & & 11 & 11 \\
\hline 23-1-1799 & 18 & & 12 & 12 \\
\hline $25-5-1799$ & 20 & & 16 & \\
\hline 13-9-1799 & 20 & & 18 & 18 \\
\hline $17-2-1800$ & 18 & & 10 & 10 \\
\hline $30-6-1800$ & 20 & & 10 & 17 \\
\hline $25-9-1800$ & 22 & & 12 & 16 \\
\hline $23-2-1801$ & 20 & & 16 & 16 \\
\hline $27-7-1801$ & 24 & & 20 & 20 \\
\hline
\end{tabular}




\begin{tabular}{|c|c|c|c|}
\hline $24-9-1801$ & 24 & 20 & 20 \\
\hline $14-1-1802$ & 16 & 12 & 12 \\
\hline $31-5-1802$ & 16 & 6 & 12 \\
\hline $9-9-1802$ & 8 & 4 & 6 \\
\hline $1-2-1803$ & 8 & 4 & 6 \\
\hline $5-5-1803$ & 12 & 8 & \\
\hline $12-9-1803$ & 14 & 8 & 14 \\
\hline $6-2-1804$ & 24 & 14 & \\
\hline $16-5-1804$ & & & \\
\hline $19-9-1804$ & 24 & 16 & \\
\hline $22-1-1805$ & 20 & 12 & \\
\hline $7-5-1805$ & 24 & 16 & \\
\hline $6-9-1805$ & 36 & 20 & \\
\hline $30-1-1806$ & 32 & 18 & \\
\hline $22-5-1806$ & 32 & 18 & \\
\hline $22-10-1806$ & 28 & 16 & \\
\hline $20-1-1807$ & 30 & 20 & \\
\hline $25-9-1807$ & & 12 & \\
\hline $5-5-1808$ & 24 & 16 & \\
\hline 23-9-1808 & 24 & 16 & \\
\hline $10-1-1809$ & 20 & 16 & \\
\hline $6-5-1809$ & 20 & 16 & \\
\hline $6-9-1809$ & 20 & 16 & \\
\hline $10-1-1810$ & 16 & 10 & \\
\hline $2-5-1810$ & 24 & 16 & \\
\hline 5-11-1811 & 12 & 6 & \\
\hline $24-2-1813$ & 14 & 9 & \\
\hline $8-5-1813$ & 12 & 9 & \\
\hline $10-1-1814$ & 12 & 9 & \\
\hline $26-8-1814$ & 18 & 16 & \\
\hline $13-1-1815$ & 14 & 12 & \\
\hline
\end{tabular}

Fuente: Elaboración propia a partir de Acuerdos del Cabildo de Montevideo 
Cuadro A 13. Venta de bienes inmuebles rurales en Buenos Aires, Montevideo y Maldonado, 1701-1810

\begin{tabular}{|c|c|c|c|c|}
\hline Año & $\begin{array}{c}\text { Buenos } \\
\text { Aires }\end{array}$ & Montevideo & Maldonado & Total \\
\hline 1701 & 11 & & & 11 \\
\hline 1702 & 6 & & & 6 \\
\hline 1703 & 9 & & & 9 \\
\hline 1704 & 7 & & & 7 \\
\hline 1705 & 5 & & & 5 \\
\hline 1706 & 7 & & & 7 \\
\hline 1707 & 6 & & & 6 \\
\hline 1708 & 14 & & & 14 \\
\hline 1709 & 6 & & & 6 \\
\hline 1710 & 12 & & & 12 \\
\hline 1711 & 16 & & & 16 \\
\hline 1712 & 3 & & & 3 \\
\hline 1713 & 3 & & & 3 \\
\hline 1714 & 10 & & & 10 \\
\hline 1715 & 3 & & & 3 \\
\hline 1716 & 11 & & & 11 \\
\hline 1717 & 10 & & & 10 \\
\hline 1718 & 10 & & & 10 \\
\hline 1719 & 7 & & & 7 \\
\hline 1720 & 10 & & & 10 \\
\hline 1721 & 21 & & & 21 \\
\hline 1722 & 13 & & & 13 \\
\hline 1723 & 8 & & & 8 \\
\hline 1724 & 16 & & & 16 \\
\hline 1725 & 8 & & & 8 \\
\hline 1726 & 10 & & & 10 \\
\hline 1727 & 13 & & & 13 \\
\hline 1728 & 6 & & & 6 \\
\hline 1729 & 9 & & & 9 \\
\hline 1730 & 20 & & & 20 \\
\hline 1731 & 10 & & & 10 \\
\hline 1732 & 7 & & & 7 \\
\hline 1733 & 12 & & & 12 \\
\hline 1734 & 9 & & & 9 \\
\hline 1735 & 9 & 1 & & 10 \\
\hline 1736 & 8 & 0 & & 8 \\
\hline
\end{tabular}




\begin{tabular}{|c|c|c|c|}
\hline 1737 & 5 & 1 & 6 \\
\hline 1738 & 10 & 0 & 10 \\
\hline 1739 & 13 & 0 & 13 \\
\hline 1740 & 17 & 0 & 17 \\
\hline 1741 & 22 & 1 & 23 \\
\hline 1742 & 10 & 1 & 11 \\
\hline 1743 & 12 & 0 & 12 \\
\hline 1744 & 18 & 1 & 19 \\
\hline 1745 & 13 & 2 & 15 \\
\hline 1746 & 15 & 1 & 16 \\
\hline 1747 & 10 & 2 & 12 \\
\hline 1748 & 14 & 0 & 14 \\
\hline 1749 & 14 & 2 & 16 \\
\hline 1750 & 16 & 3 & 19 \\
\hline 1751 & 14 & 0 & 14 \\
\hline 1752 & 8 & 0 & 8 \\
\hline 1753 & 5 & 2 & 7 \\
\hline 1754 & 17 & 2 & 19 \\
\hline 1755 & 19 & 2 & 21 \\
\hline 1756 & 21 & 1 & 22 \\
\hline 1757 & 19 & 2 & 21 \\
\hline 1758 & 21 & 2 & 23 \\
\hline 1759 & 30 & 1 & 31 \\
\hline 1760 & 20 & 0 & 20 \\
\hline 1761 & 19 & 2 & 21 \\
\hline 1762 & 15 & 2 & 17 \\
\hline 1763 & 23 & 2 & 25 \\
\hline 1764 & 23 & 9 & 32 \\
\hline 1765 & 27 & 0 & 27 \\
\hline 1766 & 28 & 6 & 34 \\
\hline 1767 & 16 & 2 & 18 \\
\hline 1768 & 11 & 4 & 15 \\
\hline 1769 & 6 & 4 & 10 \\
\hline 1770 & 8 & 4 & 11 \\
\hline 1771 & 5 & 11 & 16 \\
\hline 1772 & 14 & 8 & 22 \\
\hline 1773 & 7 & 11 & 18 \\
\hline 1774 & 9 & 6 & 15 \\
\hline 1775 & 9 & 8 & 17 \\
\hline 1776 & 13 & 15 & 28 \\
\hline 1777 & 19 & 5 & 24 \\
\hline 1778 & 21 & 14 & 35 \\
\hline
\end{tabular}




\begin{tabular}{|c|c|c|c|c|}
\hline 1779 & 23 & 16 & & 39 \\
\hline 1780 & 18 & 18 & & 36 \\
\hline 1781 & 20 & 18 & & 38 \\
\hline 1782 & 8 & 15 & 1 & 24 \\
\hline 1783 & 12 & 12 & 4 & 28 \\
\hline 1784 & 18 & 0 & 4 & 22 \\
\hline 1785 & 15 & 16 & 2 & 33 \\
\hline 1786 & 28 & 8 & 8 & 44 \\
\hline 1787 & 10 & 8 & 0 & 18 \\
\hline 1788 & 17 & 10 & 11 & 38 \\
\hline 1789 & 26 & 7 & 9 & 42 \\
\hline 1790 & 22 & 4 & 3 & 29 \\
\hline 1791 & 11 & 15 & 1 & 27 \\
\hline 1792 & 22 & 9 & 4 & 35 \\
\hline 1793 & 20 & 17 & 3 & 40 \\
\hline 1794 & 19 & 10 & 2 & 31 \\
\hline 1795 & 19 & 17 & 3 & 39 \\
\hline 1796 & 20 & 17 & 4 & 41 \\
\hline 1797 & 22 & 14 & 2 & 38 \\
\hline 1798 & 24 & 24 & 6 & 54 \\
\hline 1799 & 31 & 18 & 12 & 61 \\
\hline 1800 & 18 & 13 & 6 & 37 \\
\hline 1801 & 23 & 15 & 7 & 45 \\
\hline 1802 & 24 & 10 & 1 & 35 \\
\hline 1803 & 19 & 9 & 2 & 30 \\
\hline 1804 & 29 & 13 & 5 & 47 \\
\hline 1805 & 14 & 18 & 12 & 44 \\
\hline 1806 & 9 & 11 & 7 & 27 \\
\hline 1807 & 9 & 3 & 0 & 12 \\
\hline 1808 & 23 & 11 & 1 & 35 \\
\hline 1809 & 24 & 17 & 1 & 42 \\
\hline 1810 & 30 & 10 & 1 & 41 \\
\hline
\end{tabular}

Fuente: Elaboración propia a partir de Saguier (1993: 69-71), Pivel Devoto (1964: 683685, 746-747) y AGN XIII Maldonado Legajos de 3288 a 3312 
Cuadro A. 14. Venta de chacras y estancias en Montevideo

\begin{tabular}{|c|c|c|c|}
\hline Año & Chacras & Estancias & Total \\
\hline 1735 & 1 & 0 & 1 \\
\hline 1736 & 0 & 0 & 0 \\
\hline 1737 & 1 & 0 & 1 \\
\hline 1738 & 0 & 0 & 0 \\
\hline 1739 & 0 & 0 & 0 \\
\hline 1740 & 0 & 0 & 0 \\
\hline 1741 & 0 & 1 & 1 \\
\hline 1742 & 1 & 0 & 1 \\
\hline 1743 & 0 & 0 & 0 \\
\hline 1744 & 0 & 1 & 1 \\
\hline 1745 & 2 & 0 & 2 \\
\hline 1746 & 1 & 0 & 1 \\
\hline 1747 & 2 & 0 & 2 \\
\hline 1748 & 0 & 0 & 0 \\
\hline 1749 & 1 & 1 & 2 \\
\hline 1750 & 2 & 1 & 3 \\
\hline 1751 & 0 & 0 & 0 \\
\hline 1752 & 0 & 0 & 0 \\
\hline 1753 & 0 & 2 & 2 \\
\hline 1754 & 2 & 0 & 2 \\
\hline 1755 & 1 & 1 & 2 \\
\hline 1756 & 1 & 0 & 1 \\
\hline 1757 & 1 & 1 & 2 \\
\hline 1758 & 2 & 0 & 2 \\
\hline 1759 & 0 & 1 & 1 \\
\hline 1760 & 0 & 0 & 0 \\
\hline 1761 & 0 & 2 & 2 \\
\hline 1762 & 0 & 2 & 2 \\
\hline 1763 & 1 & 1 & 2 \\
\hline 1764 & 6 & 3 & 9 \\
\hline 1765 & 0 & 0 & 0 \\
\hline 1766 & 5 & 1 & 6 \\
\hline 1767 & 2 & 0 & 2 \\
\hline 1768 & 2 & 2 & 4 \\
\hline 1769 & 3 & 1 & 4 \\
\hline 1770 & 3 & 1 & 4 \\
\hline 1771 & 10 & 1 & 11 \\
\hline 1772 & 7 & 1 & 8 \\
\hline 1773 & 10 & 1 & 11 \\
\hline 1774 & 5 & 1 & 6 \\
\hline
\end{tabular}




\begin{tabular}{|c|c|c|c|}
1775 & 6 & 2 & 8 \\
1776 & 5 & 10 & 15 \\
1777 & 3 & 2 & 5 \\
1778 & 8 & 6 & 14 \\
1779 & 11 & 5 & 16 \\
1780 & 15 & 3 & 18 \\
1781 & 11 & 7 & 18 \\
1782 & 10 & 5 & 15 \\
1783 & 8 & 4 & 12 \\
1784 & 0 & 0 & 0 \\
1785 & 8 & 8 & 16 \\
1786 & 6 & 2 & 8 \\
1787 & 5 & 3 & 8 \\
1788 & 5 & 6 & 11 \\
1789 & 4 & 3 & 7 \\
1790 & 1 & 3 & 4 \\
1791 & 9 & 6 & 15 \\
1792 & 3 & 6 & 9 \\
1793 & 11 & 6 & 17 \\
1794 & 4 & 6 & 10 \\
1795 & 9 & 6 & 15 \\
1796 & 7 & 10 & 17 \\
1797 & 8 & 6 & 14 \\
1798 & 9 & 15 & 24 \\
1799 & 8 & 10 & 18 \\
1800 & 5 & 8 & 13 \\
1801 & 11 & 4 & 15 \\
1802 & 7 & 3 & 10 \\
1803 & 6 & 3 & 9 \\
1804 & 6 & 7 & 13 \\
1805 & 12 & 6 & 19 \\
1806 & 6 & 5 & 11 \\
1807 & 3 & 0 & 3 \\
1808 & 4 & 6 & 10 \\
1809 & 7 & 11 & 18 \\
1810 & 6 & 4 & 11 \\
\hline Total & 319 & 223 & 544 \\
\hline
\end{tabular}

Fuente: Elaboración propia a partir de Pivel Devoto (1964: 683-685, 746-747) 


$$
[
$$


Anexo 3. Vecinos firmantes del acuerdo del Cabildo de Montevideo de 28 de junio de 1784

Claudio Márquez

A ruego de Dn. Andrés Hiraola, Claudio Márquez

Fernando Martínez

Antonio de Castro

Pedro Franca

A ruego de dn. Julián Ibarra por no saber firmar, Antonio de San Vicente

A ruego de dn. Vicente Gonzáles, Pedro Franca

A ruego de Pedro Maciel, Manuel Silva

Manuel Silva

Lorenzo Velasco

A ruego de Mariano Armada, Antonio de San Vicente

Antonio Gordillo

A ruego de Pedro Gonzáles por no saber firmar, Luis Antonio Gutiérrez

Francisco Antonio Maciel

A ruego de Domingo Gonzáles, Francisco Antonio Maciel

José Patricio Cardoso

A ruego de Santiago Chiribao, Francisco Antonio Maciel

A ruego de Luis Moreno, José Patricio Cardoso

A ruego de Ramón Basualdo, José Abad

Martín de Artigas

Fernando José Rodríguez

Gaspar Melgarejo

Miguel Otermin

Francisco de la Peña

Francisco Garrido

Juan Francisco Rexis de Mora

Por Domingo Baldenegro y Juan de Araujo firmo yo Juan Francisco Rexis de Mora

Manuel Vázquez de España

Manuel Pérez 


\section{Lorenzo José López}

José Antonio Artigas

A ruego de José Nicolás Montero, Francisco de la Peña

A ruego de Dn. Esteban Artigas, José Antonio Artigas

Pedro Montero

Nicolás de Zamona

Juan Francisco Meloy

A ruego de Bartolomé Quiroga, Nicolás de Zamona

A ruego de Gaspar Rodríguez, Nicolás de Zamona

A ruego de Francisco Milán y Alejandro Medina, Nicolás de Zamona

Gregorio Bordón

Antonio Santos de Almeda

Luis Porrillo

Antonio Glassi

Baltazar Aguirre

Manuel Bayarra

Felipe Pires

A ruego de Hermenegildo Laguna por no saber firmar, Luis Antonio Gutiérrez

Silvestre Pirez

Feliciano Portal

A ruego de Ramón Carrasco, Cosme Gari, Dn. Pedro Luna y Lorenzo Rodas, Tomás Estrada

A ruegos de dn. Francisco López y de dn. Juan Severino, Feliciano Portal

A ruego de Manuel Gonzáles, Joaquín de Chopitea

A ruego de mi Sor. Padre dn. Cristobal Callorda de Castro, Bartolomé Castro

Pedro Esteban

Juan Castilla

A ruego de Juan Bautista Arezo, Antonio de San Vicente

A ruego de Tomás Guevara, Joaquín de Chopitea

Tomás Estrada como apoderado de la Sra. da. María Francisca de Alzaybar y da.

Gabriela

Juan Balbín de Vallejo apoderado de los herederos del difunto Jorge Burgués 
Sebastián de León

Miguel Herrera

Juan Rebollo

Por mi suegro dn. Rudesindo Sáenz, y por mi Luis Antonio Gutiérrez

Dor. Francisco de los Ángeles Múñoz

A ruego de José Antonio Puchavert, Dor. Múñoz

Melchor de Viana

Por mi y por da. Petrona Pajón, Manuel Vázquez

A ruego de Antonio Galván, José Abad

Por Alejo de Nieba y Castillo, José Abad

Como apoderado de mi padre dn. Bartolomé Pérez, Dor. José Manuel Pérez

Por mi madre, hermana y yo, Luis Ramón Vidal

Ignacio Berci

En nombre de mi señora madre da. Rita Pérez, Lorenzo Figueredo

Por mi tío, Francisco Rodríguez 
Anexo 4. Cabildantes de Montevideo 1730-1808

\begin{tabular}{|c|c|}
\hline Año Nombre & Cargo \\
\hline 1730 Vera, José de & Alcalde de primer voto \\
\hline 1730 Fernández Medina, José & Alcalde de segundo voto \\
\hline 1730 Herrera, Cristóbal Cayetano & Alguacil Mayor \\
\hline 1730 Camejo Soto, Juan & Alferez Real \\
\hline 1730 Gaitan, Bernardo & Alcalde Provincial \\
\hline 1730 & Fiel Ejecutor \\
\hline 1730 Burgués, Jorge & Depositario General \\
\hline 1730 Artigas, Juan Antonio & Alcalde de la Santa Hermandad \\
\hline 1731 González, Tomás & Alcalde de primer voto \\
\hline 1731 Sotelo, Ramón & Alcalde de segundo voto \\
\hline 1731 Carrasco, Sebastián & Alguacil Mayor \\
\hline 1731 Sa, Juan Bautista de & Alferez Real \\
\hline 1731 Gaitan, Bernardo & Alcalde Provincial \\
\hline 1731 Sierra, José de la & Fiel Ejecutor \\
\hline 1731 Vera Suárez, Juan de & Depositario General \\
\hline 1731 Álvarez, Antonio & Alcalde de la Santa Hermandad \\
\hline 1731 Sosa Mascareñas, Luis de & Procurador General \\
\hline 1732 Fernández Medina, José & Alcalde de primer voto \\
\hline 1732 Mitre, José de & Alcalde de segundo voto \\
\hline 1732 Mendez, Antonio & Alguacil Mayor \\
\hline 1732 Artigas, Juan Antonio & Alferez Real \\
\hline 1732 Tejera, Tomás & Alcalde Provincial \\
\hline 1732 Sosa, Felipe & Fiel Ejecutor \\
\hline 1732 Calleros, Lorenzo & Depositario General \\
\hline 1732 Álvarez, Antonio & Alcalde de la Santa Hermandad \\
\hline 1732 Velasco, Marcos & Alcalde de la Santa Hermandad \\
\hline 1732 Pérez, Isidro & Procurador General \\
\hline 1733 González de Melo, José & Alcalde de primer voto \\
\hline 1733 Sierra, José de la & Alcalde de segundo voto \\
\hline 1733 Artigas, Juan Antonio & Alferez Real \\
\hline 1733 Calleros, Lorenzo & Alcalde Provincial \\
\hline 1733 Serpa, Jacinto de & Alguacil Mayor \\
\hline 1733 Martín, Francisco & Fiel Ejecutor \\
\hline 1733 Santos, Juan Martín de los & Depositario General \\
\hline 1733 Mendoza, Diego & Alcalde de la Santa Hermandad \\
\hline 1733 Burgués, Jorge & Procurador General \\
\hline 1734 Sosa Mascareñas, Luis de & Alcalde de primer voto \\
\hline 1734 Tejera, Tomás & Alcalde de segundo voto \\
\hline 1734 Calleros, Lorenzo & Alferez Real \\
\hline 1734 Mitre, José de & Alcalde Provincial \\
\hline 1734 Saavedra, Miguel de & Alguacil Mayor \\
\hline 1734 Pérez de Sosa, Felipe & Fiel Ejecutor \\
\hline 1734 Sa, Juan Bautista de & Depositario General \\
\hline 1734 Cabrera, Francisco & Alcalde de la Santa Hermandad \\
\hline 1735 Vera Perdomo, José de & Alcalde de primer voto \\
\hline
\end{tabular}


1735 Pérez de Sosa, Felipe

1735 Sa, Juan Bautista de

1735 Artigas, Juan Antonio

1735 Erea, Cristóbal Cayetano de

1735 Miguelena, Miguel de

1735 Mendoza, Diego

1735 Delgado Melilla, Juan

1735 González de Melo, José

1736 González de Melo, José

1736 Milena, Miguel

1736 Pérez de Sosa, Felipe

1736 Giménez, Javier

1736 Sa, Juan Bautista de

1736 Mendoza, Diego

1736 Pérez de Rojas, Isidro

1736 Cordobés, Pedro

1736 Herrera, Cristóbal Cayetano

1737 González de Melo, José

1737 Milena, Miguel

1737 Tejera, Tomás

1737 Amaro, Juan de

1737 Sa, Juan Bautista de

1737 Mendoza, Diego

1737 Pérez de Rojas, Isidro

1737 Herrera, Bartolomé

1737 Alzaibar, Francisco

1738 Fernández Medina, José

1738 Sotelo, Ramón

1738 Méndez, Antonio

1738 Delgado Melilla, Juan

1738 González, Tomás

1738 Serpa, Jacinto de

1738 Durán, José

1738 Herrera, Cristóbal Cayetano

1738 Sosa Mascareñas, Luis de

1739 Sotelo, Ramón

1739 Herrera, Cristóbal Cayetano

1739 Morares, Juan de

1739 Morares, Francisco

1739 González, Tomás

1739 Serpa, Jacinto de

1739 Durán, José

1739 Luis, Francisco

1739 Vera, José de
Alcalde de segundo voto

Alferez Real

Alcalde Provincial

Alguacil Mayor

Fiel Ejecutor

Depositario General

Alcalde de la Santa Hermandad

Procurador General

Alcalde de primer voto

Alcalde de segundo voto

Alferez Real

Alguacil Mayor

Alcalde Provincial

Fiel Ejecutor

Depositario General

Alcalde de la Santa Hermandad

Procurador General

Alcalde de primer voto

Alcalde de segundo voto

Alferez Real

Alguacil Mayor

Alcalde Provincial

Fiel Ejecutor

Depositario General

Alcalde de la Santa Hermandad

Procurador General

Alcalde de primer voto

Alcalde de segundo voto

Alferez Real

Alguacil Mayor

Alcalde Provincial

Fiel Ejecutor

Depositario General

Alcalde de la Santa Hermandad

Procurador General

Alcalde de primer voto

Alcalde de segundo voto

Alferez Real

Alguacil Mayor

Alcalde Provincial

Fiel Ejecutor

Depositario General

Alcalde de la Santa Hermandad

Procurador General 
1740 Vera, José de

1740 Delgado Melilla, Juan

1740 Herrera, Bartolomé

1740 Medina, Miguel

1740 Miguelena, Miguel de

1740 Giménez, Javier

1740 Calleros, Lorenzo

1740 Toledo, Juan de

1740 Pérez de Rojas, Isidro

1741 Vera, José de

1741 Burgués, Jorge

1741 Sosa Mascareñas, Luis de

1741 Saavedra, Miguel de

1741 Mitre, José de

1741 Pérez de Sosa, Felipe

1741 Sa, Juan Bautista de

1741 Durán, Manuel

1741 Delgado Melilla, Juan

1742 Pérez de Rojas, Isidro

1742 Velasco, Marcos

1742 Rivera, Sebastián

1742 Maciel, Luis Enrique

1742 Artigas, Juan Antonio

1742 Cordobés, Pedro

1742 Morales, Pedro

1742 Camejo, Antonio

1742 González de Melo, José

1743 Fernández Medina, José

1743 Giménez, Javier

1743 Rivera, Sebastián

1743 Maciel, Luis Enrique

1743 Artigas, Juan Antonio

1743 Almeda, Pedro de

1743 Morales, Pedro

1743 Toledo, Juan de

1743 González de Melo, José

1744 Gorriti, Francisco de

1744 Achucarro, Juan de

1744 Delgado Melilla, Juan

1744 Pagola, Francisco

1744 Ledesma, Esteban

1744 Morales, Juan de

1744 Calleros, Lorenzo

1744 Paz, Francisco de la

1744 González, Tomás
Alcalde de primer voto

Alcalde de segundo voto

Alferez Real

Alguacil Mayor

Alcalde Provincial

Fiel Ejecutor

Depositario General

Alcalde de la Santa Hermandad

Procurador General

Alcalde de primer voto

Alcalde de segundo voto

Alferez Real

Alguacil Mayor

Alcalde Provincial

Fiel Ejecutor

Depositario General

Alcalde de la Santa Hermandad

Procurador General

Alcalde de primer voto

Alcalde de segundo voto

Alferez Real

Alguacil Mayor

Alcalde Provincial

Fiel Ejecutor

Depositario General

Alcalde de la Santa Hermandad

Procurador General

Alcalde de primer voto

Alcalde de segundo voto

Alferez Real

Alguacil Mayor

Alcalde Provincial

Fiel Ejecutor

Depositario General

Alcalde de la Santa Hermandad

Procurador General

Alcalde de primer voto

Alcalde de segundo voto

Alferez Real

Alguacil Mayor

Alcalde Provincial

Fiel Ejecutor

Depositario General

Alcalde de la Santa Hermandad

Procurador General 
1745 Sosa Mascareñas, Luis de

1745 Miguelena, Miguel de

1745 Fernández Medina, José

1745 Mendoza, Diego

1745 Mitre, José de

1745 Giménez, Javier

1745 Sierra, José de la

1745 Delgado Melilla, Juan

1745 Achucarro, Juan de

1746 Montes de Oca, Pedro

1746 Mendoza, Diego

1746 Pérez de Sosa, Felipe

1746 Más, José

1746 Velasco, Marcos

1746 Sa, Juan Bautista de

1746 Gaitan, Bernardo

1746 Morales, Jacinto

1746 Medina, Miguel

1747 Delgado Melilla, Juan

1747 Cordobés, Pedro

1747 Montes de Oca, Pedro

1747 Pugnos, Cristóbal

1747 Giménez, Javier

1747 Torres, Juan de

1747 Sa, Juan Bautista de

1747 Morales, Juan de

1747 Berrotea, Miguel Antonio de

1747 González, Tomás

1748 Milan, José

1748 Más, José

1748 Morales, Francisco

1748 Medina, Juan de

1748 Medina, Miguel

1748 Pagola, Francisco

1748 Tejera, Tomás

1748 Tejera, Manuel

1748 González, Tomás

1749 González, Tomás

1749 Camejo, Antonio

1749 Milan, José

1749 Gordillo, Andrés

1749 Miguelena, Miguel de

1749 Medina, Francisco Esteban

1749 Fernández Medina, José

1749 Herrera, Francisco

1749 Pugnos, Cristóbal
Alcalde de primer voto

Alcalde de segundo voto

Alferez Real

Alguacil Mayor

Alcalde Provincial

Fiel Ejecutor

Depositario General

Alcalde de la Santa Hermandad

Procurador General

Alcalde de primer voto

Alcalde de segundo voto

Alferez Real

Alguacil Mayor

Alcalde Provincial

Fiel Ejecutor

Depositario General

Alcalde de la Santa Hermandad

Procurador General

Alcalde de primer voto

Alcalde de segundo voto

Alferez Real

Alguacil Mayor

Alcalde Provincial

Fiel Ejecutor

Depositario General

Alcalde de la Santa Hermandad

Procurador General

Procurador General

Alcalde de primer voto

Alcalde de segundo voto

Alferez Real

Alguacil Mayor

Alcalde Provincial

Fiel Ejecutor

Depositario General

Alcalde de la Santa Hermandad

Procurador General

Alcalde de primer voto

Alcalde de segundo voto

Alferez Real

Alguacil Mayor

Alcalde Provincial

Fiel Ejecutor

Depositario General

Alcalde de la Santa Hermandad

Procurador General 
1750 Camejo, Antonio

1750 Giménez, Javier

1750 Duran, Manuel

1750 Pugnos, Cristóbal

1750 Milan, José

1750 Cordobés, Pedro

1750 Morales, Juan de

1750 Velasco, Marcos

1750 Tejera, Tomás

1751 Delgado Melilla, Juan

1751 Gordillo, Andrés

1751 Pagola, Juan Bautista

1751 García, Antonio

1751 Más, José

1751 Pagola, Francisco

1751 Fernández Medina, José

1751 Herrera, Nicolás

1751 Álvarez, Cosme

1752 Cordobés, Pedro

1752 Duran, Manuel

1752 Morales, Juan de

1752 Hernández, Antonio

1752 Morales, Francisco

1752 Pugnos, Cristóbal

1752 Pérez de Sosa, Felipe

1752 Cardoso, Juan

1752 Camejo, Antonio

1753 Camejo, Antonio

1753 Montes de Oca, Pedro

1753 Ledesma, Esteban

1753 Medina, Francisco Esteban

1753 Medina, Miguel

1753 Muñoz, Bruno

1753 Pagola, Francisco

1753 Pérez, Bartolo

1753 Giménez, Javier

1754 Duran, Manuel

1754 Giménez, Javier

1754 Más, José

1754 García, Agustín

1754 Hernández, Antonio

1754 Cordobés, Pedro

1754 Morales, Francisco

1754 López, José

1754 Pérez, Isidro
Alcalde de primer voto

Alcalde de segundo voto

Alferez Real

Alguacil Mayor

Alcalde Provincial

Fiel Ejecutor

Depositario General

Alcalde de la Santa Hermandad

Procurador General

Alcalde de primer voto

Alcalde de segundo voto

Alferez Real

Alguacil Mayor

Alcalde Provincial

Fiel Ejecutor

Depositario General

Alcalde de la Santa Hermandad

Procurador General

Alcalde de primer voto

Alcalde de segundo voto

Alferez Real

Alguacil Mayor

Alcalde Provincial

Fiel Ejecutor

Depositario General

Alcalde de la Santa Hermandad

Procurador General

Alcalde de primer voto

Alcalde de segundo voto

Alferez Real

Alguacil Mayor

Alcalde Provincial

Fiel Ejecutor

Depositario General

Alcalde de la Santa Hermandad

Procurador General

Alcalde de primer voto

Alcalde de segundo voto

Alferez Real

Alguacil Mayor

Alcalde Provincial

Fiel Ejecutor

Depositario General

Alcalde de la Santa Hermandad

Procurador General 
1755 Delgado Melilla, Juan

1755 García de Tagle, Lorenzo

1755 Gordillo, Andrés

1755 Irurita, Pedro de

1755 Morales, Juan de

1755 Milan, José

1755 Pérez de Sosa, Felipe

1755 Rodríguez, Jorge

1755 Burgués, Jorge

1756 Miguelena, Miguel de

1756 Medina, Miguel

1756 Pagola, Francisco

1756 Muñoz, Bruno

1756 Herrera, Nicolás

1756 Santa Cruz, Luis de

1756 García, Antonio

1756 Jimeno, Ramón

1756 Cruz, José de la

1757 Giménez, Javier

1757 Gordillo, Andrés

1757

1757 López, José

1757 Rodríguez, Fernando José

1757

1757 Cruz, José de la

1757 Ledesma, Esteban

1757 Herrera, Nicolás

1758 García Tagle, Lorenzo

1758 Más, José

1758 Soler, Jaime

1758 Artigas, Martín José

1758 Duran, Manuel

1758 García, Agustín

1758 Morales, Francisco

1758 Chavez, Luis

1758 Giménez, Javier

1759 Muñoz, Bruno

1759 Herrera, Nicolás

1759 Medina, Miguel

1759 Pérez, Marcos

1759 Jimeno, Ramón

1759 Pagola, Francisco

1759 García, Antonio

1759 Gutiérrez, Francisco

1759 García, Lorenzo
Alcalde de primer voto

Alcalde de segundo voto

Alferez Real

Alguacil Mayor

Alcalde Provincial

Fiel Ejecutor

Depositario General

Alcalde de la Santa Hermandad

Procurador General

Alcalde de primer voto

Alcalde de segundo voto

Alferez Real

Alguacil Mayor

Alcalde Provincial

Fiel Ejecutor

Depositario General

Alcalde de la Santa Hermandad

Procurador General

Alcalde de primer voto

Alcalde de segundo voto

Alferez Real

Alguacil Mayor

Alcalde Provincial

Fiel Ejecutor

Depositario General

Alcalde de la Santa Hermandad

Procurador General

Alcalde de primer voto

Alcalde de segundo voto

Alferez Real

Alguacil Mayor

Alcalde Provincial

Fiel Ejecutor

Depositario General

Alcalde de la Santa Hermandad

Procurador General

Alcalde de primer voto

Alcalde de segundo voto

Alferez Real

Alguacil Mayor

Alcalde Provincial

Fiel Ejecutor

Depositario General

Alcalde de la Santa Hermandad

Procurador General 


\begin{tabular}{|c|c|}
\hline 1760 Gordillo, Andrés & Alcalde de primer voto \\
\hline 1760 Rodríguez, Fernando José & Alcalde de segundo voto \\
\hline 760 Cruz, José de la & Alferez Real \\
\hline 1760 Cullen, Lorenzo & Alguacil Mayor \\
\hline \multicolumn{2}{|c|}{1760 Llano y Braseras, Juan Ángel deAlcalde Provincial } \\
\hline 1760 López, José & Fiel Ejecutor \\
\hline 1760 Valdivieso, Antonio de & Depositario General \\
\hline 760 Jiménez, Luis & Alcalde de la Santa Hermandad \\
\hline 1760 Montes de Oca, Pedro & Procurador General \\
\hline 1761 Más, José & Alcalde de primer voto \\
\hline 1761 Soler, Jaime & Alcalde de segundo voto \\
\hline 1761 García, Agustín & Alferez Real \\
\hline 1761 Calleros, Lorenzo & Alguacil Mayor \\
\hline 1761 Duran, Manuel & Alcalde Provincial \\
\hline 1761 Giménez, Javier & Fiel Ejecutor \\
\hline 1761 Morales, Francisco & Depositario General \\
\hline 1761 Artigas, Martín José & Alcalde de la Santa Hermandad \\
\hline 1761 Rodríguez, Fernando José & Procurador General \\
\hline 1762 Muñoz, Bruno & Alcalde de primer voto \\
\hline 1762 Jimeno, Ramón & Alcalde de segundo voto \\
\hline 1762 Serrano, Pedro & Alferez Real \\
\hline 1762 Mitre, Bartolomé & Alguacil Mayor \\
\hline 1762 Barrenechea, Pedro & Alcalde Provincial \\
\hline 1762 García Tagle, Lorenzo & Fiel Ejecutor \\
\hline 1762 Montes de Oca, Pedro & Depositario General \\
\hline 1762 Gutiérrez, Francisco & Alcalde de la Santa Hermandad \\
\hline 1762 Alzaibar, Francisco & Procurador General \\
\hline 1763 Más, José & Alcalde de primer voto \\
\hline 1763 Gordillo, Andrés & Alcalde de segundo voto \\
\hline 1763 Baldivieso, Antonio & Alferez Real \\
\hline 1763 Guerrero, Domingo & Alguacil Mayor \\
\hline 1763 Jiménez, Luis & Alcalde Provincial \\
\hline 1763 Elizondo, José de & Fiel Ejecutor \\
\hline 1763 Peñaflor, Pedro de & Depositario General \\
\hline 1763 Duran, Manuel & Alcalde de la Santa Hermandad \\
\hline \multicolumn{2}{|c|}{1763 Soto y Romero, Pedro León de Procurador General } \\
\hline 1764 Rodríguez, Fernando José & Alcalde de primer voto \\
\hline 1764 García, Antonio & Alcalde de segundo voto \\
\hline 1764 Cuadra, Miguel Ignacio de la & Alferez Real \\
\hline 1764 Fernández, Dionisio & Alguacil Mayor \\
\hline 1764 López, José & Alcalde Provincial \\
\hline 1764 Giménez, Javier & Fiel Ejecutor \\
\hline 1764 Pla, José & Depositario General \\
\hline 1764 Chavez, Luis & Alcalde de la Santa Hern \\
\hline 1764 Alzaibar, Francisco & Procurador General \\
\hline
\end{tabular}


1765 Duran, Manuel

1765 Soler, Jaime

1765 Viana, Melchor de

1765 Barrenechea, Pedro

1765 Artigas, Martín José

1765 Pagola, Francisco

1765 Ledesma, Esteban

1765 Hernández, Antonio

1765 Álvarez, Cosme

1766 Achucarro, Juan de

1766 Vedia y la Cuadra, Joaquín de

1766 Pérez, Marcos

1766 Hernández, Nicolás

1766 Camejo, Antonio

1766 Guerrero, Domingo

1766 García, Agustín

1766 Jimeno, Ramón

1766 Álvarez, Cosme

1767 Delgado Melilla, Juan

1767 Cordobés, Pedro

1767 Duran, Juan Esteban

1767 Mitre, Bartolomé

1767 García, Antonio

1767 Jiménez, Luis

1767 Camejo, Antonio

1767 López, José

1767 Vedia y la Cuadra, Joaquín de

1768 Más, José

1768 Soler, Jaime

1768 Artigas, Martín José

1768 Rada, Pedro

1768 Duran, Manuel

1768 Jimeno, Ramón

1768 Baldivieso, Antonio

1768 Santos de Almeida, Antonio

1768 Montes de Oca, Pedro

1769 Más, José

1769 Soler, Jaime

1769 Bauzá, Salvador

1769 Rada, Pedro

1769 Duran, Manuel

1769 González, José

1769 Baldivieso, Antonio

1769 Herrera, Miguel

1769 García, Agustín
Alcalde de primer voto

Alcalde de segundo voto

Alferez Real

Alguacil Mayor

Alcalde Provincial

Fiel Ejecutor

Depositario General

Alcalde de la Santa Hermandad

Procurador General

Alcalde de primer voto

Alcalde de segundo voto

Alferez Real

Alguacil Mayor

Alcalde Provincial

Fiel Ejecutor

Depositario General

Alcalde de la Santa Hermandad

Procurador General

Alcalde de primer voto

Alcalde de segundo voto

Alferez Real

Alguacil Mayor

Alcalde Provincial

Fiel Ejecutor

Depositario General

Alcalde de la Santa Hermandad

Procurador General

Alcalde de primer voto

Alcalde de segundo voto

Alferez Real

Alguacil Mayor

Alcalde Provincial

Fiel Ejecutor

Depositario General

Alcalde de la Santa Hermandad

Procurador General

Alcalde de primer voto

Alcalde de segundo voto

Alferez Real

Alguacil Mayor

Alcalde Provincial

Fiel Ejecutor

Depositario General

Alcalde de la Santa Hermandad

Procurador General 


\begin{tabular}{|c|c|}
\hline 1770 Guerrero, Domingo & Alcalde de primer voto \\
\hline 1770 Jiménez, Luis & Alcalde de segundo voto \\
\hline 1770 Lores, Francisco de & Alferez Real \\
\hline 1770 González, José & Alguacil Mayor \\
\hline 770 Duran, Juan Esteban & Alcalde Provincial \\
\hline 1770 Pagola, Juan Bautista & Fiel Ejecutor \\
\hline 1770 García, Antonio & Depositario General \\
\hline 1770 Bauzá, Domingo & Alcalde de la Santa Hermandad \\
\hline 770 Cuadra, Miguel Ignacio de la & Procurador General \\
\hline 1771 & Alcalde de primer voto \\
\hline 1771 Rodríguez, Fernando José & Alcalde de segundo voto \\
\hline 1771 Jimeno, Ramón & Alferez Real \\
\hline 1771 Herrera, Miguel & Alguacil Mayor \\
\hline 1771 & Alcalde Provincial \\
\hline 1771 Larrañaga, Manuel & Fiel Ejecutor \\
\hline 1771 & Depositario General \\
\hline 1771 & Alcalde de la Santa Hermandad \\
\hline 1771 Barrenechea, Pedro & Procurador General \\
\hline 1772 Muñoz, Bruno & Alcalde de primer voto \\
\hline 1772 García, Agustín & Alcalde de segundo voto \\
\hline 1772 Duran, Vicente & Alferez Real \\
\hline 1772 Mendoza, José Ignacio & Alguacil Mayor \\
\hline 1772 Cáceres, Ramón de & Alguacil mayor perpetuo \\
\hline 1772 Bauzá, Salvador & Alcalde Provincial \\
\hline 1772 González, Andrés & Fiel Ejecutor \\
\hline 1772 Soler, Jaime & Depositario General \\
\hline 1772 Burgués, Roque & Alcalde de la Santa Hermandad \\
\hline 1772 Álvarez, Cosme & Procurador General \\
\hline 1773 Muñoz, Bruno & Alcalde de primer voto \\
\hline 1773 Cuadra, Miguel Ignacio de la & Alcalde de segundo voto \\
\hline 1773 Martínez, Francisco & Alferez Real \\
\hline 1773 Duran, Juan Esteban & Alcalde Provincial \\
\hline 1773 Camejo, Antonio & Fiel Ejecutor \\
\hline 1773 Lores, Francisco de & Depositario General \\
\hline 1773 Torre, Antonio de la & Alcalde de la Santa Hermandad \\
\hline 1773 Álvarez, Cosme & Procurador General \\
\hline 1774 Duran, Manuel & Alcalde de primer voto \\
\hline 1774 Fernández, Dionisio & Alcalde de segundo voto \\
\hline 1774 Robles, Francisco de & Alferez Real \\
\hline 1774 Artigas, Martín José & Alcalde Provincial \\
\hline 1774 Sánchez, Matías & Fiel Ejecutor \\
\hline 1774 Vidal, Mateo & Depositario General \\
\hline 1774 Herrera, Miguel & Alcalde de la Santa Hermandad \\
\hline 1774 Lores, Francisco de & Procurador General \\
\hline
\end{tabular}




1775 Jiménez, Luis
1775 García, Agustín
1775 Guerrero, Domingo
1775 Pérez, Felipe
1775 Bermúdez, José
1775 Baldivieso, Antonio
1775 Artigas, José Antonio
1775 Más, José
1776 Muñoz, Bruno
1776 González, José
1776 Echenique, Juan de
1776 Balbín Vallejo, Juan
1776 Cuadra, Miguel Ignacio de la
1776 Barrenechea, Pedro
1776
1776 Martínez, Fernando
1777 Duran, Manuel
1777 González, José
1777 Guzman, Juan de
1777 Cardoso, José
1777 Barrenechea, Pedro
1777 Balbín Vallejo, Juan
1777 Sierra, Francisco
1777 Cuadra, Miguel Ignacio de la
1778 Guzman, Juan de
1778 González, Andrés
1778 Yáñez, Andrés
1778 Bauzá, Domingo
1778 Zufriategui, Francisco
1778 Larrobla, Francisco
1778 Frías, Gregorio
1778 Vidal, Mateo
1779 Echenique, Juan de
1779 Sánchez, Matías
1779 Pérez, Felipe
1779 Hernández, Felipe
1779 García, Agustín
1779 Lores, Francisco de
1779 Barreiro, Manuel
1779 Baldivieso, Antonio
1779 Valle, Lorenzo del
1779 Haedo, Juan Antonio

Alcalde de primer voto

Alcalde de segundo voto

Alferez Real

Alcalde Provincial

Fiel Ejecutor

Depositario General

Alcalde de la Santa Hermandad

Procurador General

Alcalde de primer voto

Alcalde de segundo voto

Alferez Real

Alcalde Provincial

Fiel Ejecutor

Depositario General

Alcalde de la Santa Hermandad

Procurador General

Alcalde de primer voto

Alcalde de segundo voto

Alferez Real

Alcalde Provincial

Fiel Ejecutor

Depositario General

Alcalde de la Santa Hermandad

Procurador General

Alcalde de primer voto

Alcalde de segundo voto

Alferez Real

Alcalde Provincial

Fiel Ejecutor

Depositario General

Alcalde de la Santa Hermandad

Procurador General

Alcalde de primer voto

Alcalde de segundo voto

Alferez Real

Alcalde Provincial

Fiel Ejecutor

Fiel Ejecutor perpetuo

Depositario General

Depositario General perpetuo

Alcalde de la Santa Hermandad

Procurador General 
1780 Guerrero, Domingo

1780 Fernández, Dionisio

1780 Sierra, Francisco

1780 Duran, Juan Esteban

1780 Santos, Antonio

1780 Más, José

1781 Larrobla, Francisco

1781 Herrera, Miguel

1781 Artigas, Martín José

1781 Bermúdez, José

1781 Rivero, Sebastián

1781 Vidal, Mateo

1782 Sánchez, Matías

1782 Bauzá, Domingo

1782 Latorre, Bernardo

1782 Castilla, Juan de

1782 Pérez, Marcos

1783 Sánchez, Matías

1783 Duran, Juan Esteban

1783 Sierra, José de la

1783 Larrobla, Francisco

1783 Medina, Juan de

1783 Sánchez, Francisco

1784 Sánchez, Matías

1784 Muñoz, Francisco de los Ángeles

1784 Gutiérrez, Antonio

1784 Chopitea, Joaquín

1784 Hernández, Felipe

1784 Sánchez, Francisco
Alcalde de primer voto

Alcalde de segundo voto

Alcalde Provincial

Fiel Ejecutor

Alcalde de la Santa Hermandad

Procurador General

Alcalde de primer voto

Alcalde de segundo voto

Alcalde Provincial

Fiel Ejecutor

Alcalde de la Santa Hermandad

Procurador General

Alcalde de primer voto

Alcalde de segundo voto

Fiel Ejecutor

Alcalde de la Santa Hermandad

Procurador General

Alcalde de primer voto

Alcalde de segundo voto

Fiel Ejecutor

Depositario General

Alcalde de la Santa Hermandad

Procurador General

Alcalde de primer voto

Alcalde de segundo voto

Fiel Ejecutor

Depositario General

Alcalde de la Santa Hermandad

Procurador General 


\begin{tabular}{|l} 
1785 Muñoz, Francisco de los Ángeles \\
1785 Sánchez, Francisco \\
1785 Ocio, Vicente \\
1785 Cardoso, José \\
1785 Duran, Ventura \\
1785 Echenique, Juan de \\
1786 Herrera, Miguel \\
1786 Latorre, Bernardo \\
1786 Hernández, Felipe \\
1786 Méndez, Manuel \\
1786 Martínez, Juan Ignacio \\
1786 Gordillo, Manuel \\
1786 Llaure, Juan \\
1787 Latorre, Bernardo \\
1787 Sierra, Francisco \\
1787 Chopitea, Joaquín \\
1787 Gutiérrez, Luis Antonio \\
1787 Balbín Vallejo, Juan \\
1787 García, Felipe \\
1787 Muñoz, Francisco de los Ángeles \\
1788 Sierra, Francisco \\
1788 Echenique, Juan de \\
1788 Vidal, Mateo \\
1788 Ocio, Vicente \\
1788 Artigas, Martín José \\
1788 Vidal, Pedro \\
1788 Sánchez, Matías \\
1789 Rodríguez, Fernando José \\
1789 Ellauri, Juan de \\
1789 Pérez, Felipe \\
1789 Monterroso, Marcos \\
1789 Fernández, Dionisio \\
1789 Gordillo, Antonio María
\end{tabular}

Alcalde de primer voto

Alcalde de segundo voto

Fiel Ejecutor

Depositario General

Alcalde de la Santa Hermandad

Procurador General

Alcalde de primer voto

Alcalde de segundo voto

Alferez Real

Fiel Ejecutor

Depositario General

Alcalde de la Santa Hermandad

Procurador General

Alcalde de primer voto

Alcalde de segundo voto

Alferez Real

Fiel Ejecutor

Depositario General

Alcalde de la Santa Hermandad

Procurador General

Alcalde de primer voto

Alcalde de segundo voto

Alferez Real

Fiel Ejecutor

Depositario General

Alcalde de la Santa Hermandad

Procurador General

Alcalde de primer voto

Alcalde de segundo voto

Alferez Real

Fiel Ejecutor

Depositario General

Alcalde de la Santa Hermandad 
1790 Ellauri, Juan de

1790 Chopitea, Joaquín

1790 García de Zúñiga, Francisco

1790 Jerges, Juan de

1790 Silva, José de

1790 Romero, Juan

1790 Latorre, Bernardo

1791 Vidal, Mateo

1791 Gutiérrez, Luis Antonio

1791 Herrera, Miguel

1791 Otermín, Miguel

1791 Balbín Vallejo, Juan

1791 Milan, José

1791 Maciel, Francisco

1792 Duran, Manuel

1792 Monterroso, Marcos

1792 Latorre, Bernardo

1792 Artigas, Martín José

1792 Nieto, Manuel

1792 Brid, Juan José

1793 Cardoso, José

1793 Pérez, Felipe

1793 Silva, José de

1793 Medina, Juan de

1793 Fernández, Dionisio

1793 Ruíz, Francisco

1793 Martínez, Juan Ignacio

1793 Garrido, Francisco

1794 Pereira, Antonio

1794 Otermín, Miguel

1794 Vidal, Mateo

1794 San Vicente, Antonio

1794 Zubillaga, José de

1794 Sánchez, Matías
Alcalde de primer voto

Alcalde de segundo voto

Alferez Real

Fiel Ejecutor

Depositario General

Alcalde de la Santa Hermandad

Procurador General

Alcalde de primer voto

Alcalde de segundo voto

Alferez Real

Fiel Ejecutor

Depositario General

Alcalde de la Santa Hermandad

Procurador General

Alcalde de primer voto

Alcalde de segundo voto

Alferez Real

Alcalde Provincial

Fiel Ejecutor

Depositario General

Alcalde de primer voto

Alcalde de segundo voto

Alferez Real

Alcalde Provincial

Fiel Ejecutor

Depositario General

Alcalde de la Santa Hermandad

Procurador General

Alcalde de primer voto

Alcalde de segundo voto

Alferez Real

Fiel Ejecutor

Depositario General

Procurador General 
1795 Cuadra, Miguel Ignacio de la 1795 Sainz de la Maza, Félix 1795 Martínez Moldes, Juan Francisco 1795 Sierra, Francisco 1795 Bustillo, Juan Antonio 1795 Vázquez, Andrés 1795 Monterroso, Marcos 1795 Nieto, Manuel 1796 Duran, Juan Esteban 1796 Ruíz, Francisco 1796 Artigas, Martín José 1796 Pereira, Zacarías

1796 Rodríguez, Francisco

1796 Fonticeli, José 1796 Silva, José de 1797 Cardoso, José 1797 Sierra, Francisco 1797 Pérez, Manuel 1797 Fernández, Juan 1797 Gallego, Mateo 1797 Lago, Ramón de 1797 Latorre, Bernardo 1798 Gutiérrez, Luis Antonio 1798 Revuelta, José 1798 Salvañach, Cristóbal 1798 Doval, Rosendo 1798 Seco, Juan José 1798 Monterroso, Marcos 1798 Carrasco, Juan Antonio 1798 Ulibarri, Lorenzo de 1799 González, Andrés 1799 Pérez, Pedro Fabián 1799 García, Ildefonso 1799 León, Juan de 1799 Maldonado, Rafael
Alcalde de primer voto Alcalde de segundo voto

Alferez Real

Alcalde Provincial

Alcalde Provincial perpetuo

Fiel Ejecutor

Depositario General

Procurador General

Alcalde de primer voto

Alcalde de segundo voto

Alferez Real

Fiel Ejecutor

Depositario General

Alcalde de la Santa Hermandad

Procurador General

Alcalde de primer voto

Alcalde de segundo voto

Alferez Real

Fiel Ejecutor

Depositario General

Alcalde de la Santa Hermandad

Procurador General

Alcalde de primer voto

Alcalde de segundo voto

Alferez Real

Fiel Ejecutor

Depositario General

Depositario General perpetuo

Alcalde de la Santa Hermandad

Procurador General

Alcalde de primer voto

Alcalde de segundo voto

Fiel Ejecutor

Alcalde de la Santa Hermandad

Procurador General 


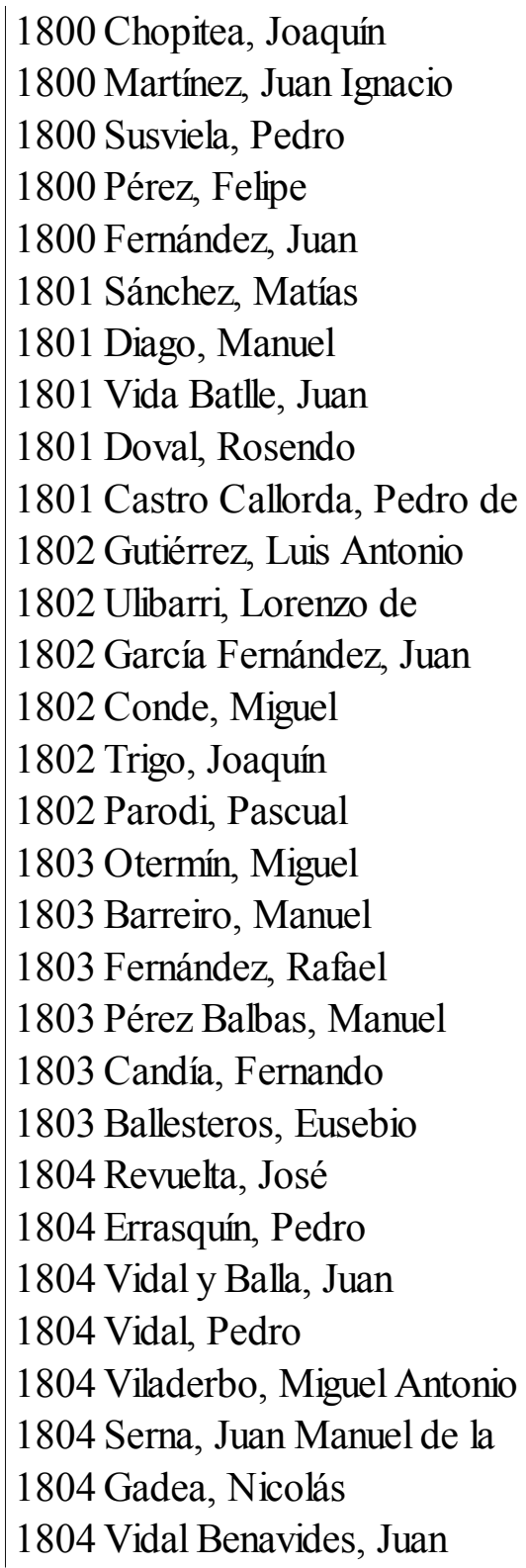

Alcalde de primer voto
Alcalde de segundo voto
Fiel Ejecutor
Alcalde de la Santa Hermandad
Procurador General
Alcalde de primer voto
Alcalde de segundo voto
Fiel Ejecutor
Alcalde de la Santa Hermandad
Procurador General
Alcalde de primer voto
Alcalde de segundo voto
Alferez Real
Fiel Ejecutor
Alcalde de la Santa Hermandad
Procurador General
Alcalde de primer voto
Alcalde de segundo voto
Alferez Real
Fiel Ejecutor
Alcalde de la Santa Hermandad
Procurador General
Alcalde de primer voto
Alcalde de segundo voto
Alferez Real
Fiel Ejecutor
Defensor de Pobres
Defensor de Menores
Alcalde de la Santa Hermandad
Procurador General




\begin{tabular}{|c|c|}
\hline 1805 Errasquín, Pedro & Alcalde de primer voto \\
\hline 1805 Vidal, Pedro & Alcalde de segundo voto \\
\hline 1805 Serna, Juan Manuel de la & Fiel Ejecutor \\
\hline 1805 Revuelta, José & Defensor de Pobres \\
\hline 1805 Vidal Benavides, Juan & Defensor de Menores \\
\hline 1805 Rodríguez, Pedro & Alcalde de la Santa Hermandad \\
\hline 1805 Viladerbo, Miguel Antonio & Procurador General \\
\hline 1806 Aguiar, Juan Bautista & Alcalde de primer voto \\
\hline 1806 Pérez Balbas, Manuel & Alcalde de segundo voto \\
\hline 1806 Camuso, Carlos & Alferez Real \\
\hline 1806 Gestal, José & Fiel Ejecutor \\
\hline 1806 Peña, Damián de la & Defensor de Pobres \\
\hline 1806 Rosa, Luis de la & Defensor de Menores \\
\hline 1806 Amutrio, Juan Patricio & Alcalde de la Santa Hermandad \\
\hline 1806 Solsona, Manuel & Procurador General \\
\hline 1807 Pereira, Antonio & Alcalde de primer voto \\
\hline 1807 Ulibarri, Lorenzo de & Alcalde de segundo voto \\
\hline 1807 Fernández, Rafael & Alferez Real \\
\hline 1807 Conde, Miguel & Fiel Ejecutor \\
\hline 1807 Carreras, Juan Domingo de las & Defensor de Pobres \\
\hline 1807 Juanicó, Francisco & Defensor de Menores \\
\hline 1807 Toscano, Francisco & Alcalde de la Santa Hermandad \\
\hline 1807 Agell, Antonio & Procurador General \\
\hline 1808 Parodi, Pascual & Alcalde de primer voto \\
\hline 1808 Berro, Pedro & Alcalde de segundo voto \\
\hline 1808 Ortega, Manuel & Alferez Real \\
\hline 1808 Gutiérrez, Manuel & Fiel Ejecutor \\
\hline 1808 Seco, Juan José & Defensor de Pobres \\
\hline 1808 Carreras, Juan Domingo de las & Defensor de Menores \\
\hline 1808 Artigas, Manuel & Alcalde de la Santa Hermandad \\
\hline 1808 García de Zúñiga, Tomás & Procurador General \\
\hline
\end{tabular}




\section{Anexo 5. Cabildantes de Maldonado 1784-1812}

$1784-1786$

Alcalde: José Ferradell

Regidores: Antonio Correa, Antonio José Méndez, Domingo Hermida

y Martín Pascual

Mayordomo: Benito Fajardo

Alguacil Mayor: Miguel Antonio Aldaya

Escribano: Tomás Navarro

1787

Alcalde Ordinario: Antonio Mondragón

Regidor Alférez Real: Miguel Antonio Zalayeta

Regidor Fiel Ejecutor: Luis Estremera

Regidor defensor de pobres y menores: Manuel Dutra

Regidor Procurador Síndico: Juan Pascual Pla

Mayordomo: Francisco Pla

Escribano: Luis Antonio de Miranda

Alguacil: Manuel de los Reyes

1788

Alcalde Ordinario: José Llorens (teniente de milicias)

Regidor Alférez Real: Manuel Fajardo

Regidor Fiel Ejecutor: Juan Lerman

Regidor defensor de pobres y menores: Francisco Cabral (capitán de milicias)

Regidor Procurador Síndico: Diego González

Mayordomo: Salvador Ciriaco Gómez

Escribano: Alejos Monegal

Alguacil: José Meriva 
Alcalde Ordinario: Francisco Montes

Regidor Alférez Real: Benito Fajardo

Regidor Fiel Ejecutor: Juan Mendoza

Regidor Defensor de Pobres y Menores: Juan Lerman

Regidor Síndico Procurador: José Silvera

Escribano: Luis Ignacio Miranda

Alguacil Mayor: Alejos Monegal

1792

Alcalde Ordinario: Francisco Aparicio

Regidor Alférez Real: José Mancebo

Regidor Fiel Ejecutor: Andrés Recalde

Regidor Defensor de Pobres y Menores: Manuel Texera

Regidor Síndico Procurador: Juan Paulino Pimienta

Alguacil Mayor: Alejos Monegal

1793

Alcalde Ordinario: José de Sosa

Regidor Alférez Real: Francisco Cabral

Regidor Fiel Ejecutor: Antonio Cortes

Regidor Defensor de Pobres y Menores: Manuel Rodríguez

Regidor Síndico Procurador: Antonio Salgueiro

Alguacil Mayor: Rosendo Verde

Mayordomo: José Fernández

Fiel de Fechos: Luis Antonio Miranda 
1794

Alcalde Ordinario: Antonio Mondragón

Regidor Alférez Real: Antonio Machado

Regidor Fiel Ejecutor: Ignacio Huertas

Regidor Defensor de Pobres y Menores: Manuel de Silva

Regidor Síndico Procurador: Pedro Labadia

Alguacil Mayor: Juan Pascual Pla

Mayordomo: Antonio Tort

Siguen los Cabildantes de 1793. Los electos en 1794 no tomaron posesión 1795

Alcalde Ordinario: Andrés Benito Fajardo

Regidor Alférez Real: Benito de Casas, después nombran a Antonio Tort

Regidor Fiel Ejecutor: Cayetano Ignacio Huertas

Regidor Defensor de Pobres y Menores: Antonio Tort, después Benito de Casas

Regidor Síndico Procurador: Diego González, después Pedro Rodríguez

Alguacil Mayor: Martín José Ubarcalde, después nombran a Diego González

Mayordomo: Vicente Carpi

Fiel de Fechos: Juan Pascual Pla

1796

Alcalde Ordinario: José Mancebo

Regidor Alférez Real: Lucas Castellano

Regidor Fiel Ejecutor: Andrés Recalde

Regidor Defensor de Pobres y Menores: José Francisco Duarte

Regidor Síndico Procurador: Luis Estremera

Alguacil Mayor: Juan Machado

Mayordomo: Vicente Carpi 
15/11 elecciones para 1797

Alcalde Ordinario: José Mancebo

Regidor Alférez Real: Vicente Plada

Regidor Fiel Ejecutor: Roque Gándara

Regidor Defensor de Pobres y Menores: Lucas Castellanos

Regidor Síndico Procurador: Domingo Miguel

Alguacil Mayor: Juan Pascual Pla

Mayordomo: Diego de Novoa

1/1/1797 elecciones

Alcalde Ordinario: Antonio Tort

Regidor Alférez Real: Juan Paulino Pimienta

Regidor Fiel Ejecutor: Antonio Freire

Regidor Defensor de Pobres y Menores: Vicente Plada

Regidor Síndico Procurador: Lázaro Vicente

Alguacil Mayor: Juan Bautista Gimeno

Mayordomo: Vicente Carpi

Fiel de Fechos: Ramón Romero

29/1/1798 Andrés Recalde presentó ante el virrey Antonio Olaguier de Feliu que se le exceptue del cargo de Alcalde Ordinario para el que fue electo, nueva elección de alcalde

Alcalde Ordinario: Antonio Salgueiro

Regidor Alférez Real: Alberto Camino

Regidor Fiel Ejecutor: Francisco Caballero

Regidor Defensor de Pobres y Menores: Cayetano Ignacio Huertas

Regidor Síndico Procurador: Pedro Cubelos

Alguacil Mayor: Alejos Monegal 
1799

Alcalde: Andrés Benito Fajardo

Regidor Alférez: Juan Machado

Regidor Fiel Ejecutor: Antonio Rebillo

Regidos defensor de Pobres y menores: Fabián Zerron

Regidor Síndico Procurador: José Ferradell

Alguacil Mayor: Juan Pascual Pla

Mayordomo: Vicente Carpi

1800

Alcalde Ordinario: Miguel O’Ryan

Regidor Alférez Real: José Francisco Duarte

Regidor Fiel Ejecutor: Benito de Casas

Regidor Defensor de Pobres y Menores: Andrés Recalde

Regidor Síndico Procurador: Vicente Cortes

Alguacil Mayor: Juan Bautista Gimeno

Mayordomo: Juan Lacort

1801

Alcalde Ordinario: Francisco Montes

Regidor Alférez Real: José Mancebo

Regidor Fiel Ejecutor: José Braña

Regidor Defensor de Pobres y Menores: Pedro Cubelos

Regidor Síndico Procurador: Lázaro Vicente

Alguacil Mayor: Diego Novoa

Mayordomo: Juan Lacort 
1805

Alcalde Ordinario: Ventura Gutiérrez

Regidor Alférez Real y Fiel Ejecutor: Juan Mendoza

Regidor Defensor de Pobres y Menores y Sindico Procurador: Manuel Pereira (no sabe escribir)

Alguacil Mayor: Juan Pascual Pla

Mayordomo: Luis Estremera

1806

Alcalde Ordinario: Ventura Gutiérrez

Regidor Alférez Real y Fiel Ejecutor: Vicente Plada

Regidor Defensor de Pobres y Menores y Síndico Procurador: Juan Machado

Alguacil Mayor: Juan Pascual Pla

Mayordomo: Luis Estremera

1808

Alcalde Ordinario: Manuel Lázaro Cortes

Regidor Alférez Real y Fiel Ejecutor: Juan Manuel Fernández

Regidor Defensor de Pobres y Menores y Síndico Procurador: Francisco Cahue Alguacil Mayor: Alejos Monegal

Mayordomo: Luis Estremera

1809

Alcalde Ordinario: Juan Mendoza

Regidor Alférez Real y Fiel Ejecutor: Pedro Cubelos

Regidor Defensor de Pobres y Menores y Síndico Procurador: Mariano Oribe Alguacil Mayor: Antonio Jesús de la Fuente

Mayordomo: Luis Estremera 
1810

Alcalde Ordinario: Antonio Jesús de la Fuente

Regidor Alférez Real y Fiel Ejecutor: José Inchausti

Regidor Defensor de Pobres y Menores y Síndico Procurador: Vicente Martínez

Alguacil Mayor: Alejos Monegal

Mayordomo: Luis Estremera

1811

Alcalde Ordinario: Mariano Oribe

Regidor Alférez Real y Fiel Ejecutor: Juan Manuel Fernández

Regidor Defensor de Pobres y Menores y Síndico Procurador: Juan Pascual Pla

Alguacil Mayor: Francisco Aguin

Mayordomo: Luis Estremera

30/12 nueva elección

Regidor Alférez Real y Fiel Ejecutor: José Brañas

Regidor Defensor de Pobres y Menores y Síndico Procurador: Lázaro Vicente

1812

Alcalde Ordinario: Juan Antonio del Casal y Freire

Regidor Alférez Real y Fiel Ejecutor: José Núñez

Regidor Defensor de Pobres y Menores y Síndico Procurador: Juan Pascual Pla Alguacil Mayor: Antonio Sánchez

Mayordomo de Propios: Ventura Gutiérrez 


\section{Fuentes}

Fuentes editadas

Acuerdos del Cabildo de Montevideo

Revista del Archivo General Administrativo. Volumen Primero. Montevideo, 1885.

Revista del Archivo General Administrativo. Volumen Segundo. Montevideo, 1886.

Revista del Archivo General Administrativo. Volumen Tercero. Montevideo, 1887.

Revista del Archivo General Administrativo. Volumen Cuarto. Montevideo, 1890.

Revista del Archivo General Administrativo. Volumen Quinto. Montevideo, 1916.

Revista del Archivo General Administrativo. Volumen Sexto. Montevideo, 1917.

Revista del Archivo General Administrativo. Volumen Octavo. Anexo al volumen cuarto. Montevideo, 1918.

Revista del Archivo General Administrativo. Volumen Octavo. Montevideo, 1920.

Acuerdos del extinguido cabildo de Montevideo. Anexo. Volumen diez y seis. Montevideo, Archivo General de la Nación, 1942.

Acuerdos del extinguido cabildo de Montevideo. Anexo. Volumen diez y siete. Montevideo, Archivo General de la Nación, 1942.

Acuerdos del extinguido cabildo de Montevideo. Anexo. Volumen diez y ocho. Montevideo, Archivo General de la Nación, 1943.

Fuentes sobre tierras

Pivel Devoto, J. E. (dir.) (1964). Colección de documentos para la historia económica y financiera de la República Oriental del Uruguay. Montevideo, Ministerio de Hacienda. 
Fuentes inéditas

Archivo General de la Nación. Argentina.

Sala IX. Gobierno colonial.

Montevideo: 2-4-3, 2-4-4, 2-4-5, 2-4-6, 2-5-1, 2-5-2, 2-5-3, 2-5-4, 2-5-5, 2-5-6, 2-6-1, 2-6-2, 2-6-3, 2-6-4, 2-6-5, 2-6-6 у 2-6-7.

Montevideo. Iglesia Matriz. Cuentas: 3-2-5.

Sala XII. Tribunal de Cuentas.

Montevideo: 15-10-1 y 15-10-2

Maldonado: Legajos de 3288 a 3312.

Archivo General de la Nación. Uruguay.

Ex Archivo General Administrativo.

Maldonado: 269, 270 y 289.

Archivo Judicial.

Montevideo. Civil 1.

1773 Caja 28 Expediente 38

1776 Caja 37 Expediente 37

1777 Caja 39 Expediente 16

1779 Caja 45 Expediente 87

1780 Caja 48 Expediente 89

1785 Caja 69 Expediente 54

1790 Caja 95 Expediente 35

1791 Caja 97 Expediente 6

Maldonado. Civil 1.

1787 Caja 1 Expediente 25 y 26 


\section{Bibliografía}

Acevedo, R. E. (2014). "Nación e historia. La justificación e interpretación histórica de las naciones a finales del siglo XIX y en la primera mitad del siglo XX". Revista Coherencia, Vol. 11 , No. 21.

Alioto, S. L. (2011). Indios y ganado en la frontera. La ruta del río Negro (1750-1830). Rosario, Prohistoria, Centro de Documentación Patagónica, Departamento de Humanidades, Universidad Nacional del Sur.

Amaral, S. (1987). "Rural production and labour in late colonial Buenos Aires". Journal of Latin American Studies, Cambridge University Press, Vol. 19, No. 2, Nov.

y Ghío, J. M. (1990). “Diezmos y producción agraria. Buenos Aires, 17501800". Revista de Historia Económica, Instituto Figuerola de Historia y Ciencias Sociales, Universidad de Carlos III, VIII, 3, Madrid.

Anderson, B. (1993). Comunidades imaginadas. México, FCE.

Andreucci, B. (2011). Labradores de la frontera. La Guardia de Luján y Chivilcoy 1780-1860. Rosario, Prohistoria.

Apolant, J. A. (1966a). Padrones Olvidados de Montevideo del siglo XVIII. Montevideo, Imprenta Letras.

- (1966b). Génesis de la familia uruguaya. Los habitantes de Montevideo en sus primeros 40 años. Filiaciones. Ascendencias. Entronques. Descendencias. Montevideo, Instituto Histórico y geográfico del Uruguay.

Assadourian, C. S. (1982). El sistema de la economía colonial. Mercado interno, regiones y espacio económico. Lima, Instituto de Estudios Peruano.

Assunçao, F. O. (1963). El gaucho. Montevideo, Apartado del Tomo XXIV de la Revista del Instituto Histórico y Geográfico del Uruguay.

Azarola Gil, L. E. (1926). Contribución a la historia de Montevideo. Veinte linajes del siglo XVIII. París, Franco-ibero-americana.

Azcuy Ameghino, E. (1995). El latifundio y la gran propiedad colonial rioplatense. Buenos Aires, F. García Cambeiro. (2002). La otra historia. Economía, estado y sociedad en el Río de la Plata colonial. Buenos Aires, Imago Mundi. 
Banzato, G. (2002). Ocupación y acceso a la propiedad legal de la tierra en el nordeste del río Salado: Chascomús, Ranchos y Monte, 1780-1880. Tesis de doctorado, Facultad de Humanidades y Ciencias de la Educación, Universidad Nacional de La Plata, 2002. Barba, E. M. (1955). “Contribución documental sobre la historia de la ganadería en el Río de la Plata al finalizar el siglo XVIII". Revista Histórica, Montevideo.

Barba, F. E. (1997). Frontera ganadera y guerra con el indio. La frontera y la ocupación ganadera en Buenos Aires entre los siglos XVIII y XIX, La Plata, UNLP.

Barcos, F. (2010). De cada labrador un soldado y de cada agricultor un propietario: Economía, sociedad y política en el ejido de la guardia de Luján (Mercedes), 18101870. Tesis de doctorado, Facultad de Humanidades y Ciencias de la Educación, Universidad Nacional de La Plata.

Barrán, J. P. (1998). La espiritualización de la riqueza. Catolicismo y economía en Uruguay (1730-1900). Montevideo, Ediciones de la Banda Oriental.

y Nahum, B. (1964). Bases económicas de la revolución artiguista. Montevideo, Ediciones de la Banda Oriental.

Barriera, D. (2010). "Derechos, justicia y territorio: asignación de derechos sobre ganado cimarrón en la justicia ordinaria Santafesina (Gobernación del Río de la Plata, siglo XVII). En: Conte, E. y Madero, M. (eds.). Entre hecho y derecho: tener, poseer, usar, en perspectiva histórica. Buenos Aires, Manantial.

Bentancur, A. A. (1997) El puerto colonial de Montevideo. Tomo I. Guerras y apertura comercial: tres lustros de crecimiento económico 1791-1806, Montevideo, Facultad de Humanidades y Ciencias de la Educación, Universidad de la República.

(1999). El puerto colonial de Montevideo. Tomo II. Los años de la crisis (1807-1814). Montevideo, Facultad de Humanidades y Ciencias de la Educación, Universidad Nacional de la República.

Biangardi, N. (2013a) "Una nueva área para la región. Poblamiento y crecimiento económico en Maldonado (1755-1814)". Revista Uruguaya de Historia Económica, Vol. III, $\mathrm{N}^{\mathrm{o}} 4$.

(2013b). Poblamiento, crecimiento y poderes locales en un área de la región Río de la Plata. Maldonado 1755-1814. Tesis de maestría, Universidad Nacional de Tres de Febrero. 
Bibenca, D. y Miñaro, F. (2004). Identificación de Áreas Valiosas de Pastizal (AVPS) en las Pampas y los Campos de Argentina, Uruguay y sur de Brasil. Buenos Aires, Fundación Vida Silvestre Argentina.

Birocco, C. M. (2003). Cañada de la Cruz. Tierra, producción y vida cotidiana en un partido bonaerense durante la colonia. Municipalidad de Exaltación de la Cruz.

Brown, J. (2002). Historia socioeconómica de la Argentina, 1776-1860. Buenos Aires, Instituto Di Tella y Siglo XXI.

Buchbinder, P. (1994). "La historiografía rioplatense y el problema de los orígenes de la nación”. En: Cuadernos del CLAEH, nº 69. Montevideo, $2^{\mathrm{a}}$ serie, año 19.

Büschges, C, "Introducción”. Schröter, B. y Büschges, C. (eds.). Beneméritos, aristócratas y empresarios. Identidades y estructuras sociales de las capas altas urbanas en América hispánica. Madrid, Iberoamericana.

Calcagno, J. y Lovich, G. (2013). El mar. Hizo falta tanta agua para disolver tanta sal. Buenos Aires, Siglo XXI.

Camarda, M. (2014). El comercio ultramarino de cueros del complejo portuario rioplatense, 1779-1799. Tesis de maestría, Universidad Nacional de Mar del Plata.

Campal, E. F. (1962). Hombres, tierras y ganado. Montevideo.

Canedo, M. (2001). Propietarios, ocupantes y labradores. San Nicolás de los Arroyos 1600-1860. Mar del Plata, Universidad Nacional de Mar del Plata.

Cardim, P., Herzog, T., Ruiz Ibáñez, J. J., y Sabatini, G. (ed.) (2012). Polycentric monarchies. How early modern Spain and Portugal achieve and maintain a global hegemony?. Brighton, Sussex Academic Press.

Cardoso, C. F. S. y Pérez Brignoli, H. (1984). Historia económica de América Latina. Tomo I. Sistemas agrarios e historia colonial. Barcelona, Crítica.

Carrera, J. (2011). Algo más que mercachifles: Pulperos y pulperías en la campaña bonaerense 1770-1820. Rosario, Prohistoria.

Chiaramonte, J. C. (1997). "La formación de los Estados nacionales en Iberoamérica". Boletín del Instituto de Historia Argentina y Americana "Dr. Emilio Ravignani", tercera serie, $\mathrm{n}^{\circ} 15$.

Ciliberto, V. (2004). Aspectos sociodemográficos del crecimiento periurbano: San José de Flores (1815-1869). Mar del Plata, Universidad Nacional de Mar del Plata. 
Clara, M. y Manegro, R. (1999). "Humedales del Uruguay. El ejemplo de los humedales del este". En: Malvárez, A. I. Tópicos sobre humedales subtropicales y templados de Sudamérica. Montevideo, MAB-ORCYT.

Coni, E. A. (1945). El gaucho. Argentina, Brasil, Uruguay. Buenos Aires, Sudamericana.

(1979). Historia de las vaquerías de Río de la Plata 1555-1755, Buenos Aires, Platero.

Contente, C. (1999). “Actividades agrícolas y el ciclo de vida: el caso de la Matanza a principios del siglo XIX” en Fradkin, Raúl; Canedo, Mariana y Mateo, José (comps.). Tierra, población y relaciones sociales en la campaña bonaerense (siglos XVIII y XIX), Mar del Plata, Universidad Nacional de Mar del Plata.

Cuesta, M. (2006). El crecimiento de una economía colonial: el caso de Buenos Aires en el siglo XVIII. Tesis de doctorado inédita, Facultad de Filosofía y Letras, Universidad Nacional de Buenos Aires.

— (2006). "Evolución de la población y estructura ocupacional de Buenos Aires, 1700-1810”. Papeles de población, vol. 12, núm. 49.

(2007). "Precios y mercados en Buenos Aires en el siglo XVIII". América Latina en la Historia Económica, n ${ }^{\circ} 28$.

Di Stefano, R. (1991). “Un rincón de la campaña bonaerense colonial: San Pedro durante la segunda mitad del siglo XVIII". Cuadernos del Instituto Ravignani, Instituto de Historia Argentina y Americana "Dr. Emilio Ravignani”, Universidad de Buenos Aires, 1, Buenos Aires.

Díaz de Guerra, M. A. (1988). Historia de Maldonado. Maldonado, Intendencia de Maldonado, 2 vols.

Djenderedjian, J. (2003). Economía y sociedad en la Arcadia criolla. Formación y desarrollo de una sociedad de frontera en Entre Ríos, 1750-1820, Tesis de doctorado inédita, Facultad de Filosofía y Letras, Universidad Nacional de Buenos Aires.

(2004). “¿Un aire de familia? Producción ganadera y sociedad en perspectiva comparada: las fronteras rioplatenses a inicios del siglo XIX”. Jahrbuch für Geschichte Lateinamerikas, $\mathrm{n}^{\circ} 41$. 
(2008). "Roots of revolution: frontiers settlement policy and the emergence of new spaces of power in the Río de la Plata borderlands, 1777-1810”. Hispanic American Historical Review, 88:4, november.

Dupuy, A. (2004). El fin de una sociedad de frontera en la primera mitad del siglo XIX: "Hacendados" y "Estancieros" en Pergamino. Mar del Plata, Universidad Nacional de Mar del Plata.

(2007). "El estanco de la carne y su crisis en Buenos Aires colonial desde una visión comparativa”. São Paulo, Revista Brasileira de História, v. 30, nº 60.

Favier Dubois, C. M. y Zárate, M. A. (2012). "Breve historia geológica y climática". En: Otero, H. (dir.). Historia de la provincia de Buenos Aires. Tomo 1. Población, ambiente y territorio, Buenos Aires, Edhasa.

Ferreira da Lima, J. “A concepção do espaço econômico polarizado". Interações. Revista Internacional de Desenvolvimento Local, 4, 7.

Flegenheimer, N., Bayón, C. y Pupio, A. (2007). Llegar a un nuevo mundo. La arqueología de los primeros pobladores del actual territorio argentino. Buenos Aires, Antropofagia.

Fradkin, R. (1986). "El Gremio de Hacendados en Buenos Aires durante la segunda mitad del siglo XVIII". Cuadernos de Historia Regional, $\mathrm{n}^{\circ} 8$.

(1993a). “¿Estancieros, hacendados o terratenientes? La formación de la clase terrateniente porteña y el uso de categorías históricas y analíticas (Buenos Aires 17501850)”. En: Bonaudo, M. y Pucciarelli, A. R. (comp.). La problemática agraria. Buenos Aires, Centro Editor de América Latina.

(comp.). (1993b). La historia agraria del Río de la Plata colonial. Los establecimientos productivos. Buenos Aires, CEAL.

(1995a). ““'Según la costumbre del pays”: costumbre y arriendo en Buenos Aires durante el siglo XVIII". Bolentín del Instituto de Historia Argentina y Americana “Dr. Emilio Ravignani”. Tercera Serie, núm. 11, primer semestre.

(1995b). ““"Labradores del instante” “Arrendatarios eventuales”: El arriendo rural en Buenos Aires a fines de la época colonial.”. En: Bjerg, M. M. y Reguera, A. (comp.). Problemas de la historia agraria. Nuevos debates y perspectivas de investigación. Tándil, IEHS. 
y Ratto, S. (2008). “Territorios en disputa. Liderazgos locales en la frontera entre Buenos Aires y Santa Fe (1815-1820)”. En: Fradkin, R. y Gelman, J. (comp.). Desafios al orden. Política y sociedades rurales durante la Revolución de Independencia. Rosario, Prohistoria.

y Garavaglia, J. C. (2009). La Argentina colonial. El Río de la Plata entre los siglos XVI y XIX. Buenos Aires, Siglo XXI.

Frega, A. (2003). "Pertenencias e identidades en una zona de frontera. La región de Maldonado entre la revolución y la invasión lusitana”. En: Henzy, F. M. y Herrlein Jr., R. Histórias Regionais do Cone Sul. Santa Cruz do Sul, EDUNISC.

(2007). Pueblos y soberanía en la revolución artiguista. La región de Santo Domingo Soriano desde fines de la colonia a la ocupación portuguesa. Montevideo, Ediciones de la Banda Oriental.

(2008). "Después de la derrota. Aportes sobre la composición de los liderazgos rurales en la campaña oriental a comienzos de la década de 1820". En: Fradkin, R. y Gelman J. (comp.). Desafios al orden. Política y sociedades rurales durante la Revolución de Independencia. Rosario, Prohistoria.

Galarza, A. (2012) Prácticas comerciales y fiscalidad sobre la circulación de mercancías en la campaña porteña: Un estudio de caso: Chascomús entre 1780 y 1850. Tesis de doctorado. Facultad de Humanidades, Universidad Nacional de Mar del Plata, 2012.

Garavaglia, J. C. (1987). "El Río de la Plata en sus relaciones atlánticas: una balanza comercial (1779-1784). En: Garavaglia, J. C. Economía, sociedad y regiones. Buenos Aires, Ediciones de la Flor.

y Gelman, J. (1995). "Rural history of the Río de la Plata, 1600-1850: Results of a Historiographical Renaissance". Latin America Research Review, 30: 3.

(1999a). Pastores y labradores de Buenos Aires. Una historia agraria de la campaña bonaerense 1700-1830, Buenos Aires, Ediciones de la Flor.

- (1999b): "Un siglo de estancias en la campaña de Buenos Aires: 1751 a 1853”. The Hispanic American Historical Review, Vol. 79, No. 4, Nov.

(2009). San Antonio de Areco, 1680-1880. Un pueblo de la campaña, del Antiguo Régimen a la modernidad argentina. Rosario, Prohistoria. 
(2011). “CCómo se mide la tierra? Las mensuras en el Río de la Plata”. En: Garavaglia, J. C. y Gautrau, P. Mensurar la tierra, controlar el territorio. América Latina, siglo XVIII-XIX. Rosario, Prohistoria.

García Belsunce, C. A. (1988). "Diezmos y producción agrícola en Buenos Aires virreinal". Investigaciones y Ensayos, $\mathrm{n}^{\mathrm{0}} 38$.

Gatreau, P. Relatos de crisis ambiental en el Río de la Plata. Una evaluación geográfica de 300 años de "destrucción” de los bosques uruguayos (siglos XVIII a XX). Tesis de doctorado, Universidad de Lille 1.

Gelman, J. (1989). "New perspectives on an old problem and the same source: the gaucho and the rural history of the colonial Río de la Plata". Hispanic American Historical Review, Duke University Press, Vol. 69, No. 4, Nov. (1993a). "En torno a la Teoría de la Dependencia, los polos de crecimiento y la crisis del siglo XVII. Algunos debates sobre Historia Colonial Americana". En: Montanari, M. et al. Problemas actuales de la Historia. Universidad de Salamanca.

— (1993b). "Los caminos del mercado: campesinos, estancieros y pulperos en una región del Río de la Plata colonial" Latin American Research Review, The Latin American Studies Association, Vol. 28, No. 2.

(1996). De mercachifle a gran comerciante. Los caminos del ascenso en el Río de la Plata colonial. Sevilla, Universidad Internacional de Andalucía, Sede Iberoamericana de la Rábida.

- (1998). Campesinos y estancieros. Una región del Río de la Plata a fines de la época colonial, Buenos Aires, Los libros del riel.

(2012). “La economía de Buenos Aires”. En: Fradkin, R. (dir.). Historia de la provincia de Buenos Aires. Tomo 2. De la conquista a la crisis de 1820. Buenos Aires, Edhasa.

Giberti, H. C. E. (1986). Historia económica de la ganadería argentina, Buenos Aires, Hyspamérica. ( $1^{\mathrm{a}}$ edición 1970$)$

Gil, T. L. (2002). Inféis Transgressores: os contrabandistas da fronteira (1760-1810). Tesis de maestría, Universidade Federal do Río de Janeiro.

Gresores, G. (1996). “Terratenientes y arrendatarios en La Magdalena: un estudio de caso". En: Azcuy Ameghino, E. et al. Poder terrateniente, relaciones de producción y orden colonial. Buenos Aires, Fernando García Cambeiro. 
Johnson, L. y Tandeter, E. (comps.) (1992). Economías coloniales. Precios y salarios en América Latina, siglo XVIII. Buenos Aires, FCE.

Jumar, F. (2000). Le comerce atlantique au Río de la Plata 1680-1778. Tesis de doctorado, École des Hautes Études en Sciences Sociales.

— , Biangardi, N., Bozzo, J., Orlowski, S., Sandrín, M. E. y Querzoli, R. (2006). "El comercio ultramarino y la economía local en el complejo portuario rioplatense. Siglo XVIII". Anuario IEHS, nº 21.

y Paredes, I. (2008a) "El comercio intrarregional en el complejo portuario rioplatense: el contrabando visto a través de los comisos, 1693-1777". América Latina en la Historia Económica, no 29.

(2008b). "El primer boom de la exportación de cueros y la sociedad local. Río de la Plata. Fines del siglo XVII, comienzos del siglo XVIII". Caseros, XXI Jornadas de Historia Económica.

(2011) "Lo que la revolución se llevó: la región del Río de la Plata com espacio económico". Boletín del Instituto de Historia Argentina y Americana Dr. Emilio Ravignani, $\mathrm{n}^{\mathrm{o}} 33$.

(2012). “La región Río de la Plata y su complejo portuario durante el Antiguo Régimen”. En: Fradkin, R. (dir.). Historia de la provincia de Buenos Aires. Tomo 2. De la conquista a la crisis de 1820. Buenos Aires, Edhasa.

y Biangardi, N. (2013). "La conjunción entre espacio económico y territorialidad. Río de la Plata. Siglo XVIII". III Jornadas Interdisciplinarias de Investigaciones Regionales. Enfoques para la historia. Siglos XVIII-XX, Mendoza, CCT Mendoza.

Kraselsky, J. (2010). Las estrategias de los actores del Río de la Plata: las Juntas y el Consulado de comercio de Buenos Aires a fines del Antiguo Régimen (1748-1809). Tesis de doctorado, Facultad de Humanidades y Ciencias de la Educación, Universidad Nacional de La Plata.

Levene, R. (1927). Investigaciones acerca de la historia económica del virreinato del Río de la Plata. La Plata, Universidad Nacional de la Plata.

Levene, R. (1940). “La ganadería en la época colonial”. En: Levene, R. (dir.). Historia de la Provincia de Buenos Aires y formación de sus pueblos. Vol. 1. La Plata, Archivo Histórico de la Provincia de Buenos Aires. 
López Laborde, J. (1998). "Marco geomorfológico y geológico del Río de la Plata”. En: Wells, P. G. y Daborn, G. R. (eds.). El Río de la Plata. Una revisión ambiental. Un informe de antecedentes del Proyecto EcoPlata. Halifax, Dalhourie University.

Maenza, R. A. y Compagnucci, R. H. (2010). "Simulación de la Pequeña Edad de Hielo usando el modelo EdGCM". GEOACTA, 35.

Malvárez, A. I. (1999). “El Delta del Río Paraná como mosaico de humedales”. En: Malvárez, A. I. (ed.). Tópicos sobre humedales subtropicales y templados de Sudamérica. Montevideo, MAB-ORCYT.

Mandrini, R. (1997). "Las fronteras y la sociedad indígena en el ámbito pampeano". Anuario IEHS $N^{\circ} 12$.

Marquiegui, D. N. (1990). Estancia y poder en un partido de la campaña bonaerense (Luján, 1756-1821). Buenos Aires, Biblos.

Mascioli, A. R. (2004). Productores y propietarios al sur del río Salado (1798-1860). Mar del Plata, Universidad Nacional de Mar del Plata.

Masello, A. y Menafra, R. (1998). “Comunidades macrobentónicas de la zona costera uruguaya y áreas adyacentes”. En: Wells, P. G. y Daborn, G. R. (eds.). El Río de la Plata. Una revisión ambiental. Un informe de antecedentes del Proyecto EcoPlata. Halifax, Dalhourie University.

Mateo, J. (2001). Población, parentesco y red social en la frontera: Lobos (Provincia de Buenos Aires) en el siglo XIX. Mar del Plata, Universidad Nacional de Mar del Plata. Mayo, C. (1991). "Landed but not powerful. The colonial estancieros of Buenos Aires (1750-1810)". Hispanic American Historical Review, Vol. 71, No. 4.

(dir.) (2000a). Pulperos y pulperías de Buenos Aires (1740-1830). Buenos Aires, Biblos.

(ed.) (2000b). Vivir en la frontera. La casa, la dieta, la pulpería, la escuela (1770-1810). Buenos Aires, Biblos.

(2004). Estancia y sociedad en la pampa (1740-1820). Buenos Aires, Biblos. ( $1^{\mathrm{a}}$ edición 1995$)$

Mir, L. B. (1999). "Mesta e intereses ganaderos en el Buenos Aires tardocolonial (17721794). Quinto Sol, $\mathrm{n}^{\mathrm{o}} 3$. 
Montañez Gómez, G. (2001) “Introducción. Razón y pasión del espacio al territorio” en MONTAÑEZ GÓMEZ, G. (Comp.) Espacio y territorios. Razón, pasión e imaginarios. Bogota, Universidad Nacional de Colombia.

Montoya, A. J. (1984). Cómo evolucionó la ganadería en la época del virreinato, Buenos Aires, Plus Ultra.

Moraes, M. I. (2004). "La historiografía de Pivel Devoto sobre el agro colonial en la Banda Oriental: un estudio de "Raíces coloniales de la revolución oriental de 1811". Boletín de Historia Económica, año 3, nº 3.

(2007). "Crecimiento del Litoral rioplatense colonial y decadencia de la economía misionera: un análisis desde la ganadería". Investigaciones de historia económica, otoño, $\mathrm{n}^{\circ} 9$.

(2011). Las economías agrarias del litoral rioplatense en la segunda mitad del siglo XVIII. Paisajes y desempeños, Tesis de doctorado, Facultad de Ciencias Sociales y Empresariales, Universidad Complutense de Madrid.

Morelli, F. (2005). Territorio o nación. Reforma y disolución del espacio imperial en Ecuador, 1765-1830. Madrid, Centro de Estudios Políticos y Constitucionales.

Moreno, J. L. (1989). "Población y sociedad en el Buenos Aires rural a mediados del siglo XVIII". Desarrollo Económico, Vol 29, N 114.

Moutoukias, Z. (1988). Contrabando y control colonial en el siglo XVII. Buenos Aires, Centro Editor de América Latina.

(1995a). "El crecimiento en una economía colonial de Antiguo Régimen: reformismo y sector externo en el Río de la Plata (1760-1796)". Paris, Arquivos do Centro Cultural Colouste Gulbenkian, Volumen XXXIV.

(1995b). "Redes sociales, comportamiento empresario y movilidad social en una economía de no mercado (El Río de la Plata en la segundad mitad del siglo XVIII)". En: Berj, M. y Otero, H. (Comp.). Inmigración y redes sociales en la Argentina moderna. Tandil, CEMLA - IEHS.

(2000). "Familias patriarcales o redes sociales: balance de una imagen de la estratificación social". Tandil, Anuario IEHS, nº 15.

Nagy, G. J., Martínez, C. M., Caffera, R. M., Pedrosa, G., Forbes, E. A., Perdomo, A. C. y Lopéz Laborde, J. (1998). "Marco hidrológico y climático del Río de la Plata”. En: 
Wells, P. G. y Daborn, G. R. (eds.). El Río de la Plata. Una revisión ambiental. Un informe de antecedentes del Proyecto EcoPlata. Halifax, Dalhourie University.

Néspolo, E. (2006). "La "frontera" bonaerense en el siglo XVIII un espacio políticamente concertado: fuertes, vecinos, milicias y autoridades civiles-militares". Mundo Agrario, 7, 13, julio/diciembre.

Pereira Prado, F. (2002). A Colonia de Sacramento: o extremo sul da América portuguesa no século XVIII. Porto Alegre, F.P.Prado.

Pérez, O. (1996). “Tipos de producción ganadera en el Río de la Plata Colonial. La estancia de alzados”. En: Azcuy Ameghino, E. et al. Poder terrateniente, relaciones de producción y orden colonial. Buenos Aires, Fernando García Cambeiro.

Pivel Devoto, J. E. (1952). Raíces coloniales de la revolución oriental de 1811. Montevideo, Medina.

(dir.) (1964). Colección de documentos para la historia económica y financiera de la República Oriental del Uruguay. Montevideo, Ministerio de Hacienda. Poggi, M. M. (2010). "La consolidación y difusión de un mito fundacional. La Revolución de Mayo en los textos escolares, 1880-1905”. Anuario del Instituto de Historia Argentina, $\mathrm{n}^{\circ} 10$.

Pollero, R. (2013). Historia demográfica de Montevideo y su campaña (1757-1860). Tesis de doctorado, Facultad de Ciencias Sociales, Universidad de la República. y Vicario, C. (2009). "Informe demográfico sobre la región platense (17601860)”, Facultad de Ciencias Sociales, Universidad de la República.

Ramírez, B. R. (2007). "La geografía regional: tradiciones y perspectivas". Investigaciones geográficas. Boletín del Instituto de Geografía, UNAM, 64.

Ratto, S. (2001). "El debate sobre la frontera a partir de Turner. La New Western History, los borderlands y el estudio de la frontera en Latinoamérica”. Boletín del Instituto de Historia Argentina y Americana “Dr. Emilio Ravignani”, Tercera Serie, $\mathrm{n}^{\circ}$ 24.

Reyes Abadie, W., Bruschera, O.H. Y Melogno, T. (1966). La Banda Oriental: pradera, puerto y frontera. Montevideo, Ediciones de la Banda Oriental.

Rodríguez Molas, R. (1968). Historia social del gaucho. Buenos Aires, Maru.

Rosal, M. A. y Schmit, R. (2004). "Las exportaciones pecuarias bonaerenses y el espacio mercantil rioplatense (1768-1854)". En: Fradkin, R. O. y Garavaglia, J. C. (ed.). 
En busca de un tiempo perdido. La economía de Buenos Aires en el país de la abundancia 1750-1865. Buenos Aires, Prometeo.

Russell, C. y Gallego, J. A. (dir.) (1996). Las monarquías del Antiguo Régimen, ¿monarquías compuestas? Madrid, Editorial Complutense.

Santilli, D. (2013). “¿Perjudiciales o beneficiosas? La discusión sobre el impacto económico de las reformas borbónicas en Buenos Aires y su entorno". Fronteras de la historia, Vol. 18, $\mathrm{n}^{\circ} 2$.

Schröter, B. (1999). "Estructuras, prestigio e identidades de la capa social alta en una ciudad portuaria y fronteriza. Montevideo del siglo XVIII a la Independencia”. Schröter, B. y Büschges, C. (eds.). Beneméritos, aristócratas y empresarios. Identidades y estructuras sociales de las capas altas urbanas en América hispánica. Madrid, Iberoamericana.

Saguier, E. (1991). "El mercado del cuero y su rol como fuente alternativa de empleo. El caso de trabajo a destajo en las vaquerías de la Banda Oriental". Revista de Historia Económica IX, $\mathrm{n}^{\mathrm{o}} 1$.

(1993). Mercado inmobiliario y estructura social. El Río de la Plata en el siglo XVIII. Buenos Aires, CEAL.

Sala de Tourón, L., de la Torre, N. y Rodríguez, J. C. (1967). Estructura económicosocial de la colonia. Montevideo, Ediciones Pueblos Unidos.

(1968). Evolución económica de la Banda Oriental. Montevideo, Ediciones Pueblos Unidos.

Salvatore, R. y Brown, J. (1987). "Trade and proletarianization in Late Colonial Banda Oriental: Evidence from the Estancia de las Vacas, 1791-1805". Hispanic American Historical Review, 67:3.

Sandrín, M. E. (2011). Bizcocheras, lancheros y demás... Los estímulos de la guerra para los sectores medios y bajos del complejo portuario rioplatense, 1735-1737. Madrid, Editorial Académica Española.

(2014). "La actividad económica de los asentistas de víveres de la marina de Montevideo, 1770-1810”. América Latina en la Historia Económica, Vol. 21, nº 1.

Sansón, T. (2006). La construcción de la nacionalidad oriental. Estudios de historiografía colonial. Montevideo, Universidad de la República. 
(2011). "La construcción de la nacionalidad en los manuales de historia rioplatense". Nuevo Mundo Mundos Nuevos [en línea].

Schmit, R. (2004) "Conceptos, herramientas y resultados recientes sobre la historia económica rioplatense de la primera mitad del siglo XIX”. En Bragoni, B. Microanálisis. Ensayos de historiografía argentina. Buenos Aires, Prometeo Libros.

(2008). "La construcción de la frontera decimonónica en la historiografía rioplatense". Mundo Agrario, vol. 8, nº 16.

Seoane, Pedro (1928). La industria de las carnes en el Uruguay. Montevideo, Castelnuovo y Berchesi.

Silva, H. A. (1993). El comercio entre España y el Río de la Plata. Banco de España, Servicio de Estudios, Estudios de Historia Económica, no 26.

Slatta, R. W. (1985). Los gauchos y el ocaso de la frontera. Buenos Aires, Sudamericana.

Socolow, S. (1988). Los mercaderes del Buenos Aires virreinal. Familia y Comercio. Buenos Aires, Ediciones de la Flor. (1 $1^{\mathrm{a}}$ ed. en inglés 1978).

Soriano, A., León, R. J. C., Sala, O. E., Lavado, R.S., Deregibus, V.A., Cahuepé, M. A., Scaglia, O. A., Velazquez, C.A. y Lemcoff, J. H. (1992). "Río de la Plata grasslands". En Coupland, R. T. (ed.). Ecosystems of the world. Natural grasslands. Amsterdam, Elsevier.

Sovarzo, J. y Errecart, M. C. (2013). "De tierra adentro al río. El complejo portuario rioplatense a partir de las guías de aduana de Buenos Aires a fines del siglo XVIII.”. XIV Jornadas Interescuelas/Departamentos de Historia, Mendoza, 2 al 5 de octubre.

Van Young, E. (1987). "Haciendo historia regional. Consideraciones metodológicas y teóricas". Anuario IEHS, No 2. 